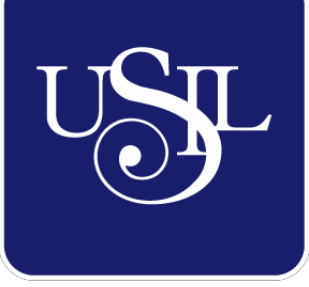

UNIVERSIDAD

SAN IGNACIO

DE LOYOLA

ESCUELA DE POSTGRADO

\title{
PLAN ESTRATÉGICO DE LA EMPRESA DIGITAL COMUNICACIONES SAC DEL ÁREA DE ATENCIÓN AL USUARIO
}

Trabajo de Investigación para optar el grado de:

KATTIA ALFARO TUPAYACHI

Maestro en Ciencias Empresariales con Mención en Gestión del Capital Humano

SANDRA YADIRA BUSTAMANTE YABAR Maestro en Ciencias Empresariales con Mención en Gestión del Capital Humano

PATRICIA CUBA CHARA

Maestro en Ciencias Empresariales con Mención en Gestión del Capital Humano

MARIA DEL CARMEN DUEÑAS CASTAÑEDA Maestro en Ciencias Empresariales con Mención en Gestión del Capital Humano

Asesor:

Julio Enrique De La Puente De La Borda

Lima - Perú

2019 


\section{CONTENIDO}

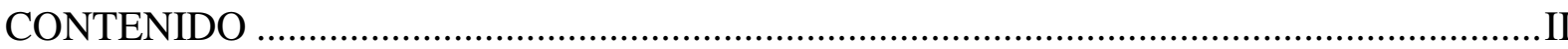

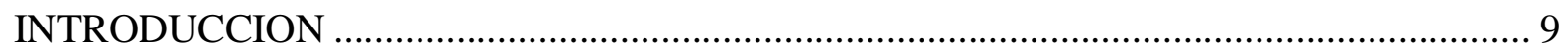

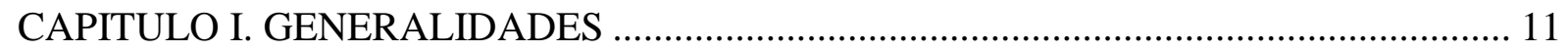

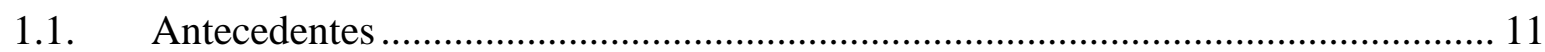

1.2. Determinación del problema u oportunidad .................................................. 16

1.3. Justificación del proyecto .......................................................................... 19

1.4. Objetivos generales y específicos .............................................................. 19

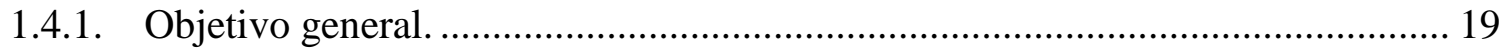

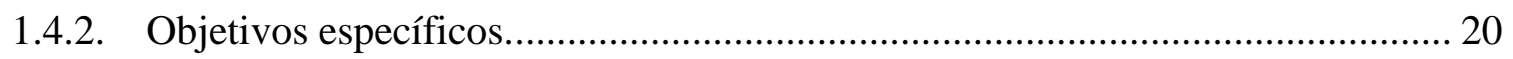

1.5. Alcances y limitaciones de la investigación ............................................... 20

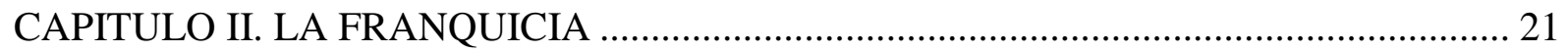

2.1. Antecedentes de la empresa ................................................................ 21

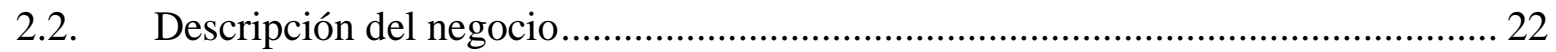

2.3. Ciclo de vida del servicio......................................................................... 22

2.4. Ciclo de vida de la empresa Digital ......................................................... 23

2.5. Ciclo de vida de la industria de telecomunicaciones ..................................... 24

2.6. Estructura organizacional actual de la empresa .......................................... 25

2.7. Situación de mercado y financiera actual de la industria................................... 28

CAPITULO III. FORMULACIÓN DE VISIÓN, MISIÓN Y VALORES DE LA EMPRESA

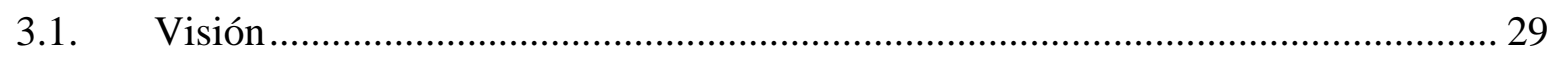

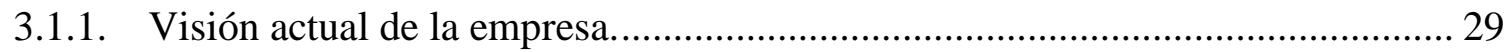




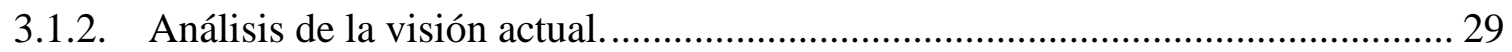

3.1.3. Matriz de la visión propuesta para la empresa. ............................................ 29

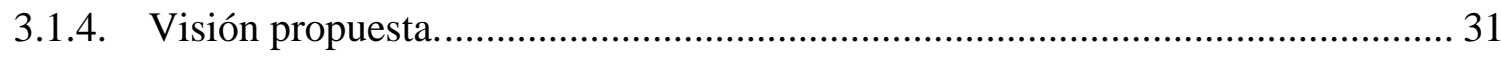

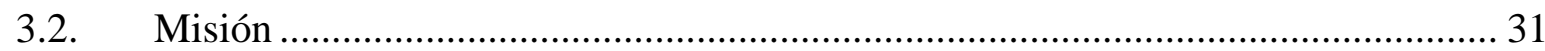

3.2.1. Misión actual de la empresa.................................................................. 31

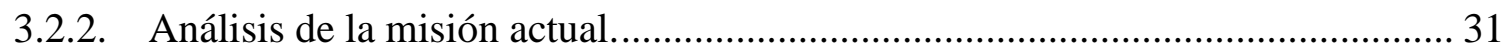

3.2.3. Elementos de la misión propuesta para la empresa........................................ 32

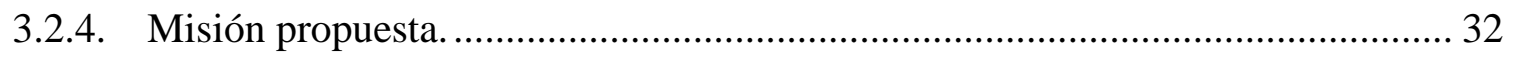

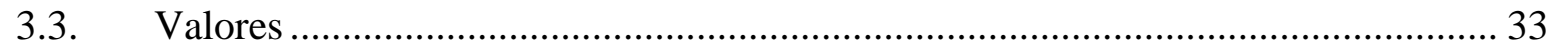

3.3.1. Valores actuales de la empresa............................................................ 33

3.3.2. Análisis de los valores actuales. ................................................................ 34

3.3.3. Elementos de los valores propuestos para la empresa................................... 35

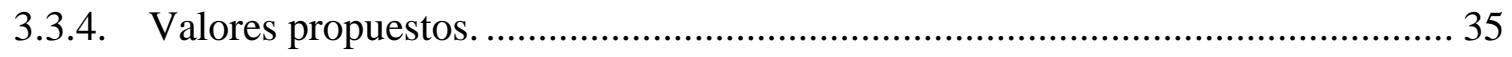

3.4. Alineamiento estratégico de la visión, misión y valores de la empresa.................. 36

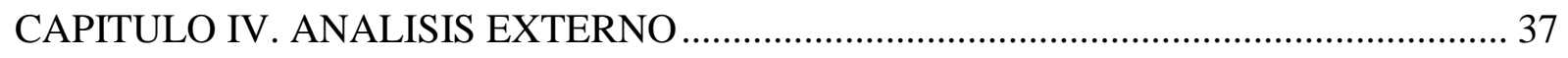

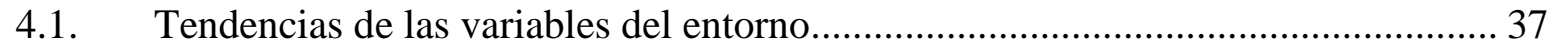

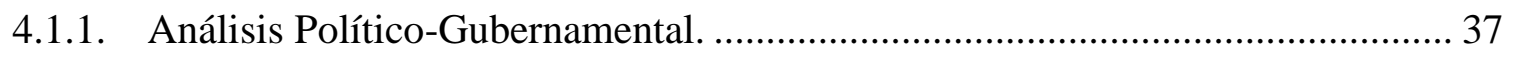

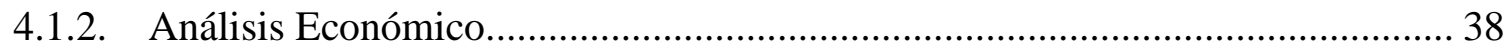

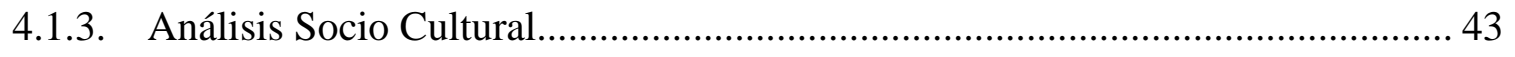

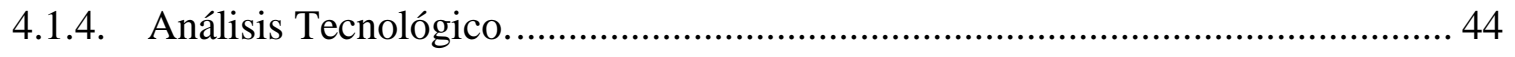

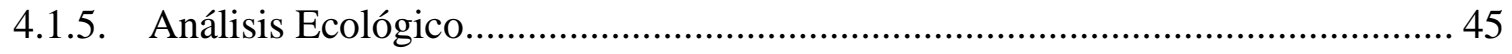

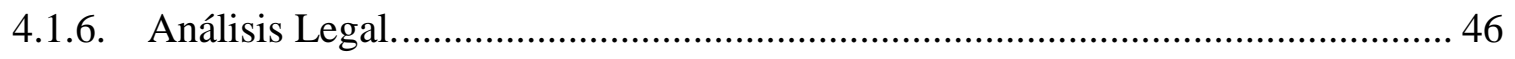

4.2. Impacto en clientes / proveedores de cada una de las variables del entorno ......... 46 
4.3. Efecto en la empresa de cada una de las variables del entorno ........................... 47

4.4. Matriz de Evaluación de los Factores Externos EFE........................................... 48

CAPÍTULO V. ANÁLISIS DE LA INDUSTRIA....................................................... 50

5.1. Descripción del Mercado (demanda) e Industria (oferta) ................................... 50

5.2. Descripción las cinco fuerzas competitivas de la industria ............................... 55

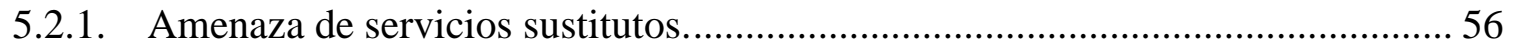

5.2.2. Amenaza de entrada de los nuevos competidores....................................... 56

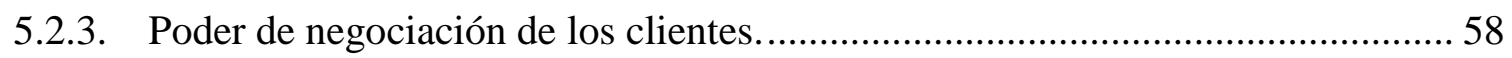

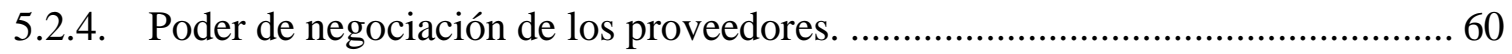

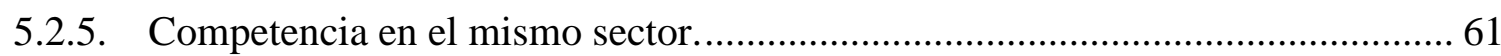

5.3. Matriz de atractividad de cada una de las cinco fuerzas.................................... 63

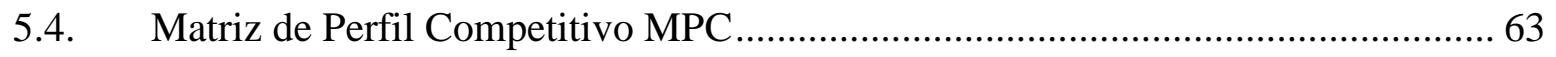

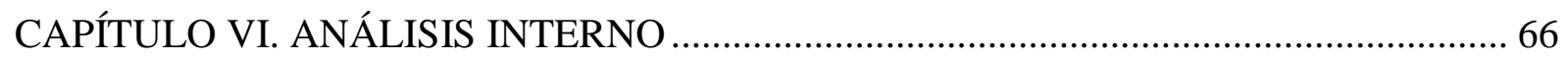

6.1. Descripción de las actividades de la cadena de valor de la empresa .................... 66

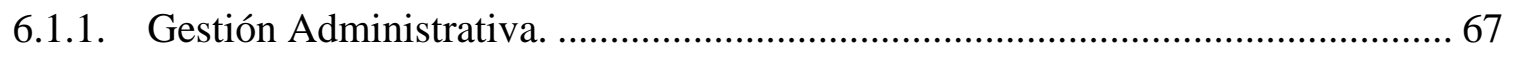

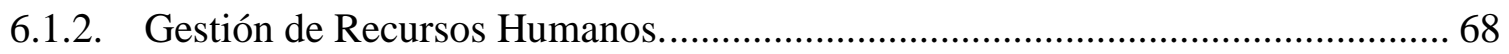

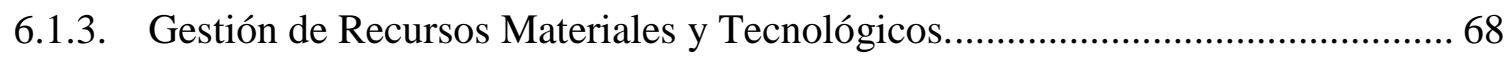

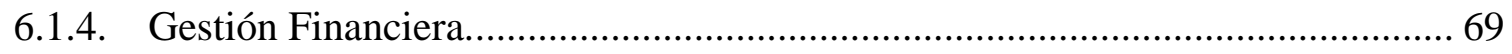

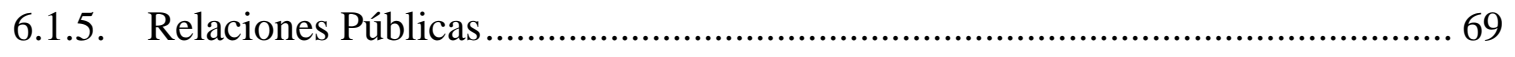

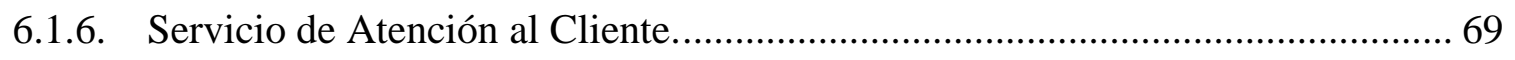

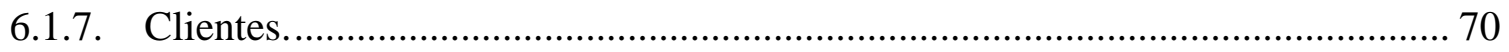

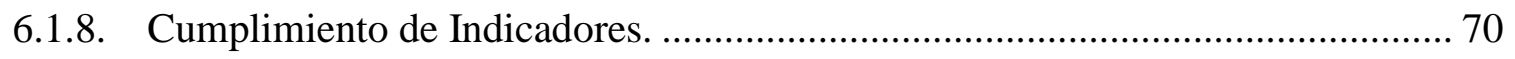

6.2. Indicadores de cada una de las actividades de la cadena de valor ....................... 71 
6.3. Benchmarking y comparación con los líderes de la industria de cada una de las

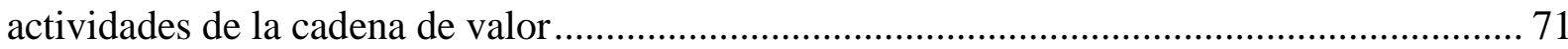

6.4. Determinar las competencias de la empresa ………........................................ 73

6.5. Identificación y determinación de las ventajas competitivas de la empresa............ 74

6.6. Matriz de Evaluación de los Factores Internos EFI ................................................. 74 CAPÍTULO VII. FORMULACIÓN DE LOS OBJETIVOS Y DISEÑO DE LAS

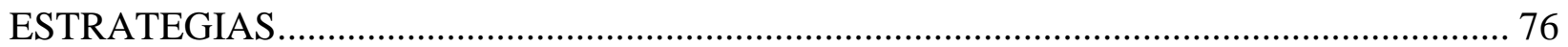

7.1. Alcance y planteamiento de los objetivos estratégicos........................................... 76

7.1.1. Objetivos Estratégicos................................................................................ 76

7.1.2. Análisis de los objetivos estratégicos................................................................ 77

7.2. Diseño y formulación de estrategias............................................................... 79

7.2.1. Lienzo de la estrategia actual de la empresa. .................................................. 80

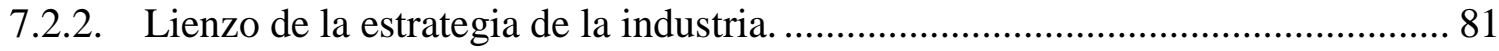

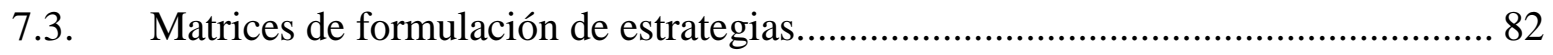

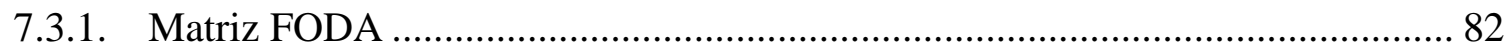

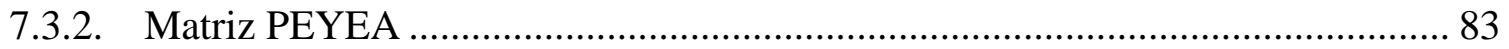

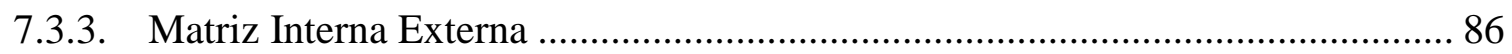

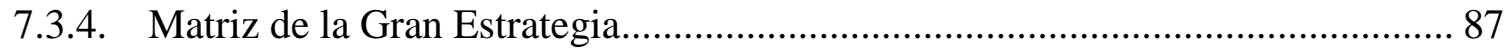

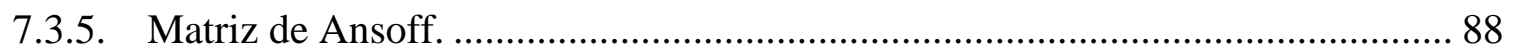

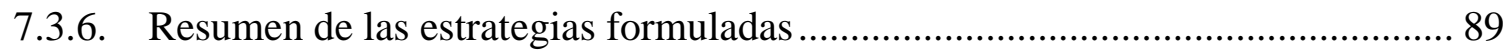

CAPÍTULO VIII. SELECCIÓN DE LA ESTRATEGIA _....................................................... 90

8.1. Método Factores Estratégicos Claves ………...................................................... 90

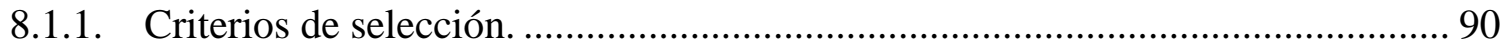




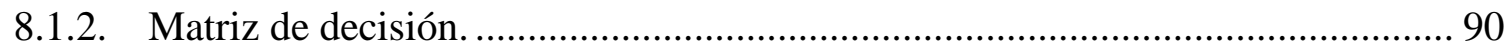

8.2. Método de Escenarios ................................................................................... 92

8.2.1. Descripción de escenarios considerados. .................................................... 93

8.2.2. Comparación de Estrategias con escenarios.................................................... 94

8.3. Matriz de Planeación Estratégica Cuantitativa MPEC ....................................... 95

8.4. Descripción de las estrategias seleccionadas .................................................... 99

8.5. Descripción de la estrategia contingentes .................................................. 99

8.6. Tipo de estrategia genérica según Porter ................................................... 100

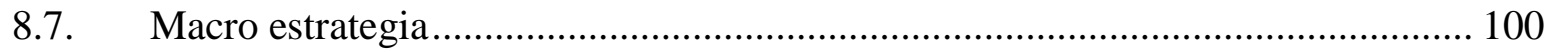

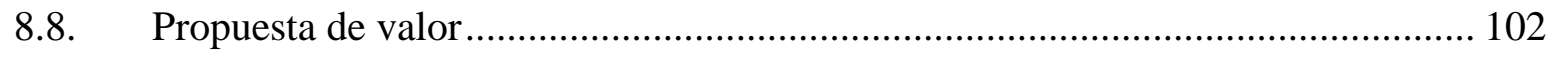

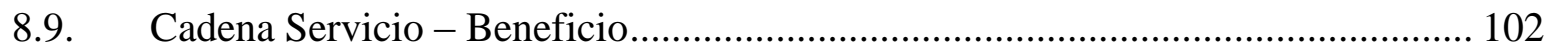

CAPÍTULO IX. IMPLANTACIÓN DE LA ESTRATEGIA …......................................... 104

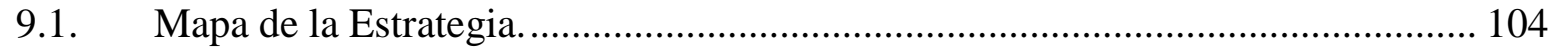

9.2. Objetivos específicos según el mapa de la estrategia ..................................... 105

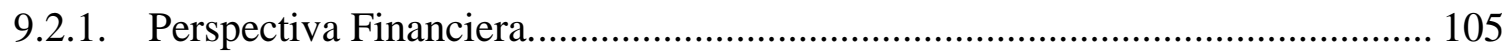

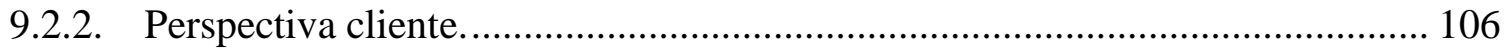

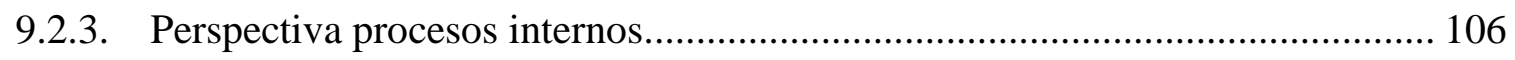

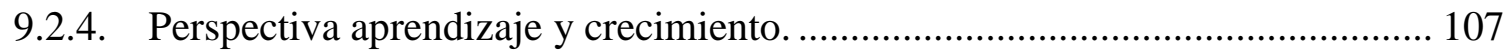

9.3. Indicadores y metas para cada uno de los objetivos específicos ....................... 109

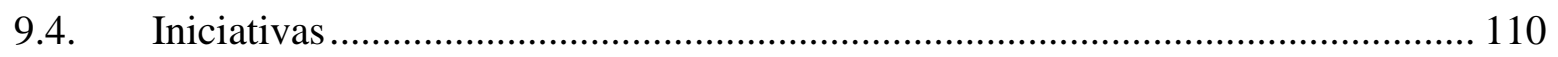

9.5. Responsable de cada una de las iniciativas................................................ 112

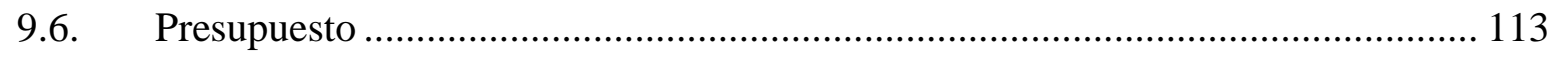

9.7. Cronograma de cada una de las iniciativas ................................................. 115 


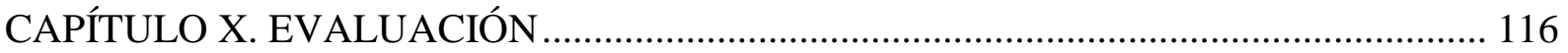

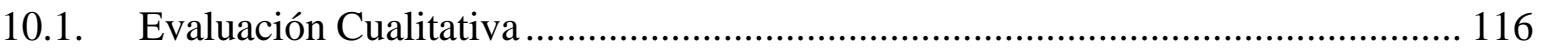

10.1.1. Criterios de Evaluación. ......................................................................... 116

10.1.2. Comparación de la estrategia con los criterios.............................................. 116

10.2. Evaluación Financiera de la Estrategia ................................................................ 117

10.2.1. Proyección de estados financieros (situación actual y la nueva estrategia). . 118

10.2.2. Estado de resultados (situación actual y con la nueva estrategia)................. 119

10.2.3. Balance general (situación actual y con la nueva estrategia)........................ 123

10.2.4. Flujo de efectivo (situación actual y con la nueva estrategia)....................... 127

10.2.5. Proyección de flujos (situación actual y con la nueva estrategia)................. 131

10.2.6. Evaluación Financiera (VAN y ratios financieros). ....................................... 132

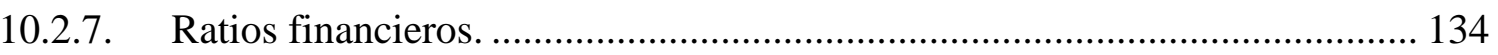

CONCLUSIONES Y RECOMENDACIONES ................................................................. 138

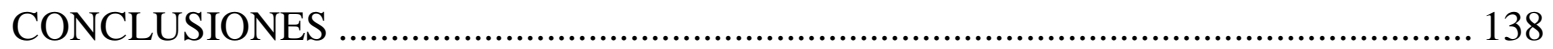

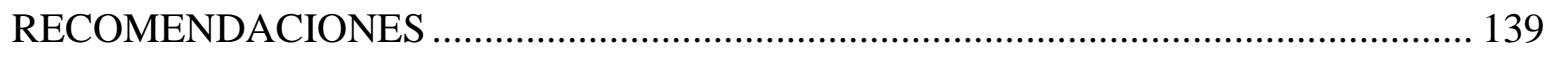

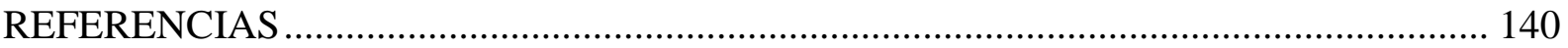

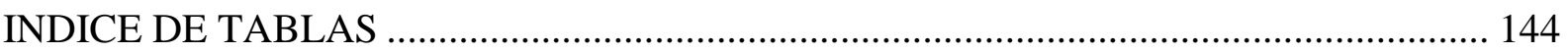

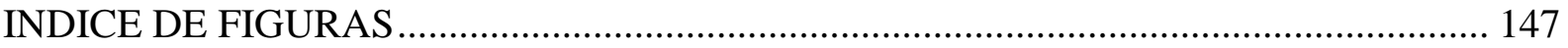

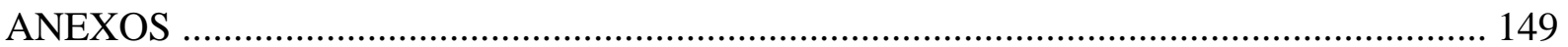

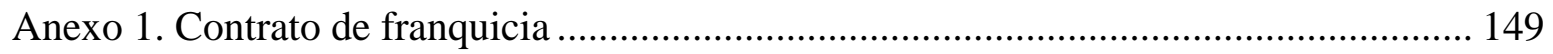

Anexo 2. Resolución de Consejo Directivo N 127-2013-CD/OSIPTEL ........................... 151

Anexo 3. Encuesta de IPSOS por encargo de OSIPTEL .................................................. 161

Anexo 4. Relación de tiendas de TDP a nivel nacional .................................................... 162 
Anexo 5. Cálculo del MPC

Anexo 6. Entrevista a funcionarios de Digital ..................................................... 170

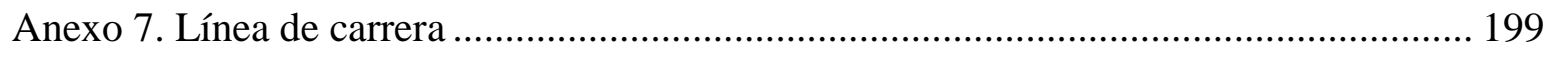

Anexo 8. Cargos de la empresa y tiempos promedio de permanencia............................ 200

Anexo 9. Compra de artículos promocionales ........................................................ 201

Anexo 10. Personal para call center de cobranzas .................................................. 201

Anexo 11. Bonificación a los trabajadores de Digital................................................ 202

Anexo 12. Taller de Capacitación: Contenido, Cronograma y Costo.............................. 203

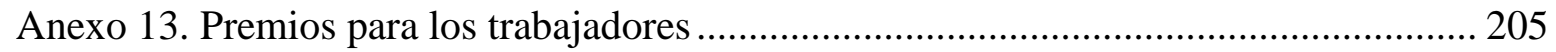

Anexo 14. Asesoría profesional externa especializada en calidad de atención ................ 205

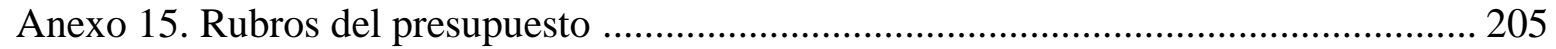




\section{INTRODUCCION}

El presente trabajo tiene por finalidad el desarrollo del Plan Estratégico para la empresa Digital Comunicaciones S.A.C. para el período 2018 - 2021, el mismo que representa una herramienta de gestión que busca establecer estrategias que permitan mejorar el funcionamiento de la empresa, incrementar las ventas y con ello mejorar las utilidades y el valor de la empresa.

En el trabajo se realizará un análisis del sector de telecomunicaciones en el país, para luego hacer una evaluación a la empresa, con dicha información se procederá a construir las diferentes matrices, teniendo como resultado la formulación de estrategias que le corresponde aplicar a la empresa, y por último se seleccionará las estrategias más adecuadas, proyectando el impacto económico que estas puedan tener producto de la implementación.

El plan estratégico consta de diez capítulos que se explican a continuación:

En el capítulo I se desarrolla la situación general de la industria donde se desenvuelve la empresa, la justificación del proyecto, el objetivo general y los objetivos específicos del trabajo, finalmente los alcances y limitaciones que se presentaron en el desarrollo.

En el capítulo II, se desarrollan los antecedentes de la empresa, el ciclo de vida del producto, así como de la industria, se describe la estructura organizacional de la empresa, y por último la oferta y demanda de la industria.

En el capítulo III, se describen y analizan la Visión, Misión y Valores de la empresa, para posteriormente proponer la nueva visión y misión. 
En el capítulo IV se analizan las variables del entorno de carácter político, macroeconómico, legal, tecnológico y ecológico, que puedan influir en el desenvolvimiento de la empresa y se construye la matriz de factores externos EFE.

En el capítulo V se analiza la industria donde se desenvuelve la empresa, se desarrollan las 5 Fuerzas Competitivas de Porter, se construye la matriz de la atractividad para cada una de las cinco fuerzas, así como la Matriz del Perfil Competitivo (MPC).

En el capítulo VI se analiza la cadena de valor de la franquicia, se comparan los resultados de la empresa con la de sus principales competidores, determinando sus principales ventajas competitivas y se construye la Matriz de Factores Internos (EFI).

En el capítulo VII se plantean los objetivos estratégicos, se desarrollan las Matrices FODA, PEYEA, Matriz Interna y Externa y Matriz de la Gran Estrategia de las cuales se seleccionan el tipo de estrategia que corresponde aplicar a la empresa.

En el capítulo VIII se plantea la selección de la estrategia a través de criterios de selección en diferentes escenarios y comparando estrategias.

En el capítulo IX se implementa la estrategia, proponiendo el mapa de la estrategia, los objetivos, y revisando los indicadores.

En el capítulo X se expone la evaluación cualitativa y financiera de la empresa y se determina el impacto de implementar el plan estratégico realizando una proyección de los estados financieros. 


\section{CAPITULO I. GENERALIDADES}

\subsection{Antecedentes}

El presente plan estratégico se desarrolla dentro del sector de telecomunicaciones, para después centrarse en el mercado de franquicias a través de las que Telefónica del Perú S.A.A., en adelante TDP, realiza la comercialización de sus productos y la prestación del servicio de post venta al cliente final; la empresa Digital Comunicaciones S.A.C. en adelante Digital, viene a ser una de las franquicias con la que TDP mantiene una relación comercial de dieciocho años.

Para ello es importante analizar el desempeño del sector telecomunicaciones y otros servicios, en la economía peruana durante los últimos 5 años, según información del Instituto Nacional de Estadística e Informática (INEI, 2017) el sector de telecomunicaciones es uno de los más dinámicos porque registra un crecimiento superior al crecimiento del PBI nacional en todos los años y en el año 2012 tuvo el mejor desempeño con $12.20 \%$, en cuanto a los siguientes cuatro años registra un crecimiento muy parejo con un promedio de $8.8 \%$, tal como se aprecia en la Figura 1.

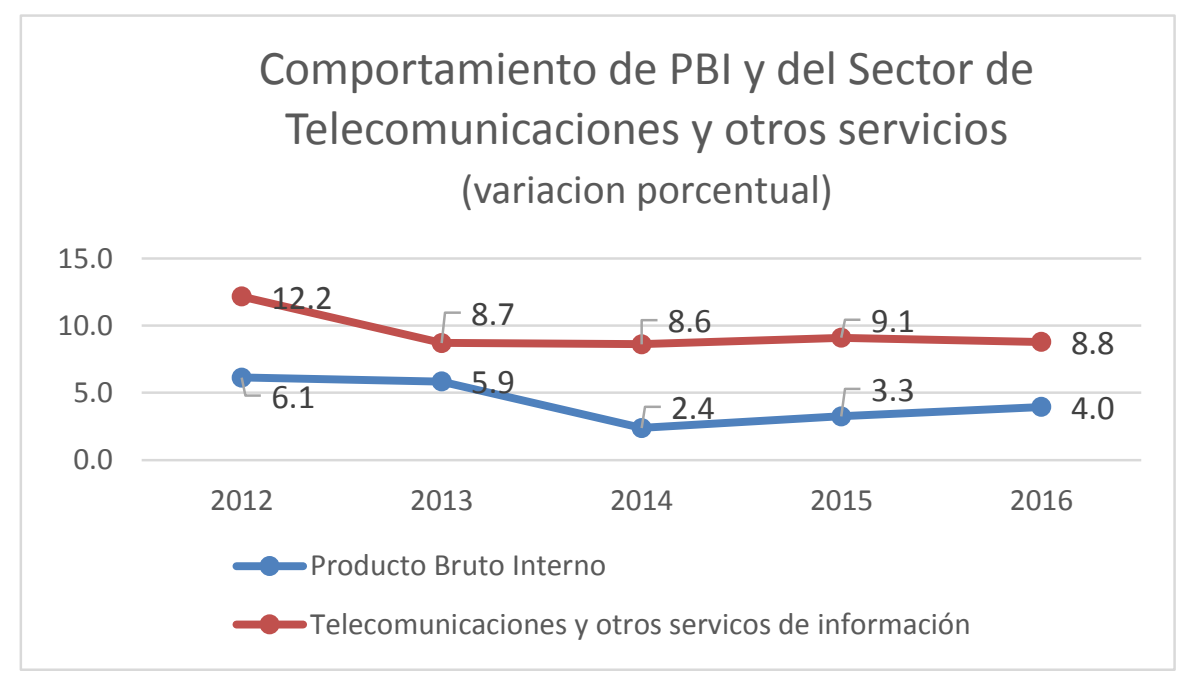

Figura 1: Comportamiento del PBI y del sector de telecomunicaciones y otros servicios hasta el 2016. Datos proporcionados por el INEI (elaboración propia). 
El sector de telecomunicaciones está muy vinculado al desarrollo de nuevas tecnologías e innovaciones por ello se espera que mantenga el comportamiento de los últimos 4 años en el Perú; según la información publicada por OSIPTEL (2017) se cuenta con 13 operadores, prestando diferentes servicios en las telecomunicaciones como son: Americatel Perú S.A., Bitel, Claro, Convergía Perú S.A., Entel Perú, Gilat to Home, IDT Perú, Impsat Perú (Level 3), Infoductos y Telecomunicaciones del Perú S.A., Optical Technologies S.A.C., Rural Telecom, Telefónica Móviles S.A, Telefónica del Perú S.A.A..

El servicio de telefonía celular es el rubro principal de la franquicia que se va a evaluar, donde según el reporte publicado por OSIPTEL a abril del 2017, muestra un incremento en el mercado de telefonía móvil, dado que con cifras al cierre del 2016 se registró una expansión de $8 \%$ al pasar de 34.24 millones de líneas el 2015 a 36.99 millones de líneas el 2016. En tanto, la penetración móvil se elevó a 122 líneas por cada 100 peruanos, nivel récord en el sector telecomunicaciones.

Dentro de este mercado son cinco operadores los que mantienen diferentes cuotas de participación, como se observa en la Figura 2: 


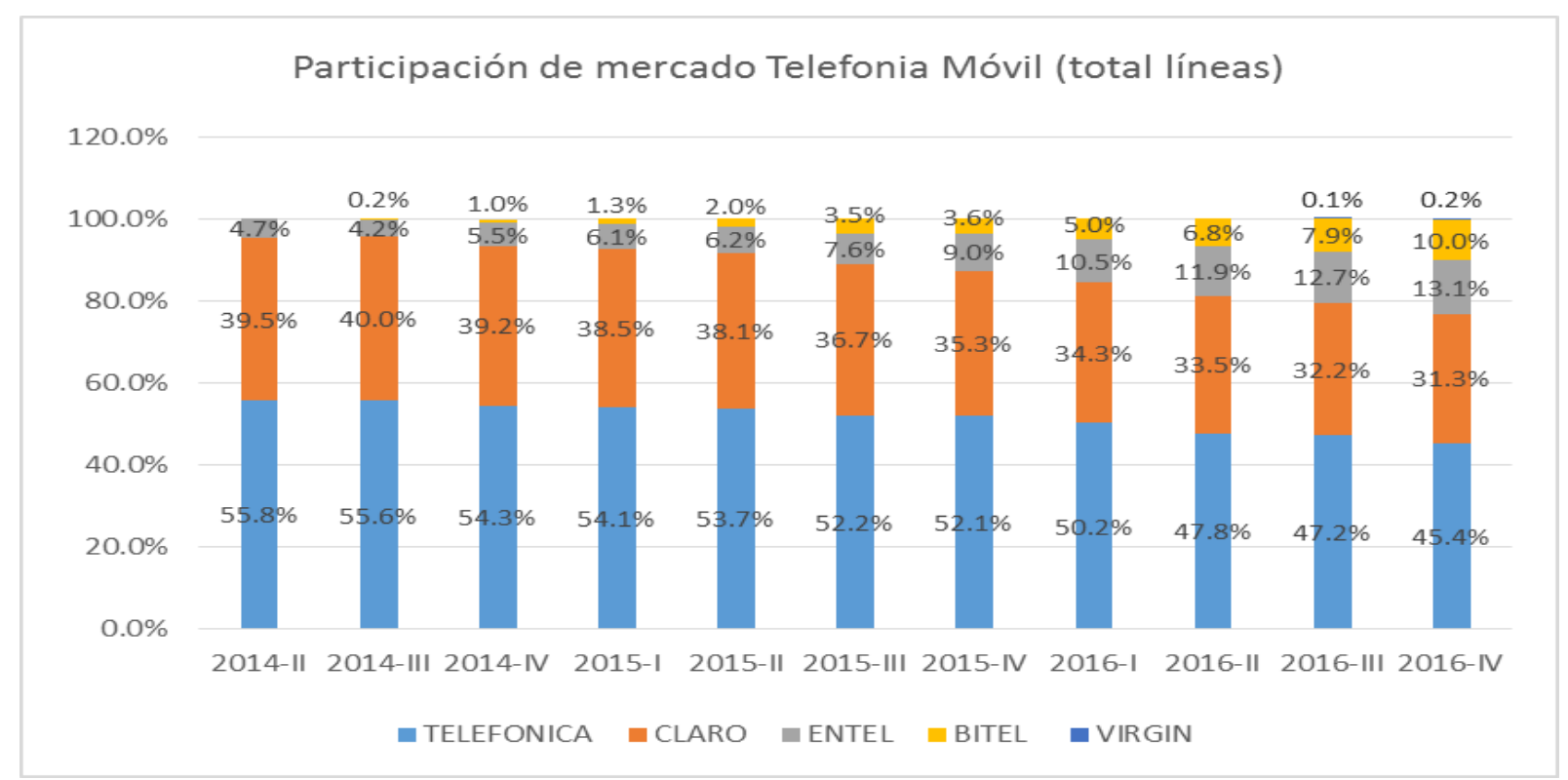

Figura 2: Participación de mercado telefónica móvil. Reporte estadístico OSIPTEL abril 2017

De los datos presentados en la Figura 2 se aprecia que los dos operadores más grandes Telefónica y Claro han perdido participación en 6.7 \% y $4.0 \%$ respectivamente en el periodo del 2015 al 2016, así mismo los nuevos operadores Entel, Bitel y Virgin registran incrementos en las líneas colocadas en el mes de setiembre 2017, Virgin Mobile primer operador virtual en Perú fue vendido a Inkacel (empresa española), y con ello el traspaso de cien mil clientes que formaban parte de la cartera tras un año de funcionamiento de acuerdo al artículo publicado en la página web de la Agencia de Noticias (EFE, 2017).

En este contexto, se puede decir que al tener en el mercado un número elevado de operadores frente a un mismo servicio, el usuario tendrá una oportunidad para elegir a la empresa que le ofrezca mayores beneficios. Por el contrario, las empresas tendrán que buscar mejorar la calidad de atención de los clientes, la imagen de la tienda, publicidad y promociones a fin de retener a sus clientes y captar nuevos clientes. 
En el 2017 TDP implementó nuevas condiciones comerciales, debido al cambio de modelo de agencias tercerizadas al formato de franquicias (Anexo 1) con lo cual cambia las condiciones de retribución económica, TDP sede derechos para usar el nombre y prestar el servicio en una determinada zona, dentro de estas condiciones da mayor énfasis a la satisfacción del cliente y establece un monto de comisión por cliente satisfecho.

A su vez dentro de la regulación peruana, se cuenta con el Organismo Supervisor de la Inversión Privada en Telecomunicaciones (OSIPTEL), el cual ha implementado normas referidas a la calidad de atención, tal como se indica en la Resolución de Consejo Directivo N 127-2013CD/OSIPTEL, Reglamento de Calidad de la Atención a Usuarios por parte de las Empresas Operadoras de servicios de Telefonía Fija y Servicios Públicos Móviles, en el (Anexo 2) se refiere a la "Calidad en el trato brindado al usuario: Las empresas operadoras deberán brindar a los usuarios un trato digno y cortés, con predisposición para la atención de sus trámites, a través de sus canales de atención presencial y telefónico”.

Con estos antecedentes se evidencia que la atención y satisfacción del cliente se convierte en el atributo más importante de las empresas de telecomunicaciones, que además esta normado, por ello la revisión a la bibliografía se puede contrastar con Paz (2005), en su libro servicio al cliente, menciona que independientemente del rubro y el sector al que las empresas pertenezcan, todos sus miembros están implicados en el servicio al cliente, elemento imprescindible para la existencia de la empresa y constituye el centro de interés fundamental y clave de su éxito o fracaso, añade que el servicio al cliente tiene como actividades principales el tratamiento de las reclamaciones y el servicio de postventa. Actualmente existen en el mercado productos y servicios con características similares, que elevan el número de alternativas disponibles a la hora de la decisión de compra, lo que hace que la fidelidad del cliente cada vez sea menor. 
Esta situación genera una coyuntura donde las empresas deberán ser más competitivas en tres aspectos:

- Servicio: Orientar la empresa al cliente como objetivo integral y prioritario dirigido a obtener su satisfacción y permanecer en el mercado.

- Relaciones: Conseguir la fidelización de clientes.

- Valor añadido: Nos diferenciará de nuestros competidores, generando una preferencia hacia nuestra empresa (Paz, 2005, pág. 3).

La comunicación juega un rol importante en el servicio al cliente, cualquier empresa se debe a sus clientes, pero solo se mantendrá en el mercado aquella que tenga mayor cantidad de clientes fieles, el vínculo más importante es la interacción persona a persona, pese al avance de la tecnológica los clientes prefieren ser atendidos de manera presencial (Paz, 2005).

En este sentido, estamos evaluando una empresa de servicios cuyo objetivo es mejorar la calidad de atención y la satisfacción del cliente, para ello su actividad principal es la atención al usuario en venta y postventa en tres zonas dentro del país, contando en total con ocho tiendas propias de la franquicia:

- Zonal Cusco, el cual abarca las regiones de Cusco (Cusco, Sicuani y Quillabamba), Apurímac (Abancay y Andahuaylas) y Madre de Dios (Puerto Maldonado)

- Zonal Ayacucho, el cual abarca la región de Ayacucho (Huamanga)

- Zonal Huancayo (Huancavelica).

Así mismo en estas zonas también operan otras franquicias de TDP ofreciendo los mismos productos y servicios. Como se puede observar en la Tabla 1, la franquicia Digital tiene una 
participación en el mercado de 53.42\%, siendo líder en el mercado y con ventas de 9,903 unidades en el período de enero a julio del 2017.

Tabla 1:

Participación de mercado de Digital

\begin{tabular}{ccccc}
\hline Nro. & Agente & Tipo & Participación & Ventas \\
& & & & En unidades \\
\hline 1 & BOUTIQUE CELULAR SCRL & Franquicia & $11.77 \%$ & 2182 \\
2 & CORPORACION MACHI SAC & Agente & $6.73 \%$ & 1248 \\
$\mathbf{3}$ & DIGITAL COMUNICACIONES SAC & Franquicia & $\mathbf{5 3 . 4 2 \%}$ & $\mathbf{9 9 0 3}$ \\
4 & GLOBAL COMUNICACIONES SAC & Agente & $3.20 \%$ & 594 \\
5 & MOVICOM ERIL & Agente & $7.88 \%$ & 1461 \\
6 & MULTICENTROS & Franquicia & $10.64 \%$ & 1973 \\
7 & NEGOCIOS Y EMPRESAS EIRL & Agente & $2.24 \%$ & 416 \\
8 & GRANDES SUPERFICIES & Agente & $4.10 \%$ & 760 \\
\hline
\end{tabular}

Nota: Reportes de ventas de telefónica del periodo de enero a julio del 2017 (elaboración propia).

Con la finalidad que la franquicia mejore y mantenga su posición en el mercado de franquicias de TDP se plantea un plan estratégico para el periodo 2018 - 2021 centrando todo el interés en la calidad de atención.

\subsection{Determinación del problema u oportunidad}

La franquicia Digital, tiene una participación de 53.42\% a comparación de las demás franquicias dentro del mercado comprendido en las tres zonas, sin embargo se observa que los clientes que fueron atendidos en las ocho tiendas Tabla 2, reflejan un nivel de insatisfacción del $50 \%$ sobre el total de los clientes atendidos, datos que fueron obtenidos a través de las encuestas realizadas por TDP utilizando la Encuesta del Nivel de Satisfacción del Cliente conocida como 
IVR, en adelante se nombrará a este indicador como IVR que viene a ser un sistema automatizado de respuesta interactiva, a través del cual los clientes califican si están o no satisfechos con el servicio, teniendo tres opciones satisfecho, indiferente o insatisfecho.

Tabla 2:

Resultados según la encuesta del nivel de satisfacción del cliente IVR de la empresa Digital

\begin{tabular}{lccc}
\hline Localidad & Satisfacción & Indiferente & Insatisfacción \\
\hline Abancay & $43 \%$ & $18 \%$ & $39 \%$ \\
Andahuaylas & $28 \%$ & $10 \%$ & $62 \%$ \\
Ayacucho & $31 \%$ & $18 \%$ & $50 \%$ \\
Cusco & $32 \%$ & $17 \%$ & $51 \%$ \\
Huancavelica & $32 \%$ & $16 \%$ & $51 \%$ \\
Puerto Maldonado & $26 \%$ & $33 \%$ & $41 \%$ \\
Quillabamba & $43 \%$ & $8 \%$ & $49 \%$ \\
Sicuani & $33 \%$ & $17 \%$ & $50 \%$ \\
Total & $\mathbf{3 3 \%}$ & $\mathbf{1 7 \%}$ & $\mathbf{5 0 \%}$
\end{tabular}

Nota: Reportes de ventas de telefónica del periodo de enero a julio del 2017 en cuanto a las 8 tiendas (elaboración propia).

En la Figura 3, se puede observar los resultados del IVR a nivel de la empresa Digital obteniendo un $49.68 \%$ de insatisfacción, prácticamente la mitad de sus clientes están insatisfechos.

De esta información se puede afirmar que la franquicia pese a ser líder en ventas en el mercado donde opera, no ha logrado tener variaciones positivas en la satisfacción de los clientes en los meses evaluados. 


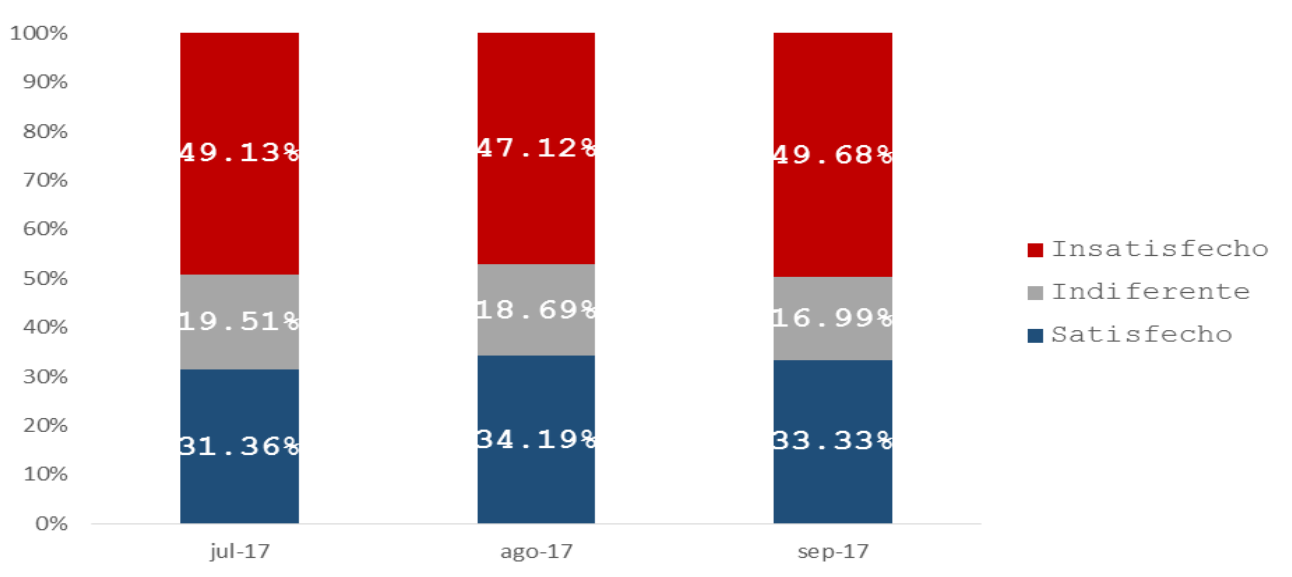

Figura 3: Encuesta del Nivel de Satisfacción del Cliente IVR de la empresa Digital. Tomado de la empresa Digital del periodo de julio a septiembre del 2017.

En la Figura 4 se observa el IVR por tiendas, es decir en las 8 tiendas pertenecientes a la franquicia Digital, en los períodos comprendidos entre julio y setiembre del 2017, el mayor nivel de insatisfacción según el IVR lo tiene la tienda de Andahuaylas y con menor nivel Puerto Maldonado.

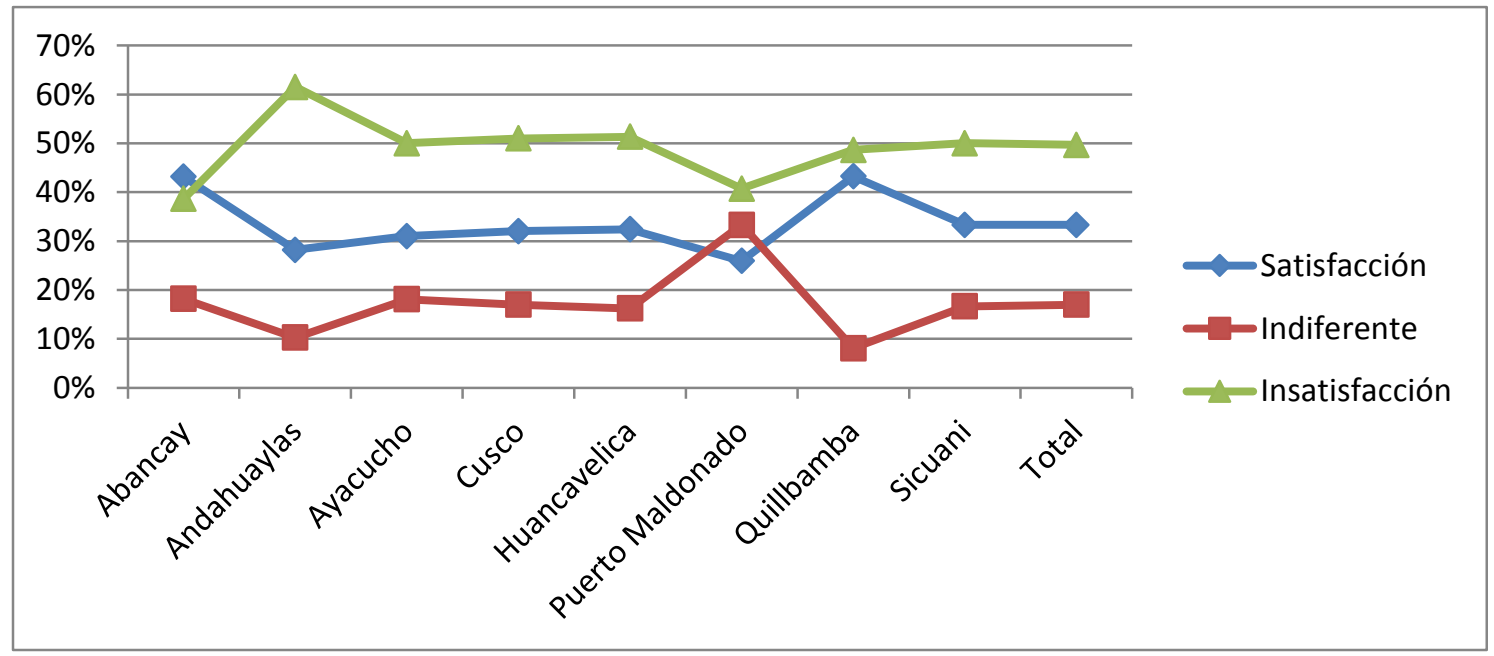

Figura 4: Evolución del nivel de Satisfacción del Cliente IVR por tiendas de la empresa Digital. Reportes de ventas de TDP del periodo de julio a setiembre del 2017 
El nivel de satisfacción de los clientes es importante para Digital porque su principal fuente de ingreso depende de este indicador que es remunerado por TDP, siendo el área responsable el de atención al cliente.

En base a los resultados descritos, el problema principal es que Digital registra un porcentaje superior al $60 \%$ de clientes insatisfechos e indiferentes, para ello se requiere encontrar una estrategia que revierta esta debilidad que presenta la empresa y a través de una planificación estratégica encontrar oportunidades de mejora y herramientas para cambiar estos resultados, en vista que, mejorando la satisfacción del cliente, se incrementará la rentabilidad y el valor de la empresa.

\subsection{Justificación del proyecto}

Dentro del contrato de franquicia con TDP se establecen indicadores relacionados a la calidad de atención del cliente, los mismos que de acuerdo a los resultados de medición determinan el pago de contraprestación a la franquicia, por ello es importante trabajar en un plan estratégico que permita mejorar las capacidades de los colaboradores (a través de planes de capacitación, procesos de reclutamiento, esquemas de bonificación) con la finalidad de mejorar los indicadores e incrementar la rentabilidad de la franquicia.

\subsection{Objetivos generales y específicos}

\subsubsection{Objetivo general.}

Elaborar un plan estratégico para los siguientes 3 años (2019 - 2021) que brinde herramientas de dirección y toma de decisiones que hagan más rentable a la empresa, mejorando la satisfacción del cliente. 


\subsubsection{Objetivos específicos.}

- Evaluar la visión, misión y valores de la franquicia.

- Analizar la situación interna y externa de la franquicia.

- Formular los objetivos y estrategias de la franquicia.

- Implementar las estrategias para la franquicia.

- Evaluar el impacto financiero de la implementación de estrategias en la franquicia.

- Establecer las acciones de seguimiento y control que permitan implementar las estrategias elegidas.

\subsection{Alcances y limitaciones de la investigación}

El alcance se dará en las ciudades donde la franquicia Digital tiene presencia a través de sus ocho tiendas, es decir: Cusco, Sicuani, Quillabamba, Abancay, Andahuaylas, Puerto Maldonado, Huancavelica y Huamanga.

Se tiene como limitación el acceso a la información, dado que OSIPTEL no maneja un criterio único en sus reportes, estadísticas, boletines y su información publicada se encuentra desactualizada, asimismo, las franquicias que compiten en el mismo sector incluida Digital, no reportan estados financieros a entes reguladores por estar catalogadas dentro del segmento de MYPES, información que no puede ser de acceso público; para la elaboración del plan se cuenta con información de TDP quien genera reportes para sus franquiciados con información referida solamente a calidad de atención. 


\section{CAPITULO II. LA FRANQUICIA}

\subsection{Antecedentes de la empresa}

La franquicia Digital, fue creada el año 1999 como pequeña empresa dedicada a la representación comercial y prestación de servicios de telecomunicaciones; fue constituida por 2 socios, con un capital inicial de S/10,000 (diez mil nuevos soles) y una participación del 50\% por cada uno. En la actualidad la franquicia cuenta con 122 trabajadores en planillas y un capital social de $\mathrm{S} / 280,000$ (Doscientos ochenta mil soles).

Digital inició sus actividades con el Grupo Telefónica, comercializando productos de la siguiente manera: celulares para Movistar, Cable Mágico para Telefónica Multimedia y teléfonos fijos e internet para Telefónica del Perú. El año 2004 Digital es seleccionada por Movistar para iniciar el piloto en la tercerización del servicio de postventa y cobranza de sus recibos en la ciudad de Cusco, más adelante apertura oficinas para realizar atención de post venta para Movistar en Abancay, Andahuaylas, Sicuani y Puerto Maldonado. En el 2007 Movistar le otorgó la administración de la oficina principal en Cusco, en el 2012 de la oficina de Huancavelica y en el 2015 hace lo propio con la oficina principal en Huamanga; consolidándose de esta manera como el socio comercial estratégico para TDP en el sur del país.

En el año 2014 TDP cambia el modelo de contratos de tiendas tercerizadas al modelo de franquicias, este cambio se realiza de manera progresiva hasta culminar el 2017 trabajando en todas las tiendas bajo este modelo; la franquicia cuenta con una sede administrativa propia en la ciudad del Cusco desde la cual brinda soporte a todas sus tiendas franquicia, las que realizan las siguientes actividades: Prestación del servicio de postventa, comercialización de productos y recaudación de recibos. 


\subsection{Descripción del negocio}

Digital es una franquicia que trabaja de manera exclusiva para TDP, siendo sus principales actividades: la prestación del servicio de postventa; comercialización masiva de telefonía móvil y fija y la recaudación de recibos telefónicos, actividades que se realizan bajo las especificaciones del contrato de franquicia (Anexo 1), en sus ocho tiendas ubicadas en las diferentes regiones del país. Es preciso mencionar que el servicio de postventa que presta Digital está orientado a todos los clientes residenciales (se excluye a todos los clientes de grandes empresas) de TDP, independientemente de dónde hayan contratado el servicio, al igual que la recaudación de recibos telefónicos; en el caso de la comercialización masiva de telefonía móvil y fija corresponde a las ventas de líneas nuevas.

Todas estas actividades forman parte del negocio teniendo cada una un valor porcentual en los ingresos de la franquicia siendo el más significativo, el de prestación del servicio de postventa.

\subsection{Ciclo de vida del servicio}

La empresa Digital cuenta con 18 años de funcionamiento prestando servicios a TDP, pese al tiempo transcurrido es importante aclarar los cambios que se viene dando en los últimos años, dado que TDP viene implementando un nuevo modelo de negocio bajo la modalidad de franquicia, por ello para el ciclo de vida del servicio se ha considerado el crecimiento de los ingresos por concepto de comisiones (venta de líneas fijas, venta de líneas móvil y servicio de post venta) tal como se aprecia en la Figura 5,encontrándose en la etapa de madurez, este crecimiento se ha dado de la siguiente manera:

- Año 2015 S/. 4’399,218 
- Año 2016 S/ 5’742,514 (30\% de crecimiento más que el 2015)

- Año 2017 S/ 7’068,388 (23\% de crecimiento más que el 2016)

- Año 2018 S/ 7’139,071 (1\% de crecimiento más que el 2017)

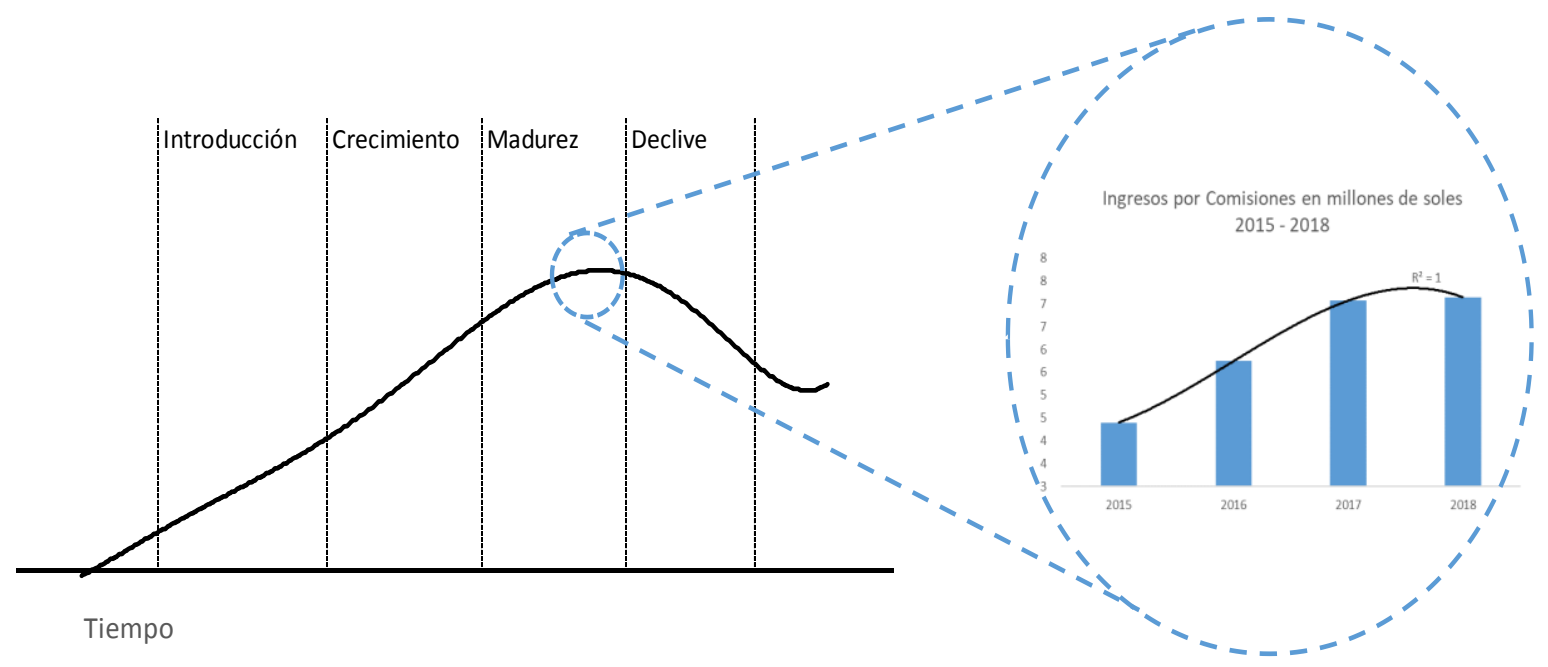

Figura 5: Ciclo de vida del servicio de Digital.

Elaboración propia.

\subsection{Ciclo de vida de la empresa Digital}

Se ha tomado en cuenta el comportamiento de la utilidad en los últimos 3 años los mismos que han ubicado a la franquicia en la etapa de madurez, como se observa en la Figura 6, dado que las utilidades vienen crecimiento a un ritmo menor, de S/ 580,197 para el año 2017 a S/ 597,319 para el año 2018. 


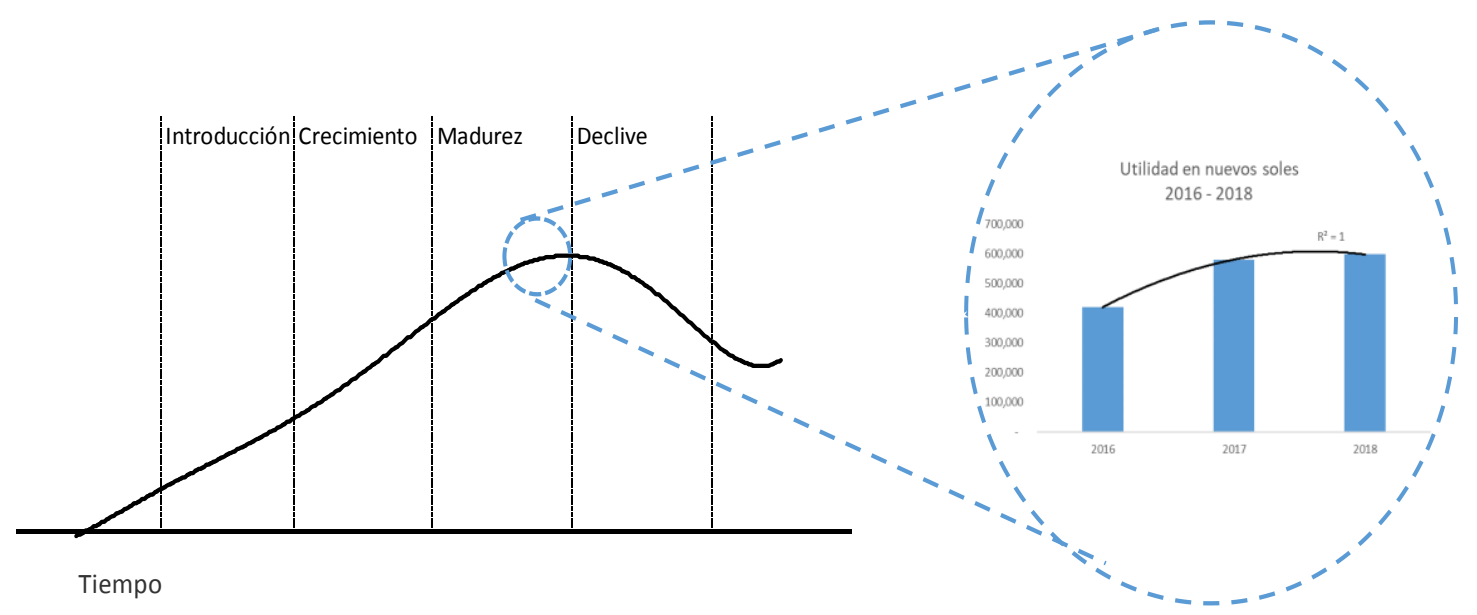

Figura 6: Ciclo de vida del servicio de Digital Elaboración propia.

\subsection{Ciclo de vida de la industria de telecomunicaciones}

Según se observa en la Figura 7, el sector de telecomunicaciones entre los años 2013 al 2016 registra un crecimiento de $26 \%$ pasando de 29 953,848 líneas a 37 719,697 líneas, no obstante se puede observar un crecimiento más bajo en el 2017 (3\%), debido a mayor seguridad en las ventas del servicio móvil la misma que se lleva a cabo previa identificación biométrica del cliente, por otro lado se dio cumplimiento al decreto supremo $\mathrm{N}^{\circ}$ 003-2016 $\mathrm{MTC}$ emitido por el Ministerio de Transportes y Telecomunicaciones, decreto que ordena el apagón telefónico que sacó del mercado 842646 líneas prepago informó Gonzalo Ruiz Diaz, quién además indicó que estas líneas pertenecían a 22,240 clientes quienes no pudieron validar su identidad. Por lo que se puede decir que la industria se encuentra en una etapa de madurez.

Los principales operadores del sector de telecomunicaciones son: Telfónica del Perú con el 38.20\% de participación del mercado seguido por América Móvil con 32.10\%, Entel con $16.40 \%$, Bitel con $13.10 \%$ y por último Virgin Móbile con $0.20 \%$. 
De acuerdo a Porter (2002) como se cita en D’Alessio (2008) “En las industrias que transitan a la madurez, la organización debe ser capaz de corregir su ritmo estratégico a través de autoevaluaciones, para que el transito se haga con éxito y extender está etapa el mayor tiempo posible" (pág. 363).

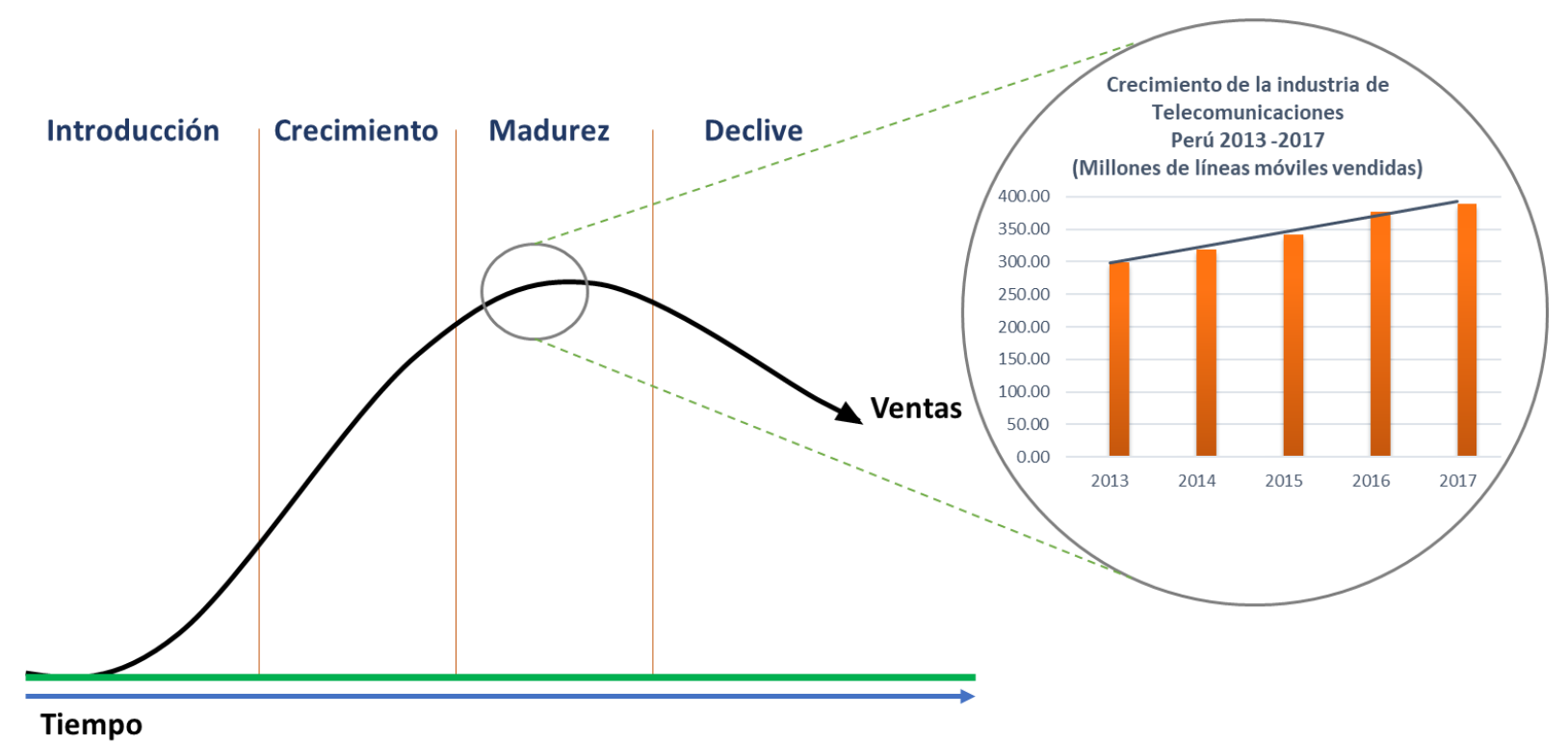

Figura 7: Ciclo de vida de la industria de TDP.

Datos proporcionados por OSIPTEL (elaboración propia).

\subsection{Estructura organizacional actual de la empresa}

De acuerdo a Taylor (2009) citado en el blog Organízate Online (2019) el organigrama de Digital es una representación gráfica de forma lineo funcional, que tiene por finalidad informar e integrar las funciones de la organización según los diferentes niveles jerárquicos desde el inicio de la actividades, hasta el logro de los objetivos de la franquicia; se puede observar que existen tres niveles, el nivel directivo que ve la parte estratégica, nivel intermedio a cargo de lo táctico y el nivel operacional; el nivel directivo representado por la Gerencia General; seguido por las 
cuatro gerencias de línea denominadas: Gerencia de Fija, Gerencia de Móviles, Gerencia de Contabilidad y Gerencia de Recursos Humanos las que se encuentra en el nivel intermedio y un staff de apoyo que brinda asesoramiento externo legal y contable, como se puede observar en la Figura 8.

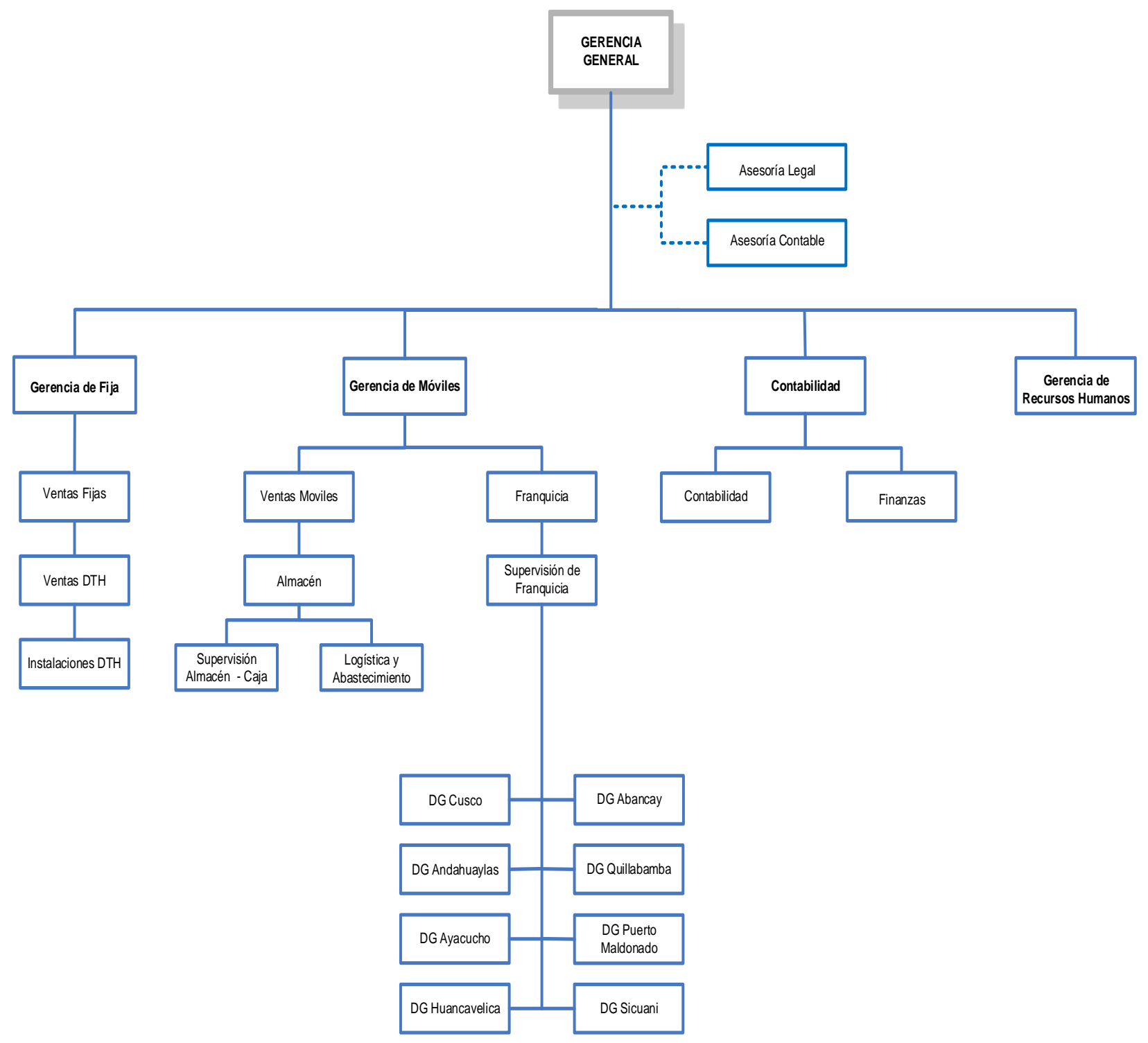

Figura 8: Organigrama de la franquicia Digital Elaboración propia. 
La Gerencia General, es la encargada de dirigir la empresa, bajo su conducción se fijan los objetivos a corto y largo plazo, así como las estrategias para alcanzar los mismos. Esta gerencia también es la encargada de las negociaciones con TDP.

La Gerencia de Móviles, se encarga de planificar, fijar y controla el cumplimiento de los objetivos de todas las tiendas franquicias, no solo de ventas sino también en todos los indicadores que se deben alcanzar en la post venta como son: IVR, NDS etc.

La Gerencia de Fija, es la encargada de planificar, fijar y controlar el cumplimiento de los objetivos de todas las tiendas franquicias de las ventas de los productos de líneas fijas, internet y televisión por cable, esta gerencia además se encarga de dirigir las ventas proactivas (ventas en campo) de estos productos.

La Gerencia de Contabilidad, es la encargada de programar y cuantificar las obligaciones dentro de los plazos previstos, como son: planillas, impuestos, pagos a proveedores etc. Así mismo velar por un control eficiente de todos los recursos de la empresa.

La Gerencia Recursos Humanos, es la encargada de gestionar el recurso humano a través de los procesos de reclutamiento, selección, capacitación, y remuneraciones y compensaciones; así como velar por la seguridad, salud, beneficio social y el buen clima laboral.

Supervisores de las diferentes áreas se encargan de velar por el cumplimiento de las metas y objetivos trazados por las diferentes gerencias de manera mensual. 


\subsection{Situación de mercado y financiera actual de la industria}

El mercado de telecomunicaciones móviles ha ido evolucionando desde sus inicios con la entrada de TDP, sin embargo, tuvo su primer gran salto de crecimiento el año 2007, con un incremento del $75.82 \%$ en relación al 2006, que permitió pasar de ocho millones de usuarios a quince millones, hasta llegar a más de treinta millones de usuarios en la actualidad. Andina (2017) afirma que en el año 2014 el sector de las telecomunicaciones representó el 3.5\% del PBI (Producto Bruto Interno), según lo informó el presidente de OSIPTEL, Gonzalo Ruíz Díaz "las empresas de telecomunicaciones facturan en conjunto cinco millones quinientos mil dólares al año frente a un millón quinientos mil dólares que facturaban el año 2,000”. De la misma forma el INEI (2017), menciona que en febrero del 2017 el sector de telecomunicaciones y otros servicios de información se incrementó en $8.8 \%$ respecto al mismo mes en el 2016. Acumulando diez años de comportamiento positivo. Hubo un avance significativo en el uso de las tecnologías de la información reflejando una expansión de la telefonía móvil (16.5\%) con la incorporación al mercado de un número mayor de empresas operadoras, mayor competitividad entre estas, así mismo mayor tráfico de llamadas de tipo local como de larga distancia.

La industria donde se desarrolla Digital, está formada por ocho empresas entre agentes y franquicias, que trabajan de forma exclusiva con TDP, la participación de mercado en lo que va del 2017 es como se muestra en la tabla 1 al inicio del trabajo, se mantiene en los 03 últimos años, liderando las ventas de los productos de TDP en las regiones de Cusco, Apurímac y Madre de Dios. Esta participación está expresada en unidades vendidas, del período de enero a julio del 2017. Digital realizó 9903 ventas de teléfonos móviles postpago lo cual representa el 53.42\% de las ventas del mercado en las 3 zonas donde opera, frente al $11.77 \%$ de la franquicia Boutique Celular. 


\section{CAPITULO III. FORMULACIÓN DE VISIÓN, MISIÓN Y VALORES DE LA EMPRESA}

\subsection{Visión}

\subsubsection{Visión actual de la empresa.}

“Aspiramos ser reconocidos por nuestros clientes y entorno como la mejor empresa de representación comercial y servicios integrales; trabajando con un sistema de alta calidad para lograr la plena satisfacción de nuestros clientes.

Buscamos dar a nuestro personal la confianza de trabajar en una empresa formal, comprometida con el bienestar de sus trabajadores. Aspiramos lograr los mejores resultados para el fortalecimiento de la empresa."

\subsubsection{Análisis de la visión actual.}

Del análisis realizado a la visión de la empresa se determina que se enfoca en dos componentes: el primero hacia el cliente y el segundo hacia el colaborador, sin embargo, se observa que la visión actual no considera elementos importantes como: su mercado objetivo, ni el tipo de compañía, por ello que se propone replantear la visión.

\subsubsection{Matriz de la visión propuesta para la empresa.}

De acuerdo a Porter (1987), "toda la visión debe ser enfocada en el futuro, lo que hace que una empresa comience a describirse a sí misma y sepa qué es lo que quiere lograr". 
Para la elaboración de la matriz de la visión se contó con la colaboración de las diferentes gerencias de línea de la empresa (presentadas anteriormente en el organigrama, Figura 8), quienes son conocedores de la situación actual de la empresa, así como los retos que enfrentan día a día, los mismos que tienen los objetivos claros respecto de a dónde quieren llegar como empresa. Como se puede observar en la tabla 3 la matriz de la visión propuesta de la empresa se han considerado otros elementos importantes para la formulación de la visión, como son el de ser: integradora, amplia y detallada, posible e inspiradora, realista y positiva.

Tabla 3:

Matriz de la visión propuesta para la empresa (Serna Gomez, 2008)

\begin{tabular}{|c|c|c|c|}
\hline $\begin{array}{l}\text { ELEMENTOS A } \\
\text { CONOCER }\end{array}$ & SI & NO & ¿POR QUE? \\
\hline $\begin{array}{l}\text { ¿Está formulada por } \\
\text { líderes? }\end{array}$ & $\mathrm{X}$ & & $\begin{array}{l}\text { Sí, porque cuenta con la participación de las } \\
\text { jefaturas y gerencia }\end{array}$ \\
\hline $\begin{array}{l}\text { ¿Está definida en el } \\
\quad \text { tiempo? }\end{array}$ & & X & $\begin{array}{l}\text { No, porque no tiene un tiempo definido, por } \\
\text { el tipo de negocio al que pertenece }\end{array}$ \\
\hline ¿Es integradora? & $X$ & & $\begin{array}{c}\text { Sí, porque considera los elementos de cliente, } \\
\text { mercado y franquicia }\end{array}$ \\
\hline ¿Es amplia y detallada? & $\mathrm{X}$ & & Sí, porque define claramente sus expectativas \\
\hline $\begin{array}{l}\text { ¿Es posible e } \\
\text { inspiradora? }\end{array}$ & $\mathrm{X}$ & & $\begin{array}{l}\text { Sí, porque el fin es la mejor experiencia de } \\
\text { servicios al cliente }\end{array}$ \\
\hline ¿Es realista y positiva? & $X$ & & $\begin{array}{l}\text { Sí, porque a la fecha ya es líder y tiene que } \\
\text { mantenerse }\end{array}$ \\
\hline
\end{tabular}

Nota: Información proporcionada por la gerencia de la empresa (elaboración propia). 


\subsubsection{Visión propuesta.}

“Ser una empresa líder e innovadora en el mercado de telefonía móvil y fija de los productos ofertados por TDP en las regiones donde operamos, reconocidos por brindar la mejor experiencia de servicio a nuestros clientes".

\subsection{Misión}

\subsubsection{Misión actual de la empresa.}

“Somos una empresa de representación comercial y prestación de servicios integrales del grupo Telefónica. Trabajamos de manera eficiente y eficaz, colaborando con las empresas a las que representamos a lograr mayor productividad, alcanzar sus objetivos, con una mejora continua en sus servicios y manteniendo un nivel de alta calidad, con la finalidad de satisfacer plenamente las necesidades de sus clientes."

\subsubsection{Análisis de la misión actual.}

Tomando en cuenta los nueve elementos de David (2013), se concluye que:

- Clientes: se observa que la misión actual considera a los clientes.

- Productos y/o servicios: se observa que no se define con claridad el principal servicio o producto que ofrece la empresa.

- Mercado: Se observa que no hace mención al área geográfica de influencia.

- Tecnología: Se observa que no se hace mención del uso de tecnología.

- Interés por el crecimiento y sostenibilidad: Se observa que la misión actual si considera este ítem.

- Filosofía: No expresa las creencias o valores. 
- Auto concepto: Se observa que, si está considerada su ventaja competitiva, pero se considera que debe ser reforzada.

- Preocupación de la imagen pública: Se observa que este elemento no está considerado.

- Interés por los empleados: Se observa que si se considera a los empleados por ser un pilar de la empresa (pág. 69).

\subsubsection{Elementos de la misión propuesta para la empresa.}

David (2013) afirma. "la declaración de la misión puede variar en cuanto a extensión, contenido, formato, y especificidad" (pág. 68). En la Tabla 4 de la matriz de la misión propuesta para la empresa se puede apreciar la misión y seis componentes de los nueve propuestos por David (2013).

\subsubsection{Misión propuesta.}

"Somos una franquicia comercial de TDP en el centro y sur oriente del Perú, con colaboradores comprometidos que prestan servicios de venta y postventa de equipos de telecomunicación, recaudación de recibos de telefonía móvil y fija, de manera eficiente con calidez de atención, innovación y tecnología”. 
Tabla 4:

Matriz de la misión propuesta para la empresa

\begin{tabular}{|c|c|c|}
\hline Elementos & Preguntas & Visión Propuesta \\
\hline \multirow{2}{*}{ Productos y servicios } & ¿Cuáles son los & Somos una franquicia de Telefónica \\
\hline principales? & ¿Dónde compite? & Zona centro y sur oriente del Perú \\
\hline Tecnología & ¿Está al día con la & Es una empresa vinculada a la \\
\hline Auto concepto & tecnología? & tecnología \\
\hline Interés por el & ¿Está comprometida su ventaja & De manera eficiente con calidez en la \\
crecimiento y & con el crecimiento y la & Si porque es eficiente, con innovación y \\
\hline rentabilidad & solidez? & tecnología \\
\hline Interés por los & un activo valioso para la & Colaboradores comprometidos y \\
\hline franquicia? & & \\
\hline
\end{tabular}

Nota: Información proporcionada por la gerencia de la franquicia (elaboración propia). Elementos de la misión según Fred R, David.

\subsection{Valores}

\subsubsection{Valores actuales de la empresa.}

Honestidad. Con este valor se busca una armonía entre las palabras y las acciones de todos los trabajadores dentro de la franquicia. La honestidad logra que la franquicia sea vista y aceptada como una organización transparente.

Ética. Está relacionada con la moral y la acción humana es la que define lo que es bueno, malo, obligatorio, permitido, etc. respecto a una acción y decisión. 
Responsabilidad. Ser responsable supone, por un lado, tomar decisiones de forma libre, voluntaria y consciente; y por otro, asumir las consecuencias que conllevan dichas decisiones. En caso de que la decisión tomada provoque un percance, la responsabilidad implica la obligación de reparar el daño causado (esta reparación puede ser económica, o puede consistir en la dimisión del cargo que ocupa la persona responsable).

Profesionalismo. Se denomina profesionalismo a la capacidad y a la preparación para el desempeño de una tarea, un profesional es una persona capacitada para cubrir debido a sus conocimientos un puesto con requerimiento específico, también profesionalismo implica compromiso con la tarea a realizar.

Perseverancia. La perseverancia es "la firmeza y constancia en la ejecución de los propósitos. Es la predisposición a mantenerse firme y constante en la prosecución de acciones y emprendimientos de manera estable o continua hasta lograr el objetivo. No hace referencia al conformismo; al contrario, alude a la fuerza interior para insistir, repetir una acción, mantener una conducta tendiente a lograr cualquier objetivo propuesto, tanto personal como de la organización” (Corzo, 2009).

\subsubsection{Análisis de los valores actuales.}

La franquicia en sus inicios contaba con cinco valores descritos en el párrafo anterior; hoy en día se observa que la honestidad y la ética han permitido el desarrollo de la franquicia durante estos 18 años, la responsabilidad y el profesionalismo también se han sumado a las buenas prácticas y por ello pese a los años transcurridos la franquicia se mantiene en el mercado, comparada con muchas otras que dejaron de trabajar con TDP, así mismo la perseverancia motivó a que se trabaje un día a la vez y se siga avanzando. 


\subsubsection{Elementos de los valores propuestos para la empresa.}

El cambio en la visión y misión tiene como consecuencia un nuevo enfoque de hacia dónde quiere llegar la franquicia, por consiguiente se necesita replantear los valores existentes e incluir nuevos valores, tomando en cuenta que los valores son importantes para una franquicia porque son fuerzas impulsoras del cómo se hace el trabajo a diario, debiendo ser verdaderas cartas de navegación que dirijan todos los esfuerzo hacia el norte deseado se plantean como nuevos valores los relacionados al trabajo en equipo, orientación al cliente, empatía, manteniendo la honestidad, como valor principal.

\subsubsection{Valores propuestos.}

Honestidad. Valor que se mantiene.

Orientación al cliente. La razón de ser de la franquicia es el cliente y por ello todos los esfuerzos de la empresa deben de estar orientadas a conseguir su satisfacción.

Orientación a resultados. Todas las franquicias en la actualidad están enfocadas a obtener resultados positivos que le permitan mantenerse en el tiempo. La franquicia deberá hacer partícipe a todo el personal de los objetivos que se quiere alcanzar en un tiempo determinado.

Empatía. Para lograr la satisfacción del cliente la franquicia busca contar con trabajadores empáticos que logren identificar las necesidades de los clientes, buscando satisfacer dichas necesidades, brindando una atención que a ellos les gustaría recibir. 
Trabajo en equipo. La franquicia debe buscar, que cada área y trabajador sea parte de una única estructura que funcione en constante comunicación y coordinación haciendo posible el logro de los objetivos en el tiempo previsto.

\subsection{Alineamiento estratégico de la visión, misión y valores de la empresa}

Según el análisis realizado a la visión, misión y objetivos de la franquicia, se presenta la figura 9 donde se observa de manera didáctica los resultados del estudio.

\section{VISION}

"Ser una franquicia líder e innovadora en el mercado de telefonía móvil y fija de los productos ofertados por TDP en las regiones donde operamos, reconocidos por brindar la mejor experiencia de servicio a nuestros clientes"

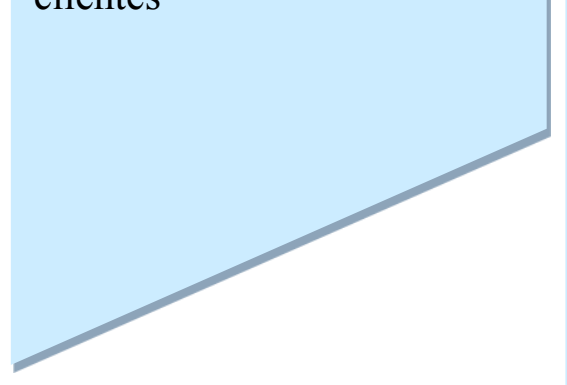

\section{MISION}

"Somos una franquicia comercial de TDP en el centro y sur oriente del Perú, con colaboradores comprometidos que prestan servicios de venta y postventa de equipos de telecomunicación, recaudación de recibos de telefonía móvil y fija, de manera eficiente con calidez de atención, innovación y tecnología"

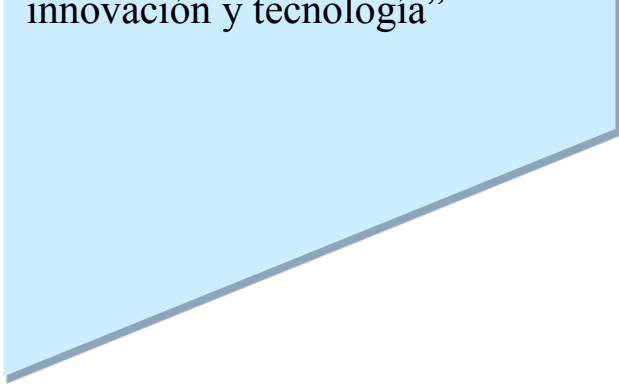

\section{VALORES}

- Honestidad

- Orientación al cliente

- Orientación a resultados

- Empatía

- Trabajo en equipo

Figura 9: Alineamiento estratégico de la visión, misión y los valores. Determinado en el estudio realizado a la franquicia Digital (elaboración propia). 


\section{CAPITULO IV. ANALISIS EXTERNO}

\subsection{Tendencias de las variables del entorno}

En este capítulo se analizarán las principales variables de carácter político, macroeconómico, legal, tecnológico, ecológico entre otras y cómo estas variables que están relacionadas al comportamiento del país, pueden influir positiva o negativamente en el desenvolvimiento de la industria.

\subsubsection{Análisis Político-Gubernamental.}

Conforme establece la Constitución Política del Perú del año 1993, el régimen bajo el cual se rige el país es una economía de libre mercado, por ello la iniciativa privada es libre.

Considerando que el estado propicia la libertad de mercado, la propiedad privada y libre competencia, se cuenta con la participación de varias empresas de telecomunicaciones en el Perú, de diferentes tamaños y coberturas. Según la información publicada por OSIPTEL noviembre del 2017, en el Perú se cuenta con 13 empresas operadoras, prestando diferentes servicios en las telecomunicaciones.

La variable político-gubernamental para el análisis se mantiene estable debido a que el gobierno continúa con un régimen de libre mercado, en ese sentido esta variable representa una amenaza para la industria de telecomunicaciones, dado que facilita el ingreso de nuevos competidores. 


\subsubsection{Análisis Económico.}

\subsubsection{Producto Bruto Interno.}

La variable que mide el desenvolvimiento de la economía es el PBI, y según este como se puede ver en la Tabla 5 el sector de las telecomunicaciones mantiene un crecimiento a julio del 2017 de $6.88 \%$ y un comportamiento interanual de $7.66 \%$. Ello muestra un contexto macroeconómico favorable para el sector que se analiza, pese a que registra una baja de $0.78 \%$ para el año 2017 en el comportamiento del PBI, aun así, esta cifra es superior al crecimiento del PBI nacional que solo registra un crecimiento a julio 2017 de $1.55 \%$ frente a un 6.88\% del sector de telecomunicaciones, por ello se considera que es favorable para el desarrollo y crecimiento de la industria. 
Tabla 5:

PBI Nacional - índice de producción sectorial (var \%)

\begin{tabular}{lcc}
\hline \multicolumn{1}{c}{ Sectores } & Julio 2017 & $\begin{array}{c}\text { Agosto 2016 - julio 2017 } \\
\text { Agosto 2015 - -julio 2016 }\end{array}$ \\
\hline Agropecuaria & 9.00 & 2.4 \\
Pesca & -49.43 & 42.87 \\
Minería e Hidrocarburos & 1.9 & 6.91 \\
Manufactura & -6.28 & 2.03 \\
Electricidad y Agua & 1.31 & 3.15 \\
Construcción & 3.8 & -4.66 \\
Comercio & 1.21 & 0.84 \\
Transporte y Mensajería & 1.77 & 2.81 \\
Telecomunicaciones & $\mathbf{6 . 8 8}$ & $\mathbf{7 . 6 6}$ \\
Financiero y Seguros & 1.36 & 1.10 \\
PBI & $\mathbf{1 . 5 5}$ & $\mathbf{2 . 8 9}$ \\
\hline
\end{tabular}

Nota: COFIDE boletín de coyuntura económica PBI 2017 (elaboración propia).

Así mismo, se ha evaluado la participación del PBI en las regiones donde la franquicia cuenta con tiendas de atención y venta de productos, siendo las siguientes: Cusco, Apurímac, Madre de Dios, Huancavelica y Ayacucho ver (tabla 6). 
Tabla 6:

PBI de las regiones a nivel nacional.

\begin{tabular}{lllll}
\hline \multicolumn{5}{l}{ Producto Bruto Interno Real (Valor en Millones de S/. de 2007) } \\
\hline Ranking & Departamento & 2015 & 2016 & $\%$ Anual \\
1 & Lima & 201,843 & 209,714 & $3.90 \%$ \\
2 & Arequipa & 22,691 & 22,884 & $0.85 \%$ \\
$\mathbf{3}$ & Cusco & $\mathbf{2 0 , 7 1 6}$ & $\mathbf{2 0 , 8 1 2}$ & $\mathbf{0 . 4 6 \%}$ \\
4 & La Libertad & 19,471 & 19,752 & $1.44 \%$ \\
5 & Piura & 17,696 & 18,443 & $4.22 \%$ \\
6 & Ancash & 18,516 & 16,255 & $12.21 \%$ \\
7 & Ica & 14,478 & 14,943 & $3.21 \%$ \\
8 & Junín & 11,177 & 12,494 & $11.78 \%$ \\
9 & Cajamarca & 11,337 & 11,239 & -0.86 \\
10 & Lambayeque & 10,274 & 10,496 & $2.16 \%$ \\
11 & Loreto & 8.429 & 8,704 & $3.26 \%$ \\
12 & Moquegua & 8,875 & 8,643 & -2.61 \\
13 & Puno & 8,314 & 8,546 & $2-79$ \\
14 & Tacna & 5,898 & 6,233 & $5.68 \%$ \\
15 & Pasco & 4,993 & 5,148 & $3.10 \%$ \\
$\mathbf{1 6}$ & Ayacucho & $\mathbf{4 , 9 9 9}$ & $\mathbf{5 , 1 1 4}$ & $\mathbf{2 . 3 0 \%}$ \\
17 & San Martin & 4,777 & 5,084 & $6.43 \%$ \\
18 & Huánuco & 4,662 & 4,871 & 4,48 \\
19 & Ucayali & 3,955 & 3,976 & $0.53 \%$ \\
$\mathbf{2 0}$ & Huancavelica & $\mathbf{3 , 2 2 6}$ & $\mathbf{3 , 3 6 0}$ & $\mathbf{4 . 1 5 \%}$ \\
21 & Amazonas & 2,730 & 2,869 & 5.09 \\
22 & Tumbes & 2,511 & 2,629 & $4.70 \%$ \\
$\mathbf{2 3}$ & Apurímac & $\mathbf{2 , 3 4 7}$ & $\mathbf{2 , 4 5 4}$ & $\mathbf{4 . 5 6 \%}$ \\
$\mathbf{2 4}$ & Madre de Dios & $\mathbf{2 , 2 0 4}$ & $\mathbf{1 , 9 0 7}$ & $\mathbf{- 1 3 . 4 8 \%}$ \\
\hline & & & & \\
\hline
\end{tabular}

Nota: Instituto Peruano de Economía - Índice de Competitividad Regional el PBI de las todas las regiones a nivel nacional.

De las 5 regiones donde se ubica la franquicia, dos de ellas registran un mayor dinamismo Apurímac con $4.56 \%$ y Huancavelica $4.15 \%$ anual, superior al comportamiento del PBI nacional.

Dada la contribución al PBI por departamento, Lima sigue siendo la región con la mayor participación según se observa en la tabla 6 considerando el tamaño de las economías por regiones, Cusco es la tercera en tamaño, lo cual representa una oportunidad para la franquicia. 


\subsubsection{Tipo de Cambio.}

Otra variable importante que afecta de manera indirecta a la industria es el comportamiento del tipo de cambio, conforme el dólar se aprecie, los equipos celulares que se importan podrían incrementar su precio, haciéndolos más caros y el efecto contrario si baja podría disminuir, en el primer semestre del año 2017 el dólar se depreció, frente a las expectativas que mantenían los analistas económicos, sistema financiero, no financiero bancario y Banco Central de Reserva del Perú (BCRP, 2017) citado por (COFIDE, 2017) donde proyectaban un tipo de cambio que a diciembre podría llegar a situarse entre S/. 3.40 y S/. 3.50 dicha expectativa fue a inicios del año 2017, sin embargo, a setiembre 2017 este panorama ha cambiado y se proyectó para el cierre de 2017 las variaciones ven entre S/. 3.27 a S/. 3.30 y un leve incremento para los próximos años (ver Tabla 7).

Tabla 7:

Expectativas de tipo de cambio

\begin{tabular}{|l|l|l|l|l|l|}
\hline $\begin{array}{l}\text { Expectativas } \\
\text { de Tipo de } \\
\text { Cambio S/. } \\
\text { US\$ }\end{array}$ & AÑOS & $\begin{array}{l}\text { Analistas } \\
\text { Económicos }\end{array}$ & $\begin{array}{l}\text { Sistema } \\
\text { Financiero }\end{array}$ & $\begin{array}{l}\text { Sistema } \\
\text { No } \\
\text { Financiero }\end{array}$ & BCRP \\
\cline { 2 - 6 } & 2017 & 3.28 & 3.27 & 3.30 & 3.28 \\
\cline { 2 - 6 } & 2018 & 3.35 & 3.30 & 3.40 & 3.35 \\
\cline { 2 - 6 } & 2019 & 3.40 & 3.34 & 3.43 & 3.40 \\
\hline
\end{tabular}

Nota: COFIDE boletín de coyuntura económica setiembre 2017

El comportamiento del dólar ha favorecido la importación de equipos celulares en el sector de telecomunicaciones y para el próximo año se esperaría solo un leve incremento. 


\subsubsection{Inflación.}

Esta variable representa la estabilidad de los precios en la economía y conforme los reportes de inflación de BCRP al 2016 estaría dentro del rango meta planteado para el 2017 (entre 1\% $3 \%$ ), ello genera una mayor confianza en la economía y en el mercado considerando que el poder adquisitivo de los consumidores se mantiene y solo se ve afectado en un porcentaje bajo, dicha inflación es una de las menores en la región (ver Tabla 8).

Tabla 8:

Expectativas de inflación

\begin{tabular}{|c|r|r|r|r|r|r|}
\hline $\begin{array}{c}\text { Expectativas } \\
\text { de Inflación (Var. }\end{array}$ & \multicolumn{2}{|c|}{2017} & \multicolumn{2}{|c|}{2018} & \multicolumn{2}{c|}{2019} \\
\cline { 2 - 7 } \%) & Junio & Set & Junio & Set & Junio & Set \\
\hline Inflación & $2,0-2,5$ & $2,0-2,5$ & $2,0-2,2$ & 2,0 & 2,0 & 2,0 \\
\hline $\begin{array}{c}\text { Inflación } \\
\text { Esperada }\end{array}$ & 3,0 & 2,8 & 2,8 & 2,7 & 2,7 & 2,7 \\
\hline
\end{tabular}

Nota: BCR (2017) setiembre 2017, panorama actual y proyecciones macroeconómicas 2017-2019.

\subsubsection{Tasa de interés.}

Para determinar el comportamiento de la tasa de interés, se toma como base la tasa de interés de referencia que establece el Banco Central de Reserva del Perú (BCRP) la misma que ha ido disminuyendo durante el año 2017, en noviembre del mismo año el BCRP acordó reducir la tasa de referencia de $3.50 \%$ a $3.25 \%$, considerando que la actividad económica se viene recuperando, ello significa que el sistema financiero ajustará sus tasas a la baja o las mantendrá para el otorgamiento de los préstamos a las empresas, lo cual representa una oportunidad para que las 
empresas accedan a créditos de capital de trabajo, cartas fianzas, u otros instrumentos financieros a tasas menores, reduciendo los costos financieros.

\subsubsection{Análisis Socio Cultural.}

Dentro del país se tiene una clasificación de la población según grupos de edades con características particulares, los cuales están divididos por generaciones donde resaltan según la Tabla 9 las siguientes: la generación Z y la generación Y que representan el 68.70\% es el grupo más representativo de la población del país, que está vinculado con los productos y servicios que se ofrece en la industria de telecomunicaciones, la población comprendida entre 0 y 17 años son un mercado potencial para los años siguientes, esta variable es una oportunidad para la industria, datos según CPI (2017).

También existen otros factores que caracterizan a estas generaciones Z y Y, requieren las cosas de manera inmediata, por ello las compras por internet están en crecimiento, no les gusta esperar en una oficina y son muy exigentes con la atención que reciben y pueden cambiar rápidamente de gustos y preferencias. 
Tabla 9:

Perú: Población por segmentos de edad 2017

\begin{tabular}{lllll}
\hline $\begin{array}{l}\text { GRUPO DE } \\
\text { EDAD }\end{array}$ & MILES & PORCENTAJE & DENOMINACION & $\begin{array}{l}\text { GRUPOS } \\
\text { GENERACIONALES }\end{array}$ \\
\hline 00 - 05 años & $3,405.50$ & $10.70 \%$ & & \\
06 - 12 años & $4,065.90$ & $12.80 \%$ & NATIVOS & $\begin{array}{l}\text { GENERACIÓN Z } \\
\text { GENERACION } \\
\text { INTERNET }\end{array}$ \\
13 - 17 años & $2,900.60$ & $9.10 \%$ & DIGITALES & GENERACION Y \\
18 - 24 años & $3,989.60$ & $12.50 \%$ & MILENNIALS \\
25 - 39 años & $7,502.80$ & $23.60 \%$ & INMIGRANTES & GENERACION X \\
40 - 55 años & $5,719.10$ & $18.00 \%$ & DIGITALES & BABY BOOBERS \\
56 - + años & $4,242.50$ & $13.30 \%$ & ANALOGOS & \\
$\begin{array}{l}\text { TOTAL } \\
\text { POBLACION }\end{array}$ & $31,826.00$ & $100.00 \%$ & & \\
\hline
\end{tabular}

Nota: CPI (2017) CPI Market Report agosto 2017

\subsubsection{Análisis Tecnológico.}

La masificación del conocimiento y convergencia tecnológica para el siglo XXI es considerada una mega tendencia según el Centro Nacional de Planeamiento Estratégico CEPLAN (2016), que está generando cambios en los modelos sociales (forma de vivir de las personas y cómo se relacionan) y en los modelos económicos (adoptando nuevas formas de hacer negocios y operaciones), creando nuevos mercados. Así mismo la globalización ha permitido compartir en tiempo record las nuevas tecnologías.

Otra tendencia según el análisis de CEPLAN, es la masificación en el acceso al conocimiento, la apertura a la información, a través de la democratización del acceso a internet, nunca antes las personas tuvieron la cantidad de información que tiene ahora y que está disponible para cualquier 
sociedad y a bajos costos, lo que está generando mayor conocimiento en la población mundial. Ello favorece a las telecomunicaciones, por estar en un rubro donde la innovación y el desarrollo de productos y servicios son vitales para seguir en el mercado, los cambios en tecnología de los equipos se dan en un periodo de 6 a 12 meses, es decir el tiempo de vida de este producto es bastante corto, por ello el requerimiento de nuevos equipos, lo que viene a ser una oportunidad para que la industria siga creciendo.

Otro aspecto que se encuentra dentro del análisis tecnológico es la desinformación en parte de la población respecto al funcionamiento de las antenas repetidoras de señal, mostrando temor y rechazo ante la instalación de las mismas, siendo esta creencia una amenaza para la industria y la empresa.

\subsubsection{Análisis Ecológico}

Actualmente se cuenta con la Ley General del Ambiente (MINAM, 2005) promulgada el 15 octubre del 2005. La cual está orientada a preservar el medio ambiente, así mismo la actividad económica debe considerar que el otro factor importante es la responsabilidad social que debería tener toda empresa bajo la premisa de "tomar en cuenta que los recursos serán necesarios para las generaciones futuras", en este contexto la sociedad está dispuesta a sancionar las malas costumbres de las empresas que atenten contra los recursos naturales o generen contaminación ambiental y lo hacen a través de las redes logrando deteriorar la imagen de ese tipo de empresas. En este sentido la industria de telecomunicaciones podría implementar a través de sus franquicias, procedimientos para reciclar equipos y baterías, con el fin de consolidar empresas responsables y orientadas a contribuir desde su posición a preservar el planeta, ello podría 
generar una ventaja en los consumidores que valoran estos aspectos para ser cliente de una determinada empresa.

\subsubsection{Análisis Legal.}

La industria de las telecomunicaciones está regulada por dos instituciones, el Ministerio de Transportes y Comunicaciones (MTC) y el Organismo Supervisor de Inversión Privada en Telecomunicaciones (OSIPTEL), ambas instituciones regulan y supervisan el mercado de servicios públicos de telecomunicaciones, a través de la normativa vigente. Estableciendo los parámetros e indicadores con los que se tiene que cumplir. Esta variable es una oportunidad para la industria porque de esta manera se cuenta con franquicias formales bien constituidas que cumplen con todas las normas legales, laborales, tributarias, etc., generando barreras para el ingreso de nuevos competidores que ofrezcan servicios similares, dado que la economía peruana tiene un porcentaje alto de informalidad en los negocios.

\subsection{Impacto en clientes / proveedores de cada una de las variables del entorno}

El análisis PESTEL tiene impactos que representan amenazas y/o oportunidades tanto en los proveedores como en los clientes, como se puede ver en la Tabla 10 se tienen más oportunidades que amenazas debido al comportamiento de la industria de las telecomunicaciones, pese a la desaceleración de la economía este sector se ha mantenido dinámico, se puede observar también que una amenaza para proveedores y clientes es el factor ecológico porque a pesar de existir políticas de reciclaje no existe una cultura para los productos que ya no se utilizan como por ejemplo, equipos móviles, cargadores baterías etc. 
Tabla 10:

Factores externos proveedor clientes

\begin{tabular}{lll}
\hline Factores Externos & Proveedor & Cliente \\
\hline Político Gubernamental & Amenaza & Oportunidad \\
Económico & Oportunidad & Oportunidad \\
PBI & Oportunidad & Oportunidad \\
Tipo de Cambio & \multicolumn{1}{c}{ Depende del comportamiento } \\
Inflación & Oportunidad & Oportunidad \\
Tasa de interés & Oportunidad & Oportunidad \\
Socio Cultural & Oportunidad & Oportunidad \\
Tecnológico & Oportunidad & Oportunidad/Amenaza \\
Ecológico & Amenaza & Amenaza \\
Legal & Oportunidad & Oportunidad \\
\hline Nota. Datos obtenidos de la encuesta realizada a los gerentes (elaboración propia).
\end{tabular}

\subsection{Efecto en la empresa de cada una de las variables del entorno}

De la evaluación de las variables PESTEL se ha determinado que tres de ellas cuentan con un efecto positivo o favorable para la empresa mientras que tres tienen un impacto negativo, visto con mayor detalle en el punto 4.1 Tendencias de las variable del entorno ver tabla 11.

Tabla 11:

Efecto variables del entorno

\begin{tabular}{ccc}
\hline Factores Externos & Positivo & Negativo \\
\hline Político Gubernamental & $X$ & $X$ \\
Económico & & \\
Socio Cultural & $X$ & \\
Tecnológico & & $X$ \\
Ecológico & $X$ & \\
Legal & $X$ & \\
\hline
\end{tabular}

Nota. Datos obtenidos de la encuesta con los gerentes (elaboración propia). 


\subsection{Matriz de Evaluación de los Factores Externos EFE}

La matriz EFE, fue elaborada tomando en cuenta los factores que afectan positiva o negativamente a la industria, según Kotler (2006) el peso muestra en qué medida los factores afectan a la industria siendo el más relevante: el acceso en línea a la información del sector de telecomunicaciones con 0.12 , el mismo que viene a ser una amenaza para la industria, seguido del factor crecimiento en el sector de telecomunicaciones con un peso de 0.12 factor que viene a ser una oportunidad para la industria. En cuanto a la calificación de la industria se puede observar cómo se maneja la misma frente a los factores de éxito, con una calificación del uno al cuatro donde:

1 = la respuesta de la industria ante el factor es deficiente

2 = la respuesta de la industria ante el factor es promedio

3 = la respuesta de la industria ante el factor está por encima del promedio

4 = la respuesta de la industria ante el factor es superior

La industria tiene la puntuación más baja 1, en el factor que viene a ser cambios culturales en los consumidores que valoran calidad de atención y tiempo, datos tomados y analizados de las encuestas hechas por IPSOS a pedido de OSIPTEL, (Anexo 3) donde se puede apreciar que el operador con menos satisfacción de clientes es TDP. Sin embargo, en el promedio final se observa que la industria alcanza un promedio de 2.56, ubicándolo justo por encima de la media, lo que significa que la industria responde positivamente, capitalizando las oportunidades y evitando o disminuyendo los efectos negativos de las amenazas, como se muestra en la tabla 12. 
Tabla 12:

Matriz EFE

Factores de Éxito

Peso Calificación

Industria Ponderado

\section{OPORTUNIDADES}

Sector de telecomunicaciones con

$\begin{array}{lll}0.12 & 4 & 0.48\end{array}$

crecimiento mayor al PBI

Expansión del mercado de telefonía móvil en provincias

Supervisión y regulación del estado,

$\begin{array}{lll}0.10 & 3 & 0.30\end{array}$

establece una competencia formal de las

empresas y franquicias en este mercado.

Crecimiento demográfico, y generaciones $\mathrm{Y}$

$\begin{array}{lll}0.10 & 3 & 0.30\end{array}$

y $\mathrm{Z}$ dependientes de la telefonía celular.

$\begin{array}{llll}\text { Mercado tecnológico en expansión } & 0.07 & 3 & 0.21\end{array}$

$\begin{array}{llll}\text { Acceso al financiamiento con bajas tasas de } & 0.05 & 2 & 0.10\end{array}$ interés

$\begin{array}{llll}\text { Implementar políticas de responsabilidad } & 0.05 & 2 & 0.10\end{array}$ social

\section{AMENAZAS}

Políticas de libre mercado permiten el

$\begin{array}{lll}0.10 & 2 & 0.20\end{array}$
ingreso de nuevos competidores

La tendencia ecológica genera temor en la

$0.12 \quad 2 \quad 0.24$

población por las antenas repetidoras de señal que impiden expandir la cobertura

Cambios culturales en los consumidores que valoran calidad de atención y tiempo

Acceso en línea a la información del sector de telecomunicaciones

$\begin{array}{lll}0.12 & 1 & 0.12\end{array}$

$\begin{array}{lll}0.12 & 3 & 0.36\end{array}$

Total de la matriz 


\section{CAPÍTULO V. ANÁLISIS DE LA INDUSTRIA}

\subsection{Descripción del Mercado (demanda) e Industria (oferta)}

En los últimos años, el mercado de telefonía móvil en el Perú, se ha convertido en uno de los más dinámicos del sector telecomunicaciones ya que según informó el MTC (2017) en el año 2016 el número de líneas de telefonía móvil presentó un crecimiento del $6.19 \%$ en comparación al mismo periodo del 2015, siendo Cusco la sexta región con mayor número de líneas telefónicas con un total de 1,107,000 líneas.

En referencia a la composición del mercado se aprecia que un 70.1\% de usuarios adquirió un servicio bajo la modalidad de prepago, mientras que el $29.9 \%$ cuenta con postpago, es decir aproximadamente 7 de cada 10 líneas son prepago.

En marzo del 2016 la densidad de líneas a nivel nacional ha alcanzado un $112.1 \%$ de líneas por cada 100 habitantes, es decir, se registró un mayor número de líneas respecto a los habitantes (MTC, 2017, pág. 17).

Según OSIPTEL las regiones que presentaron mayor densidad de líneas de telefonía móvil fueron Madre de Dios (124.5\%) Arequipa (117.2\%) y Moquegua (107.6\%), y por el contrario Loreto fue la región que presentó el menor nivel de densidad (44.0\%) seguido de Huancavelica con una densidad de $(52.4 \%)$.

Por ello la demanda dependerá de la cantidad de líneas que puede tener una persona, la cual no solo adquiere para uno, sino también para sus hijos menores de 18 años, los que pueden ser de distintos operadores, es decir la población de Perú con mayoría de edad para contratar una línea no representa necesariamente el total de la demanda. 
La participación de los diferentes operadores en el mercado se muestra en la figura 10, donde TDP a nivel nacional cuenta con una participación del $38 \%$ al 2017, superando aun a las demás empresas.

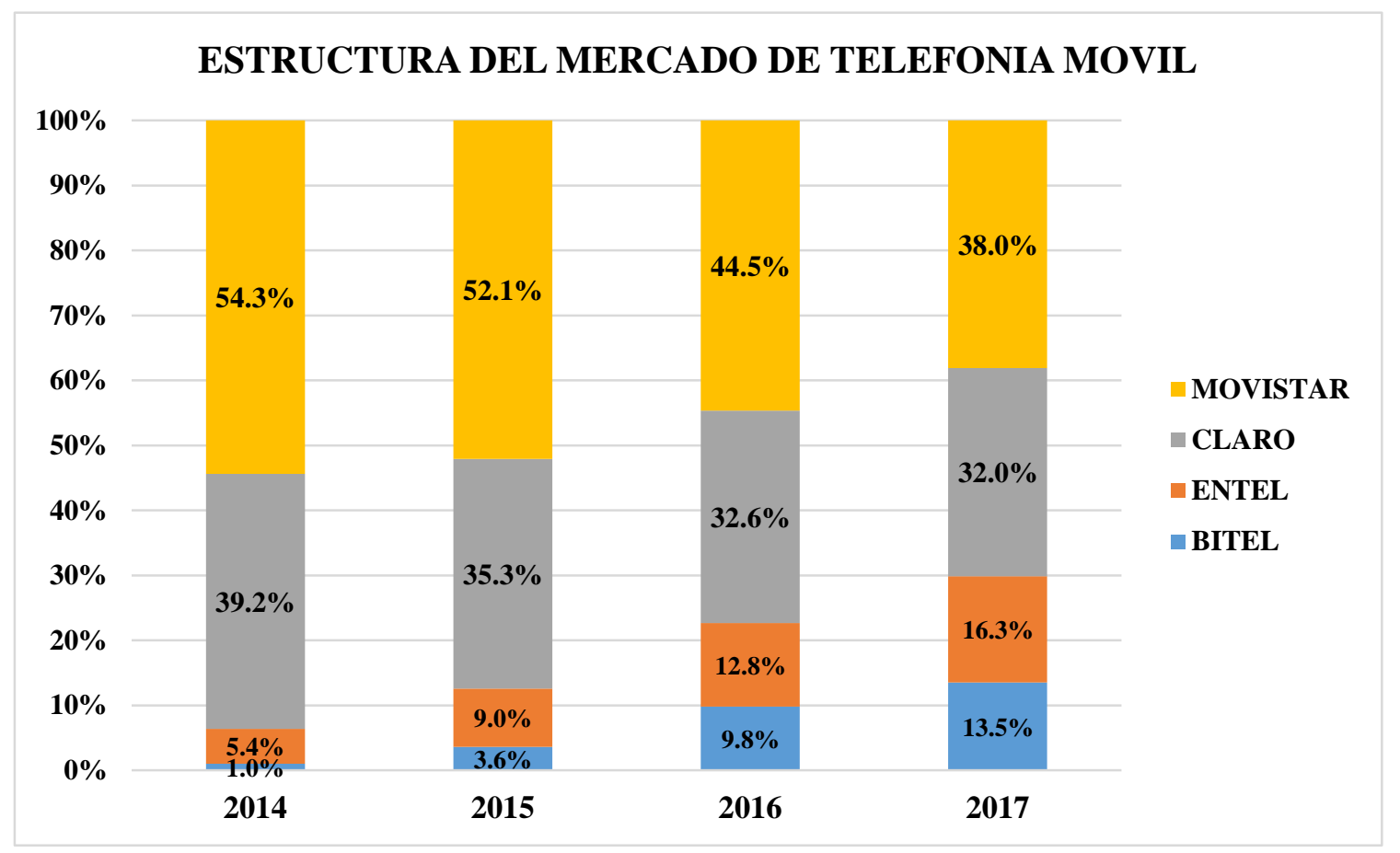

Figura 10: Participación del mercado de los operadores a nivel nacional.

Datos proporcionados por OSIPTEL (elaboración propia)

TDP, así como otras empresas, opera a través de franquicias, expandiendo de esta manera su cobertura a nivel nacional tal como se muestra en el (Anexo 4).

Digital es una franquicia que opera en las regiones de Apurímac, Cusco, Puerto Maldonado, Ayacucho y Huancavelica (Zonal Sur), como se observa en la (Figura 11). 
Digital opera en las siguientes zonas:

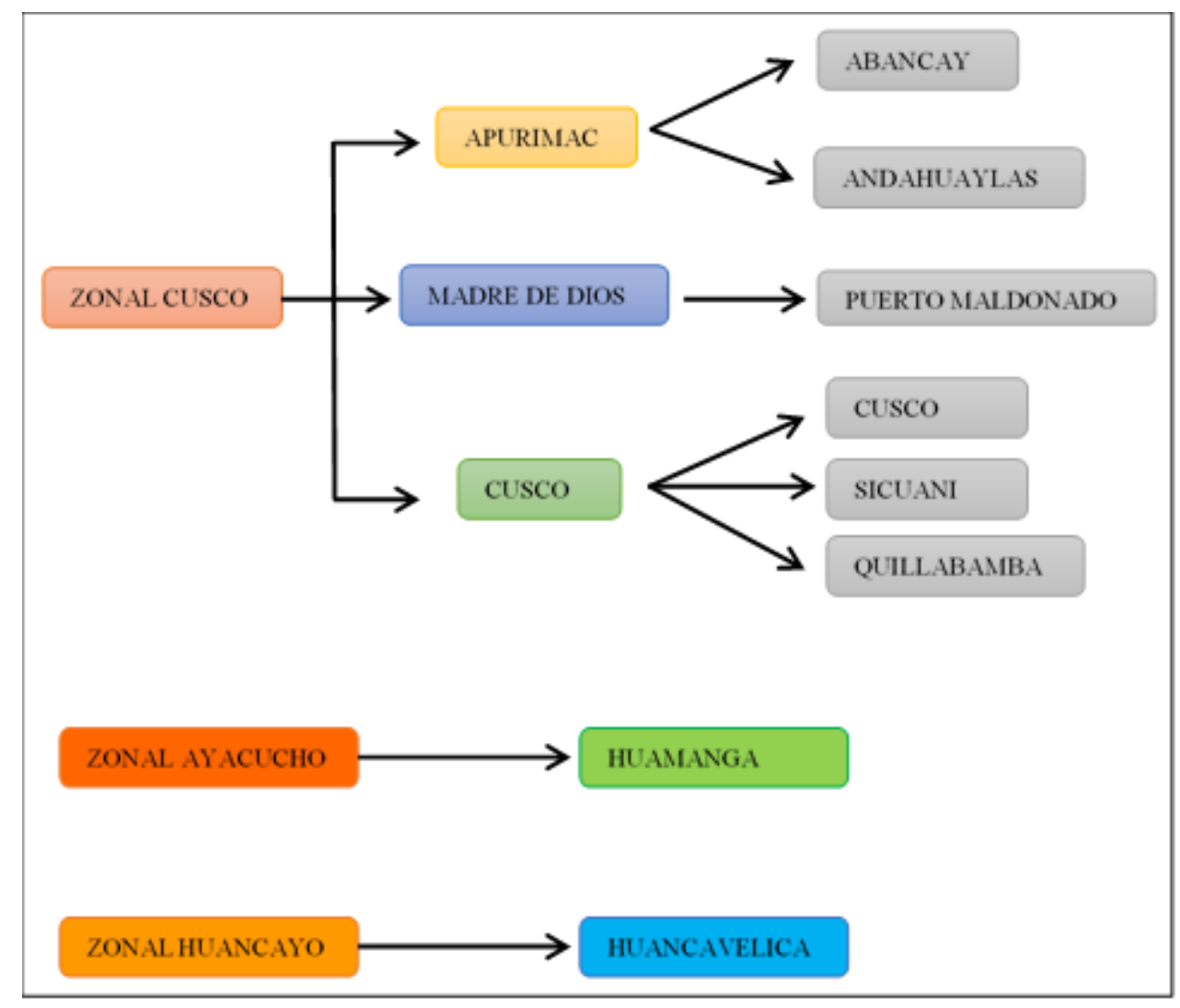

Figura 11: Distribución de la franquicia por zonas.

A nivel de las franquicias de la empresa TDP se puede observar en la Tabla 13 la participación de la franquicia Digital en las regiones donde tiene presencia, mostrando un liderazgo en las ventas con una participación del 53.42\% seguido de la franquicia Boutique Celular con $11.77 \%$. 
Tabla 13:

Participación de mercado de Digital

\begin{tabular}{rcccc}
\hline Nro. & Agente & Tipo & Participación & Ventas \\
& & & & en unidades \\
\hline 1 & BOUTIQUE CELULAR SCRL & Franquicia & $11.77 \%$ & 2182 \\
2 & CORPORACION MACHI SAC & Agente & $6.73 \%$ & 1248 \\
$\mathbf{3}$ & DIGITAL COMUNICACIONES SAC & Franquicia & $\mathbf{5 3 . 4 2 \%}$ & $\mathbf{9 9 0 3}$ \\
4 & GLOBAL COMUNICACIONES SAC & Agente & $3.20 \%$ & 594 \\
5 & MOVICOM ERIL & Agente & $7.88 \%$ & 1461 \\
6 & MULTICENTROS & Franquicia & $10.64 \%$ & 1973 \\
7 & NEGOCIOS Y EMPRESAS EIRL & Agente & $2.24 \%$ & 416 \\
8 & GRANDES SUPERFICIES & Agente & $4.10 \%$ & 760 \\
\hline
\end{tabular}

Nota: Reportes de ventas de telefónica del periodo de enero a julio del 2017 (elaboración propia).

En la Tabla 14 se puede observar el cumplimiento del nivel de servicio de las franquicias de TDP, este indicador se mide en cumplimiento a la Resolución de Consejo Directivo № 127- 2013CD/OSIPTEL, Reglamento de calidad de atención a usuarios por parte de las franquicias, participación de operadoras de móviles por departamentos a diciembre del 2016 operadoras de servicios de telefonía fija y servicios públicos móviles. Para cumplir con lo solicitado en el Reglamento en mención todas las empresas que prestan el servicio de telefonía en el Perú, deben cumplir con un indicador llamado Nivel de Servicio, en adelante NDS, que viene a ser el indicador que mide el tiempo de espera de un cliente desde que recaba un ticket hasta que es atendido por un asesor, en los diferentes locales de las empresas de telefonía sean estas tiendas propias o franquicias. 
Tabla 14:

NDS al 30 de setiembre a nivel nacional de TDP.

\begin{tabular}{|c|c|}
\hline FRANQUICIAS & $\%$ NDS \\
\hline ATENTO & $84.4 \%$ \\
\hline BOUTIQUE CELULAR & $91.7 \%$ \\
\hline CISESAC & $94.3 \%$ \\
\hline COMPUTER PHONE CENTER & $93.7 \%$ \\
\hline CONTACTO SATELITAL & $87.1 \%$ \\
\hline DIAL & $86.1 \%$ \\
\hline DIGITAL COMUNICACIONES & $91.9 \%$ \\
\hline GLOBALNET COMUNICACIONES & $99.0 \%$ \\
\hline LIDERES-SIC & $90.5 \%$ \\
\hline MACLABI & $90.6 \%$ \\
\hline MEGA TECH & $92.1 \%$ \\
\hline OVERLANDES-NEXXO & $90.6 \%$ \\
\hline SALESLAND & $89.7 \%$ \\
\hline SERVICIOS DIGITALES & $90.9 \%$ \\
\hline TDP & $86.1 \%$ \\
\hline VISATECH & $91.5 \%$ \\
\hline
\end{tabular}

Nota: Informe NDS al 30 de setiembre (elaborado por Telefónica del Perú S.A.A)

En las regiones donde Digital tiene presencia, los resultados de este indicador se muestran en la Tabla 15. 
Tabla 15:

NDS al 30 de setiembre en localidades donde Digital tiene presencia

\begin{tabular}{|c|c|c|c|c|c|c|}
\hline$\%$ NDS & & SERVICIO & & & & \\
\hline SOCIO & OFICINA & BAJA & CONSULTA & RECLAMO & VENTA & TOTAL \\
\hline TDP & Cusco - El Sol & $64.3 \%$ & $73.4 \%$ & $62.0 \%$ & $84.1 \%$ & $68.8 \%$ \\
\hline BOUTIQUE & Cusco - CC Real Plaza & & $83.4 \%$ & $100.0 \%$ & $100.0 \%$ & $83.4 \%$ \\
\hline DIGITAL & Abancay - Venezuela & & $90.3 \%$ & $66.7 \%$ & $97.3 \%$ & $90.8 \%$ \\
\hline DIGITAL & Andahuaylas - Pesce & & $95.2 \%$ & $100.0 \%$ & $96.9 \%$ & $95.4 \%$ \\
\hline DIGITAL & Ayacucho - Asamblea & $100.0 \%$ & $95.4 \%$ & $97.5 \%$ & $95.4 \%$ & $95.6 \%$ \\
\hline DIGITAL & Cusco - Mayuri & & $87.7 \%$ & $88.2 \%$ & $85.7 \%$ & $87.2 \%$ \\
\hline DIGITAL & Huancavelica - Virrey T & $100.0 \%$ & $88.5 \%$ & $69.6 \%$ & $96.5 \%$ & $89.7 \%$ \\
\hline DIGITAL & Puerto Maldonado - Puno & & $88.3 \%$ & $86.8 \%$ & $86.4 \%$ & $88.1 \%$ \\
\hline DIGITAL & Quillabamba - De la Torre & $100.0 \%$ & $97.3 \%$ & $100.0 \%$ & $100.0 \%$ & $97.3 \%$ \\
\hline DIGITAL & Sicuani - Grau & & $96.2 \%$ & & $97.5 \%$ & $96.4 \%$ \\
\hline GLOBALNET & Ayacucho-Lima & & $98.9 \%$ & & $99.6 \%$ & $99.0 \%$ \\
\hline
\end{tabular}

Nota: Informe NDS al 30 de setiembre (elaboración propia en base a informes confidenciales de TDP)

\subsection{Descripción las cinco fuerzas competitivas de la industria}

En el análisis de las cinco fuerzas, Porter (1987) hace referencia a la intensidad de la competencia y la rivalidad en la industria y lo atractivo de la industria en el mercado.

Para el presente trabajo se considera como industria de telecomunicaciones al grupo de empresas que trabajan para TDP a través de franquicias y tiendas propias, en función a ello se ha determinado cuales son las fuerzas que tiene mayor o menor intensidad según el siguiente análisis. 


\subsubsection{Amenaza de servicios sustitutos.}

\section{- Disponibilidad de servicios sustitutos.}

Las franquicias y tiendas de TDP son empresas que ofrecen servicios de postventa, venta y recaudación de recibos, de manera presencial en sus oficinas distribuidas a nivel nacional. Sin embargo TDP cuenta con una plataforma virtual ofreciendo a sus clientes los mismos servicios que pueden realizar de forma presencial, para ello los clientes tienen que ingresar a la siguiente dirección: http://www.movistar.com.pe/centros-deatencion-y-reclamo, así mismo TDP cuenta con un call center para realizar consultas, reclamos, compras etc. Por lo que estos servicios se consideran como servicios sustitutos, donde los clientes pueden elegir realizar sus transacciones de forma personal o ser atendido de forma presencial por un asesor.

\section{- Precios de los servicios sustitutos.}

La oferta de precios que manejan las franquicias son establecidas por TDP por eso son similares entre ellos, de la misma manera los precios que manejan los call center son establecidos por TDP, sin embargo, los precios que ofrecen los call center son más bajos; normalmente ofrecen sus productos y servicios con promociones especiales que las franquicias no las tienen, hecho por el cual se considera una amenaza.

\subsubsection{Amenaza de entrada de los nuevos competidores.}

Se analizarán los factores que permiten el ingreso o salida de los nuevos competidores:

\section{- Barrera de entrada}

El ingreso de nuevas franquicias competidoras para operar bajo la marca de TDP tiene una barrera bastante alta ya que los pagos de derecho de entrada y los royalties son elevados, requiere 
una carta fianza de $\$ 100,000.00$ y capital de trabajo ascendente a la suma de $\$ 200,000.00$ el mismo que debe cubrir los 3 primeros meses de operación.

\section{- Experiencia en el rubro}

La experiencia de las franquicias de TDP está dada por la cantidad de años de trabajo en el mercado, la presencia geográfica, los canales de negocio que se manejan, así como el volumen de personal especializado y las herramientas tecnológicas y operativas desarrolladas en este tiempo; por ejemplo, la franquicia en estudio: Digital cuenta con 18 años y es la empresa con mayor antigüedad y experiencia en las regiones donde opera.

\section{- Conocimiento y tecnología}

La formación de franquicias en este sector (telecomunicaciones) implica inversión en conocimiento y tecnología, Digital ha desarrollado un software logístico, administrativo y contable que permite controlar el volumen de atenciones así como el número de ventas que se realizan a diario y que se comunica a través de una interfase con TDP, los posibles competidores no cuentan con una herramienta similar lo que limita el ingreso de nuevas empresas a este mercado.

\section{- Requerimiento de capital}

Como parte de los requisitos financieros para poder constituir una franquicia, se requiere contar con una carta fianza por US\$100,000.00 y un capital de trabajo de US\$200,000.00 para iniciar operaciones, lo que dificulta el ingreso de nuevos competidores.

Tomando en cuenta las condiciones evaluadas en los ítems que corresponden a la amenaza de entrada de nuevos competidores bajo el formato de franquicia es débil. 


\section{- Barreras de salida}

El costo de transferencia de una franquicia a otro proveedor es alto, por contar con barreras de salida impuestas por el proveedor como son:

- El pago de penalidades

- El no prestar servicios a otra empresa por el lapso mínimo de un año.

\subsubsection{Poder de negociación de los clientes.}

- Número de clientes

El número de clientes con los que cuentan las franquicias de la empresa TDP son todos aquellos que están registrados en la base de clientes de la propia empresa (TDP), es decir; son clientes que pueden pedir renovación de equipo en una franquicia $\mathrm{X}$ y hacer un cambio de plan en la franquicia Y, por ello estas empresas no manejan un número exacto de clientes, ya que estos se mueven constantemente.

Cada franquicia puede captar nuevos clientes que serán considerados en la base de clientes de TDP, a la vez perderán clientes cuando estos decidan cambiar de operador móvil.

\section{- Características de los clientes}

En el sector de telecomunicaciones, los clientes son los que determinan y optan por el agente de su preferencia no existiendo una negociación que influya en su decisión.

El poder de negociación del cliente es fuerte, dado que este puede migrar de operador atraído por las promociones u ofertas que se dan frecuentemente en el mercado o por un descontento con la calidad en el servicio que le brinda su actual operador, pues el cliente valora principalmente la 
calidad del servicio y la solución de sus requerimientos como lo indica, el presidente del consejo directivo de OSIPTEL Rafael Muente Schwarz, según (Diario gestion, 2019)

Una muestra clara que los clientes no se fidelizan con los operadores, es la portabilidad numérica, siendo TDP la empresa que más clientes está perdiendo según informe de OSIPTEL al primer semestre del 2017, por este motivo las diversas franquicias de TDP están siendo afectadas directamente.

En la Tabla 16 se muestra la participación en el mercado según operador, donde se puede observar que la empresa TDP - Movistar tiene la mayor participación en el mercado con un valor de $45.40 \%$ en comparación a las diferentes empresas.

Tabla 16:

Participación de mercado.

\begin{tabular}{cc}
\hline \multicolumn{2}{c}{ PARTICIPACION DE MERCADO } \\
\hline MOVISTAR & $45.40 \%$ \\
CLARO & $31.30 \%$ \\
ENTEL & $13.10 \%$ \\
BITEL & $10.00 \%$ \\
VIRGIN & $0.20 \%$ \\
TOTAL & $100 \%$ \\
\hline
\end{tabular}

Nota: Datos proporcionados por OSIPTEL estadísticas a diciembre 2016.

Lo contrario se observa en la Tabla 17 donde se puede apreciar que pese a que TDP Movistar tiene una gran participación en el mercado, la migración de este operador a otro es mayor, presentando un valor negativo de $-413,810$. 
Tabla 17:

Lineas que cambiaron de operadora (OSIPTEL, 2018).

POSICION NETA DE PORTABILIDAD

MOVISTAR

CLARO

ENTEL

BITEL

VIRGIN

\section{$-413,810$}

22,073

420,848

$-25,041$

$-4,070$

Nota: Datos proporcionados por OSIPTEL informe de agosto del periodo enero a julio 2017

Dado el análisis del mercado en el cual Digital compite como franquicia se concluye que el poder de negociación de los clientes es alto.

\subsubsection{Poder de negociación de los proveedores.}

- Número de proveedores.

El hecho de que TDP trabaje con varias franquicias favorece su poder de negociación porque puede decidir con quien trabaja, a esto se suma el coste alto de pasar una franquicia a manos de otro proveedor. Es en este entender que Digital realiza sus actividades comerciales, al igual que las otras contando con un solo proveedor que es TDP, con el que trabajan de manera exclusiva.

\section{- Características de los proveedores.}

TDP, es una empresa trans nacional que opera en el Perú desde el año 1,994 a lo largo de todos estos años ha ido intermediando sus operaciones mediante el modelo de franquicias, utilizando 
contratos marcos, donde exige exclusividad por ende es el único proveedor tanto de marca, equipos, sistemas etc., por ello se considera que el proveedor tiene poder de negociación.

\section{- Representa una real amenaza de integración hacia delante.}

TDP, cuenta con tiendas propias, bajo el mismo modelo que las franquicias donde los clientes pueden ser atendidos de forma presencial teniendo acceso a los mismos productos, ofertas y servicios, por ello existe la posibilidad de una integración hacia adelante, dado el poder de negociación de TDP ellos podrían incrementar el número de tiendas propias y quitar participación del mercado a las franquicias.

\section{- Representa una real amenaza de integración hacia atrás.}

No se observa riesgos dado que ninguna de las franquicias podría dedicarse a producir celulares, así mismo TDP tampoco ha incursionado en este rubro, dado que el mercado tiene empresas consolidadas como son Samsung y Apple. Todas las franquicias de la empresa TDP trabajan bajo sus condiciones, las mismas que pueden cambiar con simples adendas de comunicación, el poder de negociación de TDP es fuerte aunque esto no signifique una amenaza para las distintas franquicias, porque para el modelo que ellos manejan necesita socios estratégicos que le ayuden a atender a sus clientes en localidades donde ellos no tienen presencia con personal propio, ni infraestructura donde atenderlos, bajo el modelo de franquicia TDP puede atender a sus clientes en todo el país.

\subsubsection{Competencia en el mismo sector.}

\section{- Rivalidad entre los competidores.}

Los ingresos que obtienen las franquicias de TDP están directamente relacionadas a las comisiones por venta de equipos y a la satisfacción del cliente atendido en sus tiendas, esto hace 
que cada franquicia establezca estrategias orientadas a mejorar sus resultados en estos dos aspectos, hecho que desencadena en una rivalidad por atraer y fidelizar clientes de TDP mediante una mejora en la atención en sus tiendas.

\section{- Capilaridad.}

La capilaridad de las franquicias de TDP está representada por el número de tiendas ubicadas a nivel nacional, se tiene registrado un total de 101 tiendas, como se muestra en el (Anexo 4) donde se puede apreciar el número de tiendas, región y dirección. Cabe señalar que hay franquicias con un mayor número de tiendas bajo su gestión en distintas regiones del país, permitiéndole tener mayor cobertura y mercado.

\section{- Tasa de crecimiento del sector.}

El mercado en el cual operan las franquicias de TDP, registra crecimiento en función al comportamiento de la economía; el mayor crecimiento del sector está principalmente en provincias dado que en éstas aún no se alcanza la penetración de mercado como en Lima, que según cifras difundidas por OSIPTEL Perú 21 (2018) por cada 100 habitantes existen 130 líneas de telefonía móvil en la capital. 


\subsection{Matriz de atractividad de cada una de las cinco fuerzas.}

Tomando en cuenta el modelo de franquicia y las exigencias de la misma se ha determinado como factores críticos para el éxito los siguientes:

\begin{tabular}{|c|c|c|c|c|c|}
\hline & Analisis de la cinco fuerzas & Baja & Media & Alta & Concepto \\
\hline \multicolumn{4}{|c|}{1 Servicios Sustitutos: } & & Intensidad de la fuerza media \\
\hline & Disponibilidad de servicios sustitutos & & $\mathrm{X}$ & & \multirow{2}{*}{$\begin{array}{l}\text { Conforme la población prefiera realizar } \\
\text { operaciones a travéz de un dispositivo, los } \\
\text { servicios sustitutos irán creciendo }\end{array}$} \\
\hline & Precio de los servicios sustitutos & $X$ & & & \\
\hline \multirow[t]{6}{*}{2} & Amenaza de entrada de nuevo competidores & & & & Intensidad de la fuerza baja \\
\hline & Barreras de entrada & & & $\mathrm{X}$ & \multirow{5}{*}{$\begin{array}{c}\text { Dado los requisitos, el capital y la experiencia, es } \\
\text { muy poco atractivo para que entren nuevos } \\
\text { competidores }\end{array}$} \\
\hline & Experiencia en el rubro & & & $\mathrm{X}$ & \\
\hline & Conocimiento y tecnologia & & $\mathrm{X}$ & & \\
\hline & Requerimieto de capital & & & $\mathrm{X}$ & \\
\hline & Barreras de salida & & & $\mathrm{X}$ & \\
\hline \multirow[t]{3}{*}{3} & Poder de negociacion de la clientes & & & & Intensidad de la fuerza alta \\
\hline & Número de clientes & & $\mathrm{X}$ & & \multirow{2}{*}{$\begin{array}{l}\text { Dada la libertad que tiene de elegir el poder de } \\
\text { negociación del cliente es alto }\end{array}$} \\
\hline & Caracteristicas de los clientes & & & $\mathrm{X}$ & \\
\hline \multirow[t]{5}{*}{4} & Poder de negociacion de lo proveedores & & & & Intensidad de la fuerza alta \\
\hline & Número de proveedores & & & $\mathrm{X}$ & \multirow{4}{*}{$\begin{array}{l}\text { Al mantener un solo proveedor y contar con un } \\
\text { contrato de franquicia el poder de negociación es } \\
\text { alto }\end{array}$} \\
\hline & Caracteristicas de los proveedores & & & $X$ & \\
\hline & Integracion hacia delante & & $\mathrm{X}$ & & \\
\hline & Integracion hacia atrás & $\mathrm{X}$ & & & \\
\hline \multirow[t]{4}{*}{5} & Competencia en el mismo sector & & & & Intensidad de la fuerza media \\
\hline & Rivalidad ente los competidores & & $\mathrm{X}$ & & \multirow{3}{*}{$\begin{array}{l}\text { La competencia en el sector es media y la } \\
\text { diferenciación se da por la calidad de atención } \\
\text { entre las tiendas de TDP y las franquicias }\end{array}$} \\
\hline & Capilaridad & & & $\mathrm{X}$ & \\
\hline & Tasa del crecimiento del sector & & & $\mathrm{X}$ & \\
\hline
\end{tabular}

Figura 12: Matriz de la atractividad.

Elaborado con datos según el estudio desarrollado(elaboracion propia)

\subsection{Matriz de Perfil Competitivo MPC}

La matriz del perfil competitivo, ha sido elaborada tomando como base el modelo de franquicia Anexo 1, donde se establecen dos criterios: ¿cómo se retribuye económicamente a la franquicia? al que se le otorga un peso de $75 \%$ para la ponderación y ¿qué es lo que quiere lograr TDP? que representa el otro $25 \%$. 
El primer criterio está relacionado a la retribución económica para la franquicia y es conformado por: Nivel de espera (25\% de ponderación y que explica el $60 \%$ del pago de contraprestación para la franquicia), resolutividad en la atención (15\% de ponderación y que explica el 15\% del pago de contraprestación), personal capacitado (15\%), calidad de atención (10\%) y empatía del personal (10\%) entre estos últimos tres puntos representan el 25\% de la retribución para la franquicia.

El segundo criterio, está ligado al soporte operativo para lograr los objetivos establecidos por TDP, este agrupa 4 puntos: Participación en el mercado (10\% de ponderación), procesos (5\% de ponderación), productividad del personal (5\% de ponderación) y capilaridad ( $5 \%$ de ponderación).

Estos factores de ponderación han sido elaborados con la colaboración de cuatro gerentes de línea, quienes son los responsables de recopilar y evaluar la información de Digital y de su competencia, a través de las reuniones semestrales de evaluación de resultados llevadas a cabo por TDP, así como reportes mensuales que son compartidos por TDP y la encuesta realizada al Jefe Zonal de TDP como se puede apreciar en el Anexo 5, con lo cual se obtuvo los resultados que se reflejan en la Tabla 18.

Las calificaciones de los factores importantes para el éxito tienen, carácter cuantitativo, y ha sido elaborada, realizando la comparación de los resultados de las 3 empresas competidoras, para obtener el puntaje del NDS se ha tomado en cuenta los datos de la tabla 15, asignándole el mayor puntaje al mejor resultado y los demás puntajes inversamente proporcionales a sus respectivos resultados. Y así con todos los factores utilizando los datos que se muestran a lo largo del trabajo. Calculo que se puede apreciar al detalle en el Anexo 5. 


\section{Tabla 18:}

Matriz de MPC

\begin{tabular}{|l|c|c|c|c|c|c|c|}
\hline \multicolumn{2}{|c|}{ TELEFONICA DEL PERU S.A.A. } & \multicolumn{3}{c|}{ COMPETIDORES } \\
\cline { 2 - 7 } & \multicolumn{2}{|c|}{ DIGITAL } & \multicolumn{2}{c|}{ BOUTIQUE CELULAR } & \multicolumn{2}{c|}{ MULTICENTRO } \\
\hline Factores importantes para el éxito & Ponde ración & Calific ación & Pun taje & Calific ación & Pun taje & Calific ación & Pun naje \\
\hline Personal Capacitado & & & 0.3 & 2 & 0.3 & 2 & 0.3 \\
\hline Procesos & 0.15 & 2 & 0.15 & 2 & 0.1 & 1 & 0.05 \\
\hline Productividad del Personal & 0.05 & 3 & 0.1 & 2 & 0.1 & 2 & 0.1 \\
\hline Capilaridad & 0.05 & 2 & 0.2 & 1 & 0.05 & 1 & 0.05 \\
\hline Participación de mercado & 0.05 & 4 & 0.4 & 1 & 0.1 & 1 & 0.1 \\
\hline Calidad de Atención & 0.1 & 4 & 0.3 & 2 & 0.2 & 1 & 0.1 \\
\hline Empatía del personal & 0.1 & 3 & 0.3 & 2 & 0.2 & 1 & 0.1 \\
\hline Resolutividad en la atención & 0.1 & 3 & 0.45 & 2 & 0.3 & 1 & 0.15 \\
\hline Tiempos (nivel de espera) & 0.15 & 3 & 1 & 4 & 1 & 2 & 0.5 \\
\hline
\end{tabular}

Nota: Datos proporcionados por TDP en reunión semestral julio 2017 (elaboración propia) 


\section{CAPÍTULO VI. ANÁLISIS INTERNO}

\subsection{Descripción de las actividades de la cadena de valor de la empresa}

Como indica Porter (1987) una empresa posee una ventaja competitiva frente a otra cuando es capaz de aumentar el margen de utilidad (reduciendo costos, aumentando ventas) este margen se analiza a través de la cadena de valor, la misma que es un conjunto de actividades que la empresa realiza, en el caso de Digital, se han determinado actividades de apoyo y actividades primarias:

- Dentro de las actividades de apoyo se tiene las siguientes:

Gestión administrativa.

Gestión de recursos materiales y tecnológicos.

Gestión de recursos financieros

Gestión de infraestructura

Gestión de recursos humanos

- Dentro de las actividades primarias se tiene las siguientes

Relaciones públicas

Atención al cliente

Clientes

Cumplimiento de indicadores y estándares

Como se puede apreciar en la siguiente figura. 


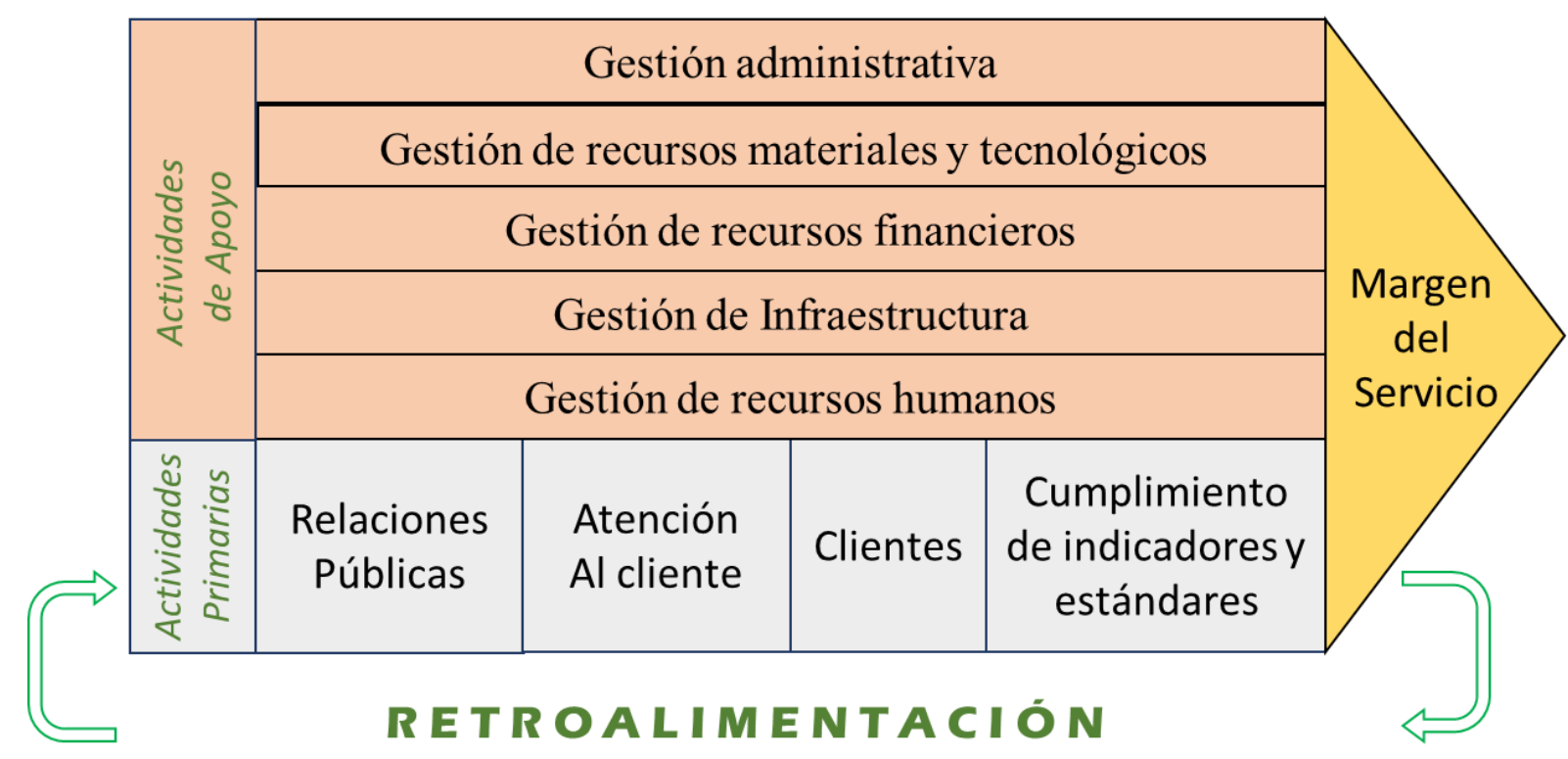

Figura 13: Cadena de valor de la empresa Digital. Elaboración propia.

\subsubsection{Gestión Administrativa.}

La gestión administrativa de la franquicia está a cargo de la gerencia de móviles que trabaja de la mano con la supervisión de franquicia, se encargan de planificar, dirigir y controlar las actividades de todas las tiendas a su cargo para lograr que éstas se realicen sin problema en el mes; para ello se lleva a cabo una estrecha coordinación con los jefes de tienda y el seguimiento de cumplimiento de indicadores por cada asesor comercial, esto impacta directamente en el resultado global del mes por cada tienda y en el consolidado final de la franquicia al cual obedece la facturación mensual, generando así valor para la empresa.

La gestión administrativa es rutinaria y busca la mejora continua en los procesos, en base al aprendizaje de la casuística que se ha venido acumulando en el tiempo, esto sin duda se convierte en un Know-how para la empresa. 


\subsubsection{Gestión de Recursos Humanos.}

El área de recursos humanos dentro de la empresa es el encargado de seleccionar y reclutar al personal nuevo que requiere la franquicia, este proceso incluye la inducción previa y la capacitación para el desarrollo de sus funciones, en esta etapa es importante la generación de un compromiso con la empresa.

Por otro lado el área de recursos humanos también se encarga del personal que ya viene laborando en la empresa, es responsable por la coordinación para permisos, salidas por vacaciones, salud, maternidad, etc. Para que estas ausencias no conlleven a un quiebre en las operaciones de la franquicia y no se vean afectados los resultados de indicadores y el ingreso generado.

\subsubsection{Gestión de Recursos Materiales y Tecnológicos.}

Para cumplimiento de los estándares de servicio establecidos, la empresa requiere contar con recursos materiales y tecnológicos como herramientas de sus diferentes áreas, estos deben ser provistos de manera oportuna en coordinación con los proveedores y clientes internos, para ello se cuenta con un área de logística y almacenes que es responsable de la adecuada distribución de equipos en las diferentes tiendas, manejando de manera eficiente la línea de crédito que tiene la empresa, este manejo adecuado evita los quiebres de stock, así como la obsolescencia de los equipos móviles y de esta manera se asegura las ventas, lo que repercute en mayores ingresos para la empresa. 


\subsubsection{Gestión Financiera.}

El área de gestión financiera de la empresa es el encargado de manejar las finanzas de la empresa, desde la obtención de fondos hasta la utilización de los mismos buscando optimizar los recursos. A diferencia de muchas otras franquicias, la gestión financiera cuenta con autonomía, es decir; es independiente del área contable y al área de ventas, ya que se cuenta con un equipo de validación que manejan un flujo de caja que permite el pago oportuno a los trabajadores y el pago oportuno de todo requerimiento de manera ágil. De esta manera se evita cortes en las líneas de crédito u otros contratiempos que puedan implicar el normal funcionamiento de las tiendas así como incurrir en mayores costos financieros.

\subsubsection{Relaciones Públicas}

Para Digital una actividad muy importante es mantener una buena relación con TDP, está relación se basa en años de trabajo y confianza mutua, ya que es una de las franquicias más antiguas con las que cuenta TDP.

El área de relaciones públicas liderada por la gerencia general y gerentes de línea son los encargados de las negociaciones de nuevos contratos y modelos que TDP cambia constantemente, así como las negociaciones para la apertura de nuevas franquicias, y es dónde se inicia la cadena de valor de las actividades primarias, ya que por ejemplo la apertura de una nueva tienda (franquicia) es el inicio de toda la actividad comercial.

\subsubsection{Servicio de Atención al Cliente.}

El área de atención al cliente está conformada por todo el personal de la empresa que tiene contacto con el cliente al que se le brinda el servicio de venta y postventa. Esta área tiene como 
actividad principal la de brindar soluciones a las necesidades de los clientes, ofreciendo un servicio de calidad, al mismo tiempo cumplir con los indicadores NDS e IVR, como se ha comentado en el presente trabajo de estos indicadores depende la retribución económica que percibe la empresa.

\subsubsection{Clientes.}

Los clientes forman parte de la cadena de valor dentro de las actividades primarias, sin embargo la empresa no tiene control sobre ellos ya que estos no forman parte de la organización, pero su participación en la generación de valor es importante; puesto que, a partir de la percepción de la calidad de nuestros servicios se puede medir su nivel de satisfacción. Es en ese entender que el presente trabajo está orientado a mejorar esta percepción y lograr que el cliente califique el servicio como satisfactorio.

\subsubsection{Cumplimiento de Indicadores.}

Los principales indicadores que cumple la franquicia son:

- Ingreso por ventas que mide el incremento de un mes a otro.

- Nivel de Servicio (NDS) tiempo de espera de un cliente hasta ser atendido por un asesor, tiene como límite 15 minutos según lo exigido por OSIPTEL.

- Encuesta del Nivel de Satisfacción del Cliente (IVR) se califica a través de llamadas aleatorias que realiza TDP, donde el cliente califica si el servicio prestado fue: Satisfactorio, Indiferente o Insatisfactorio. 
El objetivo de la empresa es cumplir con estos indicadores y todas las áreas están orientadas a ello, el cumplirlos significa generar valor, porque de ellos depende en qué medida la empresa pueden generar mayores ingresos.

\subsection{Indicadores de cada una de las actividades de la cadena de valor}

En la Tabla 19 se aprecia a los responsables de cada actividad y los objetivos que deben alcanzar, así también se muestra el indicador que medirá dicho objetivo:

Tabla 19:

Objetivos e indicadores

\begin{tabular}{|c|c|c|}
\hline Responsable & Objetivo Estratégico & Indicador \\
\hline $\begin{array}{l}\text { Gestión Administrativa y Servicio de } \\
\text { atención al cliente }\end{array}$ & $\begin{array}{l}\text { Incrementar los ingresos } \\
\text { totales }\end{array}$ & $\begin{array}{l}\text { Mínimo } 3 \%, 4 \% \text { y } 6 \% \\
\text { de ventas por cada año }\end{array}$ \\
\hline $\begin{array}{l}\text { Gestión Administrativa y Servicio de } \\
\text { atención al cliente }\end{array}$ & $\begin{array}{l}\text { Mejorar satisfacción del } \\
\text { cliente }\end{array}$ & $\begin{array}{l}\text { Incrementar en } 10 \% \\
\text { de satisfacción IVR } \\
\text { cada año }\end{array}$ \\
\hline Recursos Humanos & $\begin{array}{l}\text { Mejorar productividad de los } \\
\text { trabajadores en atención }\end{array}$ & $\begin{array}{l}\mathrm{N}^{\circ} \text { de clientes } \\
\text { atendidos por mes }\end{array}$ \\
\hline
\end{tabular}

Nota: Datos proporcionados por Digital (elaboración propia)

\subsection{Benchmarking y comparación con los líderes de la industria de cada una de las actividades de la cadena de valor}

Una de las limitaciones mencionadas anteriormente, es la nula accesibilidad a los estados financieros de las empresas que compiten directamente con Digital, lo que conlleva a que no se pueda evaluar la cadena de valor de dichas empresas. Sin embargo se ha utilizado los informes de TDP de donde se pueden obtener datos importantes para determinar el ingreso por atención al cliente; considerando la retribución económica fijada en el modelo de franquicia donde se 
establecen dos factores de retribución: Primero por el NDS y segundo por el IVR, se realizó una simulación para determinar los ingresos de dos empresas que compiten directamente con Digital resultados que se aprecian de dividir el total de ingresos entre el total de clientes atendidos en las diferentes tiendas, el cual es ligeramente mayor en Digital con respecto al competidor Boutique Celular mostrando ambas empresas un desempeño parecido, ambas tiendas obtienen mejores resultados que la tienda propia Multicentro de TDP, a pesar de atender a un número mayor de clientes, su rendimiento económico es menor, como se muestra en la Tabla 20.

\section{Tabla 20:}

\section{Ingresos por comisión de servicio de postventa}

\begin{tabular}{|c|c|c|c|c|c|c|c|}
\hline \multirow[b]{2}{*}{ Franquicia } & \multicolumn{3}{|c|}{ Ingresos IVR y NDS } & \multirow[b]{2}{*}{$\begin{array}{c}\text { Total } \\
\text { Ingresos } \\
\text { (Soles) }\end{array}$} & \multirow[b]{2}{*}{$\begin{array}{l}\text { Ingreso } \\
\text { por } \\
\text { cliente } \\
\text { atendido } \\
\text { (Soles) }\end{array}$} & & \multirow[b]{2}{*}{$\begin{array}{l}\text { Ingreso } \\
\text { Generado } \\
\text { por } \\
\text { trabajador } \\
\text { (Soles) } \\
\text { (b/c) }\end{array}$} \\
\hline & $\begin{array}{c}\text { Total } \\
\text { atenciones } \\
\text { Nro. clientes } \\
\text { (a) }\end{array}$ & $\begin{array}{c}\text { IVR } \\
\text { (Soles) }\end{array}$ & $\begin{array}{l}\text { NDS } \\
\text { (Soles) }\end{array}$ & & & $\begin{array}{c}\mathrm{N}^{\circ} \mathrm{de} \\
\text { trabajadores } \\
\text { (c) }\end{array}$ & \\
\hline Digital & 6,241 & 8,161 & 24,964 & 33,125 & 5.31 & 12 & $2,760.44$ \\
\hline Boutique & 4,893 & 5,782 & 19,572 & 25,354 & 5.18 & 14 & $1,811.04$ \\
\hline Multicentro & 9,760 & 12,450 & 0 & 12,450 & 1.28 & 15 & 830.05 \\
\hline
\end{tabular}

Nota: Datos proporcionados por Digital que corresponde a una tienda ubicada en Cusco a diciembre 2017 (elaboración propia).

Así mismo, se puede analizar el indicador IVR de las tres tiendas en la figura 13, mostrando resultados parecidos por insatisfacción, así mismo para el último mes a raíz de un trabajo de seguimiento y capacitación a los Asesores mejora el porcentaje de satisfacción a 39.6\%, sin embargo la diferencia sustancial en el ingreso está dada por la remuneración al NDS (Tabla 20), que para el análisis Multicentro no llega a cumplir el requisito de tiempo mínimo de espera de 15 minutos, superando este parámetro que exige TDP y regulado por OSIPTEL. 


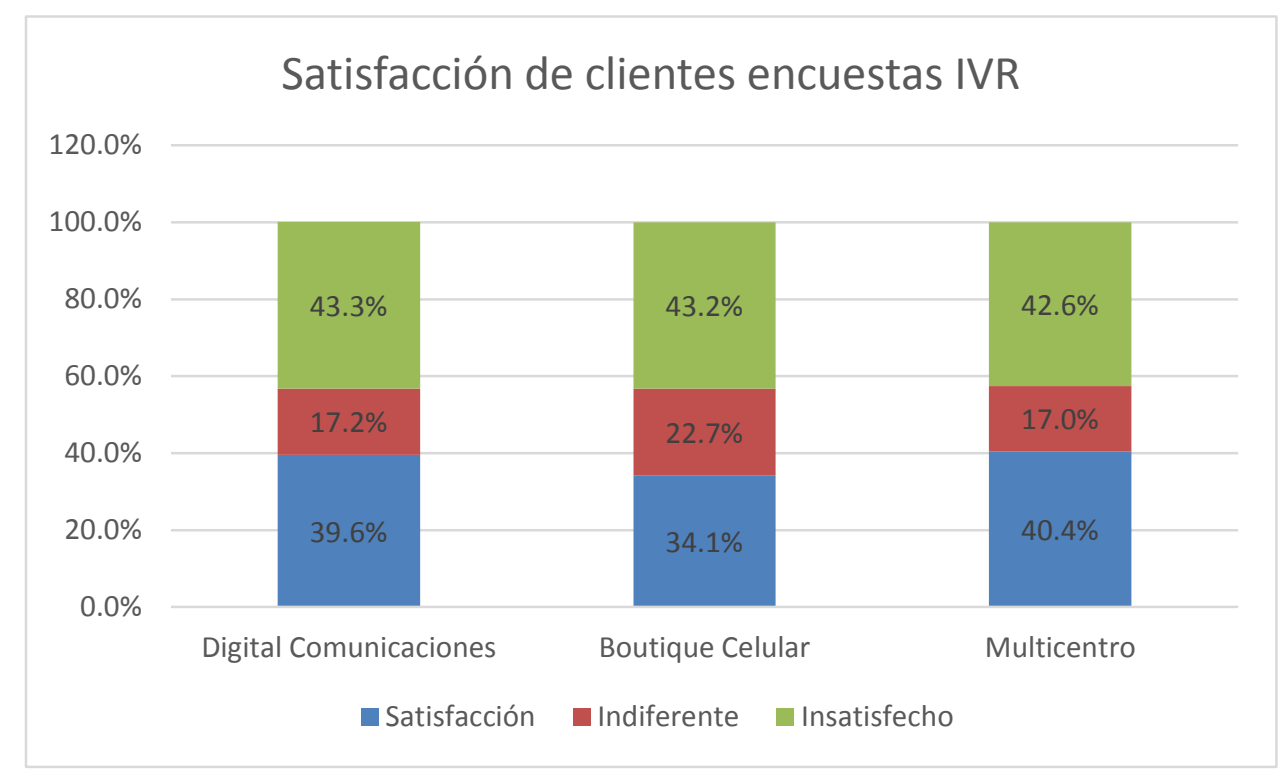

Figura 14: Encuesta del Nivel de Satisfacción del Cliente IVR de las franquicias. Datos de TDP de las encuestas IVR a diciembre 2017 (elaboración propia).

\subsection{Determinar las competencias de la empresa}

La empresa Digital al igual que las otras franquicias de TDP no pueden diferenciarse en precios y productos porque tienen las mismas condiciones comerciales, sin embargo la diferencia principal radica en la calidad del servicio que puedan ofrecer a los clientes, por ende la preferencia de estos para ser atendidos en determinada tienda.

Como se observa en la Tabla 20 y Figura 13 no hay mucha diferencia en la satisfacción de clientes, sin embargo al realizar la simulación de los ingresos, Digital tiene mejores resultados, producto de una mejor gestión, seguimiento y control, en todos sus procesos. 


\subsection{Identificación y determinación de las ventajas competitivas de la empresa}

Según Hill \& Jones (2009) afirma que:

Un modelo de negocios es una especie de modelo mental, abarca: ¿Cómo realizan las empresas las distintas actividades? y ¿qué hacen para ganar dinero?, Mientras que la estrategia habla de: ¿cómo va a competir la empresa en el mercado y ganar clientes? (pág. 40).

Considerando la teoría se ha identificado el modelo de negocios que tiene Digital, como empresa de servicios, ha desarrollado un modelo basado en la atención que brindan los trabajadores, para atender las necesidades, requerimientos y resolver los problemas de los

clientes, a través de estas actividades obtiene sus ingresos. En el caso de Digital, su ventaja competitiva radica en la participación de mercado mayor al 50\% Tabla 13.

\subsection{Matriz de Evaluación de los Factores Internos EFI}

Para determinar las fortalezas y debilidades de la empresa, se realizaron entrevistas a cuatro colaboradores: 01 Gerencia de Móviles, 01 Gerencia de Fija y 02 Supervisoras de Post Venta (Anexo 6), todos los entrevistados cuentan con más de 15 años en la empresa, de dichas entrevistas se ha determinado 8 fortalezas y 5 debilidades, la fortaleza más relevante corresponde a mejores procesos de control interno porque ello representa mayores ingresos para la empresa. Ver la Tabla 21. 
Tabla 21:

Matriz EFI

FORTALEZAS

Mantener una relación comercial por 18 años con TDP

Posicionamiento en el mercado al ser la única franquicia con mayor participación en las cinco regiones del sur del Perú.

Taller de Capacitación a todo el personal que labora para la mejor y buena atención al cliente

Proceso de control interno que se gestiona a través de un sistema informático, logístico y contable (SICEL).

Infraestructura cómoda, moderna y segura

Buena estructura financiera.

Personal especializado y con línea de carrera*.

Tiempo de permanencia del personal 22 meses frente a 12 meses que tiene la competencia**.

\section{DEBILIDADES}

Limitación en el manejo de precios, productos y servicios por el bajo poder de negociación con TDP.

Remuneración poco atractiva para el personal idóneo en servicio al cliente. 0.

Costos altos en alquileres.

Poca empatía de los trabajadores con los clientes en el área de servicio al cliente.

Penalidades impuestas por TDP

Total de la matriz EFI

Peso Calificación Ponderado

0.3

$\begin{array}{lll}0.1 & 4 & 0.4\end{array}$

$\begin{array}{lll}0.1 & 3 & 0.3\end{array}$

$\begin{array}{lll}0.08 & 3 & 0.24\end{array}$

$\begin{array}{lll}0.06 & 3 & 0.18\end{array}$

$\begin{array}{lll}0.05 & 3 & 0.15\end{array}$

$\begin{array}{lll}0.05 & 3 & 0.15\end{array}$

$\begin{array}{lll}0.05 & 3 & 0.15\end{array}$

$\begin{array}{lll}0.1 & 2 & 0.2\end{array}$

2

0.2

$\begin{array}{lll}0.1 & 2 & 0.2\end{array}$

$\begin{array}{lll}0.06 & 2 & 0.12\end{array}$

$\begin{array}{lll}0.05 & 2 & 0.1\end{array}$

Nota: Datos proporcionados por la empresa Digital (elaboración propia)

*Anexo 7

**Anexo 8 


\section{CAPÍTULO VII. FORMULACIÓN DE LOS OBJETIVOS Y DISEÑO DE LAS ESTRATEGIAS}

\subsection{Alcance y planteamiento de los objetivos estratégicos}

“Ser una franquicia líder e innovadora en el mercado de telefonía móvil y fija de los productos ofertados por TDP en las regiones donde operamos, reconocidos por brindar la mejor experiencia de servicio a nuestros clientes".

Como se puede observar en la visión, la empresa muestra su deseo de ser reconocida por brindar la mejor experiencia de servicio, por ello deberá enfocarse en objetivos estratégicos que la ayuden a llegar a la visión en un plazo determinado.

\subsubsection{Objetivos Estratégicos.}

Los objetivos estratégicos alineados a la visión son:

- Incrementar el índice de satisfacción de los clientes IVR en 10\% anual.

- Mantener el posicionamiento de la empresa con 8 tiendas en las localidades donde tiene presencia.

- Incrementar los niveles de ingresos totales mínimo en 3\%, 4\% y $6 \%$ anual.

- Crear una cultura organizacional orientada al cliente, a través de actividades de reconocimiento y capacitación con frecuencia mensual, bimensual o trimestral.

- Incrementar la productividad de los asesores otorgando un bono sobre el sueldo variable con frecuencia mensual. 


\subsubsection{Análisis de los objetivos estratégicos.}

Los objetivos estratégicos de la empresa se alinean a los objetivos SMART pues son específicos, medibles, alcanzables, relevantes y se desarrollan en un marco de tiempo, y están orientados a mejorar las ventas, la utilidad y la atención al cliente.

- Incrementar el índice de satisfacción de los clientes en 10\% anual:

Este objetivo busca incrementar la satisfacción de los clientes en 10\% anual, mediante capacitaciones, talleres y evaluaciones al personal.

- Mantener el posicionamiento de la empresa con 8 tiendas en las localidades donde tiene presencia.

Este objetivo está orientado a generar mayor presencia en el mercado por ello es importante reforzar la capacitación a los trabajadores en temas de calidad de atención lo cual será medido por el número de atenciones mensuales por tienda.

- Incrementar los niveles de ingreso mínimo en 3\%, $4 \%$ y $6 \%$ anual:

Este objetivo se fundamenta en generar retornos atractivos mediante el uso de artículos publicitarios en fechas específicas como: navidad, fiestas patrias, aniversarios etc. así como publicidad en medios locales.

- Crear una cultura organizacional orientada al cliente, a través de actividades de reconocimiento y capacitación con frecuencia mensual, bimensual o trimestral. 
Este objetivo busca contar con trabajadores más identificados con la problemática del cliente, para ello se realizarán actividades de capacitación y para generar mayor compromiso reuniones de confraternidad, cartas de felicitación y otros premios, que reconozcan al personal.

- Incrementar la productividad de los asesores otorgando un bono sobre el sueldo variable con frecuencia mensual:

Este objetivo se traza para superar los indicadores actuales del Índice del Nivel de Satisfacción al Cliente mediante una bonificación sobre el sueldo variable, lo cual conllevara a un incremento las ventas. 
Tabla 22:

Objetivos estratégicos de Digital

\begin{tabular}{|c|c|c|c|}
\hline Objetivo General & Objetivo Especifico & Medible & Tiempo \\
\hline \multirow[t]{2}{*}{ Ventas-Ingreso } & Incrementar los ingresos & $3 \%, 4 \%$ у $6 \%$ & Anual \\
\hline & $\begin{array}{l}\text { Incrementar la } \\
\text { productividad de los } \\
\text { asesores }\end{array}$ & $\begin{array}{c}\text { Mínimo } 25 \% \\
\text { bono del } \\
\text { sueldo variable }\end{array}$ & Mensual \\
\hline Posicionamiento & $\begin{array}{l}\text { Mantener los } 8 \text { franquicias } \\
\text { sin bajar el número de } \\
\text { atenciones }\end{array}$ & $\begin{array}{l}\text { Número de } \\
\text { atenciones }\end{array}$ & Anual \\
\hline Clientes & $\begin{array}{l}\text { Incrementar el índice de } \\
\text { satisfacción del cliente IVR }\end{array}$ & $10 \%$ & Anual \\
\hline \multirow[t]{2}{*}{ Procesos Internos } & $\begin{array}{l}\text { Incrementar porcentaje de } \\
\text { expedientes sin } \\
\text { observaciones }\end{array}$ & Subir $2 \%$ & Anual \\
\hline & $\begin{array}{l}\text { Disminuir morosidad de de } \\
\text { clientes que no pagan } 02 \\
\text { primeros recibos }\end{array}$ & Bajar 2\% & Anual \\
\hline \multirow{2}{*}{$\begin{array}{l}\text { Crear una cultura } \\
\text { organizacional } \\
\text { orientada al cliente }\end{array}$} & Capacitación al personal & $\begin{array}{c}\text { Plan de } \\
\text { capacitación }\end{array}$ & Anual \\
\hline & $\begin{array}{l}\text { Actividades de } \\
\text { reconocimiento al personal } \\
\text { para generar mayor } \\
\text { compromiso }\end{array}$ & $\begin{array}{l}\text { Cartas, premios } \\
\text { a los asesores }\end{array}$ & Trimestral \\
\hline
\end{tabular}

Nota: Datos proporcionados por la empresa Digital (elaboración propia)

\subsection{Diseño y formulación de estrategias.}

Para Porter (1987) la noción de estrategia procede de la reacción de la empresa frente a las fuerzas influyentes del entorno. Hay que entender que la formulación de la estrategia empresarial se apoya siempre en la necesidad de responder eficientemente y de actuar con eficacia en un entorno (genérico y específico) complejo. Digital lo que persigue es una diferenciación del 
servicio que ofrece en la atención al cliente mediante la calidad de servicio y que sea percibido como único en el mercado.

\subsubsection{Lienzo de la estrategia actual de la empresa.}

Para elaborar el lienzo de la estrategia actual de la empresa se han utilizado los mismos factores que se presentan en la determinación de la matriz EFE y la matriz EFI; dichos factores son importantes tanto para la industria como para la empresa Digital, de los cuales se han podido utilizar las valoraciones de los factores internos de la empresa mediante las entrevistas realizadas a la Gerente de Fija, Gerente de Móviles, y dos Supervisoras de Post Venta.

Se ha calificado a cada una de las variables con un puntaje de 1 a 4 , donde 1 se refiere a una calificación baja, mientras el puntaje 4 hace referencia a una calificación alta.

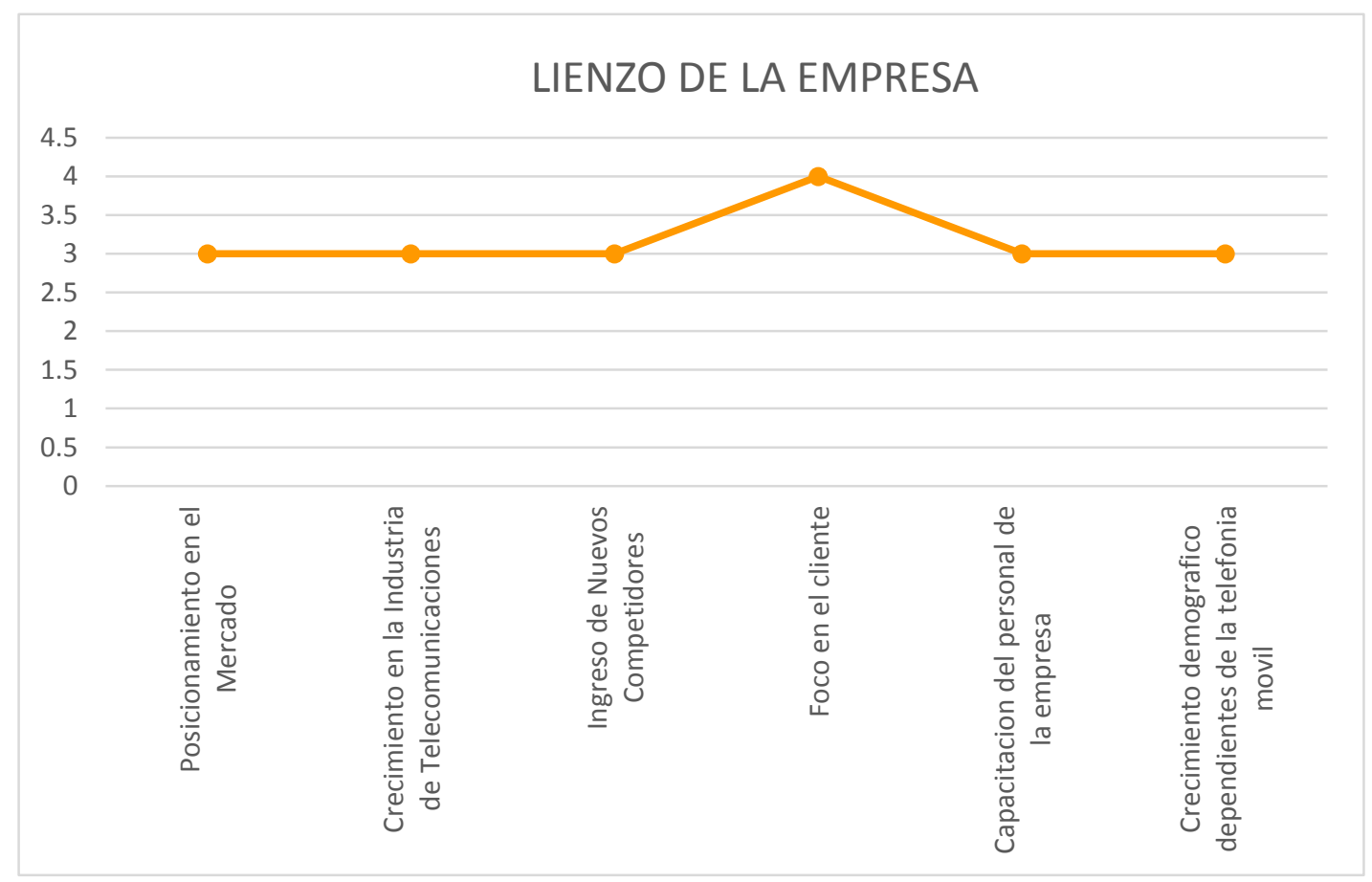

Figura 15: Lienzo de la estrategia actual de la empresa según datos de la matriz EFE y EFI.

Datos de la matriz EFE y EFI (elaboración propia) 


\subsubsection{Lienzo de la estrategia de la industria.}

Para elaborar el lienzo de la estrategia actual de la industria se han tomados factores con el apoyo de las encuestas realizadas por IPSOS a pedido de OSIPTEL (Anexo 3) de los cuales se han podido determinar los mismos factores en las matrices EFE y EFI demostrando que el pilar de la estrategia de la industria es el foco en el cliente, seguido del posicionamiento en el mercado, ingreso de nuevos competidores (franquicias) y el crecimiento demográfico que tienen la calificación más alta.

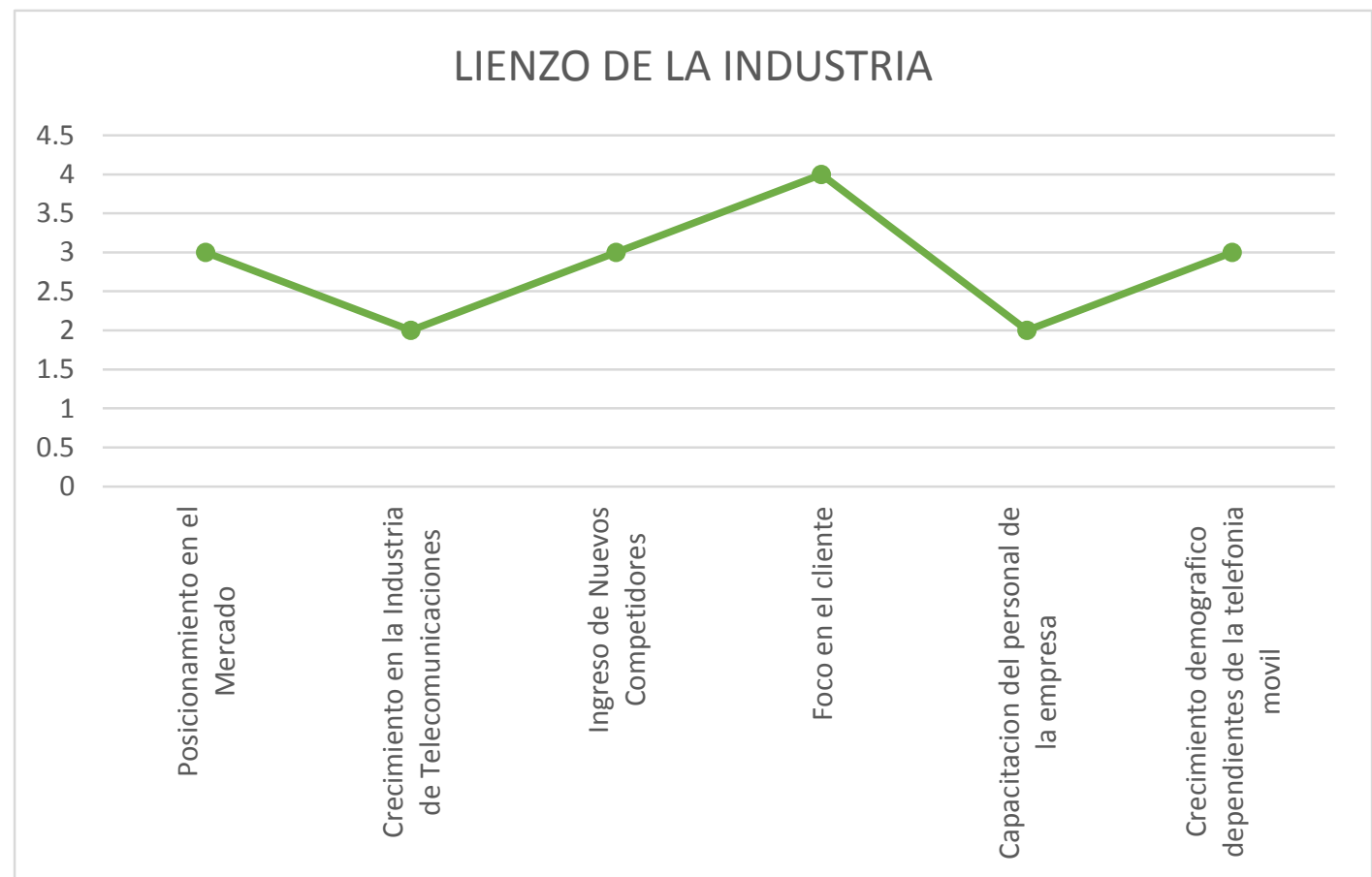

Figura 16: Lienzo de la estrategia de la Industria según datos de la matriz EFE y EFI. Datos de la matriz EFE y EFI (elaboración propia). 


\subsection{Matrices de formulación de estrategias.}

\subsubsection{Matriz FODA}

Tabla 23:

\section{Matriz FODA cruzada}

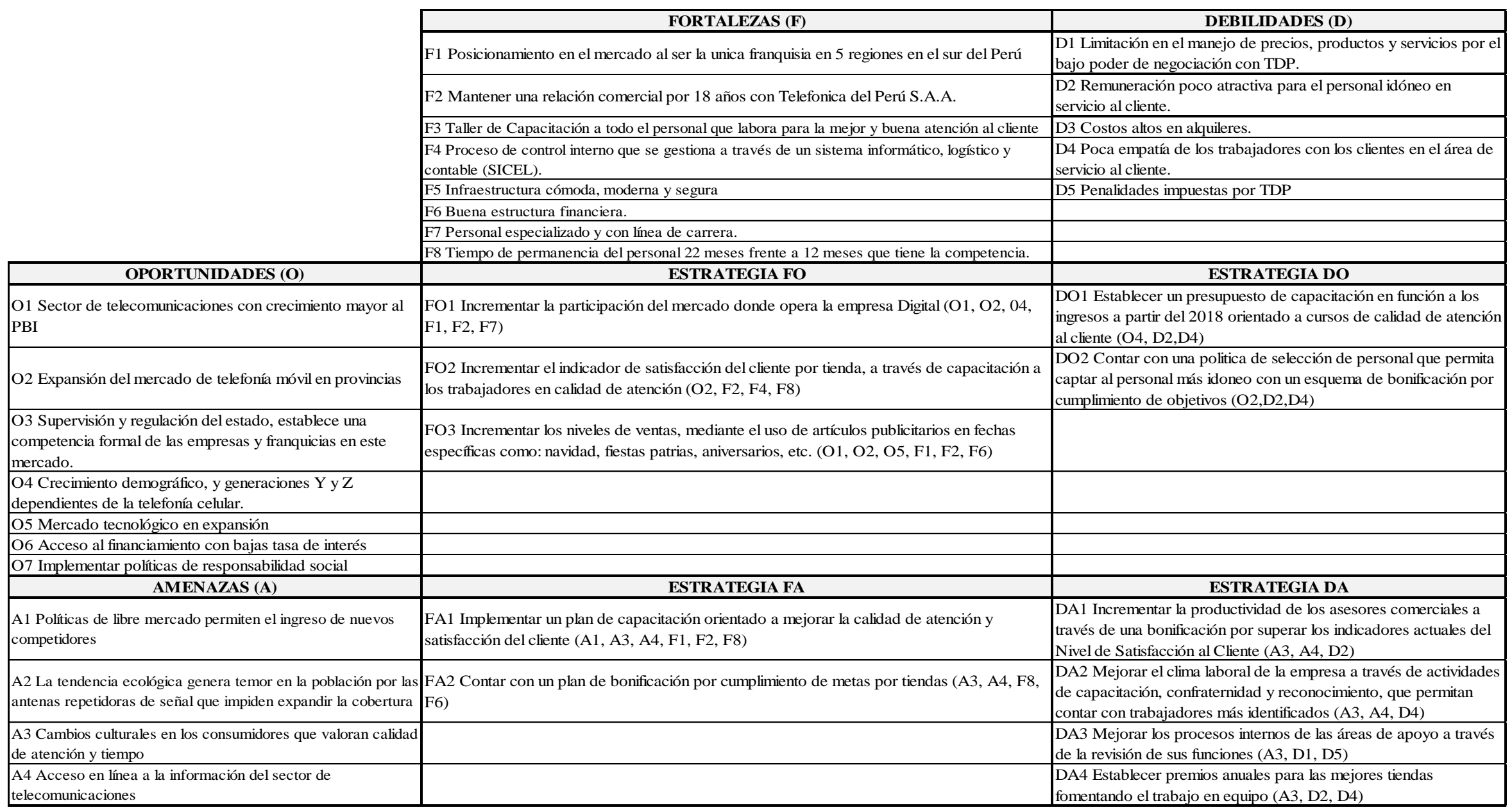

Nota: Elaboración propia 


\subsubsection{Matriz PEYEA}

Según Dickel citado en D’Alessio (2008) "la matriz PEYEA es usada para determinar la apropiada postura estratégica de la organización, tiene dos ejes que combinan factores relativos a la industria y dos ejes que combinan factores relativos a la organización” (pág. 282).

Las estrategias que corresponden al cuadrante IV Competitiva están relacionadas a: Aumentar sus esfuerzos en marketing, mejorar la fuerza de ventas, invertir en productividad, reducir costos, e intentar fusionarse con alguna compañía con liquidez.

Para realizar la matriz PEYEA, se han evaluado las dimensiones de: la fuerza financiera, la fuerza de la industria, la estabilidad del ambiente y la ventaja competitiva, a las mismas que se les ha atribuido factores de éxito, poniéndoles una calificación del uno al seis, donde uno es peor, y seis es mejor, en las dimensiones fuerza financiera y fuerza de la industria y menos uno peor y menos seis mejor a las dimensiones de estabilidad del ambiente y ventaja competitiva. 
Tabla 24:

Matriz PEYEA

\begin{tabular}{lc}
\hline DIMENSIONES Y FACTORES DEL ÉXITO & CALIFICACION \\
\hline FUERZA FINANCIERA & 3 \\
Buena calificación en el sistema financiero con línea de & 2 \\
crédito por carta fianza hasta un millón de soles & \\
Crecimiento de las ventas de manera sostenida & 5 \\
FUERZA DE LA INDUSTRIA & 5 \\
Crecimiento de la industria de las telecomunicaciones & \\
Crecimiento demográfico con potenciales clientes & -4 \\
ESTABILIDAD DEL AMBIENTE & -3 \\
Mercado tecnológico en expansión & -3 \\
Ingreso de nuevos competidores & \\
Fuerte presión de la oferta por competidores & \\
VENTAJA COMPETITIVA & \\
Posicionamiento en el mercado &
\end{tabular}

Nota: Datos tomados del estudio de la empresa para la formulación de la matriz FODA (elaboración propia)

El promedio para la fuerza financiera es: $5 / 2=2.5$

El promedio para la fuerza de la industria es: 10/2 = 5

El promedio para la estabilidad del ambiente es: $-10 / 3=-3.33$

El promedio para la ventaja competitiva es: $-12 / 3=-4$

Total resultados por ejes:

Eje $X:-4+(+5)=1$ 
Eje Y: $-3.33+(+2.5)=-0.83$

Tal como se observa en la Figura 17. Se puede apreciar los siguientes resultados

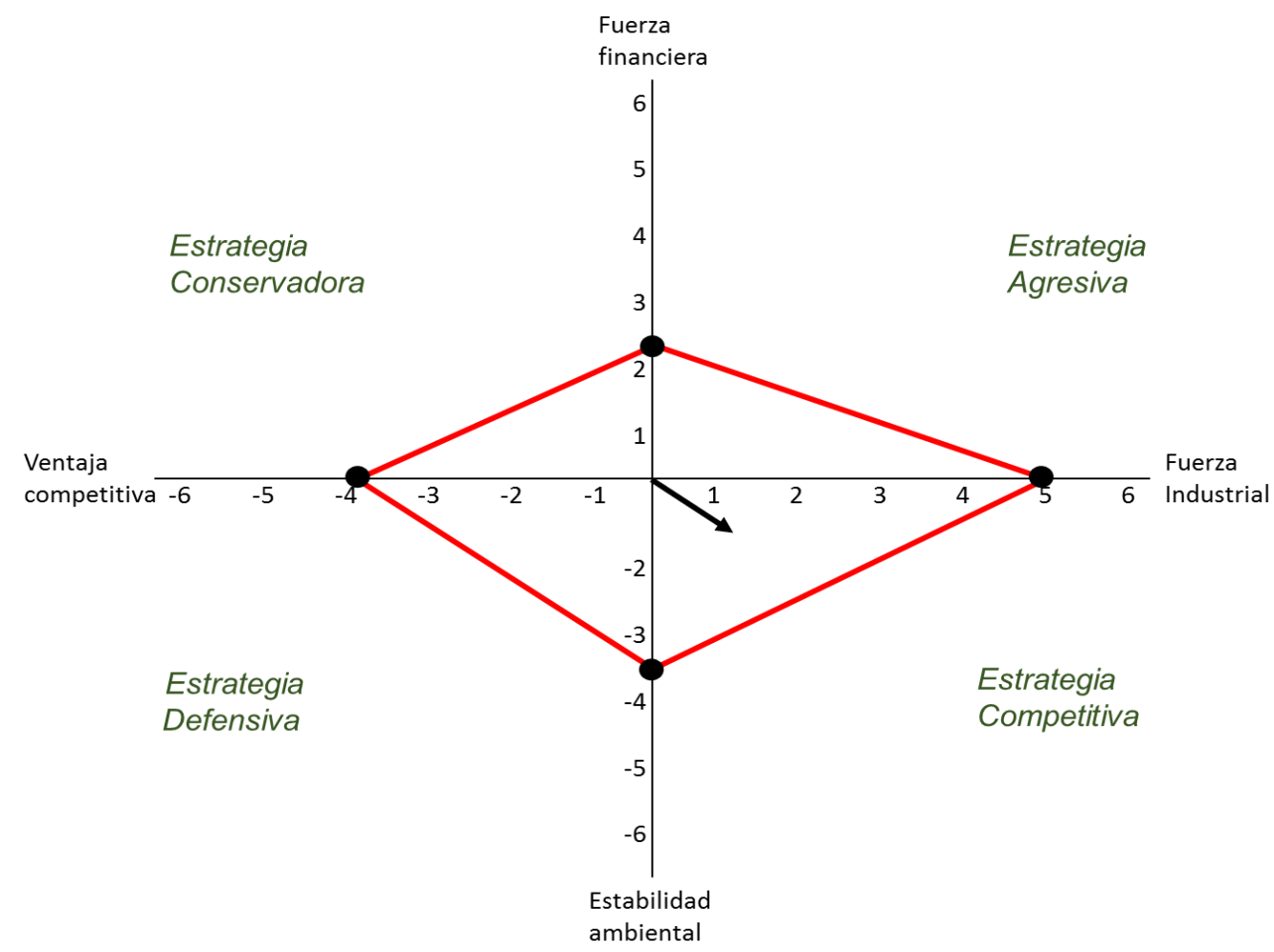

Figura 17: Matriz PEYEA.

Datos tomados en el estudio de la empresa para la formulación del FODA (elaboración propia)

Estos resultados ubican a Digital en el cuadrante IV debido a que en términos de crecimiento es lento en el mercado y sobre su posicionamiento competitivo es fuerte, el tipo de estrategia a utilizar seria:

Estrategia Horizontal.- La empresa al ser una franquicia de TDP puede absorber a otras franquicias de su zona de influencia por contar con el capital necesario y el talento humano para poder administrar una organización más grande con éxito. 


\subsubsection{Matriz Interna Externa}

Esta matriz fue desarrollado por Mckinsey \& Company; citado en D’Alessio, (2008), matriz que grafica cada una de las divisiones o de los productos de la organización ubicándolos en una de nueve celdas por medio de dos dimensiones, considerando como insumos las matrices EFE y EFI. (p. 317)

Tal como se observa en la Figura 18, la matriz EFE dio como resultado 2.56, y la matriz EFI tiene como resultado 2.69 ubicando a la empresa Digital en el cuadrante V proteger y mantener, en ese sentido las estrategias de la empresa deben estar dirigidas a la satisfacción cliente lo cual permitirá conservar y/o incrementar el nivel de ventas de la franquicia y la participación de mercado.
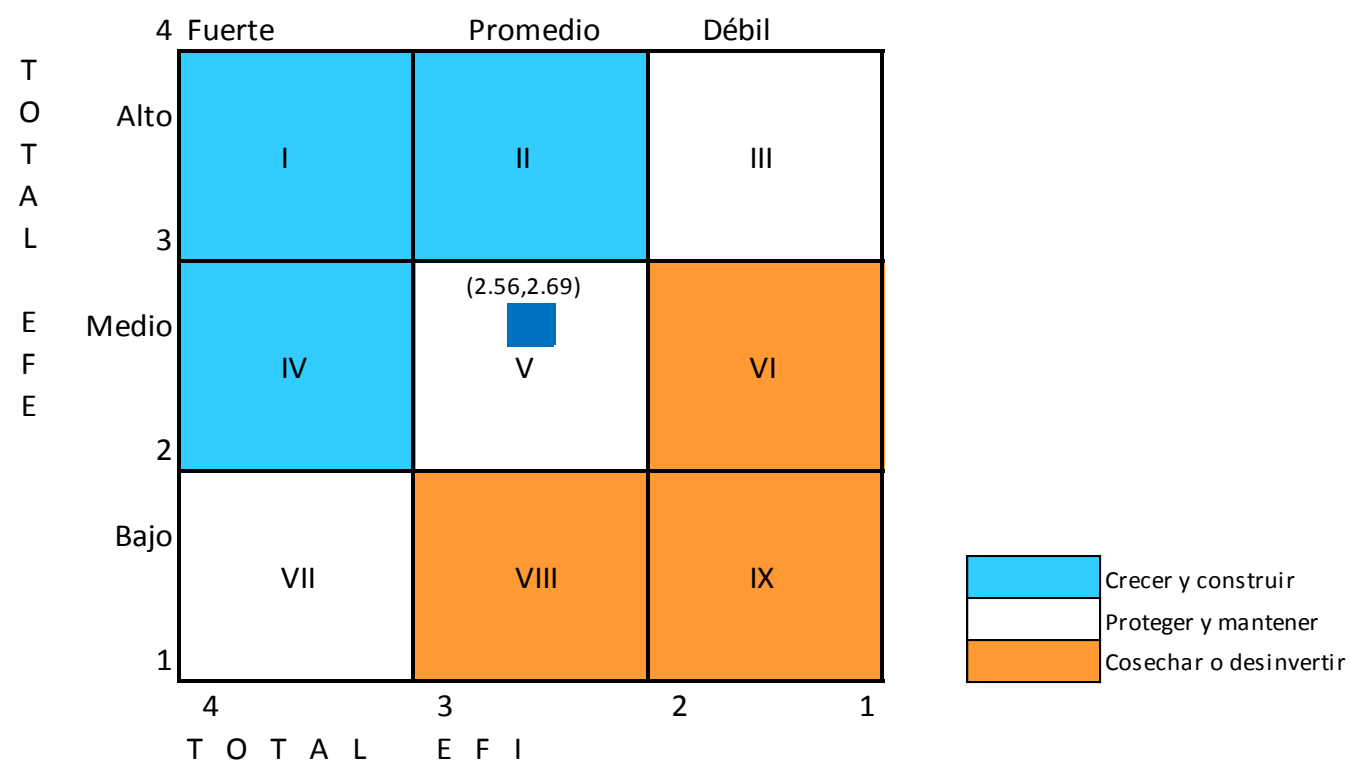

Figura 18: Matriz IE.

Datos tomados del resultado EFE y EFI tomados del estudio de la empresa Digital (elaboración propia). 


\subsubsection{Matriz de la Gran Estrategia}

Según Christensen, Berg y Salter citados en D'Alessio (2008) en esta matriz no se requiere realizar calculo alguno para llegar a los puntos x, y; puesto que, el cuadrante será definido de acuerdo a la posición competitiva de la organización y al crecimiento del mercado.

Para ubicar a la franquicia se ha evaluado el ciclo de vida de la empresa, así como el ciclo de vida de la industria, ubicándola en el cuadrante IV, porque el comportamiento de la industria en los últimos tres años ha mostrado tasas menores de crecimiento y la empresa muestra una posición competitiva fuerte. Así mismo como se observa en la figura 19, este cuadrante sugiere aplicar la estrategia de diversificación concéntrica; lo que implica un análisis de la competencia para incrementar las ventas a través de la satisfacción del cliente y llegar a más consumidores.

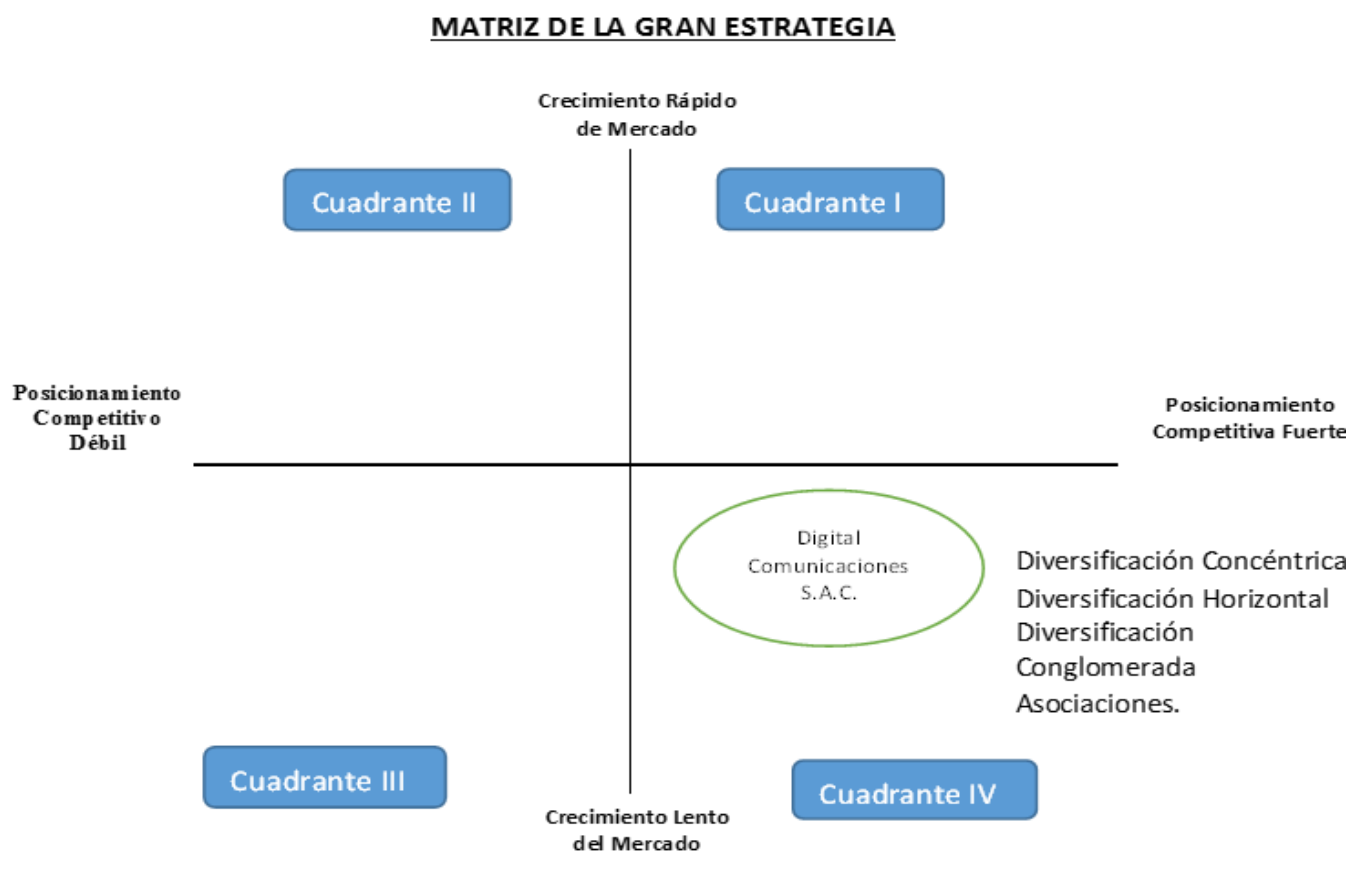

Figura 19: Matriz de la gran estrategia.

Datos tomados del resultado EFE y EFI tomados del estudio de Digital (elaboración propia). 


\subsubsection{Matriz de Ansoff.}

Esta matriz fue creada por Igor Ansoff en 1957, y también conocida como matriz producto / mercado, y es una herramienta que sirve para identificar las oportunidades de crecimiento en las unidades de negocio de una organización y por lo tanto solamente es útil para aquellas empresas que se han fijado objetivos de crecimiento.

Para ubicar a la franquicia se ha evaluado cada uno de los cuadrantes determinando la mejor opción a seguir, porque al ser Digital una franquicia de TDP, no puede desarrollar un nuevo producto, no puede penetrar en nuevos mercados, por lo tanto, el cuadrante en el que se le ubica es el I, Penetración en el mercado, porque las acciones que puede realizar están orientadas a brindar un mejor servicio y por ende incrementar la atención a un mayor número de clientes.

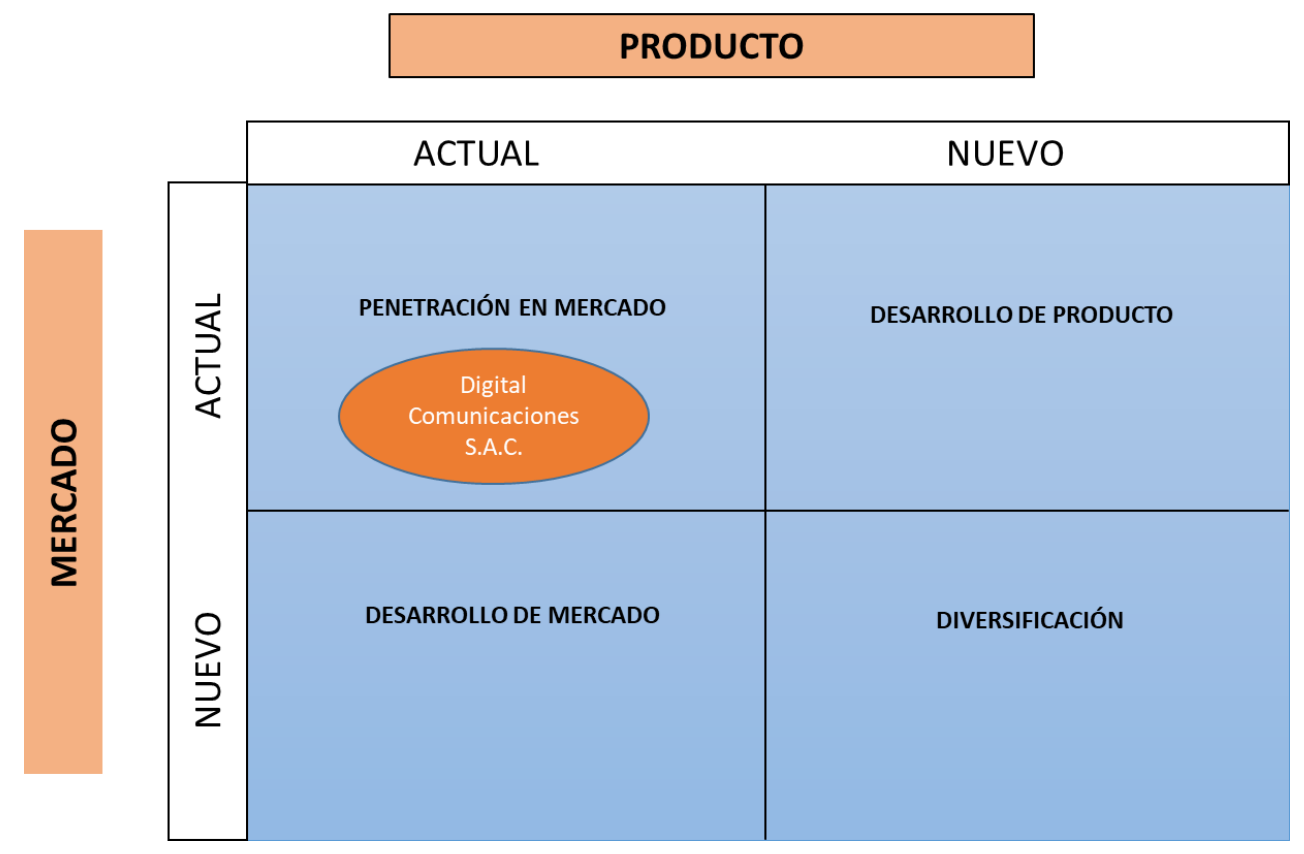

Figura 20: Matriz Ansoff.

Datos tomados del resultado EFE y EFI tomados del estudio de Digital (elaboración propia). 


\subsubsection{Resumen de las estrategias formuladas}

Para hacer el resumen de las estrategias es importante precisar que la empresa al ser una franquicia, tiene limitaciones para establecer estrategias relacionadas al desarrollo de productos, o nuevos servicios, por ello se hará un resumen en base a las cuatro matrices analizadas: FODA, PEYEA, Interna - Externa y de la Gran Estrategia.

1.- Penetración de mercado, incrementar las ventas en las regiones donde se tiene presencia mejorando la calidad en el servicio fidelizando a los clientes y aumentando el número de atenciones.

2.- Desarrollo de mercado, ampliar la red de tiendas.

3.- Reducción de costos internos, para poder proteger y mantener la posición de la empresa.

4.- Mejora de procesos, mejorar la calidad de atención al cliente, aumentar la liquidación de contratos, disminuir la morosidad de los clientes.

5.- Por tratarse de una franquicia que presta servicios, las estrategias están relacionadas con el área de Recursos Humanos quienes son los encargados de: reclutamiento, selección, capacitación, bonificación y reconocimiento al personal. 


\section{CAPÍTULO VIII. SELECCIÓN DE LA ESTRATEGIA}

\subsection{Método Factores Estratégicos Claves}

\subsubsection{Criterios de selección.}

A continuación, se presentan las estrategias encontradas a través de las matrices elaboradas con la finalidad de obtener la estrategia que más se repite y determinando que estrategia se podría utilizar en la empresa.

\subsubsection{Matriz de decisión.}

Según D’Alessio (2008):

La matriz de la decisión permite apreciar las repeticiones de las estrategias que se aplican en las diferentes matrices como FODA, PEYEA, IE y GE, de estas estrategias se elegirán las que se repitan por lo menos en 2 matrices (pág. 332).

Por lo anterior se observa que en la Tabla 25 son 2 las estrategias que se repiten en por lo menos 3 de las matrices analizadas: la estrategia principal se repite en 4 matrices, obteniendo la calificación más alta de 04 y la estrategia secundaria se repite en tres matrices, obteniendo la calificación de 03; por lo tanto, las otras estrategias que tienen una calificación menor a 03 quedan como estrategias de contingencia, complementando la estrategia principal. 
Tabla 25:

Matriz de decisión valoración del FODA

\begin{tabular}{|c|c|c|c|c|c|}
\hline ESTRATEGIAS & FODA & PEYEA & IE & GE & TOTAL \\
\hline $\begin{array}{l}\text { FO1 Incrementar la participación del mercado donde } \\
\text { opera la empresa Digital (O1, O2, 04, F1, F2, F7) }\end{array}$ & $X$ & $X$ & $\mathrm{X}$ & & 3 \\
\hline $\begin{array}{l}\text { FO2 Incrementar el indicador de satisfacción del } \\
\text { cliente por tienda, a través de capacitación a los } \\
\text { trabajadores en calidad de atención }(\mathrm{O} 2, \mathrm{~F} 2, \mathrm{~F} 4, \mathrm{~F} 8)\end{array}$ & $X$ & $X$ & & & 2 \\
\hline $\begin{array}{l}\text { FO3 Incrementar los niveles de ventas, mediante el } \\
\text { uso de artículo publicitarios en fechas específicas } \\
\text { como: navidad, fiestas patrias, aniversarios, etc. (O1, } \\
\text { O2, O5, F1, F2, F6) }\end{array}$ & $X$ & $X$ & $\mathrm{X}$ & & 3 \\
\hline $\begin{array}{l}\text { FA1 Implementar un plan de capacitación orientado a } \\
\text { mejorar la calidad de atención y satisfacción del } \\
\text { cliente. (A1, A3, A4, F1, F2, F8) }\end{array}$ & $\mathrm{X}$ & $\mathrm{X}$ & $\mathrm{X}$ & $\mathrm{X}$ & 4 \\
\hline $\begin{array}{l}\text { FA2 Contar con un plan de bonificación por } \\
\text { cumplimiento de metas por tiendas (A3, A4, F8, F6) }\end{array}$ & $\mathrm{X}$ & & & & 1 \\
\hline $\begin{array}{l}\text { DO1 Establecer un presupuesto de capacitación en } \\
\text { función a los ingresos a partir del } 2018 \text { orientados a } \\
\text { cursos de calidad de atención al cliente (O4, D4) }\end{array}$ & $\mathrm{X}$ & $X$ & & & 2 \\
\hline $\begin{array}{l}\text { DO2 Contar con una política de selección de personal } \\
\text { que permita captar al personal más idóneo con un } \\
\text { esquema de bonificación por cumplimiento de } \\
\text { objetivos (O2, D4) }\end{array}$ & $\mathrm{X}$ & & & & 1 \\
\hline $\begin{array}{l}\text { DA1 Incrementar la productividad de los asesores } \\
\text { comerciales a través de una bonificación por superar } \\
\text { los indicadores actuales del Nivel de Satisfacción al } \\
\text { Cliente. (A3, A4, D4) }\end{array}$ & $X$ & $\mathrm{X}$ & $\mathrm{X}$ & & 3 \\
\hline
\end{tabular}


DA2 Mejorar el clima laboral de la empresa a través de actividades de capacitación, confraternidad y reconocimiento, que permitan contar con trabajadores más identificados (A3, A4, D4)

DA3 Mejorar los procesos internos de las áreas de apoyo a través de la revisión de sus funciones (A3, D1)

DA4 Establecer premios anuales para las mejores tiendas fomentando el trabajo en equipo (A3, D4)

Nota: Datos tomados del estudio de la empresa Digital (Elaboración propia)

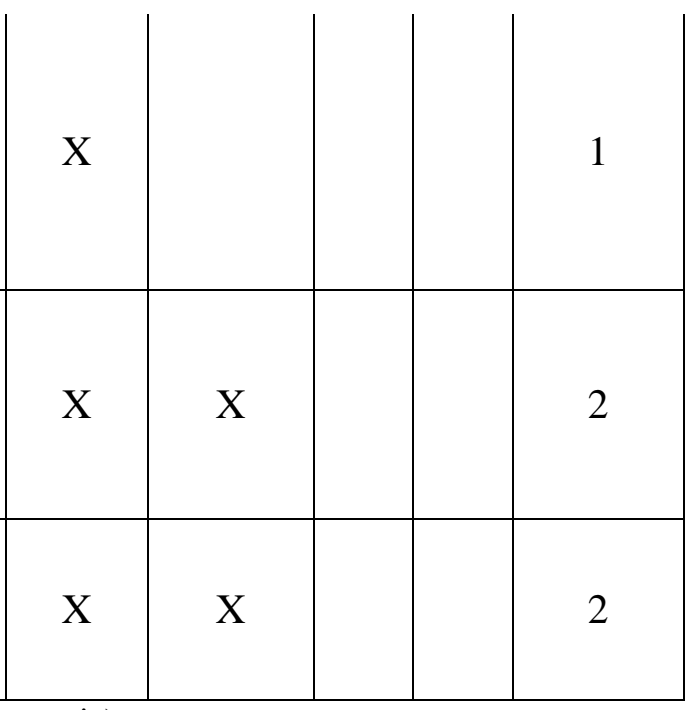

\subsection{Método de Escenarios}

Según Johnson, Scholes, \& Whittington (2006):

Los escenarios son descripciones detalladas y posibles de cómo se puede desarrollar el entorno empresarial de una organización en el futuro, a partir de la agrupación de influencias claves del entorno y de los motores de cambio sobre los que hay gran incertidumbre (pág. 76).

Para determinar los factores de gran impacto se ha tomado en cuenta las amenazas a las cuales está expuesta la empresa.

Primero, se identificaron tres factores de gran impacto e incertidumbre:

A. Comportamiento de la economía peruana, medida a través del PBI

B. Desarrollo del mercado de las telecomunicaciones

C. Aparición y uso de nuevas tecnologías

Segundo, se identificaron los posibles futuros por cada uno de los factores: 
A: $\quad$ i: Crecimiento

ii: Recesión

B: $\quad$ i: Ingresos de nuevos competidores

ii: Se mantienen o retiran empresas ya existentes

C: $\quad$ i: Favorable

ii: Desfavorable

\subsubsection{Descripción de escenarios considerados.}

Luego de establecer los factores y los cambios posibles en el futuro, se crean los escenarios a partir de las posibles configuraciones de los factores:

Escenario 1: El futuro se presenta como una oportunidad (Ai,Bii,Ci)

Quiere decir que el crecimiento económico del país se mantendrá en los próximo años, respecto a la competencia, no entran nuevas empresas de telecomunicaciones y el avance tecnológico es favorable, ya que cada vez, más usuarios requieren de un teléfono móvil y de diferentes aplicativos que están conectados a este aparato y al servicio que presta, es decir la franquicia está bajo el mejor escenario para seguir desarrollándose y creciendo, los equipos móviles se renuevan entre 6 a 12 meses dada la velocidad de la innovación tecnológica, ofreciendo lo último en tecnología a precios accesibles.

Escenario 2: El mercado se vuelve más competitivo (Ai,Bi,Ci) 
Producto del crecimiento económico positivo del país, entran más empresas a competir en el sector, lo que producirá una oferta agresiva de productos y servicios, causando una baja en los precios de la industria de telecomunicaciones, así mismo el avance tecnológico sigue favoreciendo el desarrollo de la industria.

Escenario 3: Se espera un estancamiento o lento crecimiento (Aii,Bii,Cii)

El país comienza a mostrar desaceleración económica y un crecimiento mínimo del PBI, lo cual representa una menor demanda por adquirir o renovar equipos y servicios, las empresas y franquicias se mantienen en el mercado, existe una mayor presión por captar nuevos clientes y mantenerlos, lo que genera una baja en los precios y menos márgenes de utilidad para la industria, en este escenario el uso de nuevas tecnologías es más costoso por ello tiene limitaciones para masificarse.

\subsubsection{Comparación de Estrategias con escenarios.}

En este punto se hace una evaluación a las dos estrategias que se han seleccionado en la matriz de decisión, las cuales serán analizadas en función al nivel de impacto en los tres escenarios propuestos, obteniendo el siguiente resultado: 
Tabla 26:

Comparación de estrategias en tres escenarios

\begin{tabular}{|l|l|l|l|}
\hline \multicolumn{1}{|c|}{ Estrategias } & \multicolumn{1}{|c|}{ Escenario 1 } & \multicolumn{1}{c|}{ Escenario 2 } & \multicolumn{1}{c|}{ Escenario 3 } \\
\cline { 2 - 4 } & $\begin{array}{l}\text { El futuro se presenta como } \\
\text { una oportunidad (Ai,Bii,Ci) }\end{array}$ & $\begin{array}{l}\text { El mercado se vuelve más } \\
\text { competitivo (Ai,Bi,Ci) }\end{array}$ & $\begin{array}{l}\text { Se espera un } \\
\text { estancamiento o lento } \\
\text { crecimiento (Aii,Bii,Cii) }\end{array}$ \\
\hline $\begin{array}{l}\text { Implementar un plan de capacitación } \\
\text { orientado a mejorar la calidad de } \\
\text { atención y satisfacción del cliente. }\end{array}$ & $\begin{array}{l}\text { Impacto positivo } \\
\text { probabilidad de } \\
\text { incrementar utilidad }\end{array}$ & $\begin{array}{l}\text { Impacto negativo } \\
\text { probabilidad de disminuir } \\
\text { utilidad }\end{array}$ \\
\hline $\begin{array}{l}\text { Incrementar la productividad de los } \\
\text { asesores comerciales a través de una } \\
\text { bonificación por superar los indicadores } \\
\text { actuales del Nivel de Satisfacción al } \\
\text { Cliente }\end{array}$ & $\begin{array}{l}\text { Impacto positivo } \\
\text { probabilidad de } \\
\text { incrementar utilidad }\end{array}$ & $\begin{array}{l}\text { Impacto negativo } \\
\text { probabilidad de disminuir } \\
\text { utilidad }\end{array}$ & $\begin{array}{l}\text { Impacto muy negativo } \\
\text { probabilidad de disminuir } \\
\text { utilidad }\end{array}$ \\
\hline
\end{tabular}

Nota: Elaborado con datos según el estudio desarrollado (elaboración propia)

Las dos estrategias que se han planteado logran un impacto positivo en dos combinaciones, en una combinación la situación de la empresa no varía, mientras que en las otras tres restantes impacta negativamente, dado que las estrategias generan un mayor costo por capacitaciones y bonificaciones frente a los ingresos que también se verían disminuidos.

\subsection{Matriz de Planeación Estratégica Cuantitativa MPEC}

Esta matriz ayudará a determinar el lado relativo de atracción de diversas estrategias con base a la posibilidad de aprovechar o mejorar los factores de éxito crítico externos e internos.

A continuación, se muestra la matriz MPEC con una estrategia principal y otra contingente:

- Implementar un plan de capacitación orientado a mejorar la calidad de atención y satisfacción del cliente.

- Incrementar la productividad de los asesores comerciales a través de una bonificación por superar los indicadores actuales del Nivel de Satisfacción al Cliente. Esta estrategia cuenta con el referente de los resultados obtenidos por Hay Group (2010) que manifiesta 
la necesidad de adoptar un enfoque estratégico de la retribución variable, con el fin de mantener la competitividad de la empresa frente a las exigencias del mercado actual. 
Tabla 27:

Matriz de Planeación Estratégica Cuantitativa MPEC

\begin{tabular}{|c|c|c|c|c|c|}
\hline \multirow[b]{2}{*}{ FACTOR CLAVE } & \multirow[b]{2}{*}{ PESO } & \multicolumn{2}{|c|}{$\begin{array}{l}\text { Implementar un plan de } \\
\text { capacitación orientado a mejorar } \\
\text { la calidad de atención y } \\
\text { satisfacción del cliente }\end{array}$} & \multicolumn{2}{|c|}{$\begin{array}{l}\text { Incrementar la productividad de los } \\
\text { asesores comerciales a través de una } \\
\text { bonificación por superar los } \\
\text { indicadores actuales del Nivel de } \\
\text { Satisfacción del Cliente }\end{array}$} \\
\hline & & VALOR & PONDERACION & VALOR & PONDERACION \\
\hline \multicolumn{6}{|l|}{ OPORTUNIDADES } \\
\hline O1 Sector de telecomunicaciones con crecimiento mayor al PBI & 0.12 & 2 & 0.24 & 2 & 0.24 \\
\hline $\begin{array}{l}\text { O4 Crecimiento demográfico, y generaciones Y y Z dependientes } \\
\text { de la telefonía celular. }\end{array}$ & 0.10 & 4 & 0.4 & 3 & 0.3 \\
\hline O5 Mercado tecnológico en expansión & 0.07 & 3 & 0.21 & 2 & 0.14 \\
\hline O6 Acceso al financiamiento con bajas tasa de interés & 0.05 & 3 & 0.15 & 2 & 0.1 \\
\hline $\begin{array}{l}\text { A2 La tendencia ecológica genera temor en la población por las } \\
\text { antenas repetidoras de señal que impiden expandir la cobertura }\end{array}$ & 0.12 & 1 & 0.12 & 1 & 0.12 \\
\hline $\begin{array}{l}\text { A3 Cambios culturales en los consumidores que valoran calidad de } \\
\text { atención y tiempo }\end{array}$ & 0.12 & 4 & 0.48 & 4 & 0.48 \\
\hline $\begin{array}{l}\text { A4 Acceso en línea a la información del sector de } \\
\text { telecomunicaciones }\end{array}$ & 0.12 & 3 & 0.36 & 3 & 0.36 \\
\hline FORTALEZAS & & & 0 & & 0 \\
\hline F1 Mantener una relación comercial por 18 años con TDP & 0.10 & 2 & 0.2 & 2 & 0.2 \\
\hline
\end{tabular}


F2 Posicionamiento en el mercado al ser la única franquicia con mayor participación en las cinco regiones del sur del Perú.

F3 Taller de Capacitación a todo el personal que labora para la mejor y buena atención al cliente

F4 Proceso de control interno que se gestiona a través de un sistema informático, logístico y contable (SICEL).

F5 Infraestructura cómoda, moderna y segura

F6 Buena estructura financiera.

F7 Personal especializado y con línea de carrera.

F8 Tiempo de permanencia del personal 22 meses frente a 12 meses que tiene la competencia.

\section{DEBILIDADES}

D1 Limitación en el manejo de precios, productos y servicios por el bajo poder de negociación con TDP.

D2 Remuneración poco atractiva para el personal idóneo en servicio al cliente.

D3 Costos altos en alquileres.

D4 Poca empatía de los trabajadores con los clientes, en el área del servicio al cliente.

D5 Penalidades impuestas por TDP

\begin{tabular}{|c|c|c|c|c|}
\hline 0.10 & 3 & 0.3 & 4 & 0.4 \\
\hline 0.10 & 4 & 0.4 & 4 & 0.4 \\
\hline 0.08 & 3 & 0.24 & 4 & 0.32 \\
\hline 0.06 & 3 & 0.18 & & 0 \\
\hline 0.05 & 2 & 0.1 & 3 & 0.15 \\
\hline 0.05 & 3 & 0.15 & 3 & 0.15 \\
\hline 0.05 & 2 & 0.1 & 4 & 0.2 \\
\hline & & 0 & & 0 \\
\hline 0.10 & 3 & 0.3 & 2 & 0.2 \\
\hline 0.10 & 2 & 0.2 & 3 & 0.3 \\
\hline 0.10 & 2 & 0.2 & 1 & 0.1 \\
\hline 0.06 & 3 & 0.18 & 4 & 0.24 \\
\hline 0.05 & 3 & 0.15 & 1 & 0.05 \\
\hline 2 & & 5.46 & & 4.95 \\
\hline
\end{tabular}

Nota: Datos tomados del estudio de la empresa Digital (elaboración propia). 
Con el resultado obtenido de las estrategias analizadas se observa que la estrategia con la puntuación más alta es implementar un plan de capacitación orientado a mejorar la calidad de atención y satisfacción del cliente (5.46); es decir, es la estrategia más recomendable para llevar a cabo, seguida por la estrategia de incrementar la productividad de los asesores comerciales a través de una bonificación por superar los indicadores actuales del Nivel de Satisfacción del Cliente (4.95).

\subsection{Descripción de las estrategias seleccionadas}

- Implementar un plan de capacitación y formación orientado a mejorar la calidad de atención y satisfacción del cliente, donde se puedan desarrollar y mejorar las habilidades de los colaboradores, así como su compromiso con la empresa. Para esto se definen los temas importantes que deben contener las capacitaciones, así como su respectivo cronograma, por otro lado también, se calcula el costo de su implementación.

\subsection{Descripción de la estrategia contingentes}

- Incrementar la productividad de los asesores comerciales a través de una reestructuración de la remuneración variable que percibe el trabajador, la misma que se le otorgará bajo el concepto de bonificación, por superar los indicadores actuales del Nivel de Satisfacción del Cliente, cabe mencionar que actualmente el trabajador percibe un sueldo compuesto por dos ítems: un sueldo fijo y uno variable el mismo que se encuentra sujeto a la productividad (comisiones por ventas), con esta estrategia se propone que adicionalmente el trabajador perciba una bonificación por mejorar el IVR, para ello se establecen los indicadores específicos y se realiza el costeo, de los recursos para las bonificaciones. 


\subsection{Tipo de estrategia genérica según Porter}

Según Porter, citado en D’Alessio (2008), plantea tres estrategias genéricas competitivas, de la evaluación realizada a las estrategias seleccionadas como principal y contingente planteadas en el plan estratégico, se concluye que ambas están relacionadas a la estrategia de diferenciación, la misma que busca que un producto o servicio tenga una cualidad única ( buena atención y/o servicio al cliente), ambas estrategias buscan mejorar la calidad de atención y satisfacción del cliente, sin embargo la diferenciación no es exclusiva de una sola empresa o sector, se espera que una vez implementadas los clientes de TDP perciban esta diferencia y prefieran ser atendidos en las tiendas de la franquicia.

\subsection{Macro estrategia}

Según Mc Carthy (1960), el marketing especifica el uso que se hará de las 4Ps que integran el marketing mix para adaptarse a las necesidades concretas del mercado objetivo a partir de una ventaja sostenible sobre la competencia. Sobre el producto, precio, canales de distribución y comunicaciones (o promoción) con las que se despliega la estrategia

Decisiones de producto: Este punto trata de diseñar un producto más apropiado para un mercado objetivo y contemplan también el envase, embalaje etiquetado etc. Al ser Digital una franquicia de TDP, no tiene ninguna injerencia sobre el producto que comercializa ni sobre su presentación.

Decisiones de Precio: Este punto trata de manejar los precios de los productos de acuerdo a: estaciones del año, promociones de la competencia etc. Igual que en el punto anterior Digital no tiene ninguna injerencia sobre el precio de los productos. 
Decisiones de Distribución: Este punto trata de toda la cadena que facilita el flujo del producto desde su producción hasta que llegue al cliente final. TDP, utiliza varias empresas externas que participan en los diferentes procesos, Digital cumple la función en la última etapa, realizando la venta final de los equipos celulares y ofreciendo el servicio final de postventa. El servicio de postventa está calificado por TDP mediante las encuestas IVR, y trata de la calificación que realiza el cliente al servicio prestado por las franquicias. Como se pudo ver en el punto 5.4 matriz MPC, digital tiene una calificación de 3.20 y se encuentra por encima de su competencia directa en la zona Cusco.

Decisiones de Comunicación: Este punto trata de difundir en el mercado objetivo la propuesta de valor, esta propuesta de valor es un valor único y que diferencia a la empresa de su competencia, Digital ofrece una mejor atención al cliente, porque cuenta con personal capacitado y busca dar solución a los reclamos y problemas de los clientes, así como también busca satisfacer las necesidades de los mismos.

De estas definiciones se puede establecer que nuestra macro estrategia se ubica en: La relación con el cliente, en el punto atención al cliente, puesto que digital tiene como rubro principal brindar el servicio de postventa. Por lo que las estrategias propuestas están orientadas a mejorar la calidad de atención y satisfacción del cliente, mediante capacitaciones y evaluaciones al personal. 


\subsection{Propuesta de valor}

En todas las empresas el personal es considerado como una parte importante de la organización, sin embargo, el personal, cobra mayor importancia en empresas de servicios, donde los clientes se forman una percepción en base al comportamiento y actitudes del personal, por lo tanto, el personal forma parte importante de la diferenciación de la empresa frente a su competencia. La propuesta de valor de Digital es brindar la mejor experiencia de venta y postventa a los clientes de TDP, con lo que se busca mantener e incrementar la base de clientes, logrando resolver sus problemas y satisfacer sus necesidades. Propuesta que se espera transmitir a todos los colaboradores a través de todas las capacitaciones, las mismas que se comunicarán de forma clara y sencilla.

\subsection{Cadena Servicio - Beneficio}

El plan propuesto para la empresa conforme a la Cadena Servicio - Beneficio según Scheerle (2001), considera la existencia de una relación directa entre las utilidades, la lealtad del cliente y satisfacción del colaborador, por ello el plan de reclutamiento, selección, capacitación, reconocimiento y recompensas van de la mano buscando que el colaborador se sienta motivado, comprometido y satisfecho con el fin de mejorar la productividad, ofrece un mejor servicio para incrementar la utilidad de la empresa.

Digital está enfocada en implementar talleres de capacitación para dotar de conocimientos y herramientas, para que los asesores puedan ser capaces de prestar el mejor servicio y tener la propuesta o solución para los clientes, así como poder negociar situaciones de conflicto y tener la capacidad de resolver todo tipo de requerimientos que se presentan en el área de atención al usuario. 
Así mismo, se tiene al cliente interno, quienes forman parte importante de las áreas administrativas y de soporte de la empresa, para ellos se ha considerado talleres de capacitación trimestrales y cartas de reconocimiento a fin de lograr mayor compromiso y satisfacción, que conllevará al cumplimiento de los objetivos dentro de un buen ambiente laboral.

El plan estratégico está orientado a conseguir la satisfacción de los clientes internos y externos y así conseguir mejores resultados. 


\section{CAPÍTULO IX. IMPLANTACIÓN DE LA ESTRATEGIA}

\subsection{Mapa de la Estrategia.}

Según los autores Kaplan \& Norton (2002):

El cuadro de mandos cuenta con los indicadores financieros tradicionales los que reflejan la historia de la empresa, estos indicadores por si solos son insuficientes para generar valor en el futuro a través de las inversiones en clientes, proveedores, empleados, procesos, tecnología e innovación. El cuadro de mandos combina los indicadores financieros con las actividades críticas que generan valor para la empresa (pág. 20).

Digital, utilizará el cuadro de mando como guía para medir el cumplimiento de las estrategias a largo plazo, el mismo que se presenta en la figura 21.

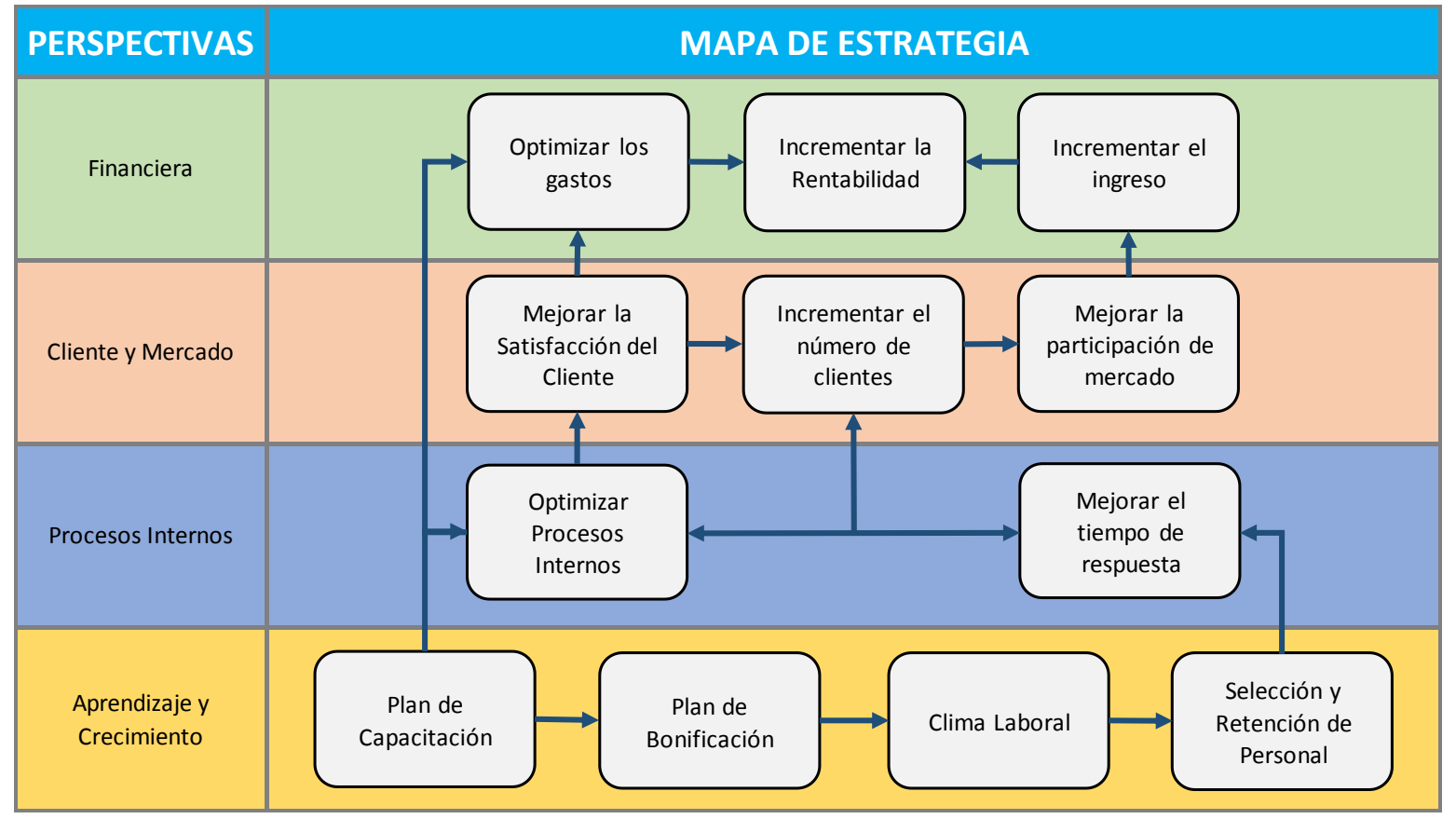

Figura 21: Mapa de la estrategia.

(elaboración propia). 


\subsection{Objetivos específicos según el mapa de la estrategia}

La empresa ha planteado los siguientes objetivos específicos según las 4 perspectivas del cuadro de mandos:

\subsubsection{Perspectiva Financiera.}

- Incrementar la rentabilidad:

- Incrementar la utilidad, mínimo en $13 \%, 15 \%$ y $22 \%$ en los tres siguientes años 2019, 2020 y 2021.

- Incrementar los ingresos:

- Incrementar los ingresos totales mínimo en 3\%, 4\% y $6 \%$ para los siguientes tres años.

- Incrementar los ingresos por comisiones de venta de líneas fijas mínimo en 3\% $3 \%$ y $4 \%$ en los tres años.

- Incrementar los ingresos por comisiones de venta móvil mínimo en 3\%, $4 \%$ y 4\% cada año.

- Incrementar los ingresos por comisiones de servicio de post venta mínimo en $5 \%, 5 \%$ y $6 \%$ cada año.

- Incrementar el número de unidades vendidas de líneas móviles en 5\% anual durante los 3 años siguientes.

\section{- Optimizar los gastos:}

- Reducir el gasto por penalidades mínimo en 3\%, 5\% y 7\% para los siguientes tres años 


\subsubsection{Perspectiva cliente.}

- Incrementar la satisfacción del cliente:

- Incrementar el nivel de satisfacción del cliente en $10 \%$ cada año medido a través del IVR.

- Incrementar participación en el mercado:

- Adquirir una tienda como franquicia en la zona donde la empresa ya tiene presencia, (Ayacucho ó Cusco).

- Implementar el uso de artículos promocionales:

- Adquirir artículos promocionales para que sean entregados a los clientes en fechas importantes como navidad, año nuevo, día de la madre, día del padre, fiestas patrias, y fiestas regionales.

\subsubsection{Perspectiva procesos internos.}

- Optimizar los procesos internos:

- Incrementar el porcentaje de expedientes remitidos a TDP sin observación en $2 \%$ cada año.

- Disminuir en 2\% la morosidad de los clientes con 02 primeros recibos a 60 días cada año.

- Mantener el indicador de tiempo de atención NDS los siguientes 03 años. 


\subsubsection{Perspectiva aprendizaje y crecimiento.}

\section{- Bonificación por calidad de atención al cliente}

- Otorgar un bono sobre la remuneración variable de $25 \%, 45 \%$ y $70 \%$ en los siguientes 3 años, por cumplir con incrementar el nivel de satisfacción del cliente IVR, indicador que será evaluado en forma mensual, cabe señalar que este bono será otorgado conforme a los resultados del cierre del mes siempre y cuando se lleguen a la meta planteada.

- Selección de personal

- Contar con un Manual de Organización y Funciones y Perfil del Puesto a fin de mejorar el proceso de selección en el segundo año.

\section{- Desarrollo y retención de personal}

- Implementar un plan de capacitación anual orientado a la calidad de atención.

- Implementar un proceso para medir el clima laboral.

- Plan de reconocimiento a los mejores asesores comerciales.

- Contar con una evaluación de desempeño para el tercer año.

- Plan de premiación semestral a los mejores asesores, que equivale aproximadamente a un sueldo a partir del año 2019. 
Tabla 28:

Resumen de los objetivos estratégicos y específicos

\begin{tabular}{|c|c|}
\hline Objetivos Estratégicos & Objetivos Específicos \\
\hline & Perspectiva Financiera \\
\hline Incrementar Rentabilidad & Incrementar la utilidad mínimo en 13\%, 15\% y 22\% en los tres siguientes años 2019, 2020 y 2021 \\
\hline \multirow{5}{*}{ Incrementar Ingresos } & Incrementar los ingresos totales mínimo en $3 \%, 4 \%$ y $6 \%$ para los siguientes tres años \\
\hline & Incrementar los ingresos por comisiones de venta de líneas fijas mínimo en 3\%, 3\% y $4 \%$ cada año \\
\hline & Incrementar los ingresos por comisiones de venta móvil mínimo en $3 \%, 4 \%$ y $4 \%$ cada año \\
\hline & Incrementar los ingresos por comisiones de servicio de post venta mínimo en $5 \%, 5 \%$ y $6 \%$ cada año \\
\hline & Incrementar el número de unidades vendidas de líneas móviles en $5 \%$ anual \\
\hline Optimizar los gastos & Reducir el gasto por penalidades mínimo en $3 \%, 5 \%$ y $7 \%$ para los siguientes tres años \\
\hline \multicolumn{2}{|r|}{ Perspectiva Clientes } \\
\hline Incrementar la satisfacción del cliente & Incrementar el nivel de satisfacción del cliente en $10 \%$ cada año medido a través del IVR \\
\hline $\begin{array}{l}\text { Incrementar la participación de } \\
\text { mercado }\end{array}$ & Adquirir una tienda como franquicia en la zona donde la empresa ya tiene presencia (Ayacucho o Cusco) \\
\hline $\begin{array}{l}\text { Implementar el uso de } \\
\text { artículos promocionales }\end{array}$ & $\begin{array}{l}\text { Adquirir artículos promocionales para entregarlos a los clientes en fechas importantes como navidad, año nuevo, día de la } \\
\text { madre, día del padre, fiestas patrias, y fiestas regionales. }\end{array}$ \\
\hline \multicolumn{2}{|r|}{ Perspectiva Procesos Internos } \\
\hline \multirow{3}{*}{ Optimizar los procesos internos } & Incrementar el porcentaje de expedientes remitidos a TDP sin observación en $2 \%$ cada año \\
\hline & Disminuir en $2 \%$ la morosidad de los clientes con 02 primeros recibos en 60 días \\
\hline & Mantener el indicador de tiempo de atención NDS los siguientes 03 años. \\
\hline \multicolumn{2}{|r|}{ Perspectiva Aprendizaje y Crecimiento } \\
\hline $\begin{array}{l}\text { Bonificación por calidad de atención } \\
\text { al cliente }\end{array}$ & $\begin{array}{l}\text { Otorgar un bono sobre la remuneración variable de } 25 \%, 45 \% \text { y } 70 \% \text { en los siguientes } 3 \text { años, por cumplir con incrementar } \\
\text { el nivel de satisfacción del cliente IVR. }\end{array}$ \\
\hline Selección de personal & $\begin{array}{l}\text { Contar con un Manual de Organización y Funciones y Perfil del Puesto a fin de mejorar el proceso de selección en el } \\
\text { segundo año }\end{array}$ \\
\hline \multirow{4}{*}{ Desarrollo y retención de personal } & Implementar un plan de capacitación anual en calidad de atención al cliente \\
\hline & Implementar un proceso para medir el clima laboral \\
\hline & Desarrollar un plan de reconocimiento a los mejores asesores \\
\hline & Contar con una evaluación de desempeño para el tercer año \\
\hline
\end{tabular}

Nota: Elaboración propia 


\subsection{Indicadores y metas para cada uno de los objetivos específicos}

Para gestionar el cumplimiento de los objetivos específicos, es necesario establecer

indicadores y una línea base, para poder medir y controlar su avance, así mismo evaluar cada año

para hacer los ajustes necesarios para el cumplimiento de los objetivos, todo aquello que se

puede cuantificar se podrá controlar de manera más eficiente y objetiva. Ver Tabla 29:

Tabla 29:

Resumen de los indicadores y metas para cada objetivo específico.

\begin{tabular}{|c|c|c|c|c|c|c|}
\hline Objetivos Estratégicos & Objetivos Específicos & \multirow{2}{*}{ Indicadores } & \multirow{2}{*}{$\begin{array}{l}\text { Línea base } \\
\text { año } 2018\end{array}$} & \multicolumn{3}{|c|}{ Meta } \\
\hline \multicolumn{2}{|r|}{ Perspectiva Financiera } & & & 2019 & 2020 & 2021 \\
\hline Incrementar Rentabilidad & $\begin{array}{l}\text { Incrementar la utilidad mínimo en } 13 \%, 15 \% \text { y } 22 \% \text { en los tres siguientes años } \\
2019,2020 \text { y } 2021\end{array}$ & $\%$ crecimiento utilidad & $3.0 \%$ & $13.0 \%$ & $15.0 \%$ & $22.0 \%$ \\
\hline \multirow{5}{*}{ Incrementar Ingresos } & $\begin{array}{l}\text { Incrementar los ingresos totales mínimo en } 3 \%, 4 \% \text { y } 6 \% \text { para los siguientes } \\
\text { tres años }\end{array}$ & $\begin{array}{l}\% \text { crecimiento ingresos } \\
\text { totales }\end{array}$ & $1.5 \%$ & $3.0 \%$ & $4.0 \%$ & $6.0 \%$ \\
\hline & $\begin{array}{l}\text { Incrementar los ingresos por comisiones de venta de líneas fijas mínimo en } 3 \% \text {, } \\
3 \% \text { y } 4 \% \text { cada año }\end{array}$ & $\begin{array}{l}\% \text { crecimiento de comisión } \\
\text { fijas }\end{array}$ & $1.0 \%$ & $3.0 \%$ & $3.0 \%$ & $4.0 \%$ \\
\hline & $\begin{array}{l}\text { Incrementar los ingresos por comisiones de venta móvil mínimo en } 3 \%, 4 \% \text { y } \\
4 \% \text { cada año }\end{array}$ & $\begin{array}{l}\text { \% crecimiento de comisión } \\
\text { móvil }\end{array}$ & $1.0 \%$ & $3.0 \%$ & $4.0 \%$ & $4.0 \%$ \\
\hline & $\begin{array}{l}\text { Incrementar los ingresos por comisiones de servicio de post venta mínimo en } \\
5 \%, 5 \% \text { y } 6 \% \text { cada año }\end{array}$ & $\begin{array}{l}\% \text { crecimiento de comisión } \\
\text { post venta }\end{array}$ & $1.0 \%$ & $5.0 \%$ & $5.0 \%$ & $6.0 \%$ \\
\hline & Incrementar el número de unidades vendidas de líneas móviles en $5 \%$ anual & $\begin{array}{l}\% \text { número de unidades } \\
\text { vendidas }\end{array}$ & $4.0 \%$ & $5.0 \%$ & $5.0 \%$ & $5.0 \%$ \\
\hline Optimizar los gastos & $\begin{array}{l}\text { Reducir el gasto por penalidades mínimo en } 3 \%, 5 \% \text { y } 7 \% \text { para los siguientes } \\
\text { tres años }\end{array}$ & \% reducción de penalidades & & $-3.0 \%$ & $-5.0 \%$ & $-7.0 \%$ \\
\hline \multicolumn{7}{|c|}{ Perspectiva Clientes } \\
\hline $\begin{array}{l}\text { Incrementar la satisfacción } \\
\text { del cliente }\end{array}$ & $\begin{array}{l}\text { Incrementar el nivel de satisfacción del cliente en } 10 \% \text { cada año medido a } \\
\text { través del IVR }\end{array}$ & \% satisfacción IVR & $34.0 \%$ & $44.0 \%$ & $54.0 \%$ & $64.0 \%$ \\
\hline $\begin{array}{l}\text { Incrementar la participación } \\
\text { de mercado }\end{array}$ & $\begin{array}{l}\text { Adquirir una tienda como franquicia en la zona donde la empresa ya tiene } \\
\text { presencia (Ayacucho o Cusco) }\end{array}$ & número de tiendas & 8 & & & 9 \\
\hline $\begin{array}{l}\text { Implementar el uso de } \\
\text { artículos promocionales }\end{array}$ & $\begin{array}{l}\text { Adquirir artículos promocionales para entregarlos a los clientes en fechas } \\
\text { importantes como navidad, año nuevo, día de la madre, día del padre, fiestas } \\
\text { patrias, y fiestas regionales. }\end{array}$ & $\begin{array}{l}\text { \% incremento del gasto } \\
\text { (servicios de terceros) }\end{array}$ & $5 \%$ & $10 \%$ & $18 \%$ & $22 \%$ \\
\hline \multicolumn{7}{|c|}{ Perspectiva Procesos Internos } \\
\hline \multirow{3}{*}{$\begin{array}{l}\text { Optimizar los procesos } \\
\text { internos }\end{array}$} & $\begin{array}{l}\text { Incrementar el porcentaje de expedientes remitidos a TDP sin observación en } \\
2 \% \text { cada año }\end{array}$ & $\begin{array}{l}\% \text { de expedientes sin } \\
\text { observación }\end{array}$ & $85 \%$ & $87 \%$ & $89 \%$ & $91 \%$ \\
\hline & $\begin{array}{l}\begin{array}{l}\text { Disminuir en } 2 \% \text { la morosidad de los clientes con } 02 \text { primeros recibos en } 60 \\
\text { días }\end{array} \\
\end{array}$ & \% disminución de morosidad & $20 \%$ & $18 \%$ & $16 \%$ & $14 \%$ \\
\hline & Mantener el indicador de tiempo de atención NDS los siguientes 03 años. & indicador de NDS & $89.5 \%$ & $90 \%$ & $90 \%$ & $90 \%$ \\
\hline \multicolumn{7}{|c|}{ Perspectiva Aprendizaje y Crecimiento } \\
\hline $\begin{array}{l}\text { Bonificación por calidad de } \\
\text { atención al cliente }\end{array}$ & $\begin{array}{l}\text { Otorgar un bono sobre la remuneración variable de } 25 \%, 45 \% \text { y } 70 \% \text { en los } \\
\text { siguientes } 3 \text { años, por cumplir con incrementar el nivel de satisfacción del } \\
\text { cliente IVR. }\end{array}$ & $\begin{array}{l}\text { \% incremento del bono sobre } \\
\text { la remuneración variable }\end{array}$ & Nuevo & $25 \%$ & $45 \%$ & $70 \%$ \\
\hline Selección de personal & $\begin{array}{l}\text { Contar con un Manual de Organización y Funciones y Perfil del Puesto a fin de } \\
\text { mejorar el proceso de selección en el segundo año }\end{array}$ & número de documentos & Nuevo & 1 & & \\
\hline \multirow{4}{*}{$\begin{array}{l}\text { Desarrollo y retención de } \\
\text { personal }\end{array}$} & Implementar un plan de capacitación anual en calidad de atención al cliente & $\begin{array}{l}\text { número de capacitaciones } \\
\text { por año }\end{array}$ & 1 & 2 & 6 & 8 \\
\hline & Implementar un proceso para medir el clima laboral & $\begin{array}{l}\text { número de encuestas } \\
\text { anuales }\end{array}$ & 0 & 1 & 1 & 1 \\
\hline & Desarrollar un plan de reconocimiento a los mejores asesores & $\begin{array}{c}\% \text { de cartas de felicitación de } \\
\text { asesores por trimestre }\end{array}$ & $2 \%$ & $15 \%$ & $15 \%$ & $15 \%$ \\
\hline & Contar con una evaluación de desempeño para el tercer año & 01 evaluación anual & Nuevo & & & 1 \\
\hline
\end{tabular}

Nota: Elaboración propia. 


\subsection{Iniciativas}

Se han formulado iniciativas que permitan cumplir con los objetivos específicos, dando mayor énfasis a los colaboradores a través de la Gerencia de Recursos Humanos, para ello se ha propuesto la contratación de asesoría externa especializada a fin de acompañar en el programa de capacitación en los siguientes tres años Anexo 14, medir el clima organizacional e implementar una evaluación de desempeño, con lo cual se fortalece la gestión de servicio al cliente y calidad de atención en el mediano plazo, acompañado de un plan de bonificación para los asesores comerciales que se detalla en el Anexo 11 y un plan de premios entre los asesores con frecuencia semestral considerada en el Anexo 13.

El plan de capacitación busca firmar un convenio con una empresa especializada en capacitaciones a través de módulos, las mismas que puedan otorgar certificación al trabajador. Esta iniciativa permitirá a la empresa obtener mejores resultados en el servicio brindado al cliente así como contar con trabajadores más calificados, motivados y reconocidos, se cuenta con un cronograma para realizar los talleres en el Anexo 12, también se detalla el contenido de los módulos por cada taller y se ha presupuestado el costo de los talleres y los costos por año en el mismo anexo. 
Tabla 30:

Iniciativas

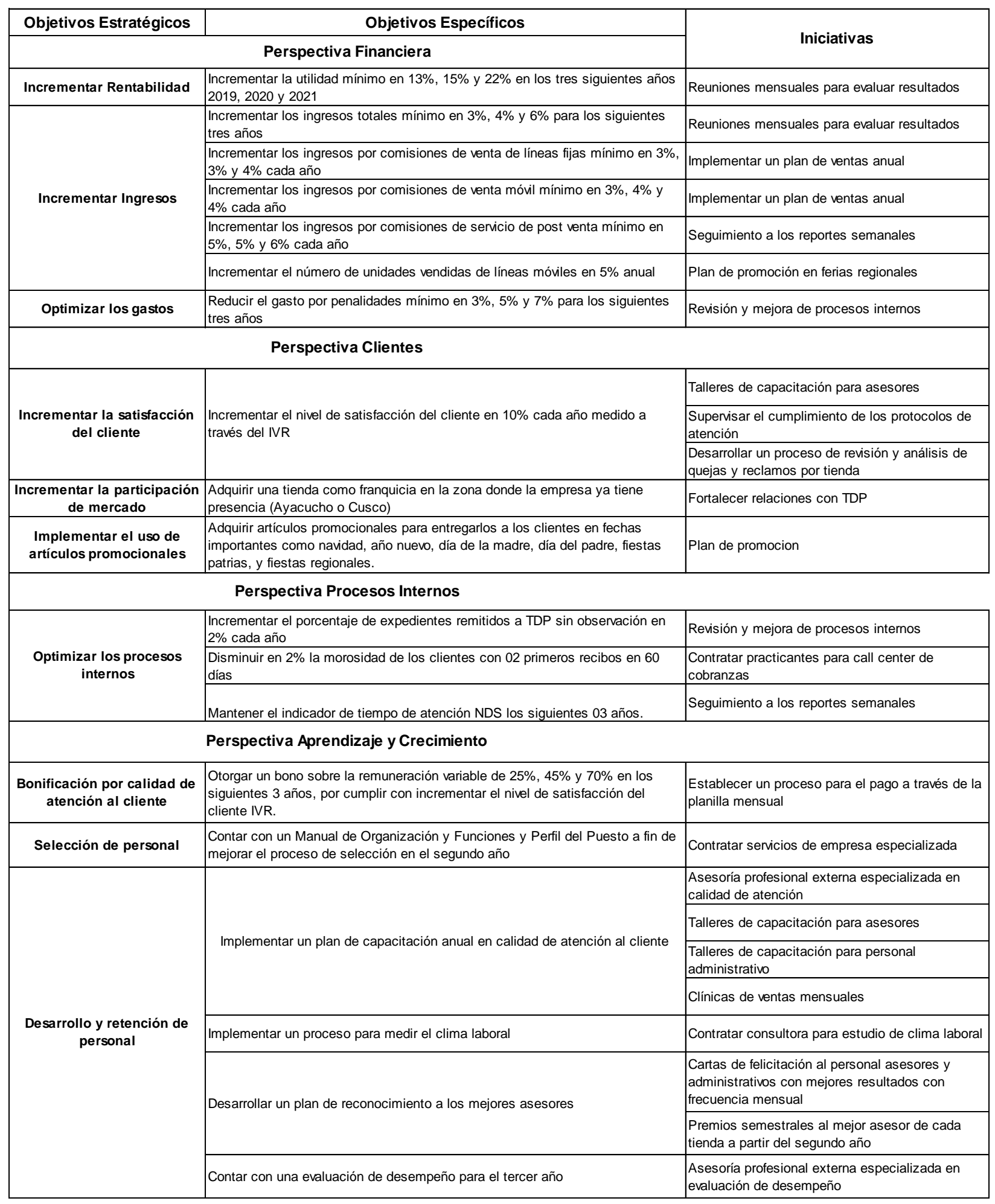

Nota: Elaboración propia 


\subsection{Responsable de cada una de las iniciativas}

Tabla 31:

Iniciativas y responsables

\begin{tabular}{|c|c|c|c|}
\hline Objetivos Estratégicos & Objetivos Específicos & \multirow{2}{*}{ Iniciativas } & \multirow{2}{*}{ Responsable } \\
\hline \multicolumn{2}{|r|}{ Perspectiva Financiera } & & \\
\hline Incrementar Rentabilidad & $\begin{array}{l}\text { Incrementar la utilidad mínimo en } 13 \%, 15 \% \text { y } 22 \% \text { en los tres siguientes años } \\
2019,2020 \text { y } 2021\end{array}$ & Reuniones mensuales para evaluar resultados & $\begin{array}{l}\text { Gerencia General y } \\
\text { Gerentes de Línea }\end{array}$ \\
\hline \multirow{5}{*}{ Incrementar Ingresos } & $\begin{array}{l}\begin{array}{l}\text { Incrementar los ingresos totales mínimo en } 3 \%, 4 \% \text { y } 6 \% \text { para los siguientes } \\
\text { tres años }\end{array} \\
\end{array}$ & Reuniones mensuales para evaluar resultados & $\begin{array}{l}\text { Gerencia General y } \\
\text { Gerentes de Línea }\end{array}$ \\
\hline & $\begin{array}{l}\text { Incrementar los ingresos por comisiones de venta de líneas fijas mínimo en } 3 \% \text {, } \\
3 \% \text { y } 4 \% \text { cada año }\end{array}$ & Implementar un plan de ventas anual & Gerencia de Fijas \\
\hline & $\begin{array}{l}\text { Incrementar los ingresos por comisiones de venta móvil mínimo en 3\%, 4\% y } \\
4 \% \text { cada año }\end{array}$ & Implementar un plan de ventas anual & Gerencia de Móviles \\
\hline & $\begin{array}{l}\text { Incrementar los ingresos por comisiones de servicio de post venta mínimo en } \\
5 \%, 5 \% \text { y } 6 \% \text { cada año }\end{array}$ & Seguimiento a los reportes semanales & $\begin{array}{l}\text { Móviles y Supervisores } \\
\text { y Jefes de tienda }\end{array}$ \\
\hline & Incrementar el número de unidades vendidas de líneas móviles en $5 \%$ anual & Plan de promoción en ferias regionales & $\begin{array}{l}\text { Móviles y Supervisores } \\
\text { y Jefes de tienda }\end{array}$ \\
\hline Optimizar los gastos & $\begin{array}{l}\text { Reducir el gasto por penalidades mínimo en } 3 \%, 5 \% \text { y } 7 \% \text { para los siguientes } \\
\text { tres años }\end{array}$ & Revisión y mejora de procesos internos & $\begin{array}{l}\text { Móviles y Supervisores } \\
\text { y Jefes de tienda }\end{array}$ \\
\hline \multicolumn{3}{|c|}{ Perspectiva Clientes } & \\
\hline \multirow{3}{*}{$\begin{array}{l}\text { Incrementar la satisfacción } \\
\text { del cliente }\end{array}$} & \multirow{3}{*}{$\begin{array}{l}\text { Incrementar el nivel de satisfacción del cliente en } 10 \% \text { cada año medido a } \\
\text { través del IVR }\end{array}$} & Talleres de capacitación para asesores & $\begin{array}{l}\text { Gerencia de Recursos } \\
\text { Humanos }\end{array}$ \\
\hline & & $\begin{array}{l}\text { Supervisar el cumplimiento de los protocolos de } \\
\text { atención }\end{array}$ & $\begin{array}{l}\text { Supervisores y Jefes de } \\
\text { tienda }\end{array}$ \\
\hline & & $\begin{array}{l}\text { Desarrollar un proceso de revisión y análisis de } \\
\text { quejas y reclamos por tienda }\end{array}$ & Gerencia de Móviles \\
\hline \begin{tabular}{|c|}
$\begin{array}{c}\text { Incrementar la participación } \\
\text { de mercado }\end{array}$ \\
\end{tabular} & $\begin{array}{l}\text { Adquirir una tienda como franquicia en la zona donde la empresa ya tiene } \\
\text { presencia (Ayacucho o Cusco) }\end{array}$ & Fortalecer relaciones con TDP & Gerencia General \\
\hline \multirow[t]{2}{*}{$\begin{array}{l}\text { Implementar el uso de } \\
\text { artículos promocionales }\end{array}$} & $\begin{array}{l}\text { Adquirir artículos promocionales para entregarlos a los clientes en fechas } \\
\text { importantes como navidad, año nuevo, día de la madre, día del padre, fiestas } \\
\text { patrias, y fiestas regionales. }\end{array}$ & Plan de promocion & $\begin{array}{l}\text { Logística y } \\
\text { abastecimiento }\end{array}$ \\
\hline & \multicolumn{3}{|l|}{ Perspectiva Procesos Internos } \\
\hline \multirow{3}{*}{$\begin{array}{l}\text { Optimizar los procesos } \\
\text { internos }\end{array}$} & $\begin{array}{l}\text { Incrementar el porcentaje de expedientes remitidos a TDP sin observación en } \\
2 \% \text { cada año }\end{array}$ & Revisión y mejora de procesos internos & $\begin{array}{l}\text { Gerencia de Fija y de } \\
\text { Móviles }\end{array}$ \\
\hline & $\begin{array}{l}\text { Disminuir en 2\% la morosidad de los clientes con } 02 \text { primeros recibos en } 60 \\
\text { días }\end{array}$ & $\begin{array}{l}\text { Contratar practicantes para call center de } \\
\text { cobranzas }\end{array}$ & $\begin{array}{l}\text { Gerencia de Recursos } \\
\text { Humanos }\end{array}$ \\
\hline & Mantener el indicador de tiempo de atención NDS los siguientes 03 años. & Seguimiento a los reportes semanales & $\begin{array}{l}\text { Gerencia de Fija y de } \\
\text { Móviles }\end{array}$ \\
\hline & \multicolumn{2}{|l|}{ Perspectiva Aprendizaje y Crecimiento } & \\
\hline $\begin{array}{l}\text { Bonificación por calidad de } \\
\text { atención al cliente }\end{array}$ & $\begin{array}{l}\text { Otorgar un bono sobre la remuneración variable de } 25 \%, 45 \% \text { y } 70 \% \text { en los } \\
\text { siguientes } 3 \text { años, por cumplir con incrementar el nivel de satisfacción del } \\
\text { cliente IVR. }\end{array}$ & $\begin{array}{l}\text { Establecer un proceso para el pago a través de la } \\
\text { planilla mensual }\end{array}$ & $\begin{array}{l}\text { Gerencia de Recursos } \\
\text { Humanos }\end{array}$ \\
\hline Selección de personal & $\begin{array}{l}\text { Contar con un Manual de Organización y Funciones y Perfil del Puesto a fin de } \\
\text { mejorar el proceso de selección en el segundo año }\end{array}$ & Contratar servicios de empresa especializada & $\begin{array}{l}\text { Gerencia de Recursos } \\
\text { Humanos }\end{array}$ \\
\hline \multirow{8}{*}{$\begin{array}{l}\text { Desarrollo y retención de } \\
\text { personal }\end{array}$} & \multirow{4}{*}{ Implementar un plan de capacitación anual en calidad de atención al cliente } & $\begin{array}{l}\text { Asesoría profesional externa especializada en } \\
\text { calidad de atención }\end{array}$ & $\begin{array}{l}\text { Gerencia de Recursos } \\
\text { Humanos }\end{array}$ \\
\hline & & Talleres de capacitación para asesores & $\begin{array}{l}\text { Gerencia de Recursos } \\
\text { Humanos }\end{array}$ \\
\hline & & $\begin{array}{l}\text { Talleres de capacitación para personal } \\
\text { administrativo }\end{array}$ & $\begin{array}{l}\text { Gerencia de Recursos } \\
\text { Humanos }\end{array}$ \\
\hline & & Clínicas de ventas mensuales & $\begin{array}{l}\text { Gerencia de Recursos } \\
\text { Humanos }\end{array}$ \\
\hline & Implementar un proceso para medir el clima laboral & Contratar consultora para estudio de clima laboral & $\begin{array}{l}\text { Gerencia de Recursos } \\
\text { Humanos }\end{array}$ \\
\hline & \multirow[t]{2}{*}{ Desarrollar un plan de reconocimiento a los mejores asesores } & $\begin{array}{l}\text { Cartas de felicitación al personal asesores y } \\
\text { administrativos con mejores resultados con } \\
\text { frecuencia mensual }\end{array}$ & $\begin{array}{l}\text { Gerencia de Recursos } \\
\text { Humanos }\end{array}$ \\
\hline & & $\begin{array}{l}\text { Premios semestrales al mejor asesor de cada } \\
\text { tienda a partir del segundo año }\end{array}$ & $\begin{array}{l}\text { Gerencia de Recursos } \\
\text { Humanos }\end{array}$ \\
\hline & Contar con una evaluación de desempeño para el tercer año & $\begin{array}{l}\text { Asesoría profesional externa especializada en } \\
\text { evaluación de desempeño }\end{array}$ & $\begin{array}{l}\text { Gerencia de Recursos } \\
\text { Humanos }\end{array}$ \\
\hline
\end{tabular}

Nota: Elaboración propia 


\subsection{Presupuesto}

En el presupuesto se han considerado solo las iniciativas que generan costos, en los que incurrirá la empresa para poder cumplir con los objetivos estratégicos, con una proyección a tres años. El cálculo de los montos se encuentra en los anexos adjuntos (9 al 13), artículos promocionales, practicantes para el call center, bonificaciones a los asesores, taller de capacitación, premios semestrales, asesoría profesional externa especializada en calidad de atención.

Los montos relacionados con contratación de empresa especializada para el Manual de Organización y Funciones y perfil del puesto, clima laboral, y evaluación de desempeño se ha considerado los montos en función a cotizaciones de empresas que ofrecen en Cusco estos servicios.

El presupuesto se divide en dos rubros gastos de personal y servicios de terceros según el detalle que se muestra en el anexo 15 . 
Tabla 32:

Presupuesto

\begin{tabular}{|c|c|c|c|c|c|c|c|}
\hline Objetivos Estratégicos & Objetivos Específicos & \multirow{2}{*}{ Iniciativas } & & \multicolumn{3}{|c|}{ Presupuesto } & \multirow{2}{*}{ Total } \\
\hline \multicolumn{2}{|r|}{ Perspectiva Procesos Internos } & & & 2019 & 2020 & 2021 & \\
\hline $\begin{array}{l}\text { Implementar el uso de } \\
\text { artículos promocionales }\end{array}$ & $\begin{array}{l}\text { Adquirir artículos promocionales para entregarlos en fechas importantes como } \\
\text { navidad, año nuevo, día de la madre, día del padre, fiestas patrias, y fiestas } \\
\text { regionales }\end{array}$ & Plan de adquisiciones & Logística y abastecimiento & $\mathrm{S} / .60,000$ & S/. 100,000 & S/. 150,000 & S/. 310,000 \\
\hline Optimizar los procesos internos & Disminuir en 2\% la morosidad de los clientes con 02 primeros recibos en 60 días & $\begin{array}{l}\text { Contratar practicantes para call center de } \\
\text { cobranzas }\end{array}$ & Gerencia de Recursos Humanos & $\mathrm{S} / .11,160$ & S/. 11,160 & $\mathrm{~S} / .48,000$ & S/. 70,320 \\
\hline & \multicolumn{3}{|l|}{ Perspectiva Aprendizaje y Crecimiento } & & & & \\
\hline $\begin{array}{l}\text { Bonificación por calidad de } \\
\text { atención al cliente }\end{array}$ & $\begin{array}{l}\text { Otorgar un bono sobre la remuneración variable de } 25 \%, 45 \% \text { y } 70 \% \text { en los } \\
\text { siguientes } 3 \text { años, por cumplir con incrementar el nivel de satisfacción del cliente } \\
\text { IVR. }\end{array}$ & $\begin{array}{l}\text { Establecer un proceso para el pago a través de } \\
\text { la planilla mensual }\end{array}$ & Gerencia de Recursos Humanos & S/. 82,000 & S/. 143,000 & $\mathrm{~S} / .220,000$ & S/. 445,000 \\
\hline Selección de personal & $\begin{array}{l}\text { Contar con un Manual de Organización y Funciones y Perfil del Puesto a fin de } \\
\text { mejorar el proceso de selección en el segundo año }\end{array}$ & Contratar servicios de empresa especializada & Gerencia de Recursos Humanos & & $\mathrm{S} / .20,000$ & & $\mathrm{~S} / .20,000$ \\
\hline \multirow{6}{*}{$\begin{array}{l}\text { Desarrollo y retención de } \\
\text { personal }\end{array}$} & \multirow{3}{*}{ Implementar un plan de capacitación anual en calidad de atención al cliente } & $\begin{array}{l}\text { Asesoría profesional externa especializado en } \\
\text { calidad de atención }\end{array}$ & Gerencia de Recursos Humanos & $\mathrm{S} / .15,000$ & S/. 40,000 & S/. 40,000 & S/. 95,000 \\
\hline & & Talleres de capacitación para asesores & Gerencia de Recursos Humanos & S/. 10,000 & $S / .30,000$ & S/. 40,000 & S/. 80,000 \\
\hline & & Talleres de capacitación para administrativos & Gerencia de Recursos Humanos & S/. 5,000 & $\mathrm{~S} / .20,000$ & S/. 20,000 & S/. 45,000 \\
\hline & Implementar un proceso para medir el clima laboral & $\begin{array}{l}\begin{array}{l}\text { Contratar consultora para estudio de clima } \\
\text { laboral }\end{array} \\
\end{array}$ & Gerencia de Recursos Humanos & $\mathrm{S} / .5,000$ & S/. 10,000 & S/. 10,000 & $\mathrm{~S} / .25,000$ \\
\hline & Desarrollar un plan de reconocimiento a los mejores asesores & $\begin{array}{l}\text { Premios semestrales al mejor asesor de cada } \\
\text { tienda a partir del segundo año }\end{array}$ & Gerencia de Recursos Humanos & & S/. 15,000 & $\mathrm{~S} / .30,000$ & S/. 45,000 \\
\hline & Contar con una evaluación de desempeño para el tercer año & $\begin{array}{l}\text { Asesoría profesional externa especializado en } \\
\text { evaluación de desempeño }\end{array}$ & Gerencia de Recursos Humanos & & & S/. 20,000 & S/. 20,000 \\
\hline \multicolumn{3}{|c|}{ TOTAL } & & $\mathrm{S} / .188,160$ & S/. 389,160 & $\mathrm{S} / .578,000$ & $\mathrm{~S} / .1,155,320$ \\
\hline
\end{tabular}

Nota: Elaboración propia 


\subsection{Cronograma de cada una de las iniciativas}

Tabla 33:

\section{Cronograma}

\begin{tabular}{|c|c|c|c|c|c|c|c|c|c|c|c|c|c|c|}
\hline Objetivos Estratégicos & Objetivos Especificos & \multirow[b]{2}{*}{ Iniciativas } & \multicolumn{12}{|c|}{ Cronograma } \\
\hline \multicolumn{2}{|r|}{ Perspectiva Financiera } & & $\begin{array}{c}\text { ITRIM } \\
2019\end{array}$ & \begin{tabular}{|c|c|c|c|}
11 TRIM \\
2019
\end{tabular} & \begin{tabular}{|c|c|}
111 TRIM \\
2019
\end{tabular} & \begin{tabular}{|c|c|} 
IV TRIM \\
2019
\end{tabular} & $\begin{array}{r}\text { ITRIM } \\
2020\end{array}$ & \begin{tabular}{|c|c|c|}
11 TRIM \\
2020
\end{tabular} & $\begin{array}{c}111 \text { TRIM } \\
2020\end{array}$ & $\begin{array}{l}\text { IV TRIM } \\
2020\end{array}$ & $\begin{array}{c}\text { ITRIM } \\
2021\end{array}$ & $\begin{array}{c}11 \text { TRIM } \\
2021\end{array}$ & $\begin{array}{ll}11 \text { TRIM } \\
2021\end{array}$ & $\begin{array}{c}\text { IV TRIM } \\
2021\end{array}$ \\
\hline Incrementar Rentabilidad & $\begin{array}{l}\text { Incrementar la utilidad mínimo en 13\%, 16\% y } 22 \% \text { en los tres siguientes años } 2019 \text {, } \\
2020 \text { y } 2021\end{array}$ & Reuniones mensuales para evaluar resultados & & & & & & & & & & & & \\
\hline \multirow{5}{*}{ Incrementar Ingresos } & Incrementar los ingresos totales mínimo en 3\%, $4 \%$ y $6 \%$ para los siguientes tres años & Reuniones mensuales para evaluar resultados & & & & & & & & & & & & \\
\hline & $\begin{array}{l}\text { Incrementar los ingresos por comisiones de venta de líneas fijas mínimo en } 3 \%, 3 \% \text { y } \\
4 \% \text { cada año }\end{array}$ & Implementar un plan de ventas anual & & & & & & & & & & & & \\
\hline & $\begin{array}{l}\begin{array}{l}\text { Incrementar los ingresos por comisiones de venta móvil mínimo en 3\%, 4\% y } 4 \% \text { cada } \\
\text { año }\end{array} \\
\end{array}$ & Implementar un plan de ventas anual & & & & & & & & & & & & \\
\hline & 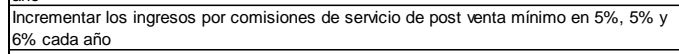 & Seguimiento a los reportes semanales & & & & & & & & & & & & \\
\hline & Incrementar el número de unidades vendidas de líneas móviles en 5\% anual & Plan de promoción en ferias regionales & & & & & & & & & & & & \\
\hline Optimizar los gastos & Reducir el gasto por penalidades mínimo en $3 \%, 5 \%$ y $7 \%$ para los siguientes tres años & Revisión y mejora de procesos internos & & & & & & & & & & & & \\
\hline \multicolumn{15}{|c|}{ Perspectiva Clientes } \\
\hline \multirow[b]{2}{*}{$\begin{array}{l}\text { Incrementar la satisfacción } \\
\text { del cliente }\end{array}$} & \multirow[b]{2}{*}{ Incrementar el nivel de satisfacción del cliente en $10 \%$ cada año medido a través del IVR } & Talleres de capacitación para asesores & & & & & & & & & & & & \\
\hline & & \begin{tabular}{|l} 
Supenisar el cumplimiento de los protocolos de atención \\
Desarorollar un proceso de revisión y análisis de quejas y \\
reclamos por tienda
\end{tabular} & & & & & & & & & & & & \\
\hline $\begin{array}{l}\text { Incrementar la participación } \\
\text { de mercado }\end{array}$ & $\begin{array}{l}\begin{array}{l}\text { Adquiri una tienda como franquicia en la zona donde la empresa ya tiene presencia } \\
\text { (Ayacucho o Cusco) }\end{array} \\
\end{array}$ & Fortalecer relaciones con TDP & & & & & & & & & & & & \\
\hline \multicolumn{15}{|c|}{ Perspectiva Procesos Internos } \\
\hline $\begin{array}{l}\text { Implementar el uso de } \\
\text { artículos promocionales }\end{array}$ & $\begin{array}{l}\text { Adquirir artículos promocionales para entregarlos en fechas importantes como navidad, } \\
\text { año nuevo, dia de la madre, dia del padre, fiestas patrias, y fiestas regionales. }\end{array}$ & Plan de adquisiciones & & & & & & & & & & & & \\
\hline \multirow{3}{*}{$\begin{array}{l}\text { Optimizar los procesos } \\
\text { internos }\end{array}$} & $\begin{array}{l}\text { Incrementar el porcentaje de expedientes remitidos a TDP sin observación en } 2 \% \text { cada } \\
\text { año }\end{array}$ & Revisión y mejora de procesos internos & & & & & & & & & & & & \\
\hline & Disminuir en 2\% la morosidad de los clientes con 02 primeros recibos en 60 días & Contratar practicantes para call center de cobranzas & & & & & & & & & & & & \\
\hline & $\begin{array}{l}\text { Mantener el indicador de tiempo de atención NDS los siguientes } 03 \text { años. } \\
\text { Perspectiva Aprendizaje y Crecimiento }\end{array}$ & Seguimiento a los reportes semanales & & & & & & & & & & & & \\
\hline $\begin{array}{l}\text { Bonificación por calidad de } \\
\text { atención al cliente }\end{array}$ & $\begin{array}{l}\text { Otorgar un bono sobre la remunueración variable de } 25 \%, 45 \% \text { y } 70 \% \text { en los siguientes } 3 \\
\text { años, por cumplir con incrementar el nivel de satisfacción del cliente IVR. }\end{array}$ & $\begin{array}{l}\text { Establecer un proceso para el pago a través de la planilla } \\
\text { mensual }\end{array}$ & & & & & & & & & & & & \\
\hline Selección de personal & $\begin{array}{l}\text { Contar con un Manual de Organización y Funciones y Perfil del Puesto a fin de mejorar } \\
\text { el proceso de selección en el segundo año }\end{array}$ & Contratar servicios de empresa especializada & & & & & & & & & & & & \\
\hline \multirow{7}{*}{$\begin{array}{l}\text { Desarrollo y retención de } \\
\text { personal }\end{array}$} & \multirow{4}{*}{ Implementar un plan de capacitación anual en calidad de atención al cliente } & $\begin{array}{l}\text { Asesoría profesional externa especializada en calidad de } \\
\text { atención }\end{array}$ & & & & & & & & & & & & \\
\hline & & 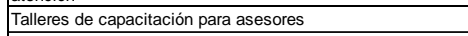 & & & & & & & & & & & & \\
\hline & & \begin{tabular}{|l|l} 
Talleres de capacitación para personal administrativo \\
Cínicas
\end{tabular} & & & & & & & & & & & & \\
\hline & & \begin{tabular}{|l|} 
Clínicas de ventas mensuales \\
Contratar consultora para estudio de clima laboral \\
\end{tabular} & & & & & & & & & & & & \\
\hline & \multirow{2}{*}{ Desarrollar un plan de reconocimiento a los mejores asesores } & $\begin{array}{l}\text { Cartas de felicititaciones al personal con mejores resultados } \\
\text { mensual }\end{array}$ & & & & & & & & & & & & \\
\hline & & $\begin{array}{l}\text { Premios semestrales al mejor asesor de cada tienda a partir } \\
\text { del segundo año }\end{array}$ & & & & & & & & & & & & \\
\hline & Contar con una evaluación de desempeño para el tercer año & $\begin{array}{l}\text { Asesoría profesional externa especializada en evaluación de } \\
\text { desempeño }\end{array}$ & & & & & & & & & & & & \\
\hline
\end{tabular}

Nota: Elaboración propia 


\section{CAPÍTULO X. EVALUACIÓN}

\subsection{Evaluación Cualitativa}

Se realizó la evaluación cualitativa bajo los criterios de la matriz de Rumelt (2011) : congruencia, consonancia, viabilidad y ventaja.

\subsubsection{Criterios de Evaluación.}

Los criterios de la matriz de Rumelt se dividen en dos grupos: el primero está conformado por la consonancia y ventaja, criterios que se basan en la evaluación externa de la empresa y el segundo conformado por la congruencia y la viabilidad; son criterios que se sustentan para la evaluación interna de la empresa.

\subsubsection{Comparación de la estrategia con los criterios.}

- Consonancia (Criterio de la estrategia debe representar una repuesta adaptativa al entorno externo y a los cambios críticos que ocurran), las estrategias propuestas se adaptan perfectamente al entorno tal como se menciona en el capítulo del análisis de la variable política; el gobierno se rige bajo una economía de libre mercado, la iniciativa privada es libre con lo cual se soportan las estrategias de crecimiento y también de incrementar la participación en el mercado al poder ampliar nuevas tiendas en la región. Así mismo la economía peruana ha venido creciendo en estos últimos años a tasas menores pero manteniendo la tendencia positiva, mientras el PBI crezca los sectores económicos seguirán creciendo. 
- Ventaja (Criterio de la estrategia que debe proveer la creación y/o mantenimiento de las ventajas competitivas), las estrategias tienen una posición de ventaja basada en la experiencia de la empresa con más de 18 años en el sector de telecomunicaciones, con pleno conocimiento del mercado a nivel técnico y comercial, así mismo con el manejo de reportes, requerimientos y exigencias vinculado a la regulación y a la calidad de atención.

- Congruencia (Criterio de la estrategia no debe presentar objetivos y políticas mutuamente inconsistentes), las estrategias mantienen completa congruencia con los objetivos de la empresa, así como la visión y misión de la misma que le han permitido mantenerse en el mercado de telecomunicaciones.

- Viabilidad (Criterio de la estrategia que no debe originar un sobre costo en los recursos disponibles ni crear sub problemas sin solución) las estrategias son factibles porque están planteados en un periodo de tiempo razonable, con costos e ingresos que cubren dicha estrategia, lo que le permitiría a la empresa un crecimiento generando oportunidades de mejora en el servicio al cliente.

\subsection{Evaluación Financiera de la Estrategia}

La composición de las ventas en Digital está formada por dos grupos:

- El primero corresponde a los ingresos por venta de equipos

- El segundo corresponde a los ingresos por comisiones

○ Por fija

○ Por móvil

- Por post venta 
Cabe mencionar que la empresa solo percibe ingresos por comisiones más no por la venta de equipos por ello en el Estado de Ganancias y Pérdidas se observa que el monto por venta de equipos celulares es el mismo que el costo de ventas donde ambas cuentas se saldan.

En la tabla 34 se puede observar las ventas proyectadas para los años 2019 - 2021 expresados en soles.

Tabla 34:

Ventas proyectadas $2019-2021$

\begin{tabular}{|l|r|r|r|r|}
\hline \multicolumn{1}{|c|}{ Rubros } & Año base 2018 & Año 2019 & Año 2020 & \multicolumn{1}{|c|}{ Año 2021 } \\
\hline INGRESOS TOTALES & $16,144,223$ & $16,395,717$ & $16,680,907$ & $17,039,721$ \\
\hline VENTAS DE EQUIPOS MOVILES & $9,005,152$ & $9,185,255$ & $9,368,960$ & $9,603,184$ \\
\hline COMISION POR VENTA DE LINEAS FIJAS & $1,321,091$ & $1,334,302$ & $1,347,645$ & $\mathbf{1 , 3 6 7 , 8 5 9}$ \\
\hline COMISION POR VENTA DE LINEAS MOVIL & $\mathbf{2 , 5 0 1 , 0 8 3}$ & $\mathbf{2 , 5 2 6 , 0 9 4}$ & $\mathbf{2 , 5 6 3 , 9 8 5}$ & $\mathbf{2 , 6 0 8 , 8 5 5}$ \\
\hline COMISION POR SERVICIO POSTVENTA & $\mathbf{3 , 3 1 6 , 8 9 8}$ & $\mathbf{3 , 3 5 0 , 0 6 7}$ & $\mathbf{3 , 4 0 0 , 3 1 8}$ & $\mathbf{3 , 4 5 9 , 8 2 3}$ \\
\hline
\end{tabular}

Nota: Digital (elaboración propia).

\subsubsection{Proyección de estados financieros (situación actual y la nueva estrategia).}

A continuación se presentan los estados financieros proyectados al año 2021, bajo los dos escenarios solicitados: primero sin estrategia proyectando solo un crecimiento en función al comportamiento de los ingresos totales de los años anteriores dando como resultado un incremento de $1.6 \%, 1.7 \%$ y $2.2 \% \%$ para los años 2019 al 2021 respectivamente según datos de la empresa, en el segundo escenario se consideran las proyecciones por rubros ingresos y gastos generados al aplicar la estrategia, incluyendo la mejora en los procesos, capacitación, seguimiento y control, como consecuencia se genera una reducción de los gastos por penalidades que forman parte de la estrategia, logrando un incremento de la utilidad y la rentabilidad. 


\subsubsection{Estado de resultados (situación actual y con la nueva estrategia).}

Para la proyección de los ingresos se ha considerado el comportamiento de la empresa en los dos últimos años, y con ello se ha proyectado un crecimiento mínimo de $1 \%$ anual para cada rubro que corresponde a las comisiones y $2 \%$ para la venta de equipos móviles, se espera que este comportamiento se mantenga en estos porcentajes si la empresa no aplica ninguna estrategia, siendo el resultado el siguiente.

Tabla 35:

Estado de Resultado sin estrategia.

\section{ESTADO DE RESULTADO - SIN ESTRATEGIA}

(Expresado en Nuevos Soles)

\begin{tabular}{|c|c|c|c|c|}
\hline Rubros & Año base 2018 & Año 2019 & Año 2020 & Año 2021 \\
\hline INGRESOS TOTALES & $16,144,223$ & $16,395,717$ & $16,680,907$ & $17,039,721$ \\
\hline VENTAS DE EQUIPOS MOVILES & $9,005,152$ & $9,185,255$ & $9,368,960$ & $9,603,184$ \\
\hline COMISION POR VENTA DE LINEAS FIJAS & $1,321,091$ & $1,334,302$ & $1,347,645$ & $1,367,859$ \\
\hline COMISION POR VENTA DE LINEAS MOVIL & $2,501,083$ & $2,526,094$ & $2,563,985$ & $2,608,855$ \\
\hline COMISION POR SERVICIO POSTVENTA & $3,316,898$ & $3,350,067$ & $3,400,318$ & $3,459,823$ \\
\hline COSTO DE VENTAS & $9,005,152$ & $9,185,255$ & $9,368,960$ & $9,603,184$ \\
\hline GANANCIA (PERDIDA) BRUTA & $7,139,071$ & $7,210,462$ & $7,311,948$ & $7,436,538$ \\
\hline INGRESOS FINANCIEROS & 5,448 & 5,993 & 6,592 & 7,251 \\
\hline GASTOS FINANCIEROS & 64,738 & 58,264 & 46,611 & 32,628 \\
\hline GANANCIA (PERDIDA) NETA & $7,079,782$ & $7,158,191$ & $7,271,928$ & 7,411,161 \\
\hline GASTOS DE VENTAS & $6,159,990$ & $6,200,585$ & $6,256,573$ & $6,309,508$ \\
\hline ALQUILERES & 734,988 & 734,988 & 749,687 & 757,184 \\
\hline GASTO DE PERSONAL & $3,677,428$ & $3,695,816$ & $3,714,295$ & $3,732,866$ \\
\hline GASTO DE VENTAS & 27,837 & 28,394 & 29,245 & 30,123 \\
\hline OTROS GASTOS (APROX. PENALIDAD 50\%) & $1,157,835$ & $1,170,578$ & $1,183,449$ & $1,196,448$ \\
\hline DEPRECIACION & 116,485 & 116,485 & 116,485 & 116,485 \\
\hline SERVICIOS & 87,645 & 89,398 & 91,186 & 93,010 \\
\hline SERVICIO DE TERCEROS & 357,771 & 364,927 & 372,225 & 383,392 \\
\hline GANANCIA (PERDIDA) OPERATIVA & 919,792 & 957,606 & $1,015,356$ & $1,101,653$ \\
\hline COMISIONES POR TRANSFERENCIAS & 72,235 & 65,011 & 58,510 & 49,734 \\
\hline OTRAS CARGAS FINANCIERAS & 297 & 311 & 327 & 343 \\
\hline RESULTADO & 847,261 & 892,283 & 956,518 & $1,051,576$ \\
\hline IMPUESTO A LA RENTA & 249,942 & 263,224 & 282,173 & 310,215 \\
\hline UTILIDAD NETA & 597,319 & 629,060 & 674,345 & 741,361 \\
\hline
\end{tabular}

Nota: Digital (elaboración propia). 
En la Tabla 36, se observa la evolución de las utilidades sin aplicar la estrategia, registrando porcentajes bajos de crecimiento $5 \%, 7 \%$ y $10 \%$ para los siguientes tres años, sin embargo, utilizando la estrategia los porcentajes crecen a dos dígitos según la tabla 37.

\section{Tabla 36:}

Utilidad Neta sin implementación estratégica

\begin{tabular}{|l|r|r|r|r|}
\hline \multicolumn{1}{|c|}{ Rubros } & Año base 2018 & Año 2019 & Año 2020 & \multicolumn{1}{c|}{ Año 2021 } \\
\hline UTILIDAD NETA SIN ESTRATEGIA & 597,319 & 629,060 & 674,345 & 741,361 \\
\hline VARIACION & & $\mathbf{5 \%}$ & $\mathbf{7 \%}$ & $\mathbf{1 0 \%}$ \\
\hline
\end{tabular}

Nota: Digital (elaboración propia).

Conforme se han planteado en los objetivos estratégicos, se espera un crecimiento de mínimo 3\% en las comisiones de fijas y de móviles 5\% mínimo por el servicio de post venta.

Así mismo estos crecimientos vienen acompañados por otras iniciativas, como las siguientes:

- La bonificación que se otorgará a los asesores con llevará a un aumento en el indicador IVR en un $10 \%$, el mismo que generará un incremento de las comisiones por servicio de post venta entre $3 \%$ y $4 \%$.

- Se espera que producto de la capacitación mejoren los procesos de remisión de expedientes de las ventas y se espera minimizar los errores; se ha calculado que por cada $2 \%$ que mejoren los procesos generará, un incremento de $2 \%$ en las comisiones por venta de líneas móvil.

- La disminución en los índices de morosidad, por cobranza dentro de los 60 primeros días (2 recibos) impactaran en las penalidades, se ha calculado que por cada $2 \%$ de disminución en la morosidad, disminuyen las penalidades entre $3 \%$ y 5\%, como se 
observa en el estado de resultados las penalidades a la fecha representan el $50 \%$ de otros gastos.

De la proyección realizada se tiene el siguiente estado de resultados:

Tabla 37:

Estado de Resultado con estrategia

\section{ESTADO DE RESULTADO - CON ESTRATEGIA}

(Expresado en Nuevos Soles)

\begin{tabular}{|c|c|c|c|c|}
\hline Rubros & Año base 2018 & Año 2019 & Año 2020 & Año 2021 \\
\hline INGRESOS TOTALES & $16,144,223$ & $16,694,888$ & $17,500,874$ & $18,572,564$ \\
\hline VENTAS DE EQUIPOS MOVILES & $9,005,152$ & $9,275,306$ & $9,739,072$ & $10,372,111$ \\
\hline COMISION POR VENTA DE LINEAS FIJAS & $1,321,091$ & $1,360,724$ & $1,408,349$ & $1,471,725$ \\
\hline COMISION POR VENTA DE LINEAS MOVIL & $2,501,083$ & $2,576,115$ & $2,679,160$ & $2,806,420$ \\
\hline COMISION POR SERVICIO POSTVENTA & $3,316,898$ & $3,482,743$ & $3,674,294$ & $3,922,308$ \\
\hline COSTO DE VENTAS & $9,005,152$ & $9,275,306$ & $9,739,072$ & $10,372,111$ \\
\hline GANANCIA (PERDIDA) BRUTA & $7,139,071$ & $7,419,582$ & $7,761,802$ & $8,200,453$ \\
\hline INGRESOS FINANCIEROS & 5,448 & 5,993 & 6,592 & 7,251 \\
\hline GASTOS FINANCIEROS & 64,738 & 58,264 & 46,611 & 32,628 \\
\hline GANANCIA (PERDIDA) NETA & $7,079,782$ & $7,367,310$ & $7,721,783$ & $8,175,076$ \\
\hline GASTOS DE VENTAS & $6,159,990$ & $6,348,734$ & $6,569,691$ & $6,788,373$ \\
\hline ALQUILERES & 734,988 & 734,988 & 749,687 & 757,184 \\
\hline GASTO DE PERSONAL & $3,677,428$ & $3,792,751$ & $3,921,384$ & $4,042,327$ \\
\hline GASTO DE VENTAS & 27,837 & 28,394 & 29,245 & 30,123 \\
\hline OTROS GASTOS (APROX. PENALIDAD 50\%) & $1,157,835$ & $1,132,349$ & $1,107,372$ & $1,095,133$ \\
\hline DEPRECIACION & 116,485 & 116,485 & 116,485 & 116,485 \\
\hline SERVICIOS & 87,645 & 89,398 & 91,186 & 93,010 \\
\hline SERVICIO DE TERCEROS & 357,771 & 454,370 & 554,331 & 654,110 \\
\hline GANANCIA (PERDIDA) OPERATIVA & 919,792 & $1,018,576$ & $1,152,092$ & $1,386,704$ \\
\hline COMISIONES POR TRANSFERENCIAS & 72,235 & 65,011 & 58,510 & 49,734 \\
\hline OTRAS CARGAS FINANCIERAS & 297 & 311 & 327 & 343 \\
\hline RESULTADO & 847,261 & 953,254 & $1,093,255$ & $1,336,627$ \\
\hline IMPUESTO A LA RENTA & 249,942 & 281,210 & 322,510 & 394,305 \\
\hline UTILIDAD NETA & 597,319 & 672,044 & 770,745 & 942,322 \\
\hline
\end{tabular}

Nota: Digital (elaboración propia) 
Al aplicar la estrategia, la empresa logra un crecimiento en los tres rubros por los cuales percibe comisiones, también crecen las ventas de equipos; pero ello no representa mayor utilidad porque genera un gasto por el mismo monto, los porcentajes de crecimiento son razonables, las iniciativas están concentradas en los recursos humanos por ello el gasto en personal se incrementa cada año, otro rubro que se incrementa es el de servicios por terceros orientados a asesorarías especializadas en atención al cliente, el resultado se observa en la tabla 38 y luego se comparan en la tabla 39.

Tabla 38:

Utilidad Neta con estrategia

\begin{tabular}{|l|r|r|r|r|}
\hline \multicolumn{1}{|c|}{ Rubros } & Año base 2018 & Año 2019 & Año 2020 & Año 2021 \\
\hline UTILIDAD NETA CON ESTRATEGIA & 597,319 & 672,044 & $\mathbf{7 7 0 , 7 4 5}$ & 942,322 \\
\hline VARIACION & & $\mathbf{1 3 \%}$ & $\mathbf{1 5 \%}$ & $\mathbf{2 2 \%}$ \\
\hline
\end{tabular}

Nota: Digital (elaboración propia)

Tabla 39:

Cuadro comparativo de utilidades con y sin estrategia.

\begin{tabular}{|l|r|r|r|r|}
\hline \multicolumn{1}{|c|}{ Rubros } & Año base 2018 & Año 2019 & Año 2020 & Año 2021 \\
\hline UTILIDAD NETA SIN ESTRATEGIA & 597,319 & 629,060 & 674,345 & 741,361 \\
\hline VARIACION & & $5 \%$ & $7 \%$ & $10 \%$ \\
\hline UTILIDAD NETA CON ESTRATEGIA & 597,319 & 672,044 & $\mathbf{7 7 0 , 7 4 5}$ & $\mathbf{9 4 2 , 3 2 2}$ \\
\hline VARIACION & & $13 \%$ & $15 \%$ & $22 \%$ \\
\hline
\end{tabular}

Nota: Digital (elaboración propia)

Se aprecia un incremento porcentual en beneficio de la empresa, dada la particularidad de la franquicia las estrategias están orientadas a lograr que los asesores comerciales mejoren la atención y la solución a los problemas o reclamos de los clientes, a través de capacitación y bonificación que van de la mano, la empresa busca ganar - ganar y para ello el mensaje es el siguiente: si la satisfacción del cliente mejora, los ingresos se incrementan para la empresa, 
impactando positivamente en los ingresos del colaborador, lo que hace sostenible la estrategia en el mediano plazo.

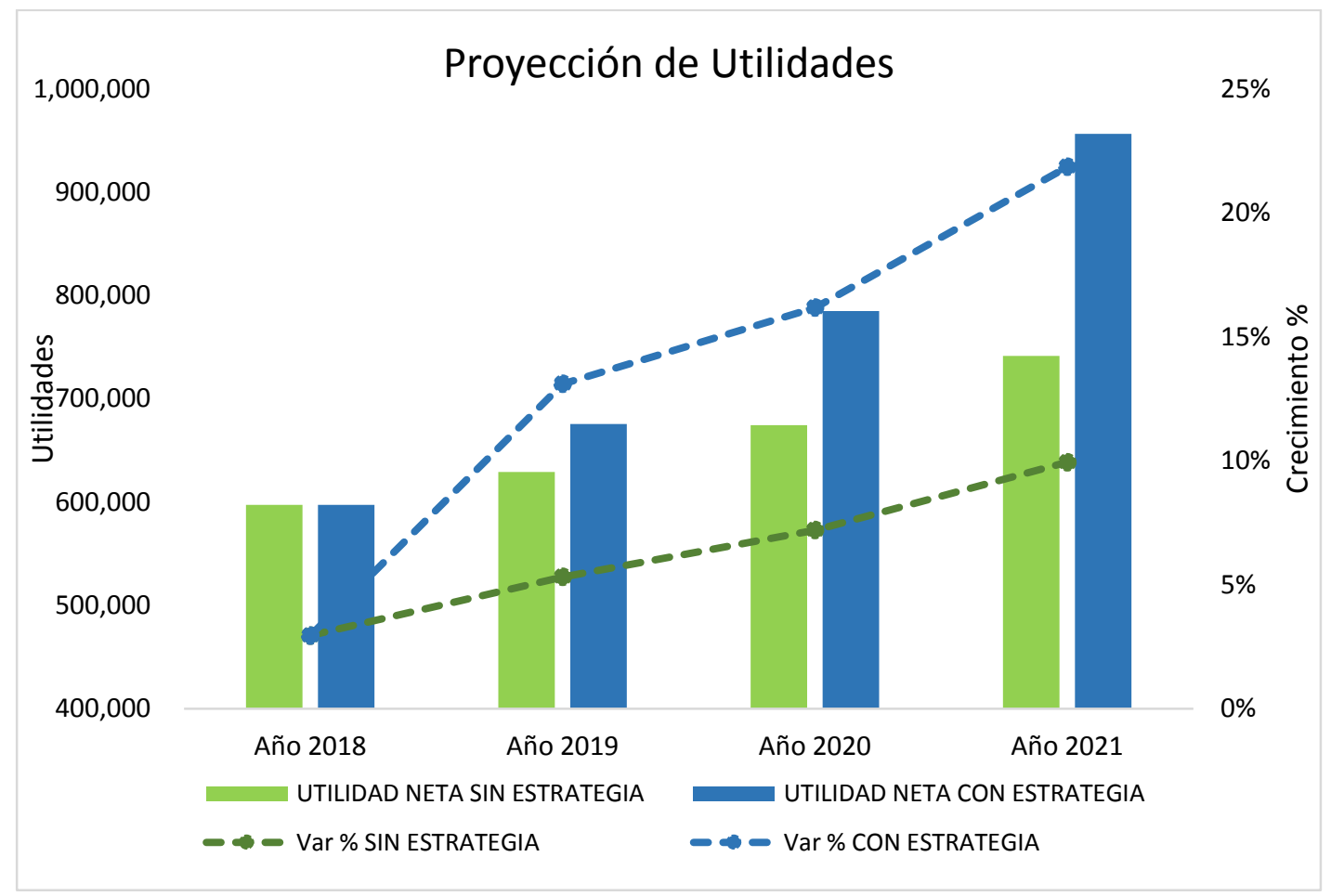

Figura 22: Utilidad Neta comparación con y sin estrategia. Datos proporcionados por Digital (elaboración propia)

\subsubsection{Balance general (situación actual y con la nueva estrategia).}

Se realizó la proyección del Balance General bajo los dos escenarios, en el primero se aprecia lo siguiente:

- El capital emitido no varía, sólo los resultados acumulados y los resultados netos generados en los siguientes ejercicios. 
- Los pasivos van disminuyendo para los siguientes años, el préstamo para la construcción de la oficina administrativa se cancela el año 2019 y los otros préstamos son a plazos menores.

- Los activos no corrientes van disminuyendo producto de ajuste que se hace por depresión cada año.

- Mantiene un comportamiento similar de crecimiento porque está vinculado con las ventas, cobranzas, inventarios los mismos que se trabajan con TDP.

- La particularidad de la empresa es que tanto las cuentas por pagar y las cuentas por cobrar, están vinculadas a TDP, las mismas que corresponden a la venta de equipos y comisiones respectivamente.

- La empresa Digital cuenta con una línea de crédito con TDP por un valor de S/ 2,800,000.00, garantizada con cartas fianzas, para la compra de equipos celulares. 
Tabla 40:

Balance General Proyectado sin estrategia

\section{BALANCE GENERAL}

\section{Sin Estrategia}

(Expresado en Nuevos Soles)

\begin{tabular}{|c|c|c|c|c|}
\hline ACTIVOS & Año base 2018 & Año 2019 & Año 2020 & Año 2021 \\
\hline \multicolumn{5}{|l|}{ ACTIVOS CORRIENTES } \\
\hline Efectivo y Equivalentes al Efectivo & 843,623 & 882,180 & 843,425 & 924,979 \\
\hline Cuentas cobrar comerciales y otras & $1,360,553$ & $1,422,735$ & $1,360,234$ & $1,491,759$ \\
\hline Inventarios & $1,329,529$ & $1,390,294$ & $1,329,217$ & $1,457,744$ \\
\hline Otros Activos IR & 215,953 & 225,823 & 215,902 & 236,779 \\
\hline TOTAL ACTIVOS CORRIENTES & $3,749,658$ & $3,921,032$ & $3,748,779$ & $4,111,260$ \\
\hline \multicolumn{5}{|l|}{ ACTIVOS NO CORRIENTES } \\
\hline Propiedades, Planta y Equipo (neto) & $1,967,406$ & $1,850,921$ & $1,734,436$ & $1,617,952$ \\
\hline TOTAL ACTIVOS NO CORRIENTES & $1,967,406$ & $1,850,921$ & $1,734,436$ & $1,617,952$ \\
\hline TOTAL DE ACTIVOS & $5,717,064$ & $5,771,953$ & $5,483,215$ & $5,729,212$ \\
\hline \multicolumn{5}{|l|}{ PASIVOS Y PATRIMONIO } \\
\hline \multicolumn{5}{|l|}{ PASIVOS CORRIENTES } \\
\hline Cuentas por pagar comerciales y otras & $3,023,880$ & $3,204,070$ & $3,056,092$ & $2,994,971$ \\
\hline Provisión por Beneficios a los Empleados & 82,509 & 83,780 & 85,592 & 84,083 \\
\hline Otras provisiones Tributos por Pagar & 992,860 & $1,044,368$ & 856,508 & 890,294 \\
\hline TOTAL PASIVOS CORRIENTES & $4,099,249$ & $4,332,217$ & $3,998,192$ & $3,969,347$ \\
\hline \multicolumn{5}{|l|}{ PASIVOS NO CORRIENTES } \\
\hline Otros Pasivos Financieros & 442,661 & 471,626 & 516,946 & 646,183 \\
\hline Cuentas por pagar comerciales y otras & 297,835 & 59,051 & 13,731 & 92,321 \\
\hline TOTAL PASIVOS NO CORRIENTES & 740,496 & 530,677 & 530,677 & 738,504 \\
\hline TOTAL PASIVOS & $4,839,745$ & $4,862,894$ & $4,528,870$ & $4,707,852$ \\
\hline \multicolumn{5}{|l|}{ PATRIMONIO } \\
\hline Capital Emitido & \multirow[t]{2}{*}{280,000} & \multirow[t]{2}{*}{280,000} & \multirow[t]{2}{*}{280,000} & \multirow[t]{2}{*}{280,000} \\
\hline Resultados Acumulados & & & & \\
\hline Resultado Neto del ejercicio (Perdida) & 597,319 & 629,060 & 674,345 & 741,361 \\
\hline TOTAL PATRIMONIO & 877,319 & 909,060 & 954,345 & $1,021,361$ \\
\hline TOTAL PASIVO Y PATRIMONIO & $5,717,064$ & $5,771,953$ & $5,483,215$ & $5,729,212$ \\
\hline
\end{tabular}

Nota: Digital (elaboración propia) 
Tabla 41:

Balance General con estrategia

\section{BALANCE GENERAL}

\section{Con Estrategia}

(Expresado en Nuevos Soles)

\begin{tabular}{|c|c|c|c|c|}
\hline ACTIVOS & Año base 2018 & Año 2019 & Año 2020 & Año 2021 \\
\hline \multicolumn{5}{|l|}{ ACTIVOS CORRIENTES } \\
\hline Efectivo y Equivalentes al Efectivo & 843,623 & 898,774 & 878,975 & 996,281 \\
\hline Cuentas cobrar comerciales y otras & $1,360,553$ & $1,449,497$ & $1,417,565$ & $1,606,750$ \\
\hline Inventarios & $1,329,529$ & $1,416,445$ & $1,385,242$ & $1,570,113$ \\
\hline Otros Activos IR & 215,953 & 230,071 & 225,002 & 255,031 \\
\hline TOTAL ACTIVOS CORRIENTES & $3,749,658$ & $3,994,786$ & $3,906,784$ & $4,428,174$ \\
\hline \multicolumn{5}{|l|}{ ACTIVOS NO CORRIENTES } \\
\hline Propiedades, Planta y Equipo (neto) & $1,967,406$ & $1,850,921$ & $1,734,436$ & $1,617,952$ \\
\hline TOTAL ACTIVOS NO CORRIENTES & $1,967,406$ & $1,850,921$ & $1,734,436$ & $1,617,952$ \\
\hline TOTAL DE ACTIVOS & $5,717,064$ & $5,845,707$ & $5,641,221$ & $6,046,126$ \\
\hline \multicolumn{5}{|l|}{ PASIVOS Y PATRIMONIO } \\
\hline \multicolumn{5}{|l|}{ PASIVOS CORRIENTES } \\
\hline Cuentas por pagar comerciales y otras & $3,023,880$ & $3,204,070$ & $3,056,092$ & $2,994,971$ \\
\hline Provisión por Beneficios a los Empleados & 82,509 & 91,563 & 86,860 & 95,946 \\
\hline Otras provisiones Tributos por Pagar & 992,860 & $1,063,829$ & 902,746 & 980,284 \\
\hline TOTAL PASIVOS CORRIENTES & $4,099,249$ & $4,359,461$ & $4,045,698$ & $4,071,200$ \\
\hline \multicolumn{5}{|l|}{ PASIVOS NO CORRIENTES } \\
\hline Otros Pasivos Financieros & 442,661 & 471,626 & 516,946 & 646,183 \\
\hline Cuentas por pagar comerciales y otras & 297,835 & 59,051 & 13,731 & 92,321 \\
\hline TOTAL PASIVOS NO CORRIENTES & 740,496 & 530,677 & 530,677 & 738,504 \\
\hline TOTAL PASIVOS & $4,839,745$ & $4,890,138$ & $4,576,375$ & $4,809,704$ \\
\hline \multicolumn{5}{|l|}{ PATRIMONIO } \\
\hline Capital Emitido & 280,000 & 280,000 & 280,000 & 280,000 \\
\hline \multicolumn{5}{|l|}{ Resultados Acumulados } \\
\hline Resultado Neto del ejercicio (Perdida) & 597,319 & 672,044 & 770,745 & 942,322 \\
\hline TOTAL PATRIMONIO & 877,319 & 952,044 & $1,050,745$ & $1,222,322$ \\
\hline TOTAL PASIVO Y PATRIMONIO & $5,717,064$ & $5,842,182$ & $5,627,120$ & $6,032,026$ \\
\hline
\end{tabular}

Nota: Digital (elaboración propia)

- En el balance con estrategia se incrementan las cuentas del activo como efectivo, cuentas por cobrar a raíz del incremento en las ventas, los inventarios suben muy poco. 
- El capital se mantiene, los resultados del ejercicio se incrementan y con ello también el patrimonio.

- Los pasivos no cambian considerando que no requieren mayor capital para la estrategia, porque son cargados como gasto en cada ejercicio.

- Las cuentas por pagar se mantienen porque realiza menores compras al crédito por tener más liquidez como se observa en el flujo de efectivo.

- Los activos no corrientes mantienen el mismo comportamiento con y sin estrategia.

- La depreciación se mantiene con y sin estrategia, considerando que no hay inversión en activos fijos.

- La empresa cuenta con una línea de créditos con TDP, por ello no tiene mayor requerimiento de préstamos del sistema financiero.

\subsubsection{Flujo de efectivo (situación actual y con la nueva estrategia).}

Con los estados financieros obtenidos, se realizó la proyección del flujo de efectivo, la misma que muestra las actividades de operación, inversión y financiamiento.

- Las actividades de operación disminuyen el efectivo disponible, debido al incremento en las ventas, lo cual ha generado un mayor nivel de inventarios de equipos disponibles para la venta, generando un incremento en las cuentas por cobrar.

- En el rubro que corresponde a actividades de inversión, se mantienen las inversiones de capital, donde se ha registrado el valor del activo al costo de adquisición por S/ 2,429,226, el mismo que está dentro de su periodo de vida útil, el saldo se refleja con signo negativo porque no representa efectivo disponible para la empresa y se mantiene el mismo monto porque no se tiene proyectado dar de baja. 
- Así mismo lo que corresponde a actividades de financiamiento tiene un ligero incremento por financiamiento a través de líneas de corto plazo.

- La empresa no requiere mayor financiamiento a mediano plazo puesto que trabaja con TDP con una línea de créditos por S/ 2,800,000.00.

Los comportamientos señalados se dan en el flujo de efectivo sin y con estrategia, dado que los cambios solo varían en las proporciones en que incrementan o disminuyen el efectivo disponible. 


\section{Tabla 42:}

Flujo de efectivo sin estrategia

\section{$\underline{\text { FLUJO DE EFECTIVO }}$}

\section{Sin Estrategia}

(Expresado en Nuevos Soles)

\begin{tabular}{|c|c|c|c|c|}
\hline CUENTA & Año base 2018 & Año 2019 & Año 2020 & Año 2021 \\
\hline \multicolumn{5}{|l|}{ Flujos de efectivo de actividad de operación } \\
\hline Ganancia (Pérdida) Neta del Ejercicio & 597,319 & 629,060 & 674,345 & 741,361 \\
\hline Ajustes No Monetarios: & & \multirow{3}{*}{578,305} & \multirow{3}{*}{694,789} & \multirow{3}{*}{811,274} \\
\hline Depreciación, Amortización y Agotamiento & 461,820 & & & \\
\hline $\begin{array}{l}\text { CARGOS Y ABONOS POR CAMBIOS NETOS EN LOS ACTIVOS Y } \\
\text { PASIVOS }\end{array}$ & & & & \\
\hline $\begin{array}{l}\text { (Aumento) disminución de cuentas por cobrar comerciales y } \\
\text { otras cuentas por cobrar }\end{array}$ & $-1,560,553$ & $-1,582,735$ & $-1,560,234$ & $-1,701,759$ \\
\hline (Aumento) Disminución en Inventarios & $-1,429,727$ & $-1,547,613$ & $-1,478,277$ & $-1,642,090$ \\
\hline $\begin{array}{l}\text { Aumento (disminución) de cuentas por pagar comerciales y } \\
\text { otras cuentas por pagar }\end{array}$ & $3,321,715$ & $3,263,121$ & $3,069,823$ & $3,087,291$ \\
\hline $\begin{array}{l}\text { Aumento (Disminución) de Provisión por Beneficios a los } \\
\text { Empleados }\end{array}$ & 82,510 & 83,780 & 85,592 & 84,083 \\
\hline Impuestos a las ganancias pagados (reembolsados) & 776,907 & 818,545 & 640,606 & 653,515 \\
\hline $\begin{array}{l}\text { Flujos de Efectivo y Equivalente al Efectivo Procedente de } \\
\text { Actividades de Operación }\end{array}$ & $2,249,991$ & $2,242,462$ & $2,126,645$ & 2,033,676 \\
\hline \multicolumn{5}{|l|}{ Flujos de efectivo de actividad de inversión } \\
\hline \multicolumn{5}{|l|}{ Clases de pagos en efectivo por actividades de inversión } \\
\hline Inversiones de capital & $-2,429,226$ & $-2,429,226$ & $-2,429,226$ & $-2,429,226$ \\
\hline $\begin{array}{l}\text { Flujos de Efectivo y Equivalente al Efectivo Procedente de } \\
\text { Actividades de Inversión }\end{array}$ & $-2,429,226$ & $-2,429,226$ & $-2,429,226$ & $-2,429,226$ \\
\hline \multicolumn{5}{|l|}{ Flujos de efectivo de actividad de financiación } \\
\hline Obtención de Préstamos & 442,661 & 471,626 & 516,946 & 646,183 \\
\hline Dividendos pagados & 580,197 & 597,319 & 629,060 & 674,345 \\
\hline $\begin{array}{l}\text { Flujos de Efectivo y Equivalente al Efectivo Procedente de } \\
\text { Actividades de Financiación }\end{array}$ & $1,022,858$ & $1,068,945$ & $1,146,006$ & $1,320,529$ \\
\hline $\begin{array}{l}\text { Aumento (Disminución) Neto de Efectivo y Equivalente al } \\
\text { Efectivo, antes de las Variaciones en las T.C. }\end{array}$ & 843,623 & 882,180 & 843,425 & 924,979 \\
\hline $\begin{array}{l}\text { Aumento (Disminución) Neto de Efectivo y Equivalente al } \\
\text { Efectivo }\end{array}$ & 843,623 & 882,180 & 843,425 & 924,979 \\
\hline \multicolumn{5}{|l|}{ Efectivo y Equivalente al Efectivo al Inicio del Ejercicio } \\
\hline Efectivo y Equivalente al Efectivo al Finalizar el Ejercicio & 843,623 & 882,180 & 843,425 & 924,979 \\
\hline
\end{tabular}

Nota: Digital (elaboración propia) 


\section{Tabla 43:}

Flujo de efectivo con estrategia

\section{$\underline{\text { FLUJO DE EFECTIVO }}$}

\section{Con Estrategia}

(Expresado en Nuevos Soles)

\begin{tabular}{|c|c|c|c|c|}
\hline CUENTA & Año base 2018 & Año 2019 & Año 2020 & Año 2021 \\
\hline \multicolumn{5}{|l|}{ Flujos de efectivo de actividad de operación } \\
\hline Ganancia (Pérdida) Neta del Ejercicio & 597,319 & 672,044 & 770,745 & 942,322 \\
\hline \multicolumn{5}{|l|}{ Ajustes No Monetarios: } \\
\hline Depreciación, Amortización y Agotamiento & 461,820 & 578,305 & 694,789 & 811,274 \\
\hline \multicolumn{5}{|l|}{$\begin{array}{l}\text { CARGOS Y ABONOS POR CAMBIOS NETOS EN LOS ACTIVOS Y } \\
\text { PASIVOS }\end{array}$} \\
\hline $\begin{array}{l}\text { (Aumento) disminución de cuentas por cobrar comerciales y } \\
\text { otras cuentas por cobrar }\end{array}$ & $-1,560,553$ & $-1,609,497$ & $-1,617,565$ & $-1,816,750$ \\
\hline (Aumento) Disminución en Inventarios & $-1,363,719$ & $-1,495,335$ & $-1,502,382$ & $-1,770,059$ \\
\hline $\begin{array}{l}\text { Aumento (disminución) de cuentas por pagar comerciales y } \\
\text { otras cuentas por pagar }\end{array}$ & $3,321,715$ & $3,266,646$ & $3,087,448$ & $3,115,491$ \\
\hline $\begin{array}{l}\text { Aumento (Disminución) de Provisión por Beneficios a los } \\
\text { Empleados }\end{array}$ & 16,502 & 13,134 & 8,431 & 1,047 \\
\hline Impuestos a las ganancias pagados (reembolsados) & 776,907 & 833,758 & 677,743 & 725,253 \\
\hline $\begin{array}{l}\text { Flujos de Efectivo y Equivalente al Efectivo Procedente de } \\
\text { Actividades de Operación }\end{array}$ & 2,249,991 & $2,259,055$ & $2,119,210$ & $2,008,578$ \\
\hline \multicolumn{5}{|l|}{ Flujos de efectivo de actividad de inversión } \\
\hline \multicolumn{5}{|l|}{ Clases de pagos en efectivo por actividades de inversión } \\
\hline Inversiones de capital & $-2,429,226$ & $-2,429,226$ & $-2,429,226$ & $-2,429,226$ \\
\hline $\begin{array}{l}\text { Flujos de Efectivo y Equivalente al Efectivo Procedente de } \\
\text { Actividades de Inversión }\end{array}$ & $-2,429,226$ & $-2,429,226$ & $-2,429,226$ & $-2,429,226$ \\
\hline \multicolumn{5}{|l|}{ Flujos de efectivo de actividad de financiación } \\
\hline Obtención de Préstamos & 442,661 & 471,626 & 516,946 & 646,183 \\
\hline Dividendos pagados & 580,197 & 597,319 & 672,044 & 770,745 \\
\hline $\begin{array}{l}\text { Flujos de Efectivo y Equivalente al Efectivo Procedente de } \\
\text { Actividades de Financiación }\end{array}$ & $1,022,858$ & $1,068,945$ & $1,188,990$ & $1,416,928$ \\
\hline $\begin{array}{l}\text { Aumento (Disminución) Neto de Efectivo y Equivalente al } \\
\text { Efectivo, antes de las Variaciones en las T.C. }\end{array}$ & 843,623 & 898,773 & 878,974 & 996,280 \\
\hline $\begin{array}{l}\text { Aumento (Disminución) Neto de Efectivo y Equivalente al } \\
\text { Efectivo }\end{array}$ & 843,623 & 898,773 & 878,974 & 996,280 \\
\hline \multicolumn{5}{|l|}{ Efectivo y Equivalente al Efectivo al Inicio del Ejercicio } \\
\hline Efectivo y Equivalente al Efectivo al Finalizar el Ejercicio & 843,623 & 898,773 & 878,974 & 996,280 \\
\hline
\end{tabular}

Nota: Digital (elaboración propia) 


\subsubsection{Proyección de flujos (situación actual y con la nueva estrategia).}

Para la proyección del flujo de caja, a diferencia del estado de resultados, no se considera la depreciación de los tres años que proyectamos, puesto que el flujo solo incluye las entradas y salidas de dinero, por ello la depreciación que corresponde a los tres años se suman al resultado del flujo.

Tabla 44:

Flujo de Caja proyectado sin estrategia

\section{FLUJO DE CAJA}

\section{Sin Estrategia}

(Expresado en Nuevos Soles)

\begin{tabular}{|c|c|c|c|c|}
\hline Rubros & 0 & Año 2019 & Año 2020 & Año 2021 \\
\hline INGRESOS TOTALES & & $16,395,717$ & $16,680,907$ & $17,039,721$ \\
\hline COSTO DE VENTAS & & $9,185,255$ & $9,368,960$ & $9,603,184$ \\
\hline GANANCIA (PERDIDA) BRUTA & & $7,210,462$ & $7,311,948$ & $7,436,538$ \\
\hline INGRESOS FINANCIEROS & & 5,993 & 6,592 & 7,251 \\
\hline GASTOS FINANCIEROS & & 58,264 & 46,611 & 32,628 \\
\hline GANANCIA (PERDIDA) NETA & & $7,158,191$ & $7,271,928$ & $7,411,161$ \\
\hline GASTOS TOTALES & & $6,084,100$ & $6,140,088$ & $6,193,023$ \\
\hline GASTO DE VENTAS & & $6,084,100$ & $6,140,088$ & $6,193,023$ \\
\hline DEPRECIACION & & - & - & - \\
\hline GANANCIA (PERDIDA) OPERATIVA & & $1,074,091$ & $1,131,841$ & $1,218,138$ \\
\hline COMISIONES POR TRANSFERENCIAS & & 65,011 & 58,510 & 49,734 \\
\hline OTRAS CARGAS FINANCIERAS & & 311 & 327 & 343 \\
\hline SALDO DEPRECIACION & & 349,455 & & \\
\hline RESULTADO & & 659,313 & $1,073,003$ & $1,168,061$ \\
\hline IMPUESTO A LA RENTA & & 263,224 & 282,173 & 310,215 \\
\hline UTILIDAD NETA & & 396,090 & 790,830 & 857,846 \\
\hline
\end{tabular}

Nota: Digital (elaboración propia). 
Tabla 45:

Flujo de Caja proyectado con estrategia

\section{FLUJO DE CAJA}

\section{Con Estrategia}

(Expresado en Nuevos Soles)

\begin{tabular}{|c|c|c|c|c|}
\hline Rubros & 0 & Año 2019 & Año 2020 & Año 2021 \\
\hline INGRESOS TOTALES & & $16,694,888$ & $17,500,874$ & $18,572,564$ \\
\hline COSTO DE VENTAS & & $9,275,306$ & $9,739,072$ & $10,372,111$ \\
\hline GANANCIA (PERDIDA) BRUTA & & $7,419,582$ & $7,761,802$ & $8,200,453$ \\
\hline INGRESOS FINANCIEROS & & 5,993 & 6,592 & 7,251 \\
\hline GASTOS FINANCIEROS & & 58,264 & 46,611 & 32,628 \\
\hline GANANCIA (PERDIDA) NETA & & $7,367,310$ & $7,721,783$ & $8,175,076$ \\
\hline GASTOS TOTALES & & $6,232,249$ & $6,453,206$ & $6,671,888$ \\
\hline GASTO DE VENTAS & & $6,232,249$ & $6,453,206$ & $6,671,888$ \\
\hline \multicolumn{5}{|l|}{ DEPRECIACION } \\
\hline GANANCIA (PERDIDA) OPERATIVA & & $1,135,061$ & $1,268,577$ & $1,503,189$ \\
\hline COMISIONES POR TRANSFERENCIAS & & 65,011 & 58,510 & 49,734 \\
\hline OTRAS CARGAS FINANCIERAS & & 311 & 327 & 343 \\
\hline SALDO DEPRECIACION & & 349,455 & & \\
\hline RESULTADO & & 720,284 & $1,209,740$ & $1,453,112$ \\
\hline IMPUESTO A LA RENTA & & 281,210 & 322,510 & 394,305 \\
\hline UTILIDAD NETA & & 439,074 & 887,230 & $1,058,807$ \\
\hline
\end{tabular}

Nota: Digital (elaboración propia)

\subsubsection{Evaluación Financiera (VAN y ratios financieros).}

Para calcular el VAN se tomó en cuenta los resultados de ambos flujos de caja, sin estrategia y con estrategia, aplicando el cálculo sobre la diferencia que se genera. 
Tabla 46:

Flujo de Inversión.

\begin{tabular}{|l|r|r|r|r|}
\hline \multicolumn{1}{|c|}{ DIFERENCIAS DE FLUJO DE CAJA } & 0 & 2019 & 2020 & 2021 \\
\hline FLUJO DE CAJA SIN ESTRATEGIA & & 396,090 & 790,830 & 857,846 \\
\hline FLUJO DE CAJA CON ESTRATEGIA & & 439,074 & 887,230 & $1,058,807$ \\
\hline DIFERENCIA MARGINAL & & 42,984 & 96,399 & 200,961 \\
\hline
\end{tabular}

Nota: Digital (elaboración propia)

Previamente se procedió a calcular el costo de oportunidad del capital, donde se han considerado los diferentes valores que se requiere según el modelo CAPM, la rentabilidad libre de riesgo corresponde a la curva cupón cero a 5 años de la SBS, para el dato de beta se consideró el publicado para el sector de telecomunicaciones de la página de Adamodar (2019), que corresponde a la industria americana, el dato de la rentabilidad de mercado corresponde a ROE que TDP que reportó para el año 2016, según Class \& Asociados (2018) Clasificadora de Riesgos, con ello se obtuvo una COK de $17.46 \%$.

Tabla 47:

Modelo CAPM

\begin{tabular}{|l|l|r|}
\hline Fórmula & K=Rf+B(Rm-Rf) & \multicolumn{1}{|c|}{ Valores } \\
\hline $\mathrm{Rf}$ & Rentabilidad libre de riesgo & 4.94 \\
\hline $\mathrm{B}$ & (Beta) Prima por riesgo de Mercado & 1.22 \\
\hline $\mathrm{Rm}$ & Rentabilidad de mercado (dic '16) Telefónica del Perú & 15.20 \\
\hline $\mathrm{K}$ & Costo de Oportunidad de Accionista (Anual) & $\mathbf{1 7 . 4 6}$ \\
\hline & COK en porcentaje & $\mathbf{1 7 . 4 6 \%}$ \\
\cline { 2 - 3 }
\end{tabular}

Nota: Elaboración propia.

Una vez que se ha obtenido la COK se procedió a hallar el VAN de la empresa, concluyendo que la propuesta de implementar la estrategia generará mayores ingresos en los siguientes años, por ello el VAN es positivo, se afirma que los resultados obtenidos los próximos tres años 
cubrirán la inversión que se generará producto de implementar la estrategia, orientada a gastos de personal y servicios de terceros.

Tabla 48:

Costo de oportunidad del capital

\begin{tabular}{|r|r|}
\hline COK & $17.46 \%$ \\
\hline VAN & 230,471 \\
\hline
\end{tabular}

Nota: Elaboración propia

\subsubsection{Ratios financieros.}

\section{- Ratios de liquidez}

Los ratios de liquidez muestran la capacidad que tiene la empresa para poder afrontar sus deudas de corto plazo, la liquidez corriente para el 2019 es 1.09 y luego mayor a uno, es decir cuenta con los recursos necesarios para hacer pago a las obligaciones en el corto plazo, la liquidez ácida muestra que esta disminuye a casi la mitad, es decir por cada sol que debe cuenta con S/ 0.54 céntimos para cubrir las obligaciones, sin utilizar el inventario, el mismo que mejora para el año 2021 incrementándose a S/ 0.64, del comportamiento de los ratios se puede indicar que la empresa cuenta con buenos niveles de liquidez que van mejorando en los próximos años.

Tabla 49:

Ratios de liquidez

\begin{tabular}{|l|r|r|r|r|}
\hline \multicolumn{1}{|c|}{ RATIOS DE LIQUIDEZ } & Año base 2018 & Año 2019 & \multicolumn{1}{c|}{ Año 2020 } & \multicolumn{1}{c|}{ Año 2021 } \\
\hline LIQUIDEZ CORRIENTE & 0.91 & 0.92 & 0.97 & 1.09 \\
\hline LIQUIDEZ ACIDA & 0.54 & 0.54 & 0.57 & 0.64 \\
\hline
\end{tabular}

Nota: Digital (elaboración propia) 


\section{- Ratios de gestión}

La rotación de inventarios no indica cuantas veces en el año la empresa logra vender el inventario, para el análisis se da entre 6 a 7 veces, lo cual es bueno porque está relacionado con el periodo de pago que concede TDP, cuando entrega los inventarios se tiene un plazo entre $30 \mathrm{y}$ 60 para pagar, estando alineado al movimiento comercial de la empresa.

Respecto a la eficiencia en el uso de activos, se interpreta que por cada sol invertido en el activo la empresa vendió 2.82 el año 2017 y para el 2021 se espera que sea 3.07. También se puede indicar que los activos totales rotaron más de una vez en el año.

Los ratios proyectados de cobranzas respecto a los actuales mantiene la misma tendencia respecto del año 2018, los días de cobranza mejoran y se situación entre 29 y 33 días, lo cual es saludable porque son periodos cortos, es decir que las cobranzas se realizan en el mes. La rotación de las cuentas por cobrar es de 11 a 12 veces durante el ejercicio, lo cual se corrobora con el periodo medio de 30 días.

\section{Tabla 50:}

Ratios de gestión

\begin{tabular}{|l|r|r|r|r|}
\hline \multicolumn{1}{|c|}{ RATIOS DE GESTION } & Año base $\mathbf{2 0 1 8}$ & Año 2019 & Año 2020 & Año 2021 \\
\hline ROTACION DE INVENTARIOS & 6.77 & 6.55 & 7.03 & 6.61 \\
\hline ROTACION DEL ACTIVO & 2.82 & 2.86 & 3.10 & 3.07 \\
\hline PERIODO MEDIO DE CUENTAS POR COBRAR & 30.34 & 31.26 & 29.16 & 31.14 \\
\hline ROTACION DE CUENTAS POR COBRAR & 11.87 & 11.52 & 12.35 & 11.56 \\
\hline
\end{tabular}

Nota: Digital (elaboración propia). 


\section{- Ratios de solvencia}

Las razones de endeudamientos muestran cuan comprometidos estas los recursos de la empresa con terceros, como se observa la autonomía financiera es baja ya que solo cuenta con 0.15 por cada sol que tiene comprometido en pasivos de corto y largo plazo el año 2018, sin embargo este compromiso es principalmente con un acreedor al que está ligada la empresa que es TDP, por la modalidad del negocio mantiene pasivos a través de una línea de crédito por los equipos que son distribuidos en todas las tiendas, cuenta también con otros pasivos en el sistema financiero por montos menores a corto plazo, para el año 2021 este ratio llega a 0.20.

El endeudamiento del activo indica que por cada sol que tiene en el activo debe el S/ 0.85 para el año 2018, mejorando el 2021 a S/ 0.80. También indica cuan comprometido está el activo con los acreedores es decir alrededor del $80 \%$. El ratio de solvencia mine la capacidad de la empresa para pagar sus deudas con todo el activo, como se observa el ratio debe ser superior a 1.0 a fin de no tener comprometido todo el activo, para el año 2021 la empresa contará con S/ 1.26 veces más por cada S/ 1.0 que mantiene en el pasivo.

Tabla 51:

Ratios de solvencia.

\begin{tabular}{|l|r|r|r|r|}
\hline \multicolumn{1}{|c|}{ RATIOS DE SOLVENCIA } & Año base 2018 & Año 2019 & \multicolumn{1}{c|}{ Año 2020 } & \multicolumn{1}{c|}{ Año 2021 } \\
\hline AUTONOMIA FINANCIERA & 0.15 & 0.16 & 0.19 & 0.20 \\
\hline ENDEUDAMIENTO DEL ACTIVO & 0.85 & 0.84 & 0.81 & 0.80 \\
\hline SOLVENCIA & 1.18 & 1.20 & 1.23 & 1.26 \\
\hline
\end{tabular}

Nota: Digital (elaboración propia) 


\section{- Ratios de rentabilidad}

Los ratios de rentabilidad son muy importantes para la continuidad del negocio y el ROE representa cuánto gana el accionista, alrededor de $68.1 \%$ que representa una alta rentabilidad, así mismo este ratio crece hasta $77.1 \%$ en el 2021, es decir el accionista estará ganando un $77.1 \%$ sobre el capital invertido, lo cual hace realmente atractivo este negocio frente a otras oportunidades de inversión. El ROA que representa el rendimiento sobre los activos también tiene un peso importante que llega hasta el $15.6 \%$.

Como se observa en el último ratio la utilidad sobre las ventas es baja por tratarse de un negocio de volúmenes, los ingresos se encuentran alrededor de diecisiete millones de soles lo cual hace atractivo ganar un $3.7 \%$ de ese volumen y mucho mejor llegar hasta un $5.1 \%$ para el 2021.

Tabla 52:

Ratios de rentabilidad

\begin{tabular}{|l|r|r|r|r|}
\hline \multicolumn{1}{|c|}{ RATIOS DE RENTABILIDAD } & Año base 2018 & Año 2019 & \multicolumn{1}{c|}{ Año 2020 } & \multicolumn{1}{c|}{ Año 2021} \\
\hline RENTABILIDAD DEL PATRIMONIO (ROE) & $68.1 \%$ & $70.6 \%$ & $73.4 \%$ & $77.1 \%$ \\
\hline RENTABILIDAD DEL ACTIVO (ROA) & $10.4 \%$ & $11.5 \%$ & $13.7 \%$ & $15.6 \%$ \\
\hline RENTABILIDAD DE LAS VENTAS & $3.7 \%$ & $4.0 \%$ & $4.4 \%$ & $5.1 \%$ \\
\hline
\end{tabular}

Nota: Digital (elaboración propia). 


\section{CONCLUSIONES Y RECOMENDACIONES}

\section{CONCLUSIONES}

El trabajo desarrollado ha permitido ampliar los conocimientos y al mismo tiempo aplicar todo lo aprendido a lo largo de la maestría, en una empresa en marcha haciendo posible la mejora cuantitativa y cualitativa a través de formular y aplicar estrategias para lograr un plan estratégico estructurado y proyectado hasta el 2021. El capital humano es el factor clave para el éxito de una empresa y todos los esfuerzos y recursos invertidos en los trabajadores a través de programas de capacitación, bonificaciones, línea de carrera, evaluación de desempeño, tendrá un resultado que generará valor para la empresa.

Se logrará un crecimiento del 10\% del IVR para el 2021, según las proyecciones observadas en los estados financieros, luego de implementar las estrategias de capacitación y reconocimiento al personal orientadas a mejorar el servicio al cliente.

La productividad de los trabajadores se incrementará a través de las bonificaciones percibidas de manera mensual según el desempeño de cada uno, el cual se reflejará en la reducción de las penalidades en un $2 \%$ de forma anual, lo que permitirá el incremento en las utilidades según las proyectadas realizadas. 


\section{RECOMENDACIONES}

- Se recomienda a la Gerencia General considerar la ejecución del presente plan estratégico para los próximos tres años, dado que se evidencia una oportunidad para seguir creciendo y trabajando con TDP.

- Comunicar y socializar a toda la empresa sobre el plan estratégico que se plantea, los beneficios que traerá en el corto y mediano plazo, comprometer a las Gerencias de línea y especialmente a la Gerencia de Recursos Humanos.

- Implementar las estrategias propuestas, las mismas que requieren un monto de inversión que está orientado principalmente al capital humano de la empresa, que será recuperado a través del incremento de los ingresos.

- La aplicación de las estrategias permitirá mejorar el compromiso, la productividad de los trabajadores y con ello el valor de la empresa en un mediano plazo, para mantener el liderazgo en el mercado donde opera.

- La Gerencia General deberá establecer tiempos para la revisión, control y monitoreo del presente plan estratégico, se sugiere sea de forma trimestral a fin de cumplir en los tiempos previstos todos los objetivos e iniciativas y hacer las mejoras o correcciones de las desviaciones que se puedan presentar, ya que el plan define la ruta hacia dónde quiere llegar la empresa. 


\section{REFERENCIAS}

Adamodar. (January de 2019). Betas by Sector (US). Obtenido de Multiple data services: http://pages.stern.nyu.edu/ adamodar/New_Home_Page/datafile/Betas.html

ANDINA. (Mayo de 2017). Andina, Agencia peruana de noticias. Obtenido de Mercado de telecomunicaciones en Perú: https://andina.pe/agencia/noticia-mercadotelecomunicaciones-peru-representa-35-del-pbi-506340.aspx

BCR. (setiembre de 2017). Reporte de inflacion. Obtenido de Panorama actual y proyecciones macroeconomicas: $\quad$ http://www.bcrp.gob.pe/docs/Publicaciones/ReporteInflacion/2017/setiembre/reporte-de-inflacion-setiembre-2017.pdf

Carthy, M. (12 de Octubre de 1960). Fundamentos de Mercadotecnia Marketing. Obtenido de Fundamentos de Mercadotecnia Marketing: https://utecno.files.wordpress.com/2013/09/fundamentos-de-mercadotecnia1.pdf

CEPLAN. (2016). Megatendencias: Un analisis del estado global. Lima: CEPLAN. Obtenido de https://www.ceplan.gob.pe/wp-content/uploads/2016/08/Megatendencias-Unan\%C3\%A1lisis-del-estado-global-Ceplan.pdf

Class \& Asociados S.A. (2018). Informe de clasificacion de riesgo Telefonica del Perú S.A. Clasificadora de riesgo, 1-20.

COFIDE. (20 de Setiembre de 2017). Boletin COFIDE. Obtenido de Reporte de coyuntura economica: http://www.cofide.com.pe/COFIDE/images/home/Reporte\%20de\%20Coyuntura\%20Eco n\%C3\%B3mica\%20Setiembre\%202017.pdf

Corzo, S. M. (21 de Octubre de 2009). Formacion y talento. Obtenido de Formacion y talento: http://www.formacionytalento.com/2009/10/competencias-iii-perseverancia.html 
CPI. (Agosto de 2017). Market Report. Obtenido de Market Report: http://cpi.pe/images/upload/paginaweb/archivo/26/mr_poblacion_peru_2017.pdf

D'Alessio, F. A. (2008). Proceso Estrategico: Un Enfoque de Gerencia. Mexico: Pearson Educacion S.A.

David, F. R. (2013). Conceptos de administracion estrategica (Decimo cuarta ed.). Mexico D.C: Pearson Educacion S.A.

Diario gestion. (04 de Enero de 2019). Portabilidad. Más de 14.2 millones de peruanos cambiaron de operador móvil , págs. https://gestion.pe/economia/portabilidad-14-2-millonesperuanos-cambiaron-operador-movil-254776.

EFE. (11 de Septiembre de 2017). Agencia EFE. Obtenido de Agencia EFE: https://www.efe.com/efe/america/economia/la-espanola-inkacel-compra-sucursalperuana-de-virgin-con-unas-100-000-lineas/20000011-3376095

Hay Group. (Octubre de 2010). Una estrategia ganadora: Hacer de la retribucion variable una inversion con retorno. Hay group Informa, 01 - 08.

Hill, C. W., \& Jones, G. R. (2009). Administracion Estrategica (Octava ed.). Mexico: McGrawHill.

INEI. (2017). Encuesta nacional de hogares. Lima: Instituto Nacional de Estadistica e Informatica.

INEI. (21 de Abril de 2017). Instituto Nacional de Estadistica e Informatica. Obtenido de Produccion del sector de telecomunicaciones: https://www.inei.gob.pe/prensa/noticias/produccion-del-sector-telecomunicaciones-yotros-servicios-de-informacion-crecio-en-88-9684/

Johnson, G., Scholes, K., \& Whittington, R. (2006). Direccion Estrategica (Septima ed.). Madrid: Pearson Educacion S.A. 
Kaplan, R. S., \& Norton, D. P. (2002). El Cuadro de Mando Integral: The Balanced Scorecard (Segunda ed.). Barcelona: Gestion 2000.

Kotler, P. (2006). DIreccion de Marketing (Vol. (12va ed.)). Mexico D.F.: Pearson Educacion.

MINAM. (2005). Ley general del ambiente - Ley $N^{\circ} 28611$. Lima: Ministerio del ambiente.

MINAM. (s.f.). $l$.

Mongrut Principe, J. A. (2018). Plan estrategico Eterna Perú. Tesis de postgrado. Universidad San Ignacio de Loyola, Lima.

MTC. (01 de junio de 2017). Estadísticas de Servicios Públicos de Telecomunicaciones. Obtenido de Boletin estadistico: https://portal.mtc.gob.pe/comunicaciones/regulacion_internacional/estadistica_catastro/d ocumentos/2017/Bolet\%C3\%ADn\%20II\%202017.pdf

Organizate Online. (11 de Abril de 2019). Organizacion y Metodos. Obtenido de Organizacion y Metodos: http://organizaonline.blogspot.com/2009/07/organizacion-lineo-funcional$\mathrm{y} \cdot \mathrm{html}$ ?m=1

OSIPTEL. (16 de Diciembre de 2017). OSIPTEL. Obtenido de Empresas operadoras: https://www.osiptel.gob.pe/categoria/enlaces-empresas-operadoras

OSIPTEL. (09 de Enero de 2018). OSIPTEL. Obtenido de Portabilidad movil: https://www.osiptel.gob.pe/noticia/ndp-portabilidadmovil-recordhistorico-2017

Paz, R. (2005). Servicio al cliente. La comunicacion y la calidad del servicio en la atencion al cliente (primera ed.). Madrid: Ideaspropias editorial.

Peru 21. (25 de Mayo de 2018). Hay mas de 40 millones de lineas activas en el Perú. Hay mas de 40 millones de lineas activas en el Perú, págs. https://peru21.pe/peru/osiptel-hay-40millones-lineas-moviles-activas-peru-408082. 
Porter, M. E. (1987). Ventaja competitiva. Mexico D.F.: Grupo Editorial Patria S.A.

Rumelt, R. P. (2011). Good Strategy/Bad Strategy. New York: The crown publishing group.

SBS. (01 de febrero de 2019). Curva cupon cero CD BCRP. Obtenido de Curva cupon cero CD BCRP: http://www.sbs.gob.pe/app/pu/CCID/Paginas/cc_unacurva.aspx

Scheerle, F. (2001). Satisfacción de Empleados. Satisfacción de Empleados. Universidad del CEMA, Buenos Aires.

Serna Gomez, H. (2008). Gerencia estrategica (Tercera ed.). Bogota: Panamericana Editorial Ltda. 


\section{INDICE DE TABLAS}

Tabla 1: Participación de mercado de Digital 16

Tabla 2: Resultados según la encuesta del nivel de satisfacción del cliente IVR de la empresa

Digital 17

Tabla 3: Matriz de la visión propuesta para la empresa (Serna Gomez, 2008)..................... 30

Tabla 4: Matriz de la misión propuesta para la empresa.................................................. 33

Tabla 5: PBI Nacional - índice de producción sectorial $(\operatorname{var} \%)$........................................ 39

Tabla 6: PBI de las regiones a nivel nacional. ............................................................ 40

Tabla 7: Expectativas de tipo de cambio................................................................. 41

Tabla 8: Expectativas de inflación ............................................................................ 42

Tabla 9: Perú: Población por segmentos de edad 2017................................................. 44

Tabla 10: Factores externos proveedor clientes ...................................................... 47

Tabla 11: Efecto variables del entorno................................................................... 47

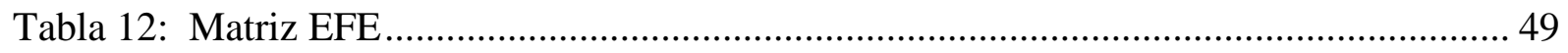

Tabla 13: Participación de mercado de Digital .............................................................. 53

Tabla 14: NDS al 30 de setiembre a nivel nacional de TDP............................................ 54

Tabla 15: NDS al 30 de setiembre en localidades donde Digital tiene presencia ................. 55

Tabla 16: Participación de mercado........................................................................... 59

Tabla 17: Líneas que cambiaron de operadora (OSIPTEL, 2018) ..................................... 60

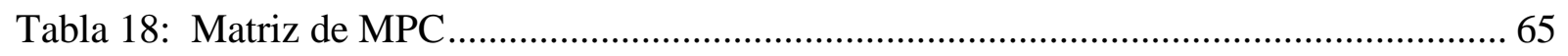

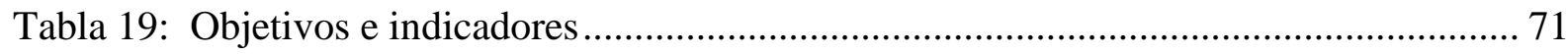

Tabla 20: Ingresos por comisión de servicio de postventa ............................................. 72

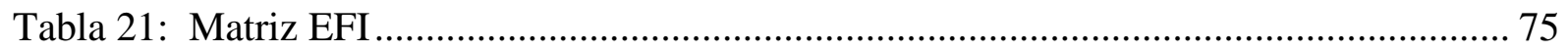


Tabla 22: Objetivos estratégicos de Digital 79

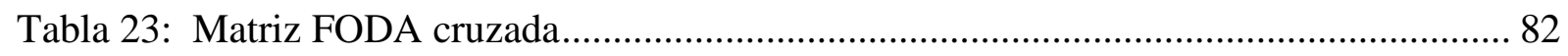

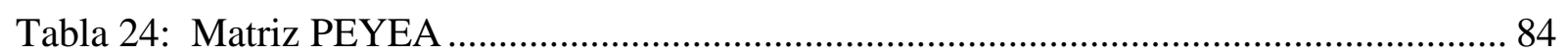

Tabla 25: Matriz de decisión valoración del FODA …........................................................ 91

Tabla 26: Comparación de estrategias en tres escenarios ............................................... 95

Tabla 27: Matriz de Planeación Estratégica Cuantitativa MPEC ........................................ 97

Tabla 28: Resumen de los objetivos estratégicos y específicos ...................................... 108

Tabla 29: Resumen de los indicadores y metas para cada objetivo específico................... 109

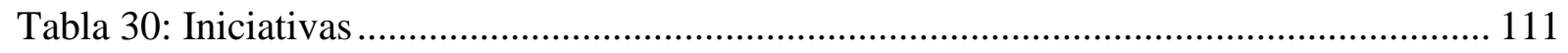

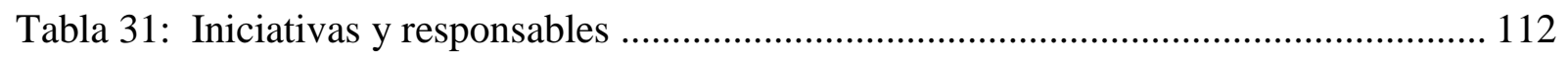

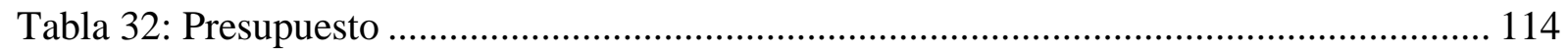

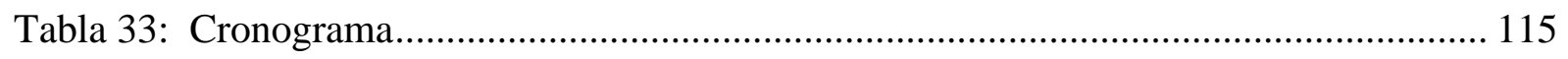

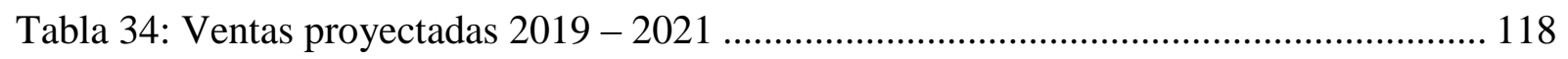

Tabla 35: Estado de Resultado sin estrategia.............................................................. 119

Tabla 36: Utilidad Neta sin implementación estratégica ............................................. 120

Tabla 37: Estado de Resultado con estrategia ............................................................ 121

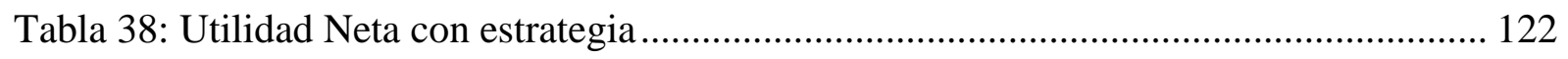

Tabla 39: Cuadro comparativo de utilidades con y sin estrategia.................................... 122

Tabla 40: Balance General Proyectado sin estrategia ................................................. 125

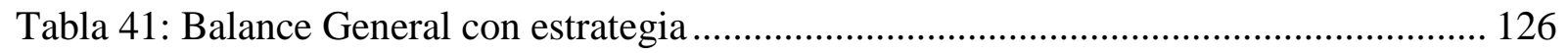

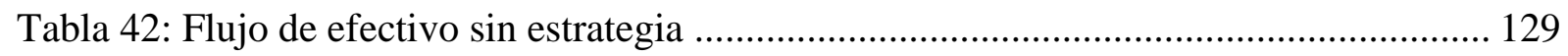

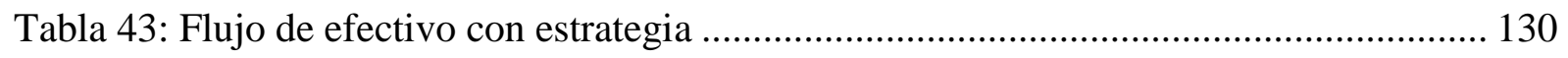

Tabla 44: Flujo de Caja proyectado sin estrategia ...................................................... 131 
Tabla 45: Flujo de Caja proyectado con estrategia .............................................................. 132

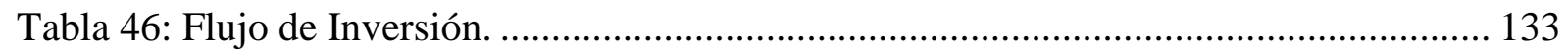

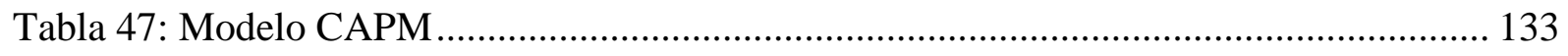

Tabla 48: Costo de oportunidad del capital............................................................................ 134

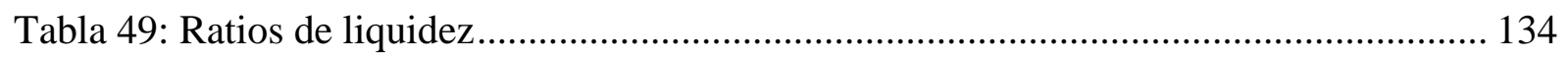

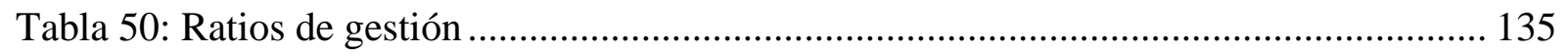

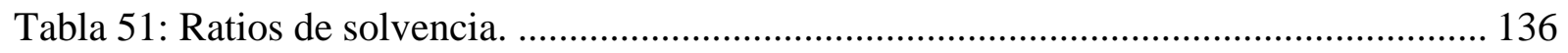

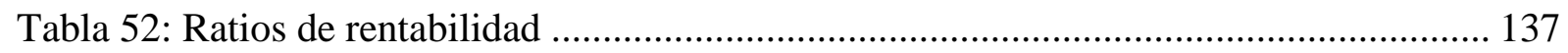




\section{INDICE DE FIGURAS}

Figura 1: Comportamiento del PBI y del sector de telecomunicaciones y otros servicios hasta el 2016. 11

Figura 2: Participación de mercado telefónica móvil. .............................................................. 13

Figura 3: Encuesta del Nivel de Satisfacción del Cliente IVR de la empresa Digital. ............. 18

Figura 4: Evolución del nivel de Satisfacción del Cliente IVR por tiendas de la empresa

Digital. 18

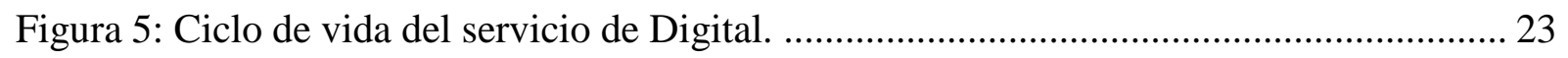

Figura 6: Ciclo de vida del servicio de Digital ..................................................................... 24

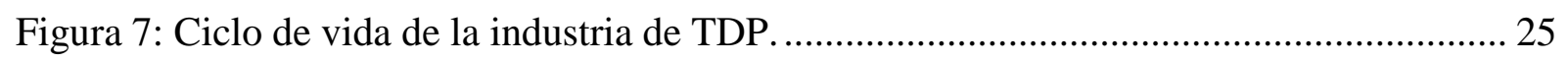

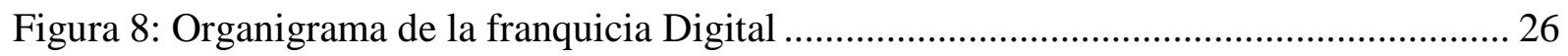

Figura 9: Alineamiento estratégico de la visión, misión y los valores.......................................... 36

Figura 10: Participación del mercado de los operadores a nivel nacional. ............................... 51

Figura 11: Distribución de la franquicia por zonas.............................................................. 52

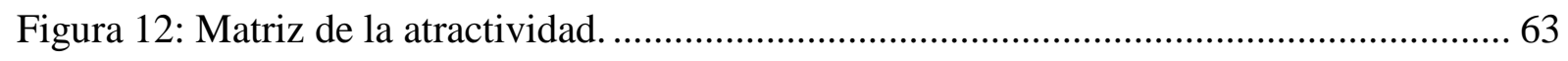

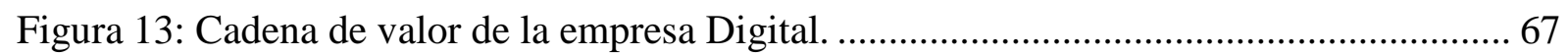

Figura 14: Encuesta del Nivel de Satisfacción del Cliente IVR de las franquicias. ................. 73

Figura 15: Lienzo de la estrategia actual de la empresa según datos de la matriz EFE y EFI. 80 Figura 16: Lienzo de la estrategia de la Industria según datos de la matriz EFE y EFI. .......... 81

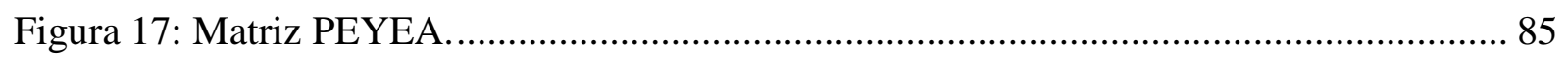

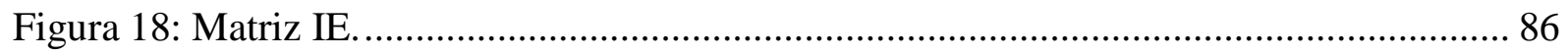

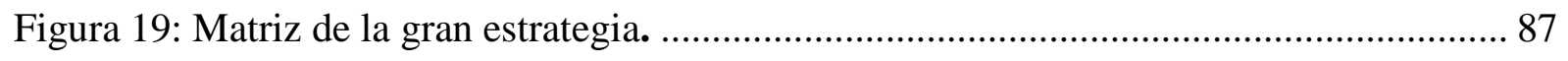

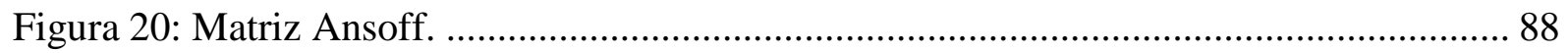


Figura 21: Mapa de la estrategia. ............................................................................... 104

Figura 22: Utilidad Neta comparación con y sin estrategia. ............................................. 123 


\section{ANEXOS}

Anexo 1. Contrato de franquicia

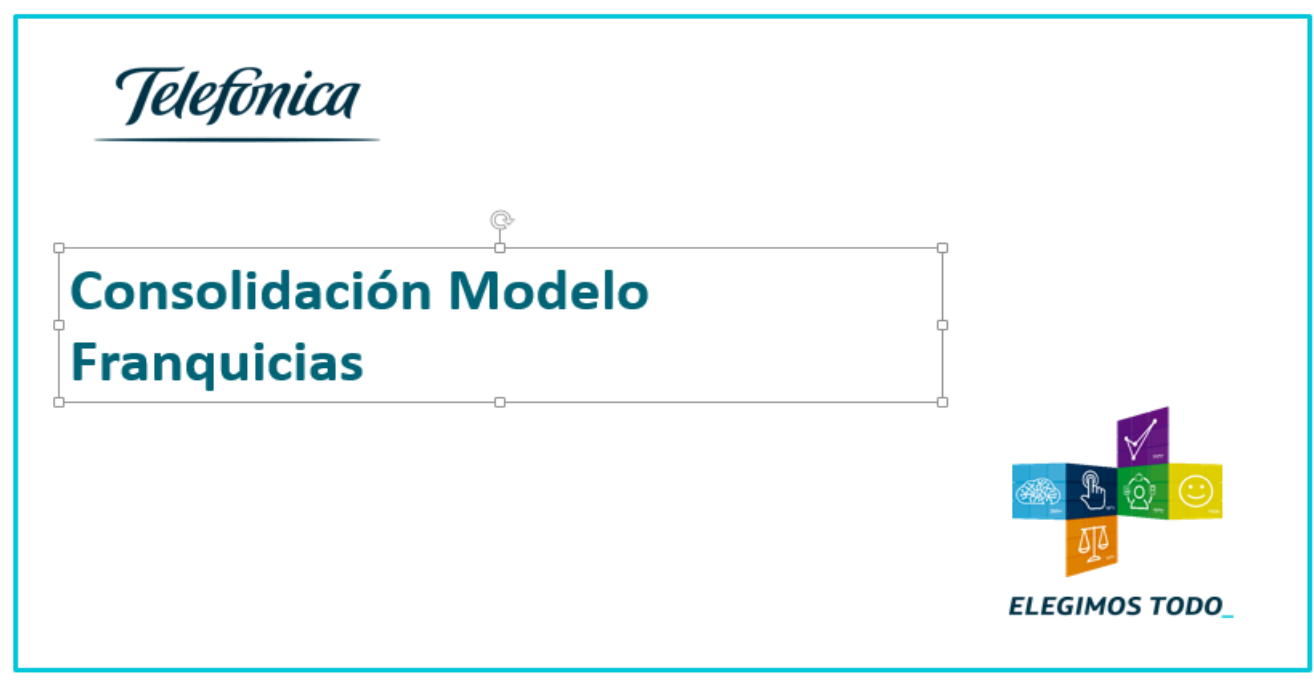

Hace 4 años iniciamos el proceso de franquiciar nuestras tiendas buscando:

Tener mayor capacidad
ejecución a través de

nuestros socios

Ampliar nuestra

capilaridad con una

operación estandarizada

Manteniendo nuestra

identidad de marca 
La Comisión por Atención (2) se paga en función a la valoración del cliente y la Comisión de NDS 3 en función de tiempos de Atención
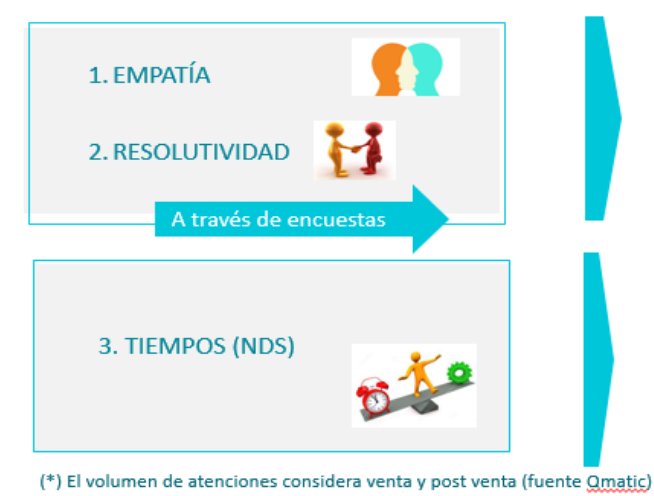

Pago por Atención $n^{*}$

$\left(^{*}\right)$ El volumen de atenciones considera venta y post venta (fuente Qmatic)

Tarifas:

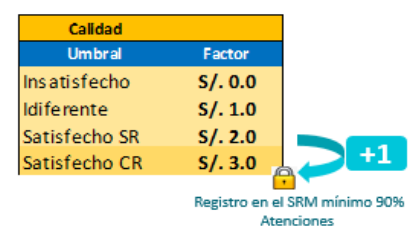

Tarifas:

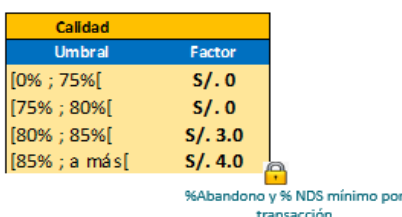
transacción

Necesitamos reenfocar la gestión de tiendas hacia 3 pilares
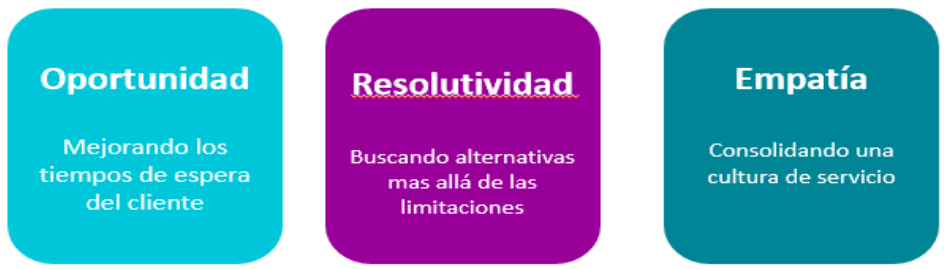

Teniendo al cliente como el centro de la operación 


\title{
Anexo 2. Resolución de Consejo Directivo N 127-2013-CD/OSIPTEL
}

\author{
RESOLUCIÓN DE CONSEJO DIRECTIVO Nº 127- 2013-CD/OSIPTEL 1
}

Lima, 05 de setiembre de 2013.

MATERIA : REGLAMENTO DE CALIDAD DE LA ATENCIÓN A USUARIOS POR PARTE DE LAS EMPRESAS OPERADORAS DE SERVICIOS DE TELEFONIA FIJA Y SERVICIOS PÚBLICOS MÓVILES VISTOS:

\section{TITULO II CALIDAD DE ATENCION EN LOS CANALES PRESENCIAL Y}

\section{TELEFÓNICO}

CAPITULO I SISTEMAS DE ATENCIÓN AL USUARIO Artículo 6º.- Registro de Eventos de Inoperatividad del Sistema de Atención en canales de atención presencial y telefónico Las empresas operadoras deberán contar con un registro correlativo de los eventos de inoperatividad de sus sistemas de atención que afecten la realización de los trámites de los usuarios en los canales de atención presencial y telefónico. Este registro deberá encontrarse a disposición del OSIPTEL cuando éste lo requiera, debiendo contener: 6 (i) La fecha y hora (a nivel de minutos) del inicio de la inoperatividad de sus sistemas. (ii) Los tipos de trámite que no pudieron ser ingresados en sus sistemas. (iii) La causa que originó la inoperatividad en sus sistemas. (iv) La fecha y hora (a nivel de minutos) del reinicio de la operatividad del canal de atención. En estos casos, cuando se produzcan eventos de inoperatividad en los sistemas de atención, las empresas operadoras deberán implementar mecanismos alternativos que permitan la realización de los trámites críticos de los usuarios ante la inoperatividad de sus sistemas de atención. Para efectos de este artículo, se considerarán como trámites críticos, la suspensión del servicio por motivo de 
robo, hurto o extravío del equipo terminal móvil, reporte de averías, formulación de reclamos, presentación de recursos y quejas por parte de los usuarios. Las empresas operadoras deberán reportar al OSIPTEL, de acuerdo a las instrucciones que para tal efecto haya comunicado, la ocurrencia de los eventos de inoperatividad de sus sistemas de atención al usuario, a más tardar a los tres (3) días hábiles siguientes de producido el hecho, incluyendo la información contenida en el Registro de Eventos. No se considerará como inoperatividad en los sistemas de atención, a las ventanas de mantenimiento que la empresa operadora pueda programar periódicamente en el horario de 0 a 6 horas del día, siempre que este hecho se haya comunicado previamente al OSIPTEL.

\section{CAPITULO II INDICADORES DE CALIDAD DE ATENCION EN LOS CANALES}

\section{PRESENCIALES Y TELEFÓNICOS}

Artículo $7^{\circ}$.- Indicador de Inoperatividad del Sistema de Atención a Usuarios en Oficinas

Comerciales y Servicio de Información y Asistencia Telefónica Con la finalidad de impulsar la mejora de las empresas operadoras en cuanto a los sistemas de atención, de tal manera que los usuarios no se encuentren impedidos de realizar sus trámites por la inoperatividad de los sistemas informáticos empleados para tales fines, se deberá tener en consideración el siguiente indicador: 7.1. Indicador de Tasa de Caídas del Sistema de Atención (CSA): Medido como el porcentaje del total de horas en que los sistemas de atención se encuentran imposibilitados de atender los trámites de los usuarios, respecto del total de horas en que los referidos sistemas debieron estar operativos. El procedimiento de medición de este indicador se describe en el Anexo A.

TITULO III CALIDAD DE ATENCION EN OFICINAS COMERCIALES CAPITULO I CONDICIONES MÍNIMAS PARA LA ATENCION EN OFICINAS COMERCIALES 
Artículo $8^{\circ}$.- Sistemas de control e información de atenciones en oficinas comerciales 7 Las empresas operadoras deberán implementar los sistemas necesarios que permitan un adecuado control de las atenciones que se brinden a los usuarios en todas sus oficinas comerciales, así como el almacenamiento de la información sobre el referido control de las atenciones. Dicho sistema deberá contener como mínimo, información acerca de la fecha y la hora (a nivel de minutos) de arribo de cada usuario a la oficina comercial de la empresa operadora. El referido sistema deberá permitir su auditabilidad, debiendo conservarse la información de dicho sistema por un período mínimo de doce (12) meses. Los reportes y el acceso a la información de dicho sistema deberán encontrarse a disposición del OSIPTEL cuando éste lo requiera. Artículo $9^{\circ}$.Entrega de constancia de arribo al usuario en oficinas comerciales Las empresas operadoras deberán entregar al usuario una constancia de arribo a la oficina comercial en el que se consigne información relativa a la fecha y la hora (a nivel de minutos) de entrega de la referida constancia. Dicha constancia de arribo deberá ser entregada al usuario de manera inmediata a su llegada a la oficina comercial, independientemente si por razones de aforo no pudiera ingresar a ella. Lo dispuesto en el presente artículo solo resulta aplicable a los trámites que se regulan en la presente norma. La constancia de arribo entregada al usuario para una atención preferente, de conformidad con lo dispuesto en la Ley $\mathrm{N}^{\circ} 27408$, Ley que establece la atención preferente a las mujeres embarazadas, las niñas, niños, los adultos mayores, en lugares de atención al público, no requiere ser diferenciada en base al tipo de trámite que se solicite. Artículo $10^{\circ}$.- Mobiliario necesario para la espera en oficinas comerciales Las empresas operadoras deberán implementar en sus oficinas comerciales una zona que incluya el mobiliario necesario, como asientos o sillas, que permita la espera de los usuarios para la atención de sus trámites. 


\section{CAPITULO II INDICADORES DE CALIDAD DE ATENCION EN OFICINAS}

COMERCIALES Artículo $11^{\circ}$.- Indicadores de Calidad de Atención Presencial A efectos de evaluar la calidad de la atención brindada en las oficinas comerciales, las empresas operadoras deberán tener en consideración los siguientes indicadores: 11.1. Indicador de Tiempo de Espera para Atención Presencial (TEAP): Medido como el porcentaje de atenciones presenciales en oficinas comerciales que se llevaron a cabo dentro de los quince (15) minutos contados desde que el usuario recibió la constancia de arribo a la oficina comercial. El procedimiento de medición y las metas mínimas de este indicador se describe en el Anexo B. Se excluye de la medición de los indicadores, las constancias de arribo entregadas para la atención preferente. 8 11.2. Indicador de Deserción en Atención Presencial (DAP): Medido como el porcentaje de usuarios que recibieron una constancia de arribo a la oficina comercial, pero que se retiraron antes de realizar su trámite. El procedimiento de medición y las metas mínimas de este indicador se describe en el Anexo C.

\section{TITULO IV CALIDAD DE ATENCION EN LOS SERVICIOS DE INFORMACIÓN Y} ASISTENCIA TELEFÓNICA

\section{CAPITULO I CONDICIONES MÍNIMAS PARA LA ATENCIÓN EN LOS SERVICIOS} DE INFORMACIÓN Y ASISTENCIA TELEFÓNICA Artículo 12º.- Sistema de Registro de Atenciones en los Servicios de Información y Asistencia Telefónica Las empresas operadoras deberán contar con un sistema que permita el registro de las atenciones telefónicas, el cual será auditable, debiendo conservarse la información de las atenciones telefónicas por un período mínimo de veinticuatro (24) meses. Este registro deberá encontrarse a disposición del OSIPTEL cuando éste lo requiera, debiendo contener, como mínimo: (i) El número telefónico o de abonado que realiza el trámite. (ii) La fecha y hora (a nivel de minutos) del inicio de la atención 
telefónica. (iii) Identificación del tipo de trámite, especificándose el tipo de consulta o reclamo que se realice, cuando corresponda. Artículo $13^{\circ}$.- Publicidad en los Servicios de Información y Asistencia Telefónica En caso las empresas operadoras decidan incluir publicidad comercial en los servicios de información y asistencia telefónica, el tiempo utilizado para estos efectos será contabilizado como parte del cálculo del Indicador de Rapidez en Atención por Voz Humana $(\mathrm{AVH})$, con excepción de la información regulatoria que pueda ser establecida expresamente por el OSIPTEL y el Ministerio de Transportes y Comunicaciones.

\section{CAPITULO II INDICADORES DE CALIDAD DE ATENCION EN LOS SERVICIOS DE} INFORMACIÓN Y ASISTENCIA TELEFÓNICA Artículo 14‥- Indicadores de Calidad de Atención Telefónica 14.1. Indicador de Corte de la Atención Telefónica (CAT): Medido como el porcentaje de llamadas que no fueron finalizadas por el usuario (ej. asistente de empresa operadora finalizó la llamada). El procedimiento de medición y las metas mínimas de este indicador se describe en el Anexo D. 14.2. Indicador de Rapidez en Atención por Voz Humana (AVH): Medido en dos tramos como el porcentaje de llamadas atendidas: (i) dentro de los primeros 40 (cuarenta) segundos de iniciada la llamada por parte del usuario hasta acceder a la opción que 9 le permita comunicarse con un operador humano y (ii) dentro de los primeros 20 (veinte) segundos desde que el usuario elige la opción indicada en el numeral (i) hasta ser atendido por un operador humano. El procedimiento de medición y las metas mínimas de este indicador se describe en el Anexo E.

\section{TITULO V MEDICIÓN, METAS, DIFUSIÓN DE LOS INDICADORES DE CALIDAD DE} ATENCIÓN Artículo 15.- Metodología de Medición Los indicadores de calidad de atención establecidos en la presente norma deberán ser calculados con una periodicidad mensual y conforme a los criterios establecidos en cada uno de los Anexos A, B, C, D y E. Artículo $16^{\circ}$.- 
Metas de los Indicadores Las empresas operadoras deberán cumplir con las metas establecidas para cada uno de los indicadores de atención, conforme a lo dispuesto en los Anexos B, C, D y E. Artículo $17^{\circ}$.- Difusión de los Resultados de Medición Las empresas operadoras deberán publicar los resultados de la medición de sus respectivos indicadores de calidad de atención en el vínculo de "Información a Abonados y Usuarios" de sus páginas web de Internet, a que se hace referencia en las Condiciones de Uso. Esta información deberá mantenerse publicada en forma permanente en la página web de las empresas operadoras. Estos resultados deberán ser remitidos al OSIPTEL y publicados en forma mensual, de acuerdo a los formatos que se muestran en los Anexos F, G, H, I y J dentro de los quince (15) días hábiles siguientes al término del período de medición. El OSIPTEL elaborará cuadros estadísticos que permitan que los usuarios de las empresas operadoras puedan realizar un análisis comparativo respecto de la calidad de atención ofrecida por ellas.

TITULO VI MONITOREO DE LA SATISFACCION DEL USUARIO Artículo $18^{\circ}$.Monitoreo del OSIPTEL sobre la satisfacción del usuario El OSIPTEL realizará el monitoreo de la calidad de la atención a los usuarios por parte de las empresas operadoras, con la finalidad de conocer el nivel de satisfacción de los usuarios respecto a las atenciones brindadas en los canales de atención presencial y telefónico. Los resultados de dicho monitoreo deberán ser publicados en la página web institucional del OSIPTEL.

\section{TITULO VII REGIMEN DE INFRACCIONES Y SANCIONES 10 Artículo $19^{\circ}$.-} Infracciones y Sanciones Constituye infracción leve el incumplimiento por parte de la empresa operadora, de cualquiera de las disposiciones contenidas en los artículos: $4^{\circ}, 9^{\circ}, 15^{\circ}$ y $17^{\circ}$. Asimismo, constituyen infracciones graves los incumplimientos por parte de la empresa operadora, de cualquiera de las disposiciones contenidas en los artículos: $6^{\circ}, 8^{\circ}, 12^{\circ}$ y $16^{\circ}$. 


\section{ANEXO B PROCEDIMIENTO PARA LA MEDICIÓN Y CÁLCULO DEL INDICADOR DE TIEMPO DE ESPERA PARA LA ATENCIÓN PRESENCIAL (TEAP) OBJETIVO DEL INDICADOR}

Propiciar la disminución del tiempo de espera de los usuarios en las oficinas comerciales de las empresas operadoras, así como evitar la discriminación respecto al tipo de atención requerido. Cálculo mensual por oficina de atención y trámite: TEAPij = Número de atenciones personales por trámite y oficina en un mes, atendidas dentro los primeros 15 minutos de espera $\mathrm{x}$ 100 Número total de atenciones personales por trámite y oficina, en un mes Donde: $\mathrm{i}=$ nombre de la oficina de atención j = tipo de trámite (alta, baja, consulta y reclamo) atenciones personales $=$ constancias de arribo entregadas a los usuarios Nota: Los quince (15) minutos deben ser contabilizados desde la entrega al usuario de la constancia de arribo hasta que se inicia la atención al usuario. Se excluye de la medición las constancias de arribo entregadas para atención preferente. Cálculo mensual del indicador general: TEAP = Número total de atenciones personales en un mes, atendidas dentro de los primeros 15 minutos de espera x 100 Número total de atenciones personales en un mes Meta del TEAP general: Indicador mensual/ Año Año 1 Año 2 Año 3 Año 4 en adelante TEAP 55\% 65\% 75\% 80\% Unidad de Medida: Porcentajes Meta del TEAP específica: En ningún caso el valor del TEAPij deberá ser inferior al $40 \%$.

17 ANEXO G INDICADOR TIEMPO DE ESPERA PARA ATENCIÓN PRESENCIAL FORMATO DE PRESENTACIÓN EN PÁGINA WEB EMPRESA: AÑO: MES: INDICADOR: TIEMPO DE ESPERA PARA ATENCIÓN PRESENCIAL (TEAP) OBJETIVO: Medir el porcentaje de los usuarios que esperaron menos de 15 minutos. OFICINAS RECLAMOS BAJAS CONSULTAS ALTAS TOTAL 
Teniendo en consideración lo anteriormente señalado, el OSIPTEL se encuentra habilitado para establecer normas de protección de los derechos de los usuarios e indicadores vinculados con el grado de satisfacción de éstos. Cabe señalar que, la calidad de la atención a los usuarios debe constituirse en un elemento importante de las condiciones del servicio prestado por las empresas operadoras, debe constituirse en un factor de competencia en el mercado, en la medida que la aplicación de los estándares de calidad pueda ser conocida por los usuarios en general, y pueda influir en las decisiones de elección del consumidor. En tal sentido, atendiendo al crecimiento del mercado de los servicios públicos de telecomunicaciones, en especial de los servicios de telefonía fija y servicios públicos móviles y, por tanto, el incremento de los usuarios de estos servicios, los cuales requieren y esperan de las empresas operadoras una atención de calidad, corresponde al OSIPTEL velar porque los usuarios accedan a los servicios de atención en forma eficiente y adecuada, a través del establecimiento de estándares mínimos de atención en los trámites que decidan realizar. 22 En consecuencia, mediante esta norma el OSIPTEL tiene como objetivos principales: - Promover la mejora continua de la calidad de la atención que brindan las empresas operadoras a sus usuarios. - Evitar que se generen desincentivos en los usuarios para el cabal ejercicio de sus derechos. - Obtener información sobre la gestión y organización de las empresas operadoras para la atención de los trámites que decidan realizar los usuarios. - Medir la capacidad de respuesta de las empresas operadoras para la atención de los trámites de los usuarios. - Establecer indicadores que garanticen la adecuada atención del usuario en los canales de atención telefónica y presencial establecidos por las empresas operadoras. Ámbito de aplicación (Artículo $2^{\circ}$ ) Las decisiones relativas a la mejora de la calidad de atención de las empresas operadoras deben estar enfocadas a la atención brindada por aquellas empresas que cuentan con un número tal de abonados, que pueda dar lugar a ciertas ineficiencias en la 
atención y calidad de la misma. El mercado de telecomunicaciones es dinámico y muestra tendencias de crecimiento, tanto en el número de abonados que reciben los servicios prestados, como en la cantidad y variedad de los mismos. Asimismo, existen numerosas empresas que cuentan con concesión para brindar cada uno de los servicios públicos de telecomunicaciones, muchas de ellas brindan servicios en un ámbito regional, contando con relativamente pocos abonados

INDICADORES TIEMPO DE ESPERA PARA ATENCION PRESENCIAL FORMATO DE PRESENTACION ENPAGINA WEB

Empresa:

Año:

Mes:

Indicadores: Tiempo de espera para atención presencial (TEAP)

\begin{tabular}{|c|c|c|c|c|c|c|}
\hline \multicolumn{2}{|l|}{ OFICINAS } & RECLAMOS & BAJAS & CONSULTAS & ALTAS & TOTAL \\
\hline \multirow[t]{3}{*}{ OFICINAS A } & $\begin{array}{l}\text { Nro de atenciones con } \\
\text { espera menor de } 5 \text { min }\end{array}$ & & & & & \\
\hline & Nro de atenciones totales & & & & & \\
\hline & $\%(\mathrm{TEAPij})$ & $\%$ (TEAPa1) & $\%$ (TEAPa2) & $\%($ TEAPa3) & $\%$ (TEAPa4) & $\%$ (TEAPa5) \\
\hline \multirow[t]{2}{*}{ OFICINAS B } & $\begin{array}{l}\text { Nro de atenciones con } \\
\text { espera menor de } 5 \text { min }\end{array}$ & & & & & \\
\hline & Nro de atenciones totales & & & & & \\
\hline
\end{tabular}




\begin{tabular}{|c|c|c|c|c|c|c|}
\hline & $\%($ TEAPij) & $\%(\mathrm{TEAPb} 1)$ & $\%(\mathrm{TEAPb} 2)$ & $\%(\mathrm{TEAPb} 3)$ & $\%(\mathrm{TEAPb} 4)$ & $\%(\mathrm{TEAPb} 5)$ \\
\hline \multirow[t]{3}{*}{ OFICINAS C } & $\begin{array}{l}\text { Nro de atenciones con } \\
\text { espera menor de } 5 \text { min }\end{array}$ & & & & & \\
\hline & Nro de atenciones totales & & & & & \\
\hline & $\%($ TEAPij) & $\%$ (TEAPc1) & $\%$ (TEAPc2) & $\%$ (TEAPc3) & $\%$ (TEAPc4) & $\%$ (TEAPc5) \\
\hline \multirow[t]{3}{*}{ TOTAL } & $\begin{array}{l}\text { Nro de atenciones con } \\
\text { espera menor de } 5 \text { min }\end{array}$ & & & & & \\
\hline & Nro de atenciones totales & & & & & \\
\hline & $\%($ TEAPj) & $\%($ TEAP1) & $\%$ (TEAP2) & $\%$ (TEAP3) & $\%$ (TEAP4) & $\%$ (TEAP5) \\
\hline
\end{tabular}

Nota se refiere al nombre de la oficina; j se refiere al tipo de trámite 


\section{Anexo 3. Encuesta de IPSOS por encargo de OSIPTEL}

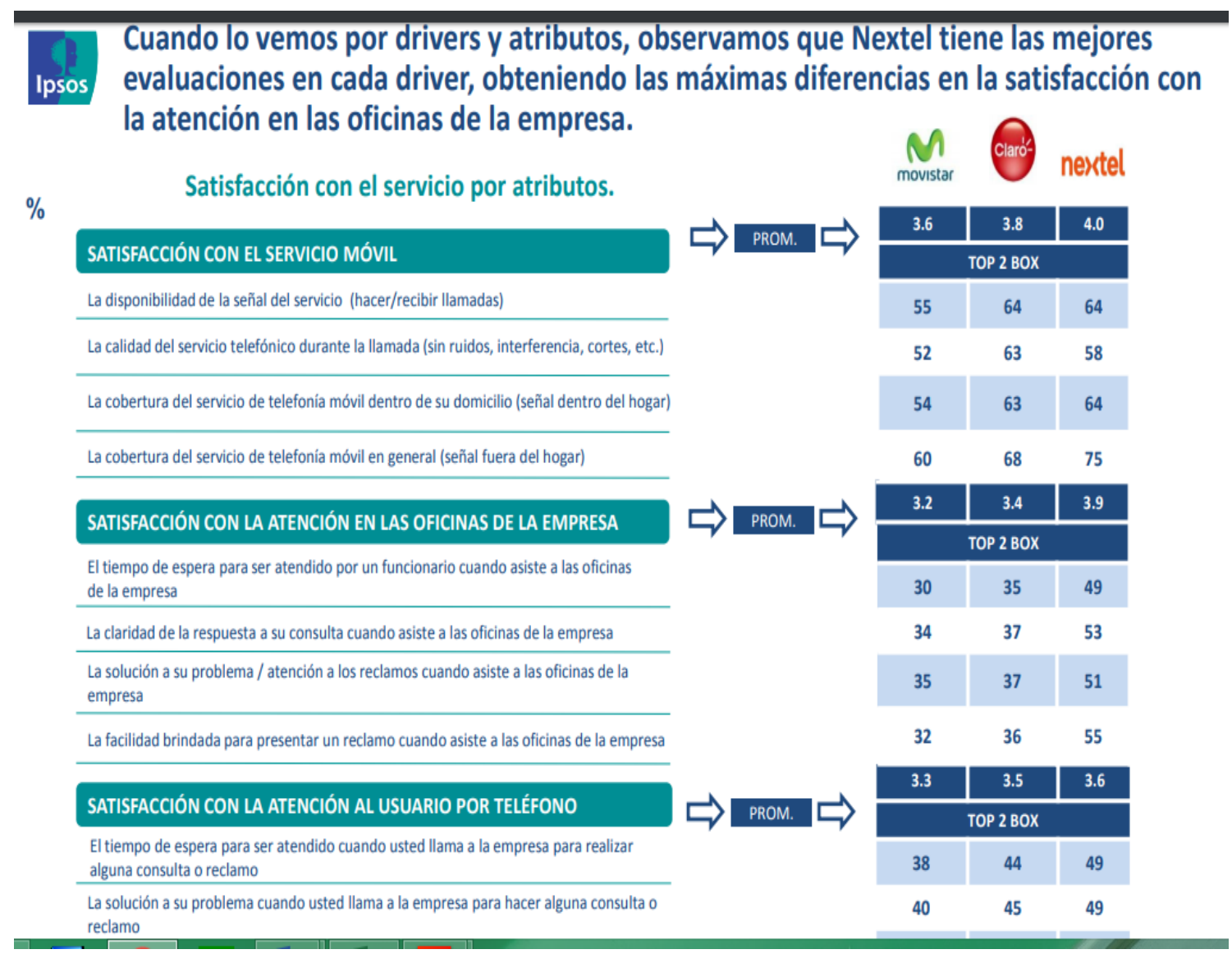


Anexo 4. Relación de tiendas de TDP a nivel nacional

\begin{tabular}{|c|c|c|}
\hline NÚMERO & SOCIO & TIENDA \\
\hline 1 & ATENTO & San Isidro - Camino Real \\
\hline 2 & ATENTO & Cercado - CC Centro Cívico \\
\hline 3 & ATENTO & Huánuco - 28 de Julio \\
\hline 4 & ATENTO & Pucallpa - Tarapacá \\
\hline 5 & ATENTO & Callao - CC Minka \\
\hline 6 & ATENTO & Tarapoto - Leguía \\
\hline 7 & ATENTO & Pucallpa - CC Open Plaza \\
\hline 8 & ATENTO & Huánuco - CC Real Plaza \\
\hline 9 & ATENTO & Iquitos - Arica \\
\hline 10 & ATENTO & Miraflores - Benavides \\
\hline 11 & BOUTIQUE CELULAR & Arequipa - Ejercito \\
\hline 12 & BOUTIQUE CELULAR & Huancayo - Cusco \\
\hline 13 & BOUTIQUE CELULAR & Cusco - CC Real Plaza \\
\hline 14 & BOUTIQUE CELULAR & Juliaca - San Martin \\
\hline 15 & BOUTIQUE CELULAR & Arequipa - Moran \\
\hline 16 & BOUTIQUE CELULAR & Puno - Arequipa \\
\hline 17 & BOUTIQUE CELULAR & Juliaca - CC Real Plaza \\
\hline 18 & BOUTIQUE CELULAR & Moquegua - Ancash \\
\hline 19 & BOUTIQUE CELULAR & Puno - Moore \\
\hline 20 & BOUTIQUE CELULAR & Ilo - Abtao \\
\hline 21 & BOUTIQUE CELULAR & Tacna - Zela \\
\hline 22 & BOUTIQUE CELULAR & Tacna - Deustua \\
\hline 23 & BOUTIQUE CELULAR & Mollendo - Arequipa \\
\hline 24 & CISESAC & Piura - Libertad \\
\hline 25 & CISESAC & Huaraz - Luzuriaga \\
\hline 26 & CISESAC & Talara - Centro Cívico \\
\hline 27 & CISESAC & Pucallpa - Coronel Portillo \\
\hline 28 & CISESAC & Iquitos - Huallaga \\
\hline 29 & CISESAC & Chimbote - Bolognesi \\
\hline 30 & CISESAC & Huaraz - San Martin \\
\hline 31 & CISESAC & Trujillo - Grau \\
\hline 32 & CISESAC & Chepen - Cajamarca \\
\hline 33 & CISESAC & Moyobamba - Pedro Canga \\
\hline 34 & CISESAC & Tarapoto - Morey \\
\hline 35 & COMPUTER PHONE CENTER & Piura - Tacna \\
\hline 36 & CONTACTO SATELITAL & San Juan de Miraflores - San Juan \\
\hline 37 & CONTACTO SATELITAL & Villa El Salvador - Juan Velasco \\
\hline 38 & DIAL & Trujillo - Larco \\
\hline 39 & DIAL & Piura - CC Open Plaza \\
\hline
\end{tabular}




\begin{tabular}{|c|c|c|}
\hline NÚMERO & SOCIO & TIENDA \\
\hline 40 & DIGITAL & Cusco - Mayuri \\
\hline 41 & DIGITAL & Ayacucho - Asamblea \\
\hline 42 & DIGITAL & Abancay - Venezuela \\
\hline 43 & DIGITAL & Andahuaylas - Pesce \\
\hline 44 & DIGITAL & Huancavelica - Virrey Toledo \\
\hline 45 & DIGITAL & Quillabamba - De la Torre \\
\hline 46 & DIGITAL & Puerto Maldonado - Puno \\
\hline 47 & DIGITAL & Sicuani - Grau \\
\hline 48 & GLOBALNET COMUNICACIONES & Ayacucho - Lima \\
\hline 49 & LIDERES-SIC & Independencia - CC Mega Plaza \\
\hline 50 & LIDERES-SIC & Santa Anita - CC Mall Aventura Plaza \\
\hline 51 & LIDERES-SIC & Cercado - Bolivia \\
\hline 52 & LIDERES-SIC & Huancayo - CC Real Plaza \\
\hline 53 & LIDERES-SIC & San Juan de Lurigancho - Gran Chimu \\
\hline 54 & LIDERES-SIC & San Borja - CC Real Plaza Primavera \\
\hline 55 & LIDERES-SIC & Puente Piedra - Mdo Huamantanga \\
\hline 56 & LIDERES-SIC & Cerro de Pasco - Circunvalación \\
\hline 57 & LIDERES-SIC & Tarma - Arequipa \\
\hline 58 & LIDERES-SIC & Pueblo Libre - Sucre \\
\hline 59 & MACLABI & Chiclayo - Eufemio Lora \\
\hline 60 & MACLABI & Trujillo - CC Mall Aventura Plaza \\
\hline 61 & MACLABI & Cajamarca - CC El Quinde \\
\hline 62 & MACLABI & Chachapoyas - Ayacucho \\
\hline 63 & MACLABI & Cajamarca - Angamos \\
\hline 64 & MEGA TECH & Nazca - Arica \\
\hline 65 & OVERLANDES-NEXXO & San Miguel - CC San Miguel \\
\hline 66 & OVERLANDES-NEXXO & Independencia - CC Plaza Lima Norte \\
\hline 67 & OVERLANDES-NEXXO & Surco - CC Jockey Plaza \\
\hline 68 & OVERLANDES-NEXXO & Chorrillos - Plaza Lima Sur \\
\hline 69 & OVERLANDES-NEXXO & Los Olivos - Las Palmeras \\
\hline 70 & OVERLANDES-NEXXO & Ica-Bolívar \\
\hline 71 & OVERLANDES-NEXXO & Surco - Aviación \\
\hline 72 & OVERLANDES-NEXXO & Breña - CC La Rambla Brasil \\
\hline 73 & OVERLANDES-NEXXO & San Juan de Miraflores - CC Atocongo \\
\hline 74 & OVERLANDES-NEXXO & Ica - CC El Quinde \\
\hline 75 & OVERLANDES-NEXXO & Ica - Huánuco \\
\hline 76 & OVERLANDES-NEXXO & Chincha - 28 de Julio \\
\hline 77 & OVERLANDES-NEXXO & Pisco - Bolognesi \\
\hline 78 & SALESLAND & Cercado - Jirón de la Unión \\
\hline 79 & SALESLAND & San Borja - Javier Prado \\
\hline 80 & SALESLAND & Piura - CC Real Plaza \\
\hline
\end{tabular}




\begin{tabular}{|c|c|c|}
\hline NÚMERO & SOCIO & TIENDA \\
\hline 81 & SALESLAND & San Juan de Miraflores - CC Mall del Sur \\
\hline 82 & SALESLAND & Tumbes - San Martin \\
\hline 83 & SALESLAND & Tacna - San Martin \\
\hline 84 & SALESLAND & Cajamarca - Comercio \\
\hline 85 & SALESLAND & Arequipa - CC Mall Aventura Plaza \\
\hline 86 & SALESLAND & Jesús María - CC Real Plaza Salaverry \\
\hline 87 & SALESLAND & Huacho - CC Plaza El Sol \\
\hline 88 & SALESLAND & La Victoria - CC Canepa \\
\hline 89 & SALESLAND & Huacho - San Martin \\
\hline 90 & SERVICIOS DIGITALES & Chiclayo - Cervantes \\
\hline 91 & SERVICIOS DIGITALES & Sullana - San Martin \\
\hline 92 & SERVICIOS DIGITALES & Jaén - Mariscal Ureta \\
\hline 93 & TDP & San Isidro - Juan de Arona \\
\hline 94 & TDP & Arequipa - Los Arces \\
\hline 95 & TDP & Huancayo - Real \\
\hline 96 & TDP & Piura - Loreto \\
\hline 97 & TDP & Chimbote - Tumbes \\
\hline 98 & TDP & Chiclayo - Elías Aguirre \\
\hline 99 & TDP & Trujillo - Bolívar \\
\hline 100 & TDP & Cusco - El Sol \\
\hline 101 & VISATECH & Arequipa - CC Mall Plaza Cayma \\
\hline
\end{tabular}




\section{Anexo 5. Cálculo del MPC}

Para realizar el cálculo del MPC, primero se han determinado los factores de éxito y su ponderación, los mismos que están divididos en dos grupos el primero y de más peso contiene los factores que influyen en los ingresos de la franquicia, y el segundo grupo se encuentran los factores que son determinantes para obtener los resultados que busca tanto TDP como digital tal como se muestra a continuación:

\begin{tabular}{|c|c|c|c|c|}
\hline \multirow{5}{*}{$\begin{array}{l}\text { Contraprestación } \\
\text { económica }\end{array}$} & \multirow{5}{*}{$75 \%$} & Tiempos (nivel de espera) & $25 \%$ & El $60 \%$ del pago depende de este factor \\
\hline & & Resolutividad en la atención & $15 \%$ & El $15 \%$ del pago depende de este factor \\
\hline & & Personal Capacitado & $15 \%$ & \multirow{3}{*}{ El $25 \%$ del pago depende de este factor } \\
\hline & & Calidad de Atención & $10 \%$ & \\
\hline & & Empatía del personal & $10 \%$ & \\
\hline \multirow{4}{*}{ Soporte operativo } & \multirow{4}{*}{$25 \%$} & Participación de mercado & $10 \%$ & \\
\hline & & Procesos & $5 \%$ & \\
\hline & & Productividad del Personal & $5 \%$ & \\
\hline & & Capilaridad & $5 \%$ & \\
\hline
\end{tabular}

En segundo lugar, se ha procedido con la calificación de las tres empresas, para lo cual se realizó el siguiente procedimiento:

Tiempo de Espera. - Conocido como NDS, es el factor más relevante porque de este depende el $60 \%$ de los ingresos que pueden tener las franquicias, así como también las multas que podría poner OSIPTEL, si estas no cumplen con llegar al mínimo de 80\% mensual. Para la calificación se ha tomado como datos el resultado de NDS, y su ponderación de acuerdo al resultado de cada franquicia como se muestra en el siguiente cuadro: 


\begin{tabular}{|l|r|c|}
\hline Franquicia & \multicolumn{1}{|c|}{ NDS } & Puntaje \\
\hline Boutique & $83.38 \%$ & 4 \\
\hline TDP & $68.77 \%$ & 2 \\
\hline Digital & $87.16 \%$ & 4 \\
\hline
\end{tabular}

Resolutividad.- Este factor mide si los clientes satisfechos han indicado que su consulta, reclamo u avería, ha sido solucionado, resultado que sale del IVR (encuesta realizada al cliente). Para esta calificación se realiza una comparación de resultados del porcentaje de clientes satisfechos, porcentaje de resolutividad versus el número de atenciones como se muestra en el siguiente cuadro:

\begin{tabular}{|l|r|r|r|r|c|}
\hline Franquicia & Atenciones & Resolutividad SI & Satisfacción & $\begin{array}{c}\text { Satisfacción } \\
+ \\
\text { Resolución }\end{array}$ & Puntaje \\
\hline Boutique & 5023 & $58.00 \%$ & $28.51 \%$ & 830.59 & 2 \\
\hline TDP & 7544 & $50.00 \%$ & $16.66 \%$ & 628.42 & 1 \\
\hline Digital & 5536 & $60.00 \%$ & $39.42 \%$ & 1309.37 & 3 \\
\hline
\end{tabular}

Personal capacitado - Productividad del personal. - En estos dos puntos se ha tomado como base el número de atenciones el mismo que se ha dividido entre el número de asesores tal como se muestra en el siguiente cuadro:

\begin{tabular}{|l|r|r|r|c|}
\hline \multicolumn{1}{|c|}{ Franquicia } & Atenciones & \multicolumn{1}{|c|}{ Asesores } & & Puntaje \\
\hline Boutique & 5023 & 14 & 358.79 & 2 \\
\hline TDP & 7544 & 15 & 502.93 & 2 \\
\hline Digital & 5536 & 12 & 461.33 & 2 \\
\hline
\end{tabular}

Calidad de atención - Empatía del personal - Procesos. - Estos tres puntos están directamente relacionados al IVR, puesto que, de la calidad en la atención, y la empatía del personal depende 
que el cliente termine satisfecho, por otro lado, influye el flujo de los procesos para poder cumplir con los indicadores:

\begin{tabular}{|l|r|c|}
\hline Franquicia & \multicolumn{1}{c|}{ IVR } & Puntaje \\
\hline Boutique & $28.51 \%$ & 2 \\
\hline TDP & $16.66 \%$ & 1 \\
\hline Digital & $39.42 \%$ & 3 \\
\hline
\end{tabular}

Participación de mercado - Capilaridad. - Para estos dos puntos se ha tomado en cuenta el número de tiendas que tiene cada franquicia en la zonal Cusco donde las tres tienen participación, como se puede observar en el siguiente cuadro:

\begin{tabular}{|l|r|c|}
\hline Franquicia & $\mathbf{N}^{\circ}$ Tiendas & Puntaje \\
\hline Digital & 6.00 & 4 \\
\hline TDP & 1.00 & 1 \\
\hline Boutique & 1.00 & 1 \\
\hline
\end{tabular}

Encuesta para determinar los factores de éxito para la Matriz del Perfil Competitivo

Nombre: Wilber Vargas Valencia

\section{Empresa: Telefónica del Perú}

\section{Cargo: Jefe Zonal}

1.- Tomando en cuenta, el modelo del contrato de franquicia (2017), cuáles cree usted que son los atributos más importantes que debe tener las franquicias en su zonal respecto a:

1. Capilaridad

2. Capacidad de Ejecución (X)

3. Personal

2.-De todos los atributos antes mencionados cuáles cree usted que son los más importantes 
Rpta.- El modelo comisional de atención toma en consideración la valoración del Cliente y la Comisión del NDS; por ello, es necesario que las acciones y planes establecidos de gestión tenga como prioridad una efectiva ejecución.

3.-Tomando en cuenta que en su zonal existen 2 franquicias y una tienda propia, cómo las calificaría usted (donde 1 es menor desempeño y 4 mayor desempeño) respecto a:

Personal capacitado

TDP (2) Digital (3) Boutique (2)

Procesos

TDP (3) Digital (3) Boutique (2)

Productividad del personal

TDP (1) Digital (3) Boutique (1)

Capilaridad

TDP (1) Digital (3) Boutique (1)

Participación de mercado

TDP (1) Digital (3) Boutique (1)

Calidad de atención

TDP (1) Digital (3) Boutique (1) 
Empatía del personal

TDP (1) Digital (3) Boutique (1)

Resolutividad en la atención

TDP (2) Digital (3) Boutique (1)

Tiempos (nivel de espera)

TDP (1) Digital (3) Boutique (2) 


\section{Anexo 6. Entrevista a funcionarios de Digital}

\section{Entrevistado: Fernando Tejeda San Román}

Posición: Gerente de Móviles

Lugar: Cusco

Fecha: agosto 2018

1. ¿Cuáles son las funciones principales que tiene a su cargo?

- Establecer objetivos generales y específicos de las áreas de móviles.

- Gestionar y adecuar los recursos para un mejor desempeño.

- Lograr tener una comunicación fluida dentro y a través de la empresa que permitan conseguir los objetivos de cada área de móviles.

- Mantener las mejores relaciones con el personal y exigir el cumplimiento de sus funciones.

- Concertar y conseguir compromiso del personal de la agencia con su empresa.

2. ¿Cuál es el principal objetivo de su área?

- Lograr que las áreas involucradas (Almacén, Ventas, Postventa, etc.) de la gestión de Móviles cumplan con sus objetivos cualitativos y cuantitativos, con ello lograr la rentabilidad esperada. 
3. ¿Cuáles considera usted las fortalezas y debilidades de la empresa Digital Comunicaciones S.A.C?

Fortalezas:

- Posicionamiento solido de las tiendas en cada sede o ciudad.

- $\quad$ Personal de línea y staff Capacitado.

- Espalda Financiera Sólida.

- Mobiliario y Equipamiento adecuado y consistente.

- Procesos internos de administración y control adecuados.

- Abastecimiento asegurado y permanente.

- Buena imagen institucional ante TdP

Debilidades:

- Sueldos congelados y/o poco competitivos con el mercado.

- Personal subalterno poco capacitado.

- Alta rotación del personal subalterno.

- Liderazgo débil en algunas de las tiendas

- Todos nuestros sistemas de atención dependen de Telefónica Movistar y fallan continuamente.

- Restricciones para la venta en calle : Biométrico.

4. De las debilidades mencionadas, ¿cuáles considera deberían ser prioridad para mejorarlas en los próximos 3 años? ¿Por qué? 
- La capacitación del personal, porque permitiría mejorar los indicadores de atención y venta. Importante porque ayudaría a mejorar la comprender las directivas y ser más eficientes en su ejecución,

- Fortalecer el liderazgo de los Jefes de Tienda para que tengamos tiendas con mayor autonomía y proactividad.

5. ¿Cuáles son los principales riesgos a los que se enfrenta Digital comunicaciones en el corto, mediano y largo plazo?

\section{CORTO:}

- El crecimiento muy agresivo de Bitel en las localidades donde se tiene presencia con tiendas, puede influenciar en la caída de nuestras ventas.

- Las condiciones climatológicas adversas que afectan la asistencia y la atención de los clientes a nuestras tiendas

- Cambios en la Política de pagos de atención y comisiones de parte de TdP. MEDIANO:

- Presencia de nuevos competidores en el servicio de Postventa y Venta con mayor solidez y capacidad económica.

- Mercado más adverso que el actual. Pérdida de mercado sustancial de parte de Telefónica Móviles en las zonales donde operamos.

\section{LARGO PLAZO:}

- Pérdida de licencias de parte de TdP 
- Venta de TdP a otro operador

6. ¿Cuáles son los principales retos que enfrenta la empresa en los próximos 3 años en cuanto posibilidades de expansión de la empresa?

- Los costos de poner una nueva Tienda son bastante altos y bajos y bajo el diseño de franquicia los retos son aún mayores.

- Superar las restricciones que pone TdP para otorgar nuevas tiendas de Postventa.

○ Lograr una mejorar en la calificación de los indicadores de Postventa (NDS, IST etc.)

- Crecer en el número de atenciones diarias en las tiendas.

- Mantener un crecimiento sostenido de las ventas en móviles e incrementar fuertemente en la Fija.

- El tener la capacidad de adaptarnos a las nuevas condiciones que pueda dar Telefónica del Perú.

7. ¿Cuáles son las principales oportunidades que tiene la empresa en los próximos 3 años respecto al crecimiento de las telecomunicaciones?

- Por las inversiones que se están ejecutando en el país y por los cambios que se vienen dando en las operadoras, es oportunidad para la agencia de crecer en ventas de Fija, de equipos con mayores planes de datos móviles y de atender otros territorios.

8. ¿Considera que las políticas de libre mercado son amenaza para la empresa? 
- Depende, la competencia permite que una empresa mejore, incrementa la creatividad y es una oportunidad para hacer benchmarking, pero la competencia también puede ser desleal y conlleva un riesgo grande de pérdida de mercados, pueden entrar competidores muy fuertes y desplazarte de tu posición sea por costos, por eficiencias o por malas artes. Por lo que siempre hay que estar monitoreando a la competencia y sus acciones para no perder las oportunidades que se presenten

9. Recursos clave (físicos, intelectuales, capital humano, financieros)

- Capital humano fuerte y valioso en el staff y en los mandos medios.

- Respaldo Financiero sólido

- Procesos de atención bastante prolijos y muy buen manejo por los encargados.

- Infraestructura adecuada a la labor que se desempeña.

10. ¿Cómo considera usted la atención al usuario interno dentro de la empresa y cómo se podría mejorar y marcar la diferencia?

- Considero que es la adecuada en este momento, pero siempre hay oportunidad de mejora. Por ejemplo se podría continuar con el proyecto de apoyo al estudio del personal para tener personal promedio de un mejor perfil.

11. ¿Cuán es importante creo Ud. a la Resolutividad en cuanto a la atención al cliente? 
- Es muy importante llegar a resolver un problema del cliente, porque la NO resolución trae expresiones y sentimiento de frustración en el cliente que repercuten en la calificación de toda la atención de la tienda que muchas veces no son responsabilidad de la agencia sino de los sistemas de TdP. El problema básico de la resolución de un problema no siempre depende de nuestro personal, sino por lo mismos procesos depende de TdP.

12. ¿Considera que el tiempo de espera por el cliente (NDS) está dentro de lo permitido por OSIPTEL y Telefónica del Perú S.A.A? ¿Por qué?

- No, TdP lo mantiene ajustado a tiempos mucho más cortos que la directiva de OSIPTEL y lo que logra es obligarnos a llegar a sus parámetros que son superiores a los de OSIPTEL, de esta forma no tiene problemas con la entidad regulatoria y sino como empresa no llegamos a los que piden, los pagos son menores o no nos paga.

13. ¿Cuáles considera que son las principales empresas competidores de Digital? ¿Por qué?

Enumerar de más representativa a menos representativa

- Boutique Celular

- $\quad$ Multicentro de TdP 
14. ¿Ud. considera que está en crecimiento la industria en telecomunicaciones? ¿Por qué?

$\mathrm{Si}$, porque existen nuevos productos y nuevos usos; las telecomunicaciones siguen creciendo en variedad y calidad y porque en el futuro muy cercano la integración con otros servicios (financieros, gobiernos, educativos, etc.) será más importante, fuerte y de menores costos.

15. ¿Cómo consideras el posicionamiento de Digital en el mercado de Telecomunicaciones? ¿Por qué?

- Nuestro posicionamiento es muy bueno, por varias cosa; la seriedad de la empresa cuando emprende nuevos retos y proyectos, la velocidad de respuesta frente a cambio propios de la operadora y/o de la competencia y al nivel de ventas que representa la empresa en cada localidad, ocurre por ejemplo que en algunas localidades somos los únicos representantes de TdP.

16. ¿Cómo considera los procesos de control interno de la empresa de Digital? ¿Por qué?

- Bastante aceptables, ya que contamos con áreas de supervisión y de auditoría, las que se realizan permanente y muchas de ellas bajo cierta programación. 


\section{Entrevistado: Edith Robles Cáceres}

Posición: Gerente de Fija

Lugar: Cusco

Fecha: agosto 2018

1. ¿Cuáles son las funciones principales que tiene a su cargo?

- Gestionar y coordinar el cumplimiento de venta y postventa de Fijas establecido por Telefónica.

- Coordinar las contrataciones y ceses del personal de acuerdo a la necesidad de las tiendas, con la Gerencia de Recursos Humanos.

- Gestionar el correcto funcionamiento de todas las Áreas que comprenden las tiendas franquicias (jefatura, atención al cliente, caja, anfitrionaje, almacén, seguridad).

- Coordinar abastecimiento de los bienes a las tiendas.

- Revisar y analizar los resultados de los indicadores exigidos por Telefónica y armar estrategias para el cumplimiento de estos todos los meses.

2. ¿Cuál es el principal objetivo de su área?

- Cumplimiento de todos los indicadores fijados por Telefónica para venta y postventa para asegurar los ingresos de la empresa por este canal.

3. ¿Cuáles considera usted las fortalezas y debilidades de la empresa Digital Comunicaciones S.A.C? 
Fortalezas:

- Cuenta con 18 años de funcionamiento dentro de las cuales ha podido gestionar los cambios todos los cambios que Telefónica decide implementar

- Buena relación comercial con Telefónica.

- Personal con experiencia.

- Buena gestión financiera.

- Procesos logísticos ordenados y controlados

Debilidades:

- Sueldos poco atractivos.

- Régimen laboral con condiciones no convenientes para los trabajadores.

- Personal con déficit de capacitación o preparación en algunas posiciones (ventas).

- Alta rotación de personal.

- Inconvenientes para captar personal con características de liderazgo en algunas ciudades.

- Penalidades altas por venta fijadas por Telefónica que desaniman a los vendedores.

- Inconvenientes con los sistemas y aplicativos que no permiten o dificultan el cumplimiento de los objetivos (sistemas de Telefónica).

- Que tiene un único socio comercial el cual determina los ingresos y penalidades quitando cualquier poder de negociación a Digital 
4. De las debilidades mencionadas, ¿cuáles considera deberían ser prioridad para mejorarlas en los próximos 3 años? ¿Por qué?

- Personal con déficit de capacitación o preparación en algunas posiciones (ventas).

- Que tiene un único socio comercial el cual determina los ingresos y penalidades quitando cualquier poder de negociación a Digital

- Sueldos poco atractivos.

5. ¿Cuáles son los principales riesgos a los que se enfrenta Digital comunicaciones en el corto, mediano y largo plazo?

Para el corto plazo:

- La competencia en el Perú y el ingreso de nuevas empresas transnacionales que hacen que se repartan el mercado entre más competidores.

- Constantes modificaciones de las condiciones de pago de Telefónica lo cual también afecta directamente en los ingresos de la empresa.

Para el mediano plazo:

- Perdida de presencia y participación de mercado de Telefónica a nivel nacional

- Riesgo reputacional de Telefónica relacionado al servicio que brinda al cliente.

- El fortalecimiento de otros socios comerciales que propicia Telefónica para debilitar a otros socios como Digital, siendo estos nuestra competencia directa. 
- Cambios en directivos en Telefónica que buscan intereses personales ponen en riesgo la permanencia de Digital en algunas ciudades.

Para largo plazo

- Se Telefónica se retire del Perú y venda la empresa.

6. ¿Cuáles son los principales retos que enfrenta la empresa en los próximos 3 años en cuanto posibilidades de expansión de la empresa?

- Cumplir con los indicadores y exigencias puestas por Telefónica, con la finalidad de mantener los ingresos y las utilidades.

- Adquirir una nueva tienda de presentarse.

- Lograr una mayor productividad de los recursos humanos a través de capacitación y mejora remunerativa lo cual generará compromiso a mediano plazo.

7. ¿Cuáles son las principales oportunidades que tiene la empresa en los próximos 3 años respecto al crecimiento de las telecomunicaciones?

- Digital depende de las inversiones que pueda hacer Telefónica para mejorar las condiciones competitivas para sus clientes o crecer en el mercado, esperemos que la mejora del servicio y las inversiones que están haciendo otros operadores motiven a Telefónica para mejorar sus condiciones y su servicio. 
8. ¿Considera que las políticas de libre mercado son amenaza para la empresa?

- La competencia potencia los mercados y mejora las condiciones para los consumidores principalmente, pero; también permite que las empresas refuercen otros aspectos de los que no se preocupaban en hacerlo cuando no tenían competencia, el nivel de exigencia en el servicio tiene que mejorar, se crean nuevos mecanismos de ventas, se mejora la publicidad de la empresa, pero; si no hay un control adecuado en la guerra de precios que se genera por la competencia se puede maltratar el mercado perjudicando a la empresa en sus márgenes de ingresos.

9. Recursos clave (físicos, intelectuales, capital humano, financieros)

- Recurso Humano capacitado y fidelizado en Áreas Claves.

- Solidez financiera, bajo nivel de endeudamiento.

- Infraestructura adecuada.

10. ¿Cómo considera usted la atención al usuario interno dentro de la empresa y cómo se podría mejorar y marcar la diferencia?

- Mejorar el sistema de comunicación muchas veces el aviso por mail no se entiende como realmente se quiere, así mismo para las tiendas más lejanas contactarse directamente haciendo uso de la tecnología sesiones virtuales. 
11. ¿Cuán es importante creo Ud. a la Resolutividad en cuanto a la atención al cliente?

- La resolutividad debe terminar en un cliente satisfecho, eso repercute en la reputación de la tienda y la calidad de atención, la limitación es que para resolver el problema la mayoría de las veces necesitamos aplicar los procesos de Telefónica que muchas veces demoran y son tediosos.

12. ¿Considera que el tiempo de espera por el cliente (NDS) está dentro de lo permitido por OSIPTEL y Telefónica del Perú S.A.A? ¿Por qué?

- El NDS acumulado con tiempo de espera de 15 minutos cuyo objetivo es del 84\%, SI está dentro de los parámetros estipulados y manejables de acuerdo a la realidad, pero; las modificaciones en las exigencias que hace Telefónica del NDS por hora condicionando el pago de las atenciones solo a las que están dentro del objetivo considero que si son exageradas, si se reduce el tiempo de espera se puede mejorar la satisfacción de los clientes, pero; no es justo que no paguen las atenciones que superan estos tiempos de espera.

13. ¿Cuáles considera que son las principales empresas competidores de Digital? ¿Por qué?

Enumerar de más representativa a menos representativa

- Multicentro

- Salesland 


\section{- Corporación SIC}

La primera tiene todas las otras tiendas de venta y postventa de la ciudad de Cusco, el principal mercado de Digital Comunicaciones y ha sido empoderada por Telefónica.

La segunda es otro socio que tiene pretensiones de ingresar a los mercados que actualmente tenemos y también está respaldado por Telefónica.

14. ¿Ud. considera que está en crecimiento la industria en telecomunicaciones? ¿Por qué?

La industria de las telecomunicaciones está en constante crecimiento ya que cada vez se van sacando al mercado nuevos servicios, aplicaciones, equipos, etc, como todas las industrias que están ligadas a la tecnología.

15. ¿Cómo consideras el posicionamiento de Digital en el mercado de Telecomunicaciones? ¿Por qué?

- Digital Comunicaciones es la empresa mejor posicionada en la zonal Cusco (CuscoApurimac y Madre de Dios), además; llegamos a mercados más lejanos como Ayacucho y Huancavelica, este posicionamiento se logra por las ventajas competitivas que tiene la empresa y porque abarca varios canales que también se trabajan con Telefónica. 
16. ¿Cómo considera los procesos de control interno de la empresa de Digital? ¿Por qué?

- Los procesos de control interno se han ido mejorando con el tiempo y con la experiencia y considero que a la fecha se ha avanzado bastante, ya que contamos con un sistema propio que nos permite controlar los almacenes y las cajas que son las áreas con mayor riesgo y con personal que se encarga de llevar este control de manera exclusiva.

\section{Entrevistado: Patricia Balcázar Del Barco}

Posición: Supervisora de Post Venta

Lugar: Cusco

Fecha: junio 2018

1. ¿Cuáles son las funciones principales que tiene a su cargo?

- Seguimiento y monitoreo de los principales KPIS de atención (Satisfacción de clientes IVR, Nivel de servicio, Solución de reclamos ) 
- Relacionamiento entre Telefónica y Digital Comunicaciones y entre otros Socios y Digital Comunicaciones.

- Detectar oportunidades de mejora en las tiendas.

- Soporte a los Jefes de Tienda con las casuísticas e incidencias que se presentan de manera diaria en la atención.

2. ¿Cuál es el principal objetivo de su área?

- Seguimiento y cumplimiento de los Indicadores de gestión logrando la rentabilidad de la empresa.

3. ¿Cuáles considera usted las fortalezas y debilidades de la empresa Digital?

- Debilidades

Personal poco comprometido con el negocio y sin iniciativa

Falta de capacidad de liderazgo y empoderamiento de los Jefes de Tienda

Resistencia al cambio

Falta de línea de carrera

Visión del negocio a mediano y largo plazo

Respaldo económico para inversiones 
Posicionamiento en ciudades con bajos recursos económicos a excepción de Cusco segmento E )

\section{- Fortalezas}

Ser socio de una transnacional

Trayectoria y conocimiento del mercado de las Telecomunicaciones

Participación en lugares poco atractivos para otros socios

Compromiso con los resultados

Toma de decisiones oportunas al ser una empresa pequeña.

4. De las debilidades mencionadas, ¿cuáles considera deberían ser prioridad para mejorarlas en los próximos 3 años? ¿Por qué?

- Personal poco comprometido con el negocio y sin iniciativa

- Falta de capacidad de liderazgo y empoderamiento de los Jefes de Tienda

- Visión del negocio a mediano y largo plazo

El logro de los resultados depende del personal y del Liderazgo de los Jefes de tienda, si no se logran por un periodo consecutivo la empresa deja de ser bien vista por Telefónica y por ende no hay oportunidad de crecimiento, por el contrario podrían evaluar el retiro como socio estratégico, 
es por ello la importancia de que Digital Comunicaciones pueda tener una visión a mediano y largo plazo y trabajar en conjunto para el crecimiento.

Los mandos medios (jefes de tienda) deben ser los ejes del negocio por lo que se requiere personal preparado y con liderazgo.

5. ¿Cuáles son los principales riesgos a los que se enfrenta Digital en el corto, mediano y largo plazo?

- A corto plazo, reducir los ingresos por no lograrse los objetivos, a mediano plazo tener que retirarse de algunas tiendas por no ser rentables y a largo plazo ser retirados del negocio debido a que no se ha presentado crecimiento y las tiendas ser manejadas por socios con una estructura organizacional más potente.

6. ¿Cuáles son los principales retos que enfrenta la empresa en los próximos 3 años en cuanto posibilidades de expansión de la empresa?

- Recuperar el liderazgo que se ha perdido frente al ingreso de socios con mayor respaldo económico.

- Cambiar a los Jefes de Tienda por personal preparado y comprometido con el logro de los objetivos 
7. ¿Cuáles son las principales oportunidades que tiene la empresa en los próximos 3 años respecto al crecimiento de las telecomunicaciones?

- Recuperar el posicionamiento empezando por tiendas pequeñas en localidades donde otros socios no quieren ingresar.

- Diversificar en otros rubros de telecomunicaciones como instalaciones y servicio técnico.

- Oportunidad de ingresar en ventas en nuevas ciudades para darse a conocer en el mercado

8. ¿Considera que las políticas de libre mercado son amenaza para la empresa?

- Considero que no son una amenaza

Recursos clave (físicos, intelectuales, capital humano, financieros)

- Los recursos más importantes es el capital humano y los recursos financieros para poder solventar algunas pérdidas producto de los cambios introducidos en el esquema de pago por Telefónica.

9. ¿Cómo considera usted la atención al usuario Interno dentro de la empresa y cómo se podría mejorar y marcar la diferencia?

- Se debe mejorar la comunicación en la bajada de lineamientos a los asesores, no hay un canal definido para la comunicación directa.

- El personal no cuenta con un reglamento interno de trabajo el cual debe ser de conocimiento de todos, donde se establezcan todas las amonestaciones y reconocimientos que se dan al personal y los motivos de las mismas. 
- Información del impacto que tiene en el negocio los bajos resultados de sus indicadores y tomar medidas reales en caso no se cumplan dado que actualmente si un personal de planilla no logra sus objetivos no es retirado del negocio, se debe dejar precedente de que se toman medidas cuando el personal no está comprometido.

- Reconocimiento debe ser público y de conocimiento para toda la empresa

- Creación de un correo corporativo de RR.HH donde se informe oficialmente todo lo relacionado con la empresa

10. ¿Cómo considera usted la atención al usuario interno dentro de la empresa y cómo se podría mejorar y marcar la diferencia?

Los líderes deben dar el ejemplo de un trabajo en equipo, con buen nivel de comunicación y camaradería, así propiciar que las áreas trabajen bajo un esquemas de responsabilidad y no sólo bajo el de cumplimiento, es decir hacer solo lo que está en mi función, cambiar ese pensamiento por involucrase hasta que se concluya el proceso, requerimiento o proyecto que tenga la empresa.

11. ¿Cuán es importante creo Ud. a la Resolutividad en cuanto a la atención al cliente?

- Representa el 100\% de la satisfacción del cliente, lo cual es un indicador de medición de Telefónica a través de IVR. 
12. ¿Considera que el tiempo de espera por el cliente (NDS) está dentro de lo permitido por OSIPTEL y Telefónica del Perú S.A.A? ¿Por qué?

- Si se encuentra dentro de lo establecido, si es un indicador que se logra en el $100 \%$ de las tiendas debido a que está regulado y se ha trabajado muchos meses para que los asesores lo tengan como prioridad.

13. ¿Cuáles considera que son las principales empresas competidores de Digital ¿ ¿Por qué?

- Corporación SIC, Salesland, Macdga, por ser socios con mayor respaldo económico y que se encuentran posicionados en zonas de mayor crecimiento económico.

Enumerar de más representativa a menos representativa

- Corporación SIC

- Boutique

- Salesland

- Overlandes

- Macdga

14. ¿Ud. considera que está en crecimiento la industria en telecomunicaciones? ¿Por qué? 
- Si está en crecimiento, principalmente los datos ( internet ) debido a que es la herramienta de más uso por el segmento joven y por las empresas.

15. ¿Cómo consideras el posicionamiento de Digital en el mercado de Telecomunicaciones? ¿Por qué?

- Ha presentado una pérdida de representatividad y valoración como socio el último año. Porque no ha tenido a los mandos medios preparados para afrontar los continuos cambios que ha exigido Telefónica.

16. ¿Cómo considera los procesos de control interno de la empresa de Digital? ¿Por qué?

- El área de control interno si está bastante organizada y detecta rápidamente cualquier incidencia o pérdida que se pueda presentar. 


\section{Entrevistado: Carla Tejeda Villafuerte}

Posición: Supervisora de Post venta

Lugar: Cusco

Fecha: junio 2018

1. ¿Cuáles son las funciones principales que tiene a su cargo?

1. Planificar y controlar el trabajo de todas las tiendas franquicias,

2. Planificar y controlar el trabajo de las ventas de móviles proactivas.

2. ¿Cuál es el principal objetivo de su área?

Llegar a todos los indicadores tanto de gestión como de ventas

3. ¿Cuáles considera usted las fortalezas y debilidades de la empresa Digital?

Considero que las principales fortalezas que tiene la empresa son:

1. El tiempo de relación comercial que se tiene con telefónica lo que nos da experiencia en el manejo de sistemas, negocios etc. 
2. En la zona donde tenemos presencia hay ciudades donde somos sus únicos socios comerciales como es el caso de Abancay, Andahuaylas, Sicuani, Quillabamba y Puerto Maldonado.

3. La empresa cuenta con personal de mando medio con mucha experiencia que ha hecho línea de carrera.

4. Capacidad financiera

5. Contamos con procesos internos que nos permiten tener un orden frente a otras agencias de Telefónica

Las debilidades de la empresa son:

1. El constante cambio en el modelo de negocio, en el cual nos cambian las reglas de juego.

2. No tenemos control en los precios ni de los productos

3. Costos altos de alquileres

4. Tiendas propias de telefónica que trabajan bajo otras condiciones

5. Sueldo bajos y poco atractivos para los asesores

6. Falta de capacitación en sistemas especializados por parte de telefónica

7. Depender totalmente de los sistemas de Telefónica para la atención al cliente los cuales presentan constantes fallas como caídas.

4. De las debilidades mencionadas, ¿cuáles considera deberían ser prioridad para mejorarlas en los próximos 3 años? ¿Por qué? 
Falta de capacitación en sistemas especializados y sueldo bajo y poco atractivos para los asesores

5. ¿Cuáles son los principales riesgos a los que se enfrenta Digital en el corto, mediano y largo plazo?

1. El principal riesgo es no tener un contratado definido a largo plazo, y telefónica puede cambiar con una adenda las reglas de juego

2. Hay otros operadores como Bitel, Entel que son mpas agresivos ofreciendo precios mucho más bajos, lo que hace que los clientes de Telefónica migren con ellos

6. ¿Cuáles son los principales retos que enfrenta la empresa en los próximos 3 años en cuanto posibilidades de expansión de la empresa?

1. La incertidumbre y los cambios que Telefónica pueda imponer a la empresa

2. La competencia cada vez más fuerte de otros operadores

7. ¿Cuáles son las principales oportunidades que tiene la empresa en los próximos 3 años respecto al crecimiento de las telecomunicaciones?

1. Ser el único socio comercial de Telefónica en algunas ciudades como son: Sicuani, Quillabamba, Abancay Andahuaylas y puerto Maldonado lo que nos permite tener un conocimiento de la zona y la cultura. 
2. Telefónica aún cuenta con tiendas propias las cuales en algún momento serán dadas como franquicia y Digital Comunicaciones puede administrar esta tienda como nuevas franquicias.

8. ¿Considera que las políticas de libre mercado son amenaza para la empresa?

Las políticas de libre mercado permiten que las ofertas mejoren, en nuestra posición nosotros no ponemos las condiciones de precios, sin embargo, Telefónica tiene que reaccionar ante la competencia y mejorar sus ofertas.

9. Recursos clave (físicos, intelectuales, capital humano, financieros)

1. Nuestro capital clave es el capital humano porque contamos con colaboradores que trabajan años con nosotros contando con experiencia en sistemas etc.

2. Otro recursos clave es el financiero contamos con respaldo económico para poder afrontar nuevos retos.

11. ¿Cómo considera usted la atención al usuario interno dentro de la empresa y cómo se podría mejorar y marcar la diferencia?

La atención al usuario, tiene un déficit, las oficinas centralizan reclamos y derivan por un sistema para que Telefónica coordine con sus empresas colaboradoras y estas puedan 
dar solución al reclamo de los clientes. Muchos clientes salen con la percepción de que en las tiendas no se les da solución a sus problemas.

Lamentablemente el cliente no termina de diferenciar su problema de la atención que recibió en la tienda y la calificación es complicada, se tiene que hablar con el cliente para explicarle al detalle la operación que se está realizando.

11. ¿Cuán es importante cree Ud. a la Resolutividad en cuanto a la atención al cliente?

La resolutividad al problema es muy importante, porque el cliente siente que se solucionó su problema en la tienda, sin embargo, cuando se trata de reclamos que se tienen que derivar pese a que se le explica al cliente éste siente que no se le soluciono nada además hay la incertidumbre que si algunos reclamos les darán procedente o no.

12. ¿Considera que el tiempo de espera por el cliente (NDS) está dentro de lo permitido por OSIPTEL y Telefónica del Perú S.A.A? ¿Por qué?

El tiempo de espera que impone Osiptel, es de 15 minutos promedio en un mes, esto considera que hay horas y días que este tiempo se puede superar, sin embargo, la exigencia de telefónica es mayor es de $87 \%$ promedio al mes, tiempos que haciendo un máximo esfuerzo se pueden llegar. Sin embargo, esto también afecta a la satisfacción del cliente ya que el siente que la atención fue muy rápida y que el asesor que lo atiende se quiere deshacer del él. 
13. Cuáles considera que son las principales empresas competidores de Digital? ¿Por qué?

Los principales competidores de Digital son las otras franquicias que trabajan en los mismos lugares que Digital

Por otro lado, con el tema de la portabilidad también consideraos como competidores a otros operadores porque ellos pueden ofrecer mejores precios en sus productos y así terminan llevándose a nuestros clientes.

14. ¿Ud. considera que está en crecimiento la industria en telecomunicaciones? ¿Por qué?

Si la industria de telecomunicaciones se encuentra en crecimiento porque es una empresa de tecnología la misma que cambia constantemente sacando nuevos servicios y productos.

15. ¿Cómo consideras el posicionamiento de Digital en el mercado de Telecomunicaciones? ¿Por qué?

El posicionamiento de Digital Comunicaciones es bueno, porque como lo mencionamos anteriormente somos los únicos socios de Telefónica en algunas ciudades, teniendo una presencia fuerte en ventas y postventa

16. Cómo considera los procesos de control interno de la empresa de Digital? ¿Por qué? 
Considero que en los últimos años los controles internos de la empresa han mejorado considerablemente, sin embargo, siempre hay procesos que se deben ir innovando, uno de ellos corresponde al área de recursos humanos, necesitamos innovar en el proceso de reclutamiento para contratar personal más proactivo. 


\section{Anexo 7. Línea de carrera}

\begin{tabular}{|r|l|l|l|}
\hline$N^{\circ}$ & \multicolumn{1}{|c|}{ NOMBRE } & PUESTO INICIAL & PUESTO ACTUAL \\
\hline 1 & Carla Tejeda Villafuerte & Asesor Comercial & Sup. Post Venta \\
\hline 2 & Shirley Cuba Gamarra & Asesor Comercial & Jefe de Tienda \\
\hline 3 & Karen Guzmán Berrio & Asesor Comercial & Jefe de Tienda \\
\hline 4 & Guadalupe Muñoz Loayza & Asesor Comercial & Jefe de Tienda \\
\hline 5 & Paulov Cordero Herrera & Asesor Comercial & Jefe de Tienda \\
\hline 6 & Jennifer Ashanty Rivera Avendaño & Asesor Comercial & Jefe de Tienda \\
\hline 7 & Sally Peña Huamani & Asesor Comercial & Jefe de Tienda \\
\hline 8 & Oroya Lidia Fernández Venero & Vendedora de Calle & Jefe de Tienda \\
\hline 9 & Betsabe del Pino Cóndor & Caja & Jefe de Tienda \\
\hline 10 & Charito Luz Guzmán Orihuela & Asesor Comercial & Adm. de Tienda \\
\hline 11 & Neysi Shardely Huaypar Céspedes & Almacén & Sup. de Caja \\
\hline 12 & Luis Alberto Villa Lobos Cheppe & Vendedor de Calle & Encarg de Almacén \\
\hline 13 & Hernán Fernando Tejeda San Román & Control Económico & Gerente Móviles \\
\hline 14 & Guissela Ormachea Aparicio & Asesor Comercial & Sup. de Ventas \\
\hline 15 & Heraclio Ormachea Aparicio & Asesor Comercial & Trainer \\
\hline 16 & Eugenio Pillco Huacac & Vendedor Proactivo & Sup. de Ventas \\
\hline 17 & Edhy Alfaro Tupayachi & Caja & Adm. Zonal \\
\hline 18 & Andy Leonidas Alfaro Tupayachi & Asesor Comercial & Jefe de Tienda \\
\hline 19 & Yuvitza Alira Cjumo Gonzales & Control Económico & Encargado de Área \\
\hline 20 & Maya Saemi Velasquez Carrión & Almacén & Asesora de Ventas \\
\hline 21 & Miguel Franklyn Jeri Guerrero & Control Económico & Asesor de Ventas \\
\hline
\end{tabular}




\section{Anexo 8. Cargos de la empresa y tiempos promedio de permanencia}

\begin{tabular}{|l|l|l|l|l|l|}
\hline Item & Puesto & Mas. & Fem. & $\begin{array}{l}\text { Cantidad } \\
\text { Trabajador }\end{array}$ & $\begin{array}{l}\text { Promedio permanencia } \\
\text { en meses }\end{array}$ \\
\hline 1 & Asesor de ventas & 1 & 6 & 7 & 44 \\
\hline 2 & Asesor comercial & 13 & 34 & 47 & 22 \\
\hline 3 & Control Econ./Activaciones & 2 & 8 & 10 & 13 \\
\hline 4 & Jefe tienda/Administrador & 3 & 8 & 11 & 49 \\
\hline 5 & Limpieza/Seguridad & 1 & 4 & 5 & 6 \\
\hline 6 & Almacen & 5 & 7 & 12 & 14 \\
\hline 7 & Caja/Recaudación & 3 & 11 & 14 & 21 \\
\hline 8 & Anfitriones & 2 & 6 & 8 & 11 \\
\hline 9 & Contabilidad & 1 & 2 & 3 & 44 \\
\hline 10 & Gerencias & 1 & 4 & 5 & 99 \\
\hline & Total & 32 & 90 & 122 & \\
\hline
\end{tabular}

Datos proporcionados por la empresa Digital diciembre 2017 (elaboración propia) 


\section{Anexo 9. Compra de artículos promocionales}

\begin{tabular}{|c|c|c|c|}
\hline PLAN DE ADQUISICIONES & 2019 & 2020 & 2021 \\
\hline Articulos promocionales & S/. 60,000 & S/. 100,000 & S/. 150,000 \\
\hline Valorizados en máximo S/. 5.0 soles & 12,000 & 20,000 & 30,000 \\
\hline Cuatro campañas por año & 3,000 & 5,000 & 7,500 \\
\hline \multicolumn{4}{|l|}{ Artículos que se compraran para las campañas } \\
\hline \multicolumn{4}{|l|}{ Alcancias } \\
\hline \multicolumn{4}{|l|}{ Bolsas recicladas } \\
\hline \multicolumn{4}{|l|}{ Lapiceros } \\
\hline \multicolumn{4}{|l|}{ Gorros } \\
\hline \multicolumn{4}{|l|}{ Cartucheras } \\
\hline \multicolumn{4}{|l|}{ Monederos } \\
\hline \multicolumn{4}{|l|}{ Llaveros } \\
\hline Tasas & & & \\
\hline
\end{tabular}

Anexo 10. Personal para call center de cobranzas

\begin{tabular}{|c|c|c|c|c|c|}
\hline AÑNO & PUESTO & NRO & $\begin{array}{l}\text { SUELDO } \\
\text { ACTUAL }\end{array}$ & MESES & TOTAL \\
\hline 2019 & \multirow{3}{*}{ Practicante para el call centrer } & 1 & S/.930 & 12 & $\mathrm{~S} / .11,160$ \\
\hline 2020 & & 1 & $\mathrm{~S} / .930$ & 12 & S/. 11,160 \\
\hline 2021 & & 4 & $\mathrm{~S} / .1,000$ & 12 & S/. 48,000 \\
\hline
\end{tabular}




\section{Anexo 11. Bonificación a los trabajadores de Digital}

\begin{tabular}{|l|c|c|c|c|c|r|r|r|r|}
\hline \multicolumn{1}{|c|}{2019} & $\begin{array}{c}\text { NRO } \\
\text { ASESORES }\end{array}$ & $\begin{array}{c}\text { SUELDO } \\
\text { ACTUAL }\end{array}$ & $\begin{array}{c}\text { SUELDO } \\
\text { VARIABLE }\end{array}$ & $\begin{array}{c}\text { SUELDO } \\
\text { TOTAL DE } \\
\text { PERSONAL }\end{array}$ & BONO 25\% & $\begin{array}{c}\text { SUELDO } \\
\text { CON BONO }\end{array}$ & $\begin{array}{c}\text { TOTAL } \\
\text { BONO } \\
\text { MENSUAL }\end{array}$ & $\begin{array}{c}\text { CARGAS } \\
\text { SOCIALES } \\
\text { 28\% } \%\end{array}$ & $\begin{array}{c}\text { TOTAL } \\
\text { BONO } \\
\text { MENSUAL }\end{array}$ \\
\hline $\begin{array}{l}\text { ASESOR } \\
\text { COMERCIAL }\end{array}$ & 51 & $\mathrm{~S} / .1,100$ & $\mathrm{~S} / .400$ & $\mathrm{~S} / .1,500$ & $\mathrm{~S} / .100$ & $\mathrm{~S} / .1,600$ & $\mathrm{~S} / .5,100$ & $\mathrm{~S} / .1,428$ & $\mathrm{~S} / .6,528$ \\
\hline \multicolumn{2}{|l|}{ TOTAL INCREMENTO PLANILLA ANUAL } \\
\hline
\end{tabular}

\begin{tabular}{|l|c|c|c|c|c|r|r|r|c|}
\hline \multicolumn{1}{|c|}{2020} & $\begin{array}{c}\text { NRO } \\
\text { ASESORES }\end{array}$ & $\begin{array}{c}\text { SUELDO } \\
\text { ACTUAL }\end{array}$ & $\begin{array}{c}\text { SUELDO } \\
\text { VARIABLE }\end{array}$ & $\begin{array}{c}\text { SUELDO } \\
\text { TOTAL DE } \\
\text { PERSONAL }\end{array}$ & BONO 45\% & $\begin{array}{c}\text { SUELDO } \\
\text { CON BONO }\end{array}$ & $\begin{array}{c}\text { TOTAL } \\
\text { BONO } \\
\text { MENSUAL }\end{array}$ & $\begin{array}{c}\text { CARGAS } \\
\text { SOCIALES } \\
\text { 28\% }\end{array}$ & $\begin{array}{c}\text { TOTAL } \\
\text { BONO } \\
\text { MENSUAL }\end{array}$ \\
\hline $\begin{array}{l}\text { ASESOR } \\
\text { COMERCIAL }\end{array}$ & 51 & $\mathrm{~S} / .1,100$ & $\mathrm{~S} / .400$ & $\mathrm{~S} / .1,500$ & $\mathrm{~S} / .180$ & $\mathrm{~S} / .1,680$ & $\mathrm{~S} / .9,180$ & $\mathrm{~S} / .2,570$ & $\mathrm{~S} / .11,750$ \\
\hline \multicolumn{2}{|l|}{ TOT AL INCREMENTO PLANILLA ANUAL } & & & & IMPREVISTOS & $\mathrm{S} / .1,995$ & $\mathrm{~S} / .143,000$ \\
\hline
\end{tabular}

\begin{tabular}{|l|c|c|c|c|c|r|r|r|r|}
\hline \multicolumn{1}{|c|}{2021} & $\begin{array}{c}\text { NRO } \\
\text { ASESORES }\end{array}$ & $\begin{array}{c}\text { SUELDO } \\
\text { ACTUAL }\end{array}$ & $\begin{array}{c}\text { SUELDO } \\
\text { VARIABLE }\end{array}$ & $\begin{array}{c}\text { SUELDO } \\
\text { TOTAL DE } \\
\text { PERSONAL }\end{array}$ & BONO 70\% & $\begin{array}{c}\text { SUELDO } \\
\text { CON BONO }\end{array}$ & $\begin{array}{c}\text { TOTAL } \\
\text { BONO } \\
\text { MENSUAL }\end{array}$ & $\begin{array}{c}\text { CARGAS } \\
\text { SOCIALES } \\
\text { 28\% }\end{array}$ & $\begin{array}{c}\text { TOTAL } \\
\text { BONO } \\
\text { MENSUAL }\end{array}$ \\
\hline $\begin{array}{l}\text { ASESOR } \\
\text { COMERCIAL }\end{array}$ & 51 & $\mathrm{~S} / .1,100$ & $\mathrm{~S} / .400$ & $\mathrm{~S} / .1,500$ & $\mathrm{~S} / .280$ & $\mathrm{~S} / .1,780$ & $\mathrm{~S} / .14,280$ & $\mathrm{~S} / .3,998$ & $\mathrm{~S} / .18,278$ \\
\hline \multicolumn{2}{|l|}{ TOTAL INCREMENTO PLANILLA ANUAL } & & & & $\mathrm{IMPREVISTOS}$ & $\mathrm{S} / .659$ & $\mathrm{~S} / .220,000$ \\
\hline
\end{tabular}




\section{Anexo 12. Taller de Capacitación: Contenido, Cronograma y Costo}

\begin{tabular}{|c|c|c|c|}
\hline \multicolumn{4}{|c|}{ TALLER DESERVICIO AL CLIENTE } \\
\hline CONTENIDO & OBJEIIVOS & TEMAS & AC TIVIDAD DEL MÓ DULO \\
\hline \multirow{4}{*}{$\begin{array}{l}\text { MODULO I: } \\
\text { IMPORTANCIA DEL } \\
\text { SERVICIO AL CLIENTE }\end{array}$} & \multirow{2}{*}{$\begin{array}{l}\text { Comprender la importancia del servicio al } \\
\text { cliente, y conocer el medio, los clientes y los } \\
\text { productos que maneja en su empresa. }\end{array}$} & Definición del Servicio al Cliente & Caso de análisis \\
\hline & & Ventajas del Servicio al Cliente & Proy ección de video \\
\hline & \multirow{2}{*}{$\begin{array}{l}\text { Desarrollar la habilidad de transformar las } \\
\text { características del producto en beneficios }\end{array}$} & Lealtad del cliente & Preguntas de debate \\
\hline & & $\begin{array}{l}\begin{array}{l}\text { Necesidades y deseos de los } \\
\text { clientes }\end{array} \\
\end{array}$ & \\
\hline \multirow{3}{*}{$\begin{array}{l}\text { MODULO II: UN } \\
\text { PROCESO DE SERVICIO } \\
\text { AL CLIENTE EFIC IENTE }\end{array}$} & $\begin{array}{l}\text { Desarrollar la habilidad de hacer un buen } \\
\text { servicio al cliente en el proceso de negociación. }\end{array}$ & Métodos de Servicio al Cliente & Proceso de toma de decisión del cliente \\
\hline & \multirow{2}{*}{$\begin{array}{l}\text { Comprender la importancia de darle } \\
\text { seguimiento a los clientes a partir de métodos } \\
\text { y técnicas de Servicio al Cliente. }\end{array}$} & Los tipos de cliente & \multirow{2}{*}{ Taller en equipo } \\
\hline & & El comportamiento de los clientes & \\
\hline \multirow{3}{*}{$\begin{array}{l}\text { MODULO III: } \\
\text { INTERACCION CON LOS } \\
\text { CLIENTES }\end{array}$} & \multirow{3}{*}{$\begin{array}{l}\text { Destacar la Importancia de cómo conducirse en } \\
\text { los diferentes escenarios en la comunicación al } \\
\text { cliente. }\end{array}$} & Comunicación frente a frente & \multirow{3}{*}{ Taller en equipo } \\
\hline & & Servicio por teléfono. & \\
\hline & & Interacción por escrito & \\
\hline \multirow{3}{*}{$\begin{array}{l}\text { MO DULO IV: } \\
\text { SUPERACIO N } \\
\text { PERSO NAL } \\
\text { (INTELIGENCIA } \\
\text { EMO CIO NAL) }\end{array}$} & \multirow{2}{*}{$\begin{array}{l}\text { Dotar las herramientas necesarias para } \\
\text { desarrollar la construcción de relaciones con el } \\
\text { cliente. }\end{array}$} & $\begin{array}{l}\text { Definición de inteligencia } \\
\text { emocional. }\end{array}$ & \multirow{3}{*}{ Presentación taller. } \\
\hline & & $\begin{array}{l}\text { Aplicación de la herramienta al } \\
\text { Servicio al Cliente. }\end{array}$ & \\
\hline & $\begin{array}{l}\text { Destacar la importancia de desarrollar } \\
\text { habilidades auto motivacionales. }\end{array}$ & Autovaloración. & \\
\hline \multirow{6}{*}{$\begin{array}{l}\text { MODULO V: CLAVES } \\
\text { PARA LOGRAR UN } \\
\text { SERVICIO DE } \\
\text { EXCELENCIA }\end{array}$} & \multirow{6}{*}{$\begin{array}{l}\text { Desarrollar un plan de acción personalizado } \\
\text { para aplicar estos conocimientos en sus } \\
\text { respectivas áreas }\end{array}$} & Clave \#1: El servicio es una actitud & \multirow{6}{*}{ Taller en equipo } \\
\hline & & $\begin{array}{l}\text { Clave \#2: Acérquese y } \\
\text { comuníquese }\end{array}$ & \\
\hline & & $\begin{array}{l}\text { Clave \#3: Lo que usted sabe, hace } \\
\text { la diferencia }\end{array}$ & \\
\hline & & $\begin{array}{l}\text { Clave \#4: La primera impresión } \\
\text { cuenta }\end{array}$ & \\
\hline & & Clave \#5: Sus normas personales & \\
\hline & & Clave \#6: Tome la iniciativa & \\
\hline
\end{tabular}

\begin{tabular}{|c|c|c|c|c|c|c|c|c|c|c|}
\hline \multicolumn{11}{|c|}{ CRONOGRAMA: TALLER DE SERVICIO AL CLIENTE } \\
\hline \multirow{2}{*}{ ACTIVIDADES } & \multicolumn{2}{|c|}{2019} & \multicolumn{4}{|c|}{2020} & \multicolumn{4}{|c|}{2021} \\
\hline & III TRIM. & IV TRIM. & I TRIM. & II TRIM. & III TRIM. & IV TRIM. & I TRIM. & II TRIM. & III TRIM. & IV TRIM. \\
\hline $\begin{array}{l}\text { MODULO I: IMPORTANCIA } \\
\text { DEL SERVICIO AL CLIENTE }\end{array}$ & & & & & & & & & & \\
\hline $\begin{array}{l}\text { MODULO II: UN PROCESO D } \\
\text { SERVICIO AL CLIENTE } \\
\text { EFICIENTE }\end{array}$ & & & & & & & & & & \\
\hline $\begin{array}{l}\text { MODULO III: INTERACCION } \\
\text { CON LOS CLIENTES }\end{array}$ & & & & & & & & & & \\
\hline $\begin{array}{l}\text { MODULO IV: SUPERACION } \\
\text { PERSONAL (INTELIGENCIA } \\
\text { EMOCIONAL) }\end{array}$ & & & & & & & & & & \\
\hline $\begin{array}{l}\text { MODULO V: CLAVES PARA } \\
\text { LOGRAR UN SERVICIO DE } \\
\text { EXCELENCIA }\end{array}$ & & & & & & & & & & \\
\hline
\end{tabular}




\begin{tabular}{|l|c|r|r|}
\hline \multicolumn{1}{|c|}{ COSTOS PARA EL TALLER DE SERVICIO AL CLIENTE: PARTICIPANTES } \\
\hline MATERIALES & $\begin{array}{c}\text { PARTICIPAN } \\
\text { TES }\end{array}$ & $\begin{array}{c}\text { PRECIO } \\
\text { UNITARIO }\end{array}$ & \multicolumn{1}{c|}{ TOTAL } \\
\hline UTILES DE ESCRITORIO & 60 & S/. 10.00 & S/. 600.00 \\
MORRALES: & 60 & S/. 20.00 & S/. $1,200.00$ \\
MATERIAL & 60 & S/. 25.00 & S/. $1,500.00$ \\
COFFE BREAK & 60 & S/. 20.00 & S/. $1,200.00$ \\
OTROS GASTOS & & S/. 500.00 & S/. 500.00 \\
\hline TOTAL & & & S/. 5, 000.00 \\
\hline
\end{tabular}

\begin{tabular}{|c|c|r|r|}
\hline TALLERES ASESORES & $\begin{array}{c}\text { NUMERO POR } \\
\text { AÑ }\end{array}$ & $\begin{array}{c}\text { COSTO DEL } \\
\text { TALLER }\end{array}$ & \multicolumn{1}{c|}{ TOTAL } \\
\hline 2019 & 2 & S/. $5,000.00$ & S/. $10,000.00$ \\
\hline 2020 & 6 & S/. $5,000.00$ & S/. $30,000.00$ \\
\hline 2021 & 8 & S/. $5,000.00$ & S/. $40,000.00$ \\
\hline TOTAL & & & S/. $80,000.00$ \\
\hline
\end{tabular}

\begin{tabular}{|c|c|c|r|}
\hline $\begin{array}{c}\text { TALLERES PERSONAL } \\
\text { ADMINISTRATIVO }\end{array}$ & $\begin{array}{c}\text { NUMERO POR } \\
\text { AÑ }\end{array}$ & $\begin{array}{c}\text { COSTO DEL } \\
\text { TALLER }\end{array}$ & \multicolumn{1}{c|}{ TOTAL } \\
\hline 2019 & 1 & $\mathrm{~S} / .5,000.00$ & $\mathrm{~S} / .5,000.00$ \\
\hline 2020 & 4 & $\mathrm{~S} / .5,000.00$ & $\mathrm{~S} / .20,000.00$ \\
\hline 2021 & 4 & $\mathrm{~S} / .5,000.00$ & $\mathrm{~S} / .20,000.00$ \\
\hline TOTAL & & & $\mathrm{S} / .45,000.00$ \\
\hline
\end{tabular}


Anexo 13. Premios para los trabajadores

\begin{tabular}{|l|c|c|}
\hline \multicolumn{1}{|c|}{ PREMIOS COLABORADORES } & $\mathbf{2 0 2 0}$ & $\mathbf{2 0 2 1}$ \\
\hline Mejor Asesor Comercial 10 primeros & $15,000.00$ & $30,000.00$ \\
\hline I Semestre & & $1,500.00$ \\
\hline II Semestre & $1,500.00$ & $1,500.00$ \\
\hline
\end{tabular}

Anexo 14. Asesoría profesional externa especializada en calidad de atención

\begin{tabular}{|c|c|l|r|r|}
\hline TALLERES & $\begin{array}{c}\text { NUMERO } \\
\text { POR AÑ }\end{array}$ & PERSONAL & $\begin{array}{c}\text { COSTO DEL } \\
\text { TALLER }\end{array}$ & \multicolumn{1}{c|}{ TOTAL } \\
\hline 2019 & 2 & Asesores & 7,500 & 15,000 \\
\hline 2020 & 6 & Asesores & 6,667 & 40,000 \\
\hline 2021 & 8 & Asesores & 5,000 & 40,000 \\
\hline \multicolumn{4}{|c|}{ TOTAL } & 95,000 \\
\hline
\end{tabular}

\section{Anexo 15. Rubros del presupuesto}

\begin{tabular}{|c|r|c|r|r|}
\hline \multirow{2}{*}{ INICIATIVAS } & \multicolumn{3}{|c|}{ PRESUPUESTO } & \multirow{2}{*}{ TOTAL } \\
\cline { 2 - 4 } & \multicolumn{1}{|c|}{2019} & 2020 & \multicolumn{1}{c|}{2021} & \\
\hline GASTOS DE PERSONAL & $\mathrm{S} / .97,000.00$ & $\mathrm{~S} / .208,000.00$ & $\mathrm{~S} / .310,000.00$ & $\mathrm{~S} / .615,000.00$ \\
\hline SERVICIOS DE TERCEROS & $\mathrm{S} / .91,160.00$ & $\mathrm{~S} / .181,160.00$ & $\mathrm{~S} / .268,000.00$ & $\mathrm{~S} / .540,320.00$ \\
\hline TOTAL & $\mathrm{S} / .188,160.00$ & $\mathrm{~S} / .389,160.00$ & $\mathrm{~S} / .578,000.00$ & $\mathrm{~S} / .1,155,320.00$ \\
\hline
\end{tabular}

